Portland State University

PDXScholar

10-10-2008

\title{
Challenging the New Penology: A Case-Study Analysis of Correctional Management, Interstate Inmate Transfers, and Administrative Intent
}

Robert Thomas Swan

Portland State University

Follow this and additional works at: https://pdxscholar.library.pdx.edu/open_access_etds

Part of the Criminology and Criminal Justice Commons, and the Public Affairs, Public Policy and Public Administration Commons

Let us know how access to this document benefits you.

\section{Recommended Citation}

Swan, Robert Thomas, "Challenging the New Penology: A Case-Study Analysis of Correctional Management, Interstate Inmate Transfers, and Administrative Intent" (2008). Dissertations and Theses. Paper 3825.

https://doi.org/10.15760/etd.5707

This Dissertation is brought to you for free and open access. It has been accepted for inclusion in Dissertations and Theses by an authorized administrator of PDXScholar. Please contact us if we can make this document more accessible: pdxscholar@pdx.edu. 
CHALLENGING THE NEW PENOLOGY:

A CASE-STUDY ANALYSIS OF CORRECTIONAL

MANAGEMENT, INTERSTATE INMATE TRANSFERS,

AND ADMINISTRATIVE INTENT

by

ROBERT THOMAS SWAN

A dissertation submitted in partial fulfillment of the requirements for the degree of

DOCTOR OF PHILOSOPHY

in

PUBLIC ADMINISTRATION AND POLICY

Portland State University

2008 


\section{DISSERTATION APPROVAL}

The abstract and dissertation of Robert Thomas Swan for the Doctor of Philosophy in Public Administration and Policy were presented October 10, 2008, and accepted by the dissertation committee and the doctoral program.

COMMITTEE APPROVALS:
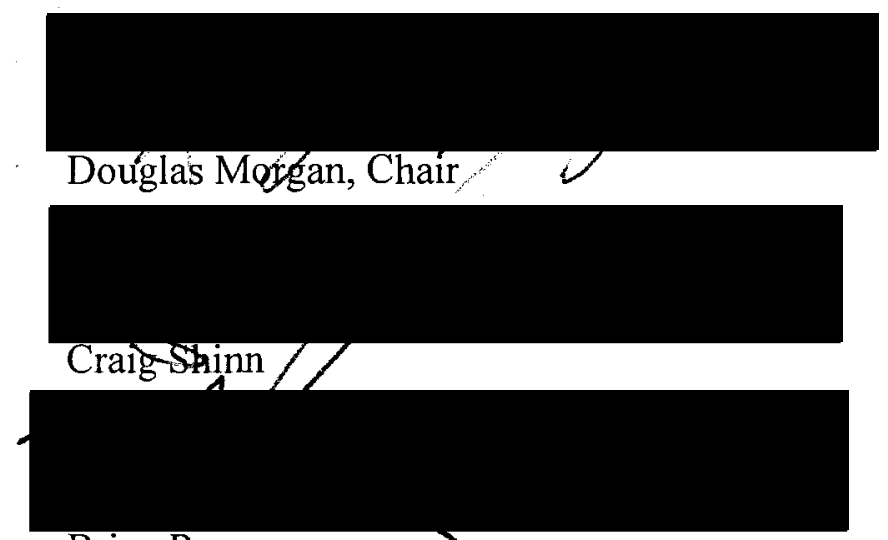

Brian Renauer
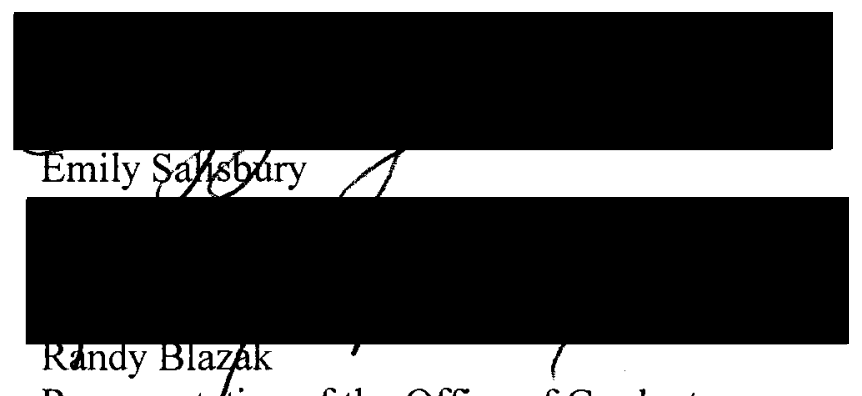

Representative of the Office of Graduate Studies

DOCTORAL PROGRAM APPROVAL:

Craig Shinn, Director

Public Administration and Policy Ph.D. Program 


\begin{abstract}
An abstract of the dissertation of Robert Thomas Swan for the Doctor of Philosophy in Public Administration and Policy presented October 10, 2008.
\end{abstract}

Title: Challenging the New Penology: A Case-Study Analysis of Correctional Management, Interstate Inmate Transfers, and Administrative Intent

The purpose of this study is to explore the use of interstate inmate transfers (IITs) by prison wardens and the administrative intent that guide their use. This study assesses the explanatory power of the new penology in three cases and asks three broad questions of two prison wardens and the DOC: What correctional goals do you hope to accomplish with interstate inmate transfers? Why? And what contextual factors (if any) are felt to inhibit or facilitate these goals?

IITs are controversial. Supporters of IITs argue that in addition to serving the needs of correctional managers, IITs may also serve to help inmates reenter society, remain physically safe while incarcerated, remain close to family and friends, and have access to appropriate correctional programming and treatment. On the other hand, critics of IITs argue that they are much more than a correctional management tool. Rather, IITs are evidence of an informally emerging "new penology" in American corrections that-due to the increasingly problematic conditions of confinement encountered by correctional managers (e.g., overcrowding)-emphasize 
a shift in focus away from what is good for the individual inmate to what is good for managing the correctional system as a whole.

The case data collected in this research contradict, to a large degree, new penological assumptions. The findings point to high levels of ideological and behavioral autonomy among prison wardens as well as high levels of individualized and moralistic thinking with regard to inmate management, and a general feeling that correctional management at the institutional level is only situationally (rather than perpetually) stressful. Thus, the new penological assumption that criminal justice actors lack human agency or that inmates are thought of only in actuarial terms, may be an incorrect or incomplete assumption in relation to prison wardens and the intent of IITs in these cases. This study concludes that in order to better understand and possibly predict the administrative intent of IITs, an alternative theoretical framework should be utilized —one that better captures the dynamism and variability of influence that unique situational and dispositional factors (and their interaction) may have on administrative intent. 


\section{DEDICATIONS}

In dedication to my mother Maureen Ryan and my grandparents Thomas and Patricia Kearns - and to all of those intrepid Irish-cowboy ancestors of mine who ran (or thought they ran) Nevada's early $20^{\text {th }}$ century prison, policing, and legislative institutions; a special emotional and intellectual connection is felt for those among them who saw fit to occasionally lay down their keys, guns and gavels in order to offer a helping hand to victims, offenders and their families.

I would also like to thank Sarah for periodically reminding me to have "fun" and for remaining patient with me as I crankily sought out arcane bits of penal knowledge in lieu of pizza and beer. Without you, I would be a much less pleasant person and even less inclined to leave my desk than I am now. 


\section{ACKNOWLEDGMENTS}

In reflecting upon my intellectual development over the past seven years, it is clear to me that without the advice and mentoring of numerous faculty members at PSU I could not have completed this dissertation project. Simply, I could not have asked for a better dissertation committee or a more stimulating intellectual environment from which to pursue my doctoral studies. That being said, I would like to begin by offering special thanks to my dissertation committee chair, Dr. Douglas Morgan for all of his hard work on my behalf. Without Doug's strong committee leadership, attention to detail and willingness to address my questions promptly and precisely, this dissertation could not have been completed. Doug's work on my dissertation went, in many cases, above and beyond the call of duty and I am most grateful to him for his willingness to address my questions and concerns even while - in at least one case - attempting to take a well-deserved vacation. In terms of dissertation leadership and mentoring, Doug has set the bar very high and I will strive to live up to his standard when placed in a similar leadership role.

I would also like to acknowledge Dr. Craig Shinn's role in my dissertation process and the importance of his intellectual modeling over the course of my sevenyear journey. I am very grateful to Craig for helping me to achieve more clarity in my thinking and writing. His constant reminders to model my thoughts and ideas in a manner that is both consistent and clear to the reader, was invaluable. These reminders have helped me (in part) to "make sense" out of the "puzzle palace" that is postmodernism. 
I would be remiss if I did not acknowledge the efforts and attention given to me and my dissertation by other committee members. I am extremely grateful to Dr. Brian Renauer for all of his formal and informal advice and assistance while completing this project. Without Brian's knowledgeable guidance and willingness to read the many pages of "false starts" I have laid on his doorstep over the past seven years, this project could not have been completed. I am particularly grateful to Brian for inculcating in me a sense of scholarly professionalism — he is truly an academic role-model worth emulating.

In addition to agreeing to allot his valuable time to my dissertation process, I am also grateful to Dr. Randy Blazak for inspiring and facilitating my natural curiosity and enthusiasm for theory-driven criminological research. I am sure that I will continue to think of Randy whenever I begin teaching a new cohort of introductory criminology students. Randy's energy and active engagement of students was truly inspirational.

I would also like to offer my sincere thanks and appreciation to Dr. Emily Salisbury for agreeing to join my dissertation process in its "final hour." I was quite fortunate to receive Emily's input (to include line-item editing work) and participation at such a late date. Emily's penal expertise and "rising star" status in the field of criminal justice greatly enhanced both the quality of my dissertation and the legitimacy (in relation to prison studies) of my dissertation committee. I am looking forward to working with Emily in the future. 
Finally, I would like to thank the University of South Dakota, and the Political Science Department and the Criminal Justice Studies program at USD for taking a chance on me prior to the completion of this dissertation. Their vote of confidence injected a much needed boost of enthusiasm and energy into the final stages of my dissertation process. Although the entire faculty in Political Science is wonderful, my special thanks go to Dr.'s Bill Richardson, Steve Feimer, and Michael Roche for making me feel that I "home" in South Dakota. Indeed, I look forward to many productive and happy years at USD. 


\section{TABLE OF CONTENTS}

Acknowledgements. .p. ii

List of Tables p. $x$

List of Figures p. $x i$

Glossary. p. xiii

Preface. p. xiv

Chapter I: Interstate Transfers (IITs) as a Research Problem: Organization of

Chapter I p. 1

IITs in Practice: Anecdotal Horror Stories \& High-Profile Cases. p. 2

Summarizing the Current Debate. .p. 9

Research issues Emerging from This Debate. .p. 16

Overview of Methodology and Brief Summary of Findings p. 28

Value of Study: Overview ..p. 30

Organization of the Project. p. 32

Chapter II: Literature Review \& Research Assumptions. ..p. 34

Purpose and Structure of Literature Review.

The New Penology and Assumptions: A Question of Human Agency, Inmate Management, and Administrative Intent.

Administrative Intent

The New Penology 
Lessons from Philip Zimbardo and the Stanford Prison Experiment: Understanding the Impact of Situational and Dispositional Influences on Administrative

Intent.

\section{Situational Factors:}

"Black Letter" Law: Overview of Legal Foundations, Types, and Status of Interstate Inmate Transfers

Discretionary Decision-Making: The IIT as a Discretionary Tool of

Corrections

The Correctional Environment

Dispositional Factors:

Correctional Management Philosophy: The Influence of Management Style and Beliefs on Administrative Intent.

Research Assumptions

Chapter III: Methodology: Viewing prison Wardens Through the Lens of

Institutional Ethnography

Telling Stories: Underlying Influences and Goals of Research..........p. 92

Organization of Chapter.......................................... 94

Why Study Prison Wardens? ................................... 94

Overview of Methodological Approach.............................p. 98

Research Setting, Access to Respondents, \& Case Anonymity.................p. 99

Getting Into (and out of) Prisons: Respondent Access Issues...........p. 101

DOC Constraints................................................ 102 
Methodology: Institutional Ethnography-The Exploratory Case

Study.

Institutional Ethnography: Understanding "Ruling Relationships" through

Narrative Analysis.

p. 103

The Case Study Design

Target Population and Sampling.

The Interview

The Telephone Interview

Pretesting

Developing Rapport. p. 118

Interview Protocol \& Screening Criteria.

Risks and Safeguards

The Interview Instrument

Data Analysis.

Data Organization .p. 124

Narrative Clauses \& Analytical Bracketing. .p. 125

Case write-ups

Chapter IV: Case 1: "Warden A"- "Old School". .p. 132

Introduction to Case.

Review of Research questions, assumptions and categories of influence.

Introduction to Warden A p. 134 
Dispositional Factors

Situational Factors

Case Findings in Relation to Administrative Intent and the New Penology

Chapter V: Case 2: "Warden B" - "New Blood"...

Introduction to Case.

Introduction to Warden B. ..p. 162

Dispositional Factors .p. 165

Situational Factors. ..p. 180

Case Findings in Relation to the New Penology. ..p. 184

Chapter VI: Case 3: “Department of Corrections" - "Command and Control” p. 194 Introduction to Case

Dispositional Factors

Situational Factors

Case Findings in Relation to the New Penology. p. 200

Chapter VII: Concluding Discussion: Findings, Difficulties, and Value of Research to Practice, Theory and Policy.

Organization of Concluding Chapter.

Findings. p. 211

Problems, Difficulties, \& Limitations of Study. p. 215

Value of Study. p. 218 
Appendix A1: Active Interstate Transfers (By Gender)....................... 262 Appendix A2: Active Interstate Transfers (By State)....................... 263 Appendix B: Interview Instrument. p. 265

Appendix C: HSRRC Conditional Memo \& Response

Appendix D: Follow-up Letter to Respondent. ..p. 275

Appendix E: Informed Consent Letter p. 277

Appendix F: HSRRC Approval Memorandum. p. 280 Appendix G: Data Table - Case 1: Warden A-Old School". ..p. 281 Appendix H: Data Table - Case 2: "Warden B-New Blood". p. 299 Appendix I: Open-ended Survey and DOC Responses.... 
LIST OF TABLES

Table 1: Administrative Intent Typology .p. 41

Table 2: Analytic Bracketing: Ruling Relationships \& Administrative Intent of IITs p. 108 and p. 126

Table 3: Yin's Model of Multiple-case, Case Studies......................p. 114

Table 4: 3 Pillars of Institutional Theory...............................p. 231

Table 5: Institutionalizing Forces and IITs..............................p. 232 
Figure 1: Key Characteristics of the New Penology. ..p. 46

Figure 2: Modeling Hierarchies of Influence: The Anticipated and Actual Influence of Situational and Dispositional Factors on the Administrative Intent of IITs p. 155 Figure 2A: The New Penology: Anticipated. p. 155

Figure 2B: Zimbardo's Model: Anticipated p. 155

Figure 2C: This Study: Anticipated. .p. 155

Figure 2D: Case 1-Warden A: Findings. p. 155

Figure 3: IIT Case 1: Ruling Relationships (Path Model) p. 158

Figure 4: Modeling Hierarchies of Influence: The Anticipated Influence of

Situational and Dispositional Factors on the Administrative Intent of IITs .p. 188

Figure 4A: The New Penology: Anticipated. p. 188

Figure 4B: Zimbardo's Model: Anticipated. p. 188

Figure 4C: This Study: Anticipated. .p. 188

Figure 4D: Case 2-Warden B: Findings p. 188

Figure 5: IIT Case 2: Ruling Relationships (Path Model) .p. 191

Figure 6: Modeling Hierarchies of Influence: The Anticipated Influence of

Situational and Dispositional Factors on the Administrative Intent of IITs.....p. 203

Figure 6A: The New Penology: Anticipated. p. 203

Figure 6B: Zimbardo's Model: Anticipated. p. 203

Figure 6C: This Study: Anticipated.... p. 203

Figure 6D: Case 3-DOC (wardens): ICC Findings. .p. 203 
Figure 6E: Case 3 -DOC: IIT Bed Rental Findings................p. 203

Figure 7: IIT Case 3: Ruling Relationships (Path Model).................. p. 207 


\section{GLOSSARY \& LIST OF ABBREVIATIONS}

Article I, Section 10: The compact clause of the U.S. Constitution

Bed Rental: A reference, typically, to the rental of available space within public or private prison institutions located in another state. Sometimes used by a department of corrections to house groups of inmates when space is limited within the originating state.

Compacted: A reference to an offender who has been transferred out of state under the legal auspices of one or more Interstate Corrections Compact agreements DOC: Department of Corrections

Ghost: A reference to an inmate who has been "compacted" or transferred as part of a bed-rental agreement. The inmate is "on the books" in an originating state, but he or she is no longer physically present.

ICAOS: Interstate Compact for Adult Offender Supervision

ICC: Interstate Corrections Compact

IIT: Interstate inmate transfers

MBWA: Management by Walking Around

NECC: New England Corrections Compact

NIC: National Institute of Corrections

NICC: National Interstate Compact for Corrections

USDOJ: United States Department of Justice

WCC: Western Corrections Compact 
Generally speaking, prisons and prison policy are a shrouded and confusing empirical reality for most people. Similarly, interstate inmate transfers are a little known and widely misunderstood penal phenomenon - even among those who have made a career of studying prisons and prison policy. However, interstate inmate transfers have proven their value as management tools and can be found in almost every correctional manager's discretionary toolbox. Problematically, interstate inmate transfers have generated some high-profile criticism. From Thurgood Marshall's (1983) scathing dissent in Olim v. Wakinekona, to an assortment of critical prison activists, scholars, and inmate advocates who insist that interstate inmate transfers always have a harmful effect on inmates, their families and their communities.

Claims made by the critics of interstate inmate transfers are true in some cases, but evidence suggests that they are not true in many others. Although some correctional officials acknowledge that a few inadvertently harmful interstate inmate transfers have occurred, they insist that the bulk of interstate inmate transfers have done more good than not. For example, interstate inmate transfers have been used to separate dangerous and disruptive gang members, protect the lives of inmates and to reunite inmates with their families. Interstate inmate transfers have also been used to transfer inmates to facilities with better treatment and training programs and youthful offenders to more appropriate (though out-of-state) juvenile correctional settings. 
But what explains this variability in our understanding of interstate inmate transfers? Can we come to some normative and empirical conclusions about IITs? The following project generally suggests that we can-but only if we apply a theoretical framework to additional data collection efforts. Simply, utilizing theory will allow us to better organize data and more productively develop and test hypotheses related to interstate transfer types, the attributes of transferred inmates, the decision-making environment in which a correctional manager is situated and the various management philosophies informing administrative intent. The goal of this project then is to move beyond the polemic and anecdotal story of inmate transfer "disasters" to a more nuanced and theoretically-based understanding of an important and largely misunderstood phenomenon. 


\section{CHAPTER I: INTRODUCTION TO INTERSTATE INMATE TRANSFERS}

\section{AS A RESEARCH PROBLEM}

"Every warden felt as did the bard of old when he affirmed that 'I am forbid to tell the secrets of my prison house."'-Warden Lewis Lawes (1932), from "20,000 years in Sing Sing."

\section{Interstate Inmate Transfers as a Research Problem: Organization of}

\section{Chapter I}

The interstate inmate transfer (IIT) phenomenon is extraordinarily complex. Unfortunately, very little descriptive or theory-driven research has been conducted in relation to their use. As one correctional manager once commented to me, "No one really understands [the phenomenon] entirely (name withheld, personal communication, 2005)." In order to correctly frame and discuss the findings of this research, a number of key elements relating to the use of IIT transfers are identified and discussed in this chapter. The first portion of Chapter I describes what IITs are, some rough estimates on their use and a few illustrative IIT examples from Arizona, California and Hawaii.

IITs have become a somewhat controversial policy. Therefore, a summary of the debate over their use is also presented in Chapter 1. These debates typically focus on the administrative intent of IITs and manifest as normative assessments derived from critical theory, personal opinion and/or media portrayals of anomalous incidents. These discussions have greatly influenced the research questions, assumptions, and methodology informing this research. Following a discussion of 
the debate over IITs, the research questions are stated, and the assumptions and methodology of this research are summarized. In concluding Chapter I, the value of this study is summarized and the organizational structure of this dissertation is presented.

\section{Interstate Inmate Transfers in Practice: Anecdotal Stories \& High-}

\section{Profile Cases}

For over thirty years, state-level prison administrators have utilized interstate inmate transfers (IITs) to manage their institutions (USDOJ, NIC, 2006). Currently, IITs are used by 46 states and are implemented by correctional managers situated at multiple levels within state correctional bureaucracies (p.2). Typically, and as the term suggests, IITs involve the transfer of incarcerated offenders from one state correctional facility to another. Jurisdictionally speaking, these transfers are facilitated (and constrained) by DOC policy and unique interstate agreements, by state and federal law, by the territorial boundaries of the United States and by the availability of receptive correctional facilities (USDOJ, NIC, 2006). IITs may also be used to transfer inmates to or from local jails or from jails or state-level correctional institutions to federal correctional facilities (Kerle, 1999 in Carlson \& Garrett; B. DeHaan, personal communication, 2005).

The following discussion describes current examples of IITs in American corrections. These anecdotal accounts are utilized as a way to breathe life into a practice that is - if it is understood to occur at all—relatively abstract and unusual, 
even for some correctional practitioners themselves. Additionally, by describing current, "high-profile" and "real-life" examples of IITs in action, this study hopes to underscore the importance of research on the topic due to the increasing scale of such transfers and the potential for unintended harm that may result from them. Finally, although the following descriptions of IITs present a number of potential research opportunities (e.g., the experiential realities of transferred inmates), it is clear from the following examples that understanding those who are ultimately tasked with implementing IITs — correctional managers — must be a logical first step in research. Simply, these illustrations are intended to add emphasis to this study's focus on the critical role of correctional managers and to give life to a phenomenon that has, for too long, been ignored or, at best, incompletely studied.

\section{$\underline{\text { Recent IIT Cases }}$}

On April 24, 2007, roughly 600 Arizona prison inmates initiated a prison riot that lasted for two hours and resulted in multiple injuries to both staff and inmates (Murphy, April 25, 2007). Interestingly, this riot did not occur in an Arizona prison. Rather, it occurred in the private Indiana correctional facility ${ }^{1}$ to which the first 600 of 1200 Arizona inmates had been transferred six weeks prior to the riot.

Commenting on the Indiana Department of Corrections' hesitance in accepting any more Arizona inmates, Indiana Corrections Commissioner J. David Donahue explained the cause of the riot in this way: "The system is different than what [Arizona inmates] are accustomed to [...] (AP, 2007, p.1)." Arizona Correctional

\footnotetext{
${ }^{1}$ New Castle Correctional Facility, New Castle, Indiana. Facility run by the Geo Group.
} 
officials added that the state had made the transfers too quickly and that many of the transferred inmates had complained about being moved (p.1). Although one condition of the transfer agreement ${ }^{2}$ between Arizona and Indiana stipulated that the Arizona inmates chosen for transfer were to be picked from among those with the best behavioral records, ${ }^{3}$ this requirement, ultimately, did not prevent prison violence, and, some argue, may have contributed to it. Simply put, the "wellbehaved" Arizona inmates seem to have become angry that they were transferred away from their families, friends, and other comforts and conditions of confinement not found in Indiana (p.1).

Interestingly, a number of private prisons in Arizona hold inmates from other parts of the country. A June 2002 article in The Arizona Republic entitled, "Transplanting [the] Aloha Spirit" discusses the "welcoming" of 300 indigenous Hawaiian inmates to the Saguaro Correctional Center in Eloy, Arizona (Bui, 2002). Hawaii, as is the case with many states, has a severe overcrowding problem. However, unlike most states, Hawaii has only a small amount of land on which to build new prisons and must find space elsewhere ${ }^{4}$. The Saguaro facility, asserts Hawaiian Department of Public Safety Spokesperson Shari Kimoto, is a medium security prison intentionally designed to be culturally sensitive to Hawaiian inmates - to include a rice bar, "plenty of pork for inmates" and programs which will allow

\footnotetext{
${ }^{2}$ The agreement between Arizona and Indiana was concluded March 9, 2007. Three days later, Arizona inmates began to arrive in New Castle (Private Corrections Institute, August $21,2007)$.

${ }^{3}$ Inmates are selected based on their behavior in prison, not on their criminal record. One third of the transferred Arizona inmates were convicted of violent offenses (Private Corrections Institute, August 21, 2007).

${ }^{4}$ So far, Hawaii has sent inmates to Mississippi, Oklahoma, Kentucky, Texas, and Arizona (Bui, 2002).
} 
inmates to remain "spiritually connected to their heritage (p. B6) $)^{5}$." Additionally, the neighboring Red Rock Correctional facility "serves an [indigenous] Alaskan population" and, like Saguaro, has also attempted to implement a number of cultural programs. LeeAnn Archuleta, Chief of Unit Management for the Saguaro facility asserts, "We are sensitive to our population's needs so they can go back out into society and be able to contribute again (p. B6)." Although there is little reason to doubt the veracity of Archuleta's statement, one can't help but wonder why Arizona's DOC-level correctional managers are sending hundred's of Arizona inmates to Indiana while Arizona's prison-level correctional managers are accepting hundred's of Hawaiian and Alaskan inmates.

Like Arizona, the state of California is currently experiencing problems with prison crowding and is considering IITs as a solution-but on a much larger scale. California is currently considering an interstate inmate transfer of between 5,000 and 7,000 state prison inmates to various state correctional facilities located throughout the United States (Vogel, 2007; Thompson, 2007) ${ }^{6}$. Perhaps the most important consideration for California correctional managers (and state policy makers) is the threat from the federal courts that if they do not reduce inmate populations, judicial administrators will take control of the California penal system and, for example, begin releasing inmates. However, the reason offered by California officials Governor Schwarzenegger in particular - for these transfers is that they will help to

\footnotetext{
${ }^{5}$ In 2007, two Saguaro correctional managers quit after they left a security door opened and seven Hawaiian inmates began fighting. The managers blamed the poor and degraded conditions of confinement at Saguaro (AP, 2007).

${ }^{6}$ California is considering sending inmates to private prisons in Arizona, Mississippi and Oklahoma (Thompson, 2007).
} 
alleviate California's crowded prison system which will, in turn, help to alleviate some problematic conditions (e.g., inmate violence) within the prisons as well as preserve the public's safety (Thompson, 2007; California Correctional Peace Officers' Association et al., v. Arnold Schwarzenegger, as Governor, etc. et al., (2008) June 04 CA1/3 C055327).

\section{Number of IIT Cases}

Exact national or state-by-state counts of IITs are very difficult to determine due to the confounding of transfer types (e.g., "bed rentals" vs. Interstate Corrections Compacts) and/or the unavailability of data on transferred inmates. The NIC reports "at least 4,900" male and female inmates on "transferred status as of July 1, 2005" (USDOJ, NIC, 2006, p.2; See: Appendices B1 \& B2). However, the number of transferred inmates is likely much higher. ${ }^{7}$ Some of the IIT numbers cited previous to the NIC report, though never systematically reported, hint at the scale of the IIT phenomenon and are briefly discussed below.

In 1998, the State of Virginia discovered that it had more than 3,300 excess prison beds, which led officials to take in prisoners from a number of other states in order to fill the void (Greene, 2002, pp. 107-110). ${ }^{8}$ In 2000, Texas alone was already housing somewhere in the neighborhood of 5000 inmates from fourteen different

\footnotetext{
${ }^{7}$ Currently, one rough estimate places the actual number at around 35,000 to 40,000 inmates. (M. Brown, University of Hawaii, personal communication, ASC Conference, Nov. 16, 2005).

${ }^{8}$ The intentional overbuilding of the prison system in Virginia and the leasing of these extra beds to at least six other states has helped to bolster the state's general fund by (after costs are deducted) $\$ 13.9$ million per year (Greene, 2002, pp. 107-110). It should also be noted here that one former acting director of the Oregon Department of Corrections, Dr. Benjamin DeHaan, vehemently disputes Greene's assertions on this matter and argues that Greene has misunderstood the entire affair.
} 
states (Dyer, 2000, p.16). By 2001, roughly 12,000 inmates from across the nation were serving their sentence in other states (Pollock, 2004). Legislation enacted by Connecticut in 2003 allows the state to transfer up to 2500 inmates per year to outof-state prisons (public or private), an increase from 500 over the previous year (OLR Research Report, 2003). In 2005, the Washington State Department of Corrections moved 300 additional inmates to out-of-state locations managed by Corrections Corporation of America, which already hold 290 Washington State inmates. In addition to those inmates, Washington State had previously relocated 525 offenders to public and private prisons in Minnesota, Colorado, Nevada, and Arizona bringing the current total of transferred Washington State inmates to between 1000 and 1,115 (AP, June 6, 2005; H. Clark, Secretary, Washington State Corrections, personal communication, March 16, 2007). Similarly, but on a much smaller scale, the State of Oregon transfers approximately 20 inmates (ODOC, 2008), or "ghosts" (B. DeHaan, personal communication, February, 2005), per year to out-of-state locations. In 2007, California considered (and is still considering) a proposal to transfer 5,000 to 7,000 inmates to prisons in other states and Arizona, which had been very active in transferring inmates to out-of-state prisons, is experiencing inmate conduct problems associated with the recent transfer of 600 inmates to a private prison in Indiana (Murphy, April 25, 2007).

Finally, Hawaii has sent roughly 2,000 inmates-“about half of the state's convicted felons" (Talvi, 2006, p.28)-to locations in other [mainland] states and currently "leads the nation in interstate inmate transfers (p.28)." Hawaii is an 
interesting case for three reasons: 1) It has an exclusive contract with Corrections Corporation of America, a controversial private contractor; 2) It is one of only two states that did not respond to the USDOJ request for information on interstate transfers (February, 2006); and 3) The type of inmates transferred from Hawaiioften indigenous Hawaiians-has led to a great deal of outrage on the part of native Hawaiians, prison activists, and scholars (Brown, 2005 and personal communication, November 16, 2005; Talvi, 2006). ${ }^{9}$

Unfortunately, there is no theory- or data-driven research to support generalized assumptions regarding interstate inmate transfers. Therein lies the problem: The increasingly widespread implementation of policy based upon intuition, "common sense" and an individual's idiosyncratic beliefs about the benefits (or harm) of IITs may lead to potentially destructive and unintended consequences. Unfortunately, the negative consequences of some high-profile transfers may lead to negative perceptions of administrative intent in all IIT cases, and catalyze reform efforts that, similarly, are based more on intuition, ideology and idiosyncratic beliefs rather than case-specific, or other systematically collected data. Reform efforts based on these foundations will, like initial implementation strategies, most likely lead to unanticipated and undesired effects (Rothman, 1971, 1980/2002)

Ultimately, the practice of transferring inmates from one jurisdiction to another - as well as the administrative law, policy and state or federal legislation 
allowing IITs- has been found to be constitutionally sound (Olim v. Wakinekona, 461 U.S. 238 [1983]) and in accordance with traditional and accepted tenets of American federalism (Wildavsky, 1998, p.5; Gary McConnell, 2001; The Council of State Government, 2001). Simply stated, IITs have become a widely accepted and legitimate administrative practice in American corrections. As evidenced by the Hawaiian case for example, the practice is not without its critics.

\section{Summarizing the Current Debate}

Over the years, interstate inmate transfers have been the subject of a number of legal disputes, normative reform proposals and dramatized media accounts. As evidenced in the previous discussions, the administrative intent of IITs - especially in high-profile cases - is both defended and criticized. In sum, some scholars, critical of the practice, have hypothesized that the use of IITs can be attributed to the informal emergence of a destructive "new penology" (Feeley \& Simon, 1992) in corrections (Shichor \& Sechrest, 2002). Others, typically correctional practitioners themselves (B. DeHaan, personal communication, 2005; U.S. Department of Justice, 2006; "Warden A", personal communication, June 9, 2008; “Warden B", personal communication, June 24,2008 ), argue (or hypothesize) that in addition to serving the needs of correctional managers, IITs may also help inmates reenter society, remain physically safe while incarcerated, remain close to family and friends, and have access to appropriate correctional programming and treatment. It is useful to examine these debates more closely. 
Critics of an emerging new penology argue that IITs - and the legislation and court decisions supporting their use - have provided correctional managers with aggregate inmate management tools which primarily serve an instrumental purpose. That is, IITs are used primarily as a way for correctional managers to maximize budgets (or profit in the case of private prisons), minimize risk, and control populations within overcrowded institutions. The new penology perspective assumes only one set of correctional goals based upon actuarial, aggregately-oriented and/or economic concerns derived from institutional needs and broad systematic demands for rationality and efficiency (Feeley \& Simon, p.454). Additionally, the new penology construct assumes that in the "contemporary setting," these internal institutional needs are rarely (if ever) related to public demands and desires (p.450). The new penology also assumes that responses to institutional needs do not vary in relation to the beliefs of individual correctional managers, and in fact form the essential ideological orientation of all correctional (and other criminal justice) managers. Feeley and Simon (p.452) write, "This strategic formation of knowledge and power offers managers of the system a more or less coherent picture of the challenges they face and the kinds of solutions that are most likely to work." This perspective assumes a somewhat homogeneous penal ideology among correctional managers. This leads to the conclusion that all correctional managers will always fail to consider the individual characteristics or circumstances of individual inmates and thus, fail in their traditional mission to facilitate individualized justice (Feeley \& Simon, 1992; Shichor \& Sechrest, 2002). In sum, the new penology construct 
assumes that the correctional context either: 1) does not vary; or 2) varies but contextual variability has no impact on the administrative intent of IITs. Similarly, it assumes that human agency is non-existent or not possible in the current penal context and/or that individual correctional managers do not share (and act on) different beliefs about the efficacy and/or appropriateness of correctional policies. Interestingly, the new penology may not be all that "new." In fact, the new penology appears to be an "emerging" penal strategy that can be understood within the bounds of the technical-rational bureaucratic tradition (Weber, in Gerth \& Mills, 1958; Adams \& Balfour, 1998). This tradition

[limits] the field of ethical behavior to questions of efficiency [...] and relieves, and even prohibits, individual administrators from making substantive value judgments. Many scholars, from various fields, have long been critical of this type of public administration (Argyris, 1954; Morgan, 1988; Block, 1993; Farmer, 1997; Adams and Balfour, 1998; Goodsell, 2004) and, much like critical criminologists' responses to the new penology, have responded vigorously. For example, in response to the perceived social impact of technical-rational bureaucracy (i.e., prioritizing efficiency over justice concerns), the New Public Administration perspective that emerged in the 1970s emphasized the importance of value-guided policy research and individualized implementation strategies (Denhart, 1984; Morgan, 1988). As Morgan (p.5) writes, the New Public Administration saw “[ ...] bureaucracy as a carrier of humane values [...]." Simply put, these scholars argued that the implementation of public policy based solely on measures of efficiency, positivist 
science, and resulting data - without a consideration of broader social values (or regime values, Rohr, 1989) - would lead to harmful policy outcomes (Denhart, 1984, pp. 110-111). Goodsell (2004) writes that scholars critical of organizational behavior on technical rational grounds base their arguments on the understanding that because modern organizations are "commit[ed] to modernist technical rationality in the absence of contextual understanding and reflexive moral thinking," they "can become the perpetrator of absolute evil without the bureaucrats realizing it."

In addition to linking an understanding of correctional management, and the use of IITs in particular, to a new penology and/or to a simple model of technicalrational bureaucratic behavior, some criminal justice scholars and observers critical of IITs (Dyer, 2000; Shichor \& Sechrest, 2002, p.399; Welch, 2005) have also linked correctional management, the new penology and the use of IITs to a market model of public administration, or rather, to a "New Public Management" (Goodsell, 2004; Osborne \& Gaebler, 1993) or “entrepreneurial model” (Morgan, Book Review, 1998) of public administration. The New Public Management framework emerged in the 1980s (Goodsell, p. 150) and articulates a contrary "reformative" notion of public administration than that expressed previously by New Public Administration scholars. The New Public Management perspective is, in many ways, anti-public administration in that it normatively links an idea of appropriate public administration reform to a general business or private market model (Morgan, 1994; Goodsell, 2004) (See: Osborne \& Gaebler, 1993; and Al Gore's NPR: National Performance Review and "reinventing government"). Although this model again 
elevates bureaucratic efficiency concerns over individualized justice, it also incorporates a "profit and/or budget maximizing" element in its notion of efficiency. From this perspective, then, prisons should operate like a business, or as critics of prison privatization argue, actually become for-profit businesses (Sarabi \& Bender, 2000; Yeoman, 2000; Shichor \& Sechrest, 2002, p.399; Welch \& Turner, 2004; Welch, 2005; Jones \& Newburn, 2005).

Critics argue that this form of public administration places a higher priority on economic efficiency in government than the individualized or collective needs of the community (Morgan, 1994; Sarabi \& Bender, 2000; Yeoman, 2000; Shichor \& Sechrest, 2002; Welch \& Turner, 2004; Welch, 2005; Jones \& Newburn, 2005; See: Anti-privatization Advocacy Coalition in Culp. 2005, Pp. 433-444). Because prisons have become more "businesses-like", they argue, individual and collective interests have been marginalized or ignored. This is true of IITs in particular, critics argue, because they are used primarily to maximize profit (as in the case of private prisons, and some public jails, see: "public proprietary" facilities, Shichor \& Sechrest, 2002, p.393; Dyer, 2000) or they are used to minimize expenses and reduce risk while maximizing available space (as in the case of public prisons) (USDOJ, NIC, 2006; Shichor \& Sechrest, 2002). Shichor and Sechrest (p.399) write:

[Questions about IITs] stem from the rational business model of other industries, which entail the outsourcing of production and services, downsizing, globalization, the proliferation of multinational corporations, and above all, the tendency for 
continuous expansion and growth that is a built-in characteristic of business organizations.

Ultimately, IIT critics argue, the emphasis placed on economic efficiency by this type of inmate management strategy is anti-democratic (See: Anti-privatization Advocacy Coalition in Culp. 2005, Pp. 433-444) because it marginalizes and exploits individual offenders in order to achieve short term "profit" and long-term "growth" at the expense of broader collective goals such as punishment and deterrence, offender treatment and training, offender reentry and the humane treatment of inmates (Welch, 2004; Talvi, 2006).

Other criticisms of IITs are linked less often to theory and more often to normative beliefs and assumptions regarding American corrections generally, and the administrative intent of IITs specifically. Typically, these critics imply that the use of IITs is a result of administrative shortcomings (e.g., poor decision-making by poorly trained managers) or that IITs have an intentionally nefarious intent (e.g., extra-legally punishing incarcerated offenders by sending them to a prison very far from their home states and/or to a prison notorious for its poor conditions of confinement; Inmate name withheld, personal communication, November 2006). In sum, these perspectives argue that the correctional managers who use IITs are incompetent, indifferent or intend to harm inmates (Sarabi \& Bender, 2000; Dyer, 2000; B. Sarabi, personal communication, April 9, 2002; Pollock, 2004). Although all of the aforementioned assumptions regarding the administrative intent of IITs may be true in some cases, they are probably not true in all cases (B. DeHaan, 
personal communication, 2005). In short, some critics of IITs may be oversimplifying the phenomenon.

On the other hand, some correctional practitioners implicitly argue that IITs serve a constitutive purpose - a purpose best described as one directly related to traditional theories of democratic governance and constitutional norms, and in which administrative power is exercised in response to the broader needs of the community and not merely for narrow, self-serving personal or organizational purposes (Rohr, 1989; Morgan, 1994; Cook, 1996). Simply stated, some correctional managers have argued that the IIT tool allows them to better serve the interests of society because it gives them more flexibility in balancing the needs of individual inmates and the management needs of their institutions ("Warden A", personal communication, June 9, 2008; "Warden B", personal communication, June 24, 2008). This is especially true, some argue, when institutions experience overcrowding (California Correctional Peace Officers' Association et al., v. Arnold Schwarzenegger, as Governor, etc. et al., (2008) June 04 CA1/3 C055327). Because the IIT tool gives managers the option to reduce inmate populations during periods of overcrowding, correctional managers are better able to adhere to traditionally held public expectations regarding incarceration: to facilitate crime control efforts through the individualized punishment, treatment and training of incarcerated offenders (Feeley \& Simon, 1992; Shichor \& Sechrest, 2002; Seiter, 2002).

Of course, some correctional managers may be overstating the constitutive sensibility that influences their decision to use IITs, especially under stressful 
institutional conditions. It is clear that IITs are used for purely instrumental purposes on at least some occasions. Unfortunately, accurately generalizing about the administrative intent of IITs is currently not possible. Very little systematic research has been conducted on them (See: USDOJ, NIC, 2006) and - aside from Shichor and Sechrest's use of anecdotal evidence to support their new penology hypothesis - no theory-driven research has been conducted at all. The absence of "hard data" may be hindering our ability to utilize the practice effectively, and, some argue, humanely (Marshall, 1983; Talvi, 2006).

Interstate inmate transfers in an empirical sense are "problematic" (Singleton \& Straits, 1999, p.65) in that they are used in an inconsistent manner (USDOJ, NIC, 2006, pp.17-18) and appear to be misunderstood or misinterpreted by most people, including some correctional managers (B. DeHaan, personal communication, 2005). Because interstate inmate transfers appear to be a discretionary, "ordermaintenance" tool of correctional managers, understanding their use of these tools is important. Unfortunately, due to the dearth of research on correctional management generally (DiIulio, 1997; Hensley \& Tewksbury, 2005), and a correctional manager's use of interstate inmate transfers specifically, we currently do not know much about how or why interstate inmate transfers are used. This study hopes to contribute to a better understanding of IITs and their use by prison wardens.

\section{Research Issues Emerging From This Debate}

A number of important research questions and issues emerge from the debate over the use of IITs. However, the most important concern of this research centers 
on whether or not the new penology adequately explains the administrative intent of IITs when they are used by prison wardens. The following subsections discuss the specific research questions and assumptions of this research (to include the operationalization of the concept "administrative intent") and briefly introduce the new penology as an interesting, but potentially flawed, theoretical framework. Additionally, this section introduces key categories of influence anticipated by this research to impact administrative intent and provides an overview of the methodology employed by this study.

\section{$\underline{\text { Research Questions }}$}

For the purposes of this study, I am interested in the discretionary role that prison wardens play in the IIT system. This study asks three broad questions of wardens: What correctional goals do you hope to accomplish with interstate inmate transfers? Why? And what contextual factors (if any) are felt to inhibit or facilitate these goals? This case study generally challenges the idea that all IITs can be attributed to the emergence of a "new penology" in corrections. Simply, this is because the new penology framework fails to anticipate the possibility that high levels of human agency and autonomy may exist among prison wardens and that these factors may, in some cases, facilitate, rather than impede, institutional, individual offender and community interests. Importantly, the new penology fails to anticipate variation in the dispositional and situational factors that may impact an individual prison warden's implementation of IITs. These factors (and their 
interaction) are likely to result in decision-making variability, and thus, variability in administrative intent.

This study, borrowing from the work of John DiIulio (1987), views prisons as governance systems. In doing so, this study necessarily focuses on the experiential realities of prison wardens as "governors," or "governmental keepers" (DiIulio, 1990). John DiIulio (p.47) writes, "From a governmental perspective, the key actors in any prison setting are the prison administrators, from the director to the warden to the most junior correctional officer in the cell block. They are the government of the prison." Therefore, the approach taken by this research focuses directly on understanding the individual tasked with implementing IITs at the prison-level and his/her interactions with a broad array of institutional actors and forces. This approach contrasts with possible studies that focus more broadly on the behavior of, and interactions between correctional and other criminal justice organizations (Crank \& Langworthy, 1992), or those studies that focus solely on the experiential realities of the transferred inmates (i.e., a more traditional focus on "the sociology of the cell block" [Sykes, 1958; DiIulio, 1990]). This study concludes in Chapter VII by suggesting that institutional theory (Selznick, 1992; Scott, 2008) may be more useful than the new penology in developing an understanding a prison warden's use of IITs.

\section{$\underline{\text { Research Assumptions }}$}

In challenging the claims of the new penology, a basic, underlying assumption of this research is that administrative intent in IIT cases are driven by a highly dynamic combination of dispositional and situational factors (Zimbardo, 
1972 \& 2008). Philip Zimbardo (p.vi, p.7) simply defines dispositional forces of influence as those "inner" influences which inhere in, or can be attributed to an “individual [decision-maker's] inner nature, genetic make-up, dispositions [\& beliefs], personality traits, and character." He describes situational forces of influence as forces external to the individual actor such as the social and political environment, the "system" in which an individual is ensconced, and other factors external from, and [at least, initially] unrelated to, an individual's dispositional characteristics. While Zimbardo emphasizes the impact of situational factors and (p.8) asks, “To what extent can an individual's actions be traced to factors outside the actor, to situational variables and environmental processes unique to a given setting [italics added]?", this research also asks to what extent (and under what conditions) can an individual's actions be traced to factors within the actor, to their attitudes, beliefs, experiences and knowledge?

In simply summarizing the results of The Stanford Prison Experiment and his related analysis of the $2004 \mathrm{Abu}$ Ghraib military torture scandal in Iraq, Zimbardo (2008, p.445) writes,

Bad systems create bad situations create bad apples create bad behaviors, even in good people.

In many ways, this simple normative summary of Zimbardo's research (drawn from a complex, 488 page work) amplifies the drier and slightly less normative assertions of the new penology perspective. In fact, like the new penology, Zimbardo's current work (2008) also places a heavy emphasis on the power of situational forces while 
greatly deemphasizing the power of dispositional forces. Zimbardo's research, in many ways - especially when human beings are placed in uniquely stressful circumstances - rejects purely dispositional explanations for human behavior and is primarily interested in examining situational decision-making influences as causes of "human failings" under stressful conditions. The research conducted here, in challenging the new penology as an explanatory framework, re-emphasizes the potential power of dispositional forces on administrative intent under "normal" and "stressful" circumstances.

Borrowing from the work of Dorothy Smith (1987 \& 2006) and viewing the interview data through the lens of institutional ethnographic research (De Vault \& McCoy, 2006), the data were organized and analyzed in terms of ruling relationships and categorically divided into dispositional and situational factors of influence. Based on Zimbardo's work this research will analyze interview and survey data in each case in relation to three main categories: 1) What dispositional factors were perceived by the respondent to have influenced the administrative intent of an IIT? 2) What situational factors were perceived to have influenced administrative intent in relation to IITs? And 3) how do the results of the previous two analyses compare with the assumptions of the new penology? Although this research borrows from Zimbardo's situational and dispositional categories, it is more simply interested in identifying these influences in relation to their perceived effect on decision-making in correctional management without normatively assessing (e.g., in terms of "good" and "evil," or "good and bad" as Zimbardo does) the behavior of the individual 
respondents, or the factors which appear to influence administrative intent. Prior to a brief discussion on the situational and dispositional factors anticipated to be influential by this research, it is necessary to first discuss the concept of "administrative intent."

\section{$\underline{\text { Administrative Intent }}$}

"Administrative intent," though not formally defined or identified as such in the literature, is an important concept and is discussed by a number of scholars in a variety of ways (Duffee, 1986; Dilulio, 1987; Morgan, Chpt.1; Cook, 1996; Vinzant \& Crothers, 1998; Stojkovic \& Farkas, 2003). Drawing from this literature, "administrative intent" is understood for purposes of this study as one or more purposive ideals that inform administrative action. Administrative intent, then, is a precursor to administrative action and is influenced by an individual administrator's personal goals, beliefs about good decision-making, organizational demands, and their perception of the rules, laws, policies, politics and public expectations which constrain, guide or facilitate administrative action. This conceptualization of "administrative intent" allows the study to remain analytically focused on subjective, individual-level decision-making influences and to underscore the potential for variability, even among prison wardens situated within the same state correctional agency. Furthermore, by remaining focused on administrative intent, this project expects to develop a better understanding of a prison warden's subjectivelyinterpreted reality and the intended, rather than actual outcomes of IITs. Thus, this study moves beyond an analysis of observable behavior to a study of, as Jerome 
Bruner (1990, p.2) writes, "[the formal discovery and description] of the meanings that human beings [create] out of their encounters with the world." A typology and discussion of "administrative intent" in relation to IITs is discussed in Chapter II of this research. This typology will be utilized during the data analysis portion of the research.

The new penology construct assumes a purely instrumental administrative intent and does not allow for the possibility that some prison wardens, under some conditions, may be inclined to use the tool both instrumentally and/or constitutively. Instrumental administrative intention and action in public administration has long been a topic of discussion for public administration scholars. Bud Kass (1998, in Adams and Balfour, p. x) writes,

The technocratic separation of means and ends and the workings of bureaucratic specialties have further obscured the moral relationship between what humans do and the effect these actions have on others.

In more direct and, perhaps, less poetic terms, instrumental thought and behavior in public administration may be considered planned or enacted administrative action that is primary designed to serve the individual administrator and/or their organization and which is disconnected from the needs of other institutions, organizations, individual clients, or the community generally (Morgan, 1988; Cook, 1996). In short, instrumentalism in public administration involves the invocation of a self-serving calculus designed to further the short-term interests of the individual administrator and/or their organization. 
A number of recent Hawaiian IIT cases (discussed previously) might be considered good examples of instrumentalism in public administration. For example, in transferring indigenous Hawaiian female inmates to a private prison in Kentucky in order to reduce crowding and to save on medical expenses, critics (Talvi, 2006) implicitly argue that Hawaiian prison administrators have instrumentally utilized their discretionary power. This argument appears to have some merit. Simply, because IITs appear to have been used without thought to the impact they would have on the transferred inmates, the indigenous Hawaiian community, or on the inmate's children (left behind in Hawaii), the intent of the transfers appears to be instrumental.

On the other hand, constitutive administrative intent and action emphasizes the role of administrators in reconciling "individual self-interest and the larger public good (Morgan, 1988)" and recognize that the long-term consequences of purely instrumental behavior may have a corrosive effect on both the public institution and on the community. As Brian Cook (1996) and Doug Morgan (1988) argue, constitutive rationality goes beyond a means-ends calculus and incorporates normative notions of "fairness," "justice,' and "the greater good" as understood in the context of the administrative action.

Examples of constitutive rationality may be found in the discretionary use of IITs as well. For example, some inmates have been transferred due to overcrowded conditions but have also been specifically chosen (or have volunteered) due to their unique attributes (e.g., juvenile status), problems (e.g., drug treatment available in 
other states) and circumstances (e.g., inmates are separated from their families and communities by thousands of miles). In cases such as these, the rights (and needs) of the individual have been balanced with the rights (and needs) of the state in a manner that may not fully satisfy either party in the short-term but may, in fact, achieve longterm collective goals not obtainable through instrumentalism.

In summary, the assumptions (and findings) of this research suggest that we view prison wardens as something more than uniformly self-serving and instrumentally-inclined public administrators. Rather, this study has found evidence of variability in the administrative intent and discretionary use of IITs due to variation in the individual dispositional characteristics of prison wardens such as their beliefs, personal attributes, knowledge and experiences. However, this study has also found evidence of variation in administrative intent and the discretionary use of IITs due to situationally powerful institutional influences.

This study identifies four broad areas of situational and dispositional factors that may have varying degrees of influence on the administrative intent of IITs. It is useful to briefly review these factors here, but they are discussed more thoroughly in the literature review in chapter II. These factors are:

Situational Factors:

1. Law

2. Discretionary decision-making: procedures, processes and limits

3. Institutional Environment/Correctional Context 
Dispositional Factors:

4. Correctional Management Philosophy: Management style and beliefs

$\underline{\text { Law }}$

In addition to state and federal legislation influenced by the U.S. Constitution permitting the use of IITs (Article I, Section 10), and the Supreme Court's decision upholding legislation authorizing their use, IITs are also an artifact of American political culture (i.e., federalism). Simply stated American law and political culture have greatly influenced the intent and uses of IITs in the past and continue to do so today. Law and political culture act to constrain and/or legitimize the use of IITs for both instrumental and constitutive purposes.

\section{Discretionary Decision-Making}

The ability to transfer inmates across state lines is a discretionary tool typically utilized at two levels of prison administration: 1) At the prison/institutional level IITs are utilized to manage specific inmates; and 2) at the Department of Corrections level IITs are utilized to manage the entire inmate population or correctional "system." 10 Variability - and its causes - in discretionary decisionmaking are largely overlooked by the new penology construct. This may lead to a distortion in our understanding of the administrative intent of IITs. For the purpose of this project, much attention is paid to the exercise of discretion, which in part and to varying degrees, is influenced by a manager's beliefs about their role and their 
beliefs about best way to implement policy in a particular field and within a particular institutional context (Rohr, 1989; Scott, 1995). Understanding the role that discretion plays in public administration — and the normative drivers that influence discretion - are an important first step in understanding variations in the administrative intent of IITs.

Institutional Environment/Correctional Context

Another group of situational factors important to our understanding of administrative intent is the institutional (and institutionalized) nature of correctional practices. This study assumes that correction officials are more than simply managers of an organization. They are agents of institutions that are embedded in multiple communities and therefore may be greatly influenced by internal (e.g., unionization, employee/staff issues, and inmate issues) and external forces of change (e.g., news $\&$ other mass media [Freeman, 2000; Surette, 2007], the politics of crime control [See: Cohen, 1996; Scheingold, 1995]; the politics of criminology [See: W. de Haan, 1990]; inmate advocacy coalitions, judicial and other court interventions). In some cases, the impact of a correctional manager's institutional environment may have an impact on the administrative intent of IITs. Under some circumstances, these influences may even "trump" a manager's correctional philosophy and beliefs about "good" prison governance. In the cases examined here, for example, "highpress" inmates and court interventions that threaten the autonomy of prison wardens and other DOC officials were found to be situationally stressful and, in some cases, may have led to an adjustment in attitudes about correctional management in order to 
avoid such threats in the future. On the other hand, the institutional environment may exert little or no influence at all on a warden, and they may feel free to implement IITs in accordance with his/her beliefs and experience. A prison warden's beliefs and experiences are dispositional factors of influence and are discussed in the following subsection under the rubric "management philosophy." Management Philosophy

John Dilulio (1998) argues that the "management variable" in corrections has been largely ignored. It is clear from the existing public administration and correctional management literature that a correctional manager's philosophical outlook toward their task may influence their decision-making and, thus, the administrative intent of IITs (Duffee, 1986; Dilulio, 1987; Pfeffer, 1992; Kouzes \& Posner, 2003; Seiter, 2004). Drawing from the work of David Duffee (1980-1986), "Management philosophy" might be simply defined as "a manager's style working in conjunction with their normative beliefs about the best way in which he or she should attempt to steer their organization towards their goal." In this study, an attempt is made to determine the influence of each prison warden's management philosophy on the administrative intent of IITs. The interview instrument (Appendix B) is designed to gather data on the respondent's style of correctional management, their beliefs about "good" correctional management and a description of how (and why) those beliefs developed. 


\section{Overview of Methodology and Brief Summary of Findings}

Due to the lack of research on IITs, this study employed an exploratory case-study methodology and simple narrative analyses based upon the epistemological assumptions of institutional ethnography, and related research techniques, in order to evaluate theoretically-derived assumptions (Burawoy, et al., 1991; Yin, 2003; Babbie, 2007) regarding the administrative intent of IITs. The case study proposed here is an initial effort to understand why, and to what end, prison wardens use IITs. It incorporates semi-structured telephone interviews designed to facilitate the discovery and exploration of unanticipated data and improve upon our understanding of correctional management and IITs generally.

This study was interested in assessing the perceived influence of a variety of context-specific internal and external organizational influences, as well as the personal beliefs and attitudes of individual prison wardens in relation to their influence on IIT transfers. The intent of this study is to use three case-specific oral and written interviews to explore the use of IITs and the administrative intent that guide their use and compare these responses to new penological assumptions. One of the cases consists of an in-depth oral interview with a prison warden who has directly implemented an IIT. The second case consists of an in-depth oral interview with a prison warden who has not directly implemented or influenced an IIT but would do so, if presented with the opportunity. The third case consists of an official written response by the Department of Corrections (DOC) to a written survey regarding the state's use of IITs. Due to formal and informal confidentiality and 
access agreements (and problems), the names of the state DOC, its wardens, or their institutions will not be identified in this research.

The data collected from this research was analytically bracketed by descriptive and causal statements. This was done in order to better interrogate and understand the rich data at hand and facilitate a more complete write up and analytical assessment in relation to the stated assumptions of this research. Each case was then "written-up" in relation to the stated assumptions of this research and organized in terms of dispositional and situational influences. The data from each case was then assessed in relation to new penological assumptions.

As anticipated, the cases examined here show that the new penology's omission of influential, dispositional factors in its framework may be problematic when studying powerful, uniquely situated and ideologically fixed prison wardens (Cullen, Latessa, Burton \& Lombardo, 1993) in relation to their use of IITs. However, the data also show that some situational factors (i.e., excessive media coverage and/or court interventions) cannot be ignored and, in some cases, may have some influence on the administrative intent of IITs. In sum, the case data collected in this research point to high levels of ideological and behavioral autonomy, high levels of individualized and moralistic thinking with regard to inmates and inmate management, and a general feeling that correctional management at the institutional level is only situationally (rather than perpetually) stressful. In Chapter VII a comprehensive discussion of the findings is presented in relation to theory, practice and policy. 


\section{Value of Study: Overview}

Correctional management realities are clearly complex (Jacobs, 1977;

Barak-Glantz, 1981; Fox, 1984; Duffee, 1986; Hart, 1995; Dilulio, 1997; Seiter, 2002). Bolman \& Deal (1991, p.309) argue that understanding “[ ...] complex [organizational] realities require complex approaches." This study assumes that IIT's are governed by complex organizational realities that require us to utilize descriptive, historical, legal and theoretical frameworks in order to acquire a full understanding of why IIT's are used. In doing so, this study intends to contribute to the field of correctional management and theory in three ways. First, this study will help us to develop a better descriptive understanding of correctional management, the correctional environment, and interstate inmate transfers generally. Adding descriptive clarity to all three phenomena will facilitate future research on the IIT phenomenon.

Second, this study is intended to qualitatively evaluate the assumptions of the new penology with an eye toward analytical generalization (rather than statistical generalization) and theory development. Contributing to the development of a falsifiable, theory-based understanding regarding how, why, and under what conditions prison wardens use discretionary administrative tools such as the IIT may allow for the development of more nuanced implementation strategies which, in turn, may achieve more predictable and more desirable outcomes (Menzel, 1987; Bolman \& Deal, 1991; Hill \& Hupe, 2002). Theory development is an important consideration in this research because new penological assumptions about IITs 
appear to fall short and no alternative theoretical frameworks have been proposed.

Although this study does not directly test institutional theory, it does use the framework to help describe and conceptually organize a prison warden's institutional environment.

Finally, through descriptive and theory-based research, this study is intended to contribute to a prescriptive understanding of how correctional managers might use IITs in the future. David Duffee (1986) and John Dilulio (1987) argue that developing a "policy-oriented knowledge" of prisons is important in helping us intentionally affect desired outcomes and avoid undesired outcomes. Dilulio argues that policy-oriented knowledge about prisons should be derived from research that focuses primarily on those who implement policy within the prison environment (e.g., wardens, administrators, correctional employees) and which attempts to understand the context in which desired and undesired penal outcomes occur (DiIulio, 1987, p.12). From this knowledge, argues Dilulio (p.12), we can better assess whether and how correctional policy should be altered. As opposed to implementing generalized reform policy based upon good intentions and deeply held assumptions regarding "good" prison policy (See also: Rothman, 1980/2002), correctional policy research must begin to be both: 1) focused on those who actually implement policy within the prison; and 2) be based upon solid empirical foundations. Gaining a better empirical understanding of the IIT tool (and variations), the contexts in which they are implemented, and by whom they are used (and why), will help us to better assess and modify (if necessary) the IIT as a tool of 
corrections. From this knowledge we may tailor, and better link IITs to inmate needs, institutional needs and conditions and externally derived crime control mandates. Ultimately, it is reasonable to conclude that through this (and continued) research on IITs, we might increase our ability to tailor interstate inmate transfer policies in such a way that unwanted outcomes (e.g., prison riots and increased offender alienation from family and community support systems) may be avoided in the future and desired outcomes become both predictable and achievable.

\section{Organization of the Project}

The following chapter (Chapter II) lays down the essential intellectual foundation needed to fully understand the complexity of the IIT phenomenon, the assumptions of this research and the problems associated with our current understanding of IITs. In this chapter, the new penology is discussed at length (though not comprehensively), and the concept "administrative intent" is introduced, operationalized and discussed in relation to the assumptions of the new penology. Following this discussion, and borrowing from Philip Zimbardo's (1971; 2008) work, a discussion regarding the potential impact of situational and dispositional factors of influence on administrative intent is presented. The remainder of the literature review in this chapter is categorically divided between the situational and dispositional factors that may influence the administrative intent of IITs at the prison-level.

Chapter III presents an in-depth discussion of the case-study methodology employed by this research. In addition to a literature-based rationale for this study's 
choice of subjects, case-design, and data analysis techniques, it also presents some interesting, though somewhat peripheral, findings in relation to the problems encountered while attempting to access prison wardens for this research. Although these findings alone might make for a respectable journal article, due to space constraints only the more important elements of these access problems are highlighted and discussed.

Chapters IV, V, and VI are the case discussions themselves. These case write-ups follow a similar format. Each case is introduced, described and discussed in terms of the respondent's perception—in their own words-of the situational and dispositional factors that influenced the administrative intent of IITs. Following these discussions, the specific case findings are discussed and visually modeled. For comparative purposes, diagrams are also presented in relation to the assumptions of the new penology, Zimbardo's model, and in relation to the original assumptions of this research prior to implementation.

Chapter VII concludes this project with a broad discussion of the findings in all three cases, the potential value of this study to correctional practices, policies, and theory and the problems and limitations of this research. Finally, the value of institutional theory is briefly explored as an alternative to the new penology. In briefly viewing some of the findings of this research through the institutional lens, this study emphasizes some of the weaknesses of the new penology in understanding complex decision-making behavior and highlights the potential value of institutional theory. 
CHAPTER II: LITERATURE REVIEW AND RESEARCH

\section{ASSUMPTIONS}

"A person's deed is understood when we know his intention." - Rudolph Steiner (in Seddon, 2005, p.69)

\section{Purpose and Structure of Literature Review}

As discussed previously, this study utilizes the concept "administrative intent" as a primary focal point and applies the concept to an understanding of individual-level decision-making in correctional management - specifically, to a prison warden's use of IITs. This study asks three broad questions of wardens: What correctional goals do you hope to accomplish with interstate inmate transfers? Why? And what contextual factors (if any) are felt to inhibit or facilitate these goals? The apparent simplicity embodied by these three questions is deceptive and their development - and refinement during the interview process - requires an extensive literature-based explanation. This chapter concludes by reintroducing and summarizing the assumptions and anticipated findings of this research and broadly linking them the reviewed literature. In Chapter VII, these assumptions and anticipated findings will be compared with the actual findings of this research.

The following six bodies of literature were utilized to craft this study and will be used to evaluate the collected data in relation to the administrative intent of IITs. Primarily, this literature is used as a way to contrast the assumptions of the new penology with enduring academic discussions related to correctional management and decision-making in public administration more generally. First, in drawing from correctional management and public administration literature, the concept of 
"administrative intent" is re-introduced and defined here in order to contrast enduring philosophical and theoretical ideas surrounding the origins of administrative action with the assumptions of the new penology. The historical use of banishment and transportation practices are then briefly discussed in order clarify the concept of administrative intent in relation to the state's use of IITs and a typology of "intent" is presented and discussed. Current discussions surrounding the new penology are then synthesized and presented in tabular form in order to provide the reader with an introductory sense of "what it is" and a clearer picture of its strengths and weaknesses. However, some time is spent discussing the broader, foundational philosophical and theoretical assumptions of the new penology in relation to administrative intent. Primarily, this is because the new penology construct contradicts the public administration and correctional management literature reviewed here and because exposure to these assumptions were the original catalyst for this research. Additionally, the assumptions of the new penology greatly informed the interview instrument and are used to identify, discuss and characterize a number of correctional attitudes and ideals that emerged during the interview and data analysis process.

Second, Phillip Zimbardo's (2008) recent work will be discussed. Key concepts are drawn from his work and are utilized to broadly categorize a variety of influences that may affect the administrative intent of IITs today. Zimbardo's work demonstrates an analytic alternative to the new penology and is utilized in this research as a way to better capture and reflect the realities of correctional 
management. Third, legal and legislative literature are utilized as a way to show a pattern of administrative and legislative intent shaped largely by the unique context of implementation (national, state and local). Fourth, public administration and correctional management literature is briefly reviewed as a way to support this study's contention that human agency - exercised in the form of administrative discretion - is influenced to a great degree by a correctional manager's beliefs and experience. Fifth, this study discusses the correctional context and its potential influence on administrative intent. A large body of literature (not all of it discussed here) emphasizes the variability and potentially stressful nature of the correctional context and its possible influence on correctional management and the institutional life of a prison warden. Finally, a literature-based explanation regarding the potential influence of a prison warden's management philosophy on administrative intent will be explored and a definition of the concept "correctional management philosophy" will be presented and discussed.

Although institutional theory (and other potentially useful frameworks) is not tested in this study, it has been used to identify and organize actual and potential influences on correctional management and administrative intent. Institutional theory will not be discussed in this chapter but will be briefly discussed in Chapter VII as an alternative framework by which we may study IITs in the future. Additionally, as discussed previously, this study employs an ethnographicallyoriented case study methodology. However, since the methodological approach used in this study will be discussed in greater detail in Chapter III, the remainder of this 
chapter will focus on the relevance of the other bodies of literature: 1) The concept of "administrative intent," the new penology and its assumptions; 2) Zimbardo's (1972 \& 2008) concepts of situational and dispositional factors of influence on human behavior and their relationship to our understanding the administrative intent of IITs; 3) The legal forms of IITs and their potential influence on the administrative intent of IITs; 4) Discretionary decision-making in public administration and correctional management and their relationship to the administrative intent of IITs;

5) the correctional context and its potential influence on the administrative intent of IITs; and 6) the correctional management philosophy concept and its potential influence on the administrative intent of IITs.

\section{The New Penology and Assumptions: A Question of Human Agency,}

\section{Inmate Management and Administrative Intent}

Administrative Intent

"Administrative intent," though not formally defined or identified as such in the literature, is an important concept and is discussed by a number of scholars in a variety of ways (Duffee, 1986; Dilulio, 1987; Morgan, Chpt.1; Cook, 1996; Vinzant \& Crothers, 1998; Stojkovic \& Farkas, 2003). Drawing from this literature, "administrative intent" is understood for purposes of this study as one or more purposive ideals that inform administrative action. Administrative intent, then, is a precursor to administrative action and is influenced by an individual administrator's personal goals, beliefs about good decision-making, organizational demands, and 
their perception of the rules, laws, policies, politics and public expectations which constrain, guide or facilitate administrative action.

This conceptualization of "administrative intent" allows the study to remain analytically focused on subjective, individual-level decision-making influences and to underscore the potential for variability, even among prison wardens situated within the same state correctional agency. Furthermore, by remaining focused on administrative intent, this study expects to develop a better understanding of a prison warden's subjectively-interpreted reality and the intended, rather than actual outcomes of IITs. Thus, this study moves beyond an analysis of observable behavior to a study of, as Jerome Bruner (1990, p.2) writes, "[the formal discovery and description] of the meanings that human beings [create] out of their encounters with the world."

In order to further clarify and contextualize the concept "administrative intent," it is useful to discuss inmate and offender transfers as traditional tools of the state, and to very briefly examine the intent of these transfers from a historical perspective. Examining the historical use of interstate (or other long-distance) inmate transfers has facilitated the development of a typology of administrative intent. Following a brief historical discussion on banishment and transportation practices, a typology of administrative intent is presented in tabular format.

All critics (including some scholars) of IITs often refer to them variably as both a form of banishment and a form of transportation under the seemingly unquestioned assumption that both terms are interchangeable. In fact, this is a 
conflation of very distinct rationales for sending inmates across state lines.

Because one purpose of this research is to begin clarifying the concept of "administrative intent" in relation to IITs, it is important at the outset to address the confusion surrounding key differences in the banishment and transportation concepts and the application of these terms to IITs today.

As administrative tools of the state, banishment and transportation have traditionally had very different meanings with regard to their intended purpose, or rather, their administrative intent. Banishment has traditionally been used to address individual deviance and, to some degree, the collective crime control needs of the community (Bleichmar, 1999; though not always, see: Spierenburg, in Morris and Rothman, 1998). By contrast, transportation has been used primarily as a convenience to the state. As a convenience to the state, transportation has been used to reduce prison/jail crowding, utilize surplus labor (e.g., penal colonies in Australia, French Guyana, \& etc.), and to make prisons safer or to otherwise reduce public risk (See: Krarup-Neilson, 1938; Morris, 2002; Clay, 2001 for origins of modern prison reform). This history will be used to help determine whether administrative intent regarding IITs is driven by the simple instrumental desire of a prison warden to "transport" an unruly inmate to some other location in order to make his/her management life easier (Feeley \& Simon (in Shichor \& Sechrest, 2002, p.386) or whether an offender was transferred for reasons more directly related to the individual offender (i.e., punishment, treatment, training, repatriation, \& etc.). This study argues that traditional notions of banishment and transportation can be applied 
to IIT's but represent very different forms of administrative intent and thus, the terms should be used carefully.

It is also possible that the administrative intent of IITs is a more complex phenomenon. That is, it can be understood to include a pragmatic concern for the needs of the institution, the inmate in question and a consideration of those needs in relation to larger issues. Drawing from the lessons of philosophical pragmatism (James, 1907/1960) and applied correctional management literature (Foster, 2006), this research assumes that some correctional managers - in response to increasingly dynamic and challenging institutional environments and their desire to maintain personal and institutional legitimacy - conceptualize their use of IITs on a case-bycase basis and in direct response to individual, organizational and community demands. Therefore, the administrative intent of some IIT transfers may simply be pragmatic in the sense that they intentionally seek to equally and simultaneously serve the needs of correctional managers, individual inmates, and the community (Morris, 1970; Foster, 2006, p.156). As Warden Pamela Withrow (In Foster, p.156) and other correctional scholars and practitioners assert, a pragmatic approach to correctional management both anticipates and facilitates adaptation to the demands of the internal and external pressures crucial to maintaining institutional legitimacy. What combinations of these considerations govern the discretionary exercise of authority by prison wardens? Table 1 (following page) summarizes these three forms of administrative intent and their attendant assumptions. It will serve as the 
anchor point in this study for understanding the term "administrative intent" in

relation to IITs.

Table 1: Administrative Intent Typology

\begin{tabular}{|c|c|c|c|}
\hline $\begin{array}{c}\text { Interstate Inmate } \\
\text { Transfers }\end{array}$ & $\begin{array}{c}\text { Administrative Intent: } \\
\text { Banishment }\end{array}$ & $\begin{array}{c}\text { Administrative Intent: } \\
\text { Transportation }\end{array}$ & $\begin{array}{c}\text { Administrative } \\
\text { Intent: Pragmatic }\end{array}$ \\
\hline $\begin{array}{c}\text { Assumptions \& } \\
\text { Goals }\end{array}$ & $\begin{array}{l}\text { The "moral and/or } \\
\text { clinical" needs of } \\
\text { individual inmates are } \\
\text { prioritized; } \\
\text { A focus on } \\
\text { individualistic inmate } \\
\text { management and } \\
\text { supervision techniques; } \\
\text { A focus on public safety } \\
\text { through individualized } \\
\text { programs of offender } \\
\text { incarceration, treatment } \\
\text { \& training; } \\
\text { Institutional risk } \\
\text { management is important } \\
\text { with reliance on } \\
\text { individualized risk } \\
\text { assessments; } \\
\text { Utilization of inmate } \\
\text { labor as an } \\
\text { individualized training } \\
\text { and reentry aid, } \\
\text { regardless of institutional } \\
\text { benefit. }\end{array}$ & $\begin{array}{l}\text { Language that utilizes } \\
\text { actuarial/probabilistic } \\
\text { terminology with respect } \\
\text { to inmates as a group; } \\
\text { A focus on aggregate } \\
\text { inmate management and } \\
\text { supervision techniques; } \\
\text { A focus on public safety } \\
\text { via inmate incapacitation } \\
\text { and control; } \\
\text { Institutional risk } \\
\text { management is a priority } \\
\text { with reliance on } \\
\text { aggregate-based risk } \\
\text { assessments; } \\
\text { Utilization of inmate } \\
\text { labor as a cost-saving } \\
\text { and/or profit \& budget } \\
\text { maximizing device. }\end{array}$ & $\begin{array}{l}\text { A strategic mixture } \\
\text { of banishment and } \\
\text { transportation goals } \\
\text { based upon an } \\
\text { administrator's } \\
\text { constitutive } \\
\text { understanding of } \\
\text { organizational, } \\
\text { offender and } \\
\text { community needs, } \\
\text { goals and desires. }\end{array}$ \\
\hline
\end{tabular}

\section{The New Penology}

In many ways, the concept of administrative intent is marginalized or ignored in the new penology framework. In its "worst-case" exemplification (Feeley \& Simon, 1992), administrative intent is a known or "fixed" entity that is beyond the power of the individual actor to formulate on their own or is a pervasive penal ideology that is uniformly shared among all criminal justice actors. In some cases 
(e.g, IITs to private prisons), administrative intent is portrayed as somewhat nefarious (Dyer, 2000; Shicor \& Sechrest, 2002). Unfortunately (and hopelessly it seems), the new penology assumes that the administrative intent of discretionary criminal justice policy will always avoid serving individual offender and community needs in favor of the broad actuarial and economic interests of the state. In order to better understand the relationship between administrative intent and the new penology construct, it is useful to elaborate on the theoretical foundations and assumptions of the new penology.

The new penology, as a phenomenon, is related directly to normative and theoretical conceptualizations of post-modernity and, some scholars argue, has manifested primarily as the emergence of a new penological language guiding current penal practices and strategies (Foucault, 1977 [also see the term “massification" in Foucault's 1978 article, Governmentality]; Feeley \& Simon, 1992; and implicit in the work of Georgio Agamben, 1998). Post modernism in criminal justice, according to Simon (1997, p.71) and implicit in the recent work of John Crank (2003) is dependent "on what one thinks has changed in the present that requires breaking the useful interpretive frames that have been associated with modernity."

As a theory, the new penology is considered a critical or post-modern theory (depending upon the epistemological assumptions of any given approach, i.e., critical theories are more tightly coupled to Marxist assumptions). Typically, postmodern and critical theories are utilized to analyze and critique penal strategies and 
their inherent reliance on asymmetrical uses of power, as well as to suggest reforms. Post modern and critical theories - in all of their many forms - generally suggest an unmanageable subjectivity and/or an indefensible determinism which could be problematic for our understanding of the administrative intent (and variability) of IITs. On the one hand, Frank De Zwart (2002, p.482) writes, “[...] postmodernists confuse wrongs of bureaucracy with arguments against modern science and then propagate relativism to clear up the muddle they created." On the other hand, some of these approaches can help us to better understand, for example, how and why prisons evolved (Foucault, 1977) and how the courts have responded to problematic prison conditions (Sullivan and Tifft, 1975; Feeley \& Rubin, 2000), which may in turn allow us to develop a better understanding of administrative intent and action in a variety of penal contexts.

In articulating a defense of postmodernism, public administration scholar John David Farmer (2002, in De Zwart, p.482) asserts that “A central aim of postmodernism is to demarginalize...groups such as women, minorities, the economically disadvantaged, those with policed sexualities, the colonized, and others [to include prison inmates, Welch, 2005]." This concern is somewhat derivative from conflict theory and the Hegelian notion that "man" will fight to the death in order to be recognized as something other than a slave (Strauss \& Cropsey, 1987; Hegel, in O'Neill, 1996). In addition to recognizing the importance of subjective, individual realities, postmodern and critical theories also highlight the role of conflict in social life - an important underlying consideration for many scholars who 
study complex organizations (Simon, 1976; Argyris, 1957; Bennis, 1967 Giddens, 1990; Block, 1993; Welch, 2005). Farmer (1997, Nov) and others argue that in understanding modern organizational forms and purposes, postmodernism can help us to understand how (and why) the instrumentalism of modern bureaucratic structures limit the ability of human beings to self-actualize. This postmodern focus is supported by a number of scholars in multiple and varied fields who continue to emphasize the negative effect that instrumentally-oriented organizations may have on society (Merton, 1957; Sykes, 1958; Arendt, 1963; Denhart, 1984; Morgan, 1988; Adams and Balfour, 1998) and on those who work (or are imprisoned) within them (Weber, in Gerth \& Mills, 1958; Sykes, 1958; Simon, 1976; Feeley \& Simon, 1992; Shichor \& Sechrest, 2002; Goodsell, 2005).

The new penology is considered both a temporal "phenomenon" and a critical theory developed by criminologists to explain purely instrumental behavior by CJ actors. Critics argue that IITs are evidence of an emerging "new penology" in American corrections, are directly related to the conditions of postmodernity, and have provided correctional managers with aggregate inmate management tools which primarily serve an instrumental purpose. Typically, arguments critical of the new penology assert that individualized "justice" cannot be achieved through current policing, adjudication, and incarceration processes due to a widespread institutional failure to recognize an individual's unique characteristics and circumstances (Feeley \& Simon, 1992; Lynch, 1998; Miller, 2001; Shichor \& Sechrest, 2002), which has been the traditional focus of criminal justice. Concern for the individual 
characteristics and circumstances of offenders, it is argued, are now ignored, having been replaced by profit/budget maximizing concerns, actuarial-based risk assessments and other aggregate management techniques that favor institutional management interests over individual and community justice (Silver \& Miller, nd; Lisa Miller, personal communication, 2004; Bohm, 2006).

While there is still some debate and confusion about what the new penology concept means, for purposes of this study, I have identified the following key characteristics and have compared it with a traditional understanding of correctional work (Figure 1, following page). This operationalization has been used to inform my interview instrument and is used to analyze the new penology's presence and influence on administrative intent (see: Table 1, p. 41) in three IIT cases. 
Figure 1: Key Characteristics of the New Penology

\begin{tabular}{|c|c|c|}
\hline & New Penology & Old Penology \\
\hline Philosophical Tradition & Postmodernity/Postmodernism & $\begin{array}{l}\text { Quakerism }\left(18^{\text {th }}-10^{\text {th }}\right. \\
\text { Century)/Progressive } \\
\left.\text { Party(early } 20^{\text {th }} \text { Century }\right)\end{array}$ \\
\hline Language/Linguistics & Actuarial/probabilistic & Moral or clinical \\
\hline $\begin{array}{l}\text { Correctional Management } \\
\text { Behavior }\end{array}$ & $\begin{array}{l}\text { Aggregate inmate management } \\
\text { styles \& techniques } \\
\text { Public Safety: Inmate } \\
\text { incapacitation \& control } \\
\text { Institutional risk management via } \\
\text { actuarial/aggregate-based risk } \\
\text { assessment } \\
\text { Utilization of inmate labor as a } \\
\text { cost-saving and/or profit and } \\
\text { budget maximizing device. }\end{array}$ & $\begin{array}{l}\text { Focus on individual } \\
\text { offenders/individualistic } \\
\text { inmate management styles } \\
\text { and techniques } \\
\text { Public Safety: successful } \\
\text { reentry through } \\
\text { individualized programs, } \\
\text { treatment \& training. } \\
\text { Institutional risk } \\
\text { management via } \\
\text { individualized risk } \\
\text { assessments. } \\
\text { Utilization of inmate labor } \\
\text { as an individualized } \\
\text { training and reentry tool } \\
\text { prioritized, institutional } \\
\text { benefit secondary. }\end{array}$ \\
\hline
\end{tabular}

This study argues that while in some situations (i.e., during stressful periods), and at some levels of the correctional organization, the new penology may have some explanatory power, overall it may not be a useful construct. In part, this is because the new penology framework places a significant emphasis on the emergence of "perpetually" influential situational forces (i.e., correctional conditions resulting from postmodernity) and does not appear to assume, nor even anticipate, the variable impact that these forces may have on individual decision makers. Significantly, the new penology does not assume or anticipate the influence of individual-level dispositional factors on decision-making, nor does it assume or anticipate the influence of these factors in relation to an individual correctional 
manager's feelings of human agency and autonomy during implementation (Cheliotis, 2006).

Contrary to new penological assumptions, the basic general assumption underlying this research is that administrative intent in IIT cases are driven by a highly dynamic combination of dispositional and situational factors (Zimbardo, $1972 \& 2008)$. The narrative data collected from the three cases examined here support this assumption and challenge the prevailing, critical views which argue that the administrative intent of all IITs can be linked to the emergence of a new penology in corrections. The following section more thoroughly describes Zimbardo's concepts of dispositional and situational factors of influence on human behavior and links these concepts to our understanding of how and why the administrative intent of IITs is may vary between cases depending on who, where and under what conditions it is implemented.

\section{Lessons from Phillip Zimbardo and the Stanford Prison Experiment:}

\section{Understanding the Impact of Situational and Dispositional influences}

\section{on Administrative Intent}

As discussed previously, in many ways Zimbardo's research amplifies the drier and slightly less normative assertions of the new penology perspective. In fact, like the new penology, Zimbardo's current work also places a heavy emphasis on the power of situational forces while greatly deemphasizing the power of dispositional forces. Problematically, Zimbardo's research, in many ways and under certain extreme circumstances, rejects (unlike this research) purely dispositional 
explanations for human behavior and is primarily interested in examining

situational decision-making influences as causes of "human failings" under stressful conditions. However, his development of the situational and dispositional categories has been useful to this research.

To review, Zimbardo (p.vi, p.7) simply defines dispositional forces of influence as those "inner" influences which inhere in, or can be attributed to an “individual [decision-maker's] inner nature, genetic make-up, dispositions [e.g., beliefs \& experiences], personality traits, and character." He describes situational forces of influence as forces external to the individual actor such as the social and political environment, the "system" in which an individual is ensconced, and other factors external from, and [at least, initially] unrelated to, an individual's dispositional characteristics. In sum, Zimbardo argues that, in varying degrees, both dispositional and situational forces influence decision-making but that situational forces may cause people to act in ways they would not ordinarily. While Zimbardo (p.8) asks, “To what extent can an individual's actions be traced to factors outside the actor, to situational variables and environmental processes unique to a given setting [italics added]?", this research also asks, "To what extent (and under what conditions) can an individual's actions be traced to factors within the actor - to their attitudes, beliefs, experiences and knowledge?" Although this research borrows from Zimbardo's situational and dispositional categories, it is more simply interested in identifying these influences in relation to their perceived effect on the administrative intent of IITs without normatively assessing (e.g., in terms of "good" and "evil," or 
"good and bad" as Zimbardo does) the behavior of the individual respondents, or the factors which appear to influence administrative intent.

Situational and dispositional factors of influence have long been recognized as having a variable influence on correctional management, and on prison wardens in particular (Jacobs, 1977; Dilulio, 1987; Sullivan, 1990). This literature contradicts the assumptions of the new penology construct. Indeed, much of the literature on prison wardens continues to emphasize the importance of situational and/or dispositional forces on their decision-making (Stojkovic \& Farkas, 2003; Mears \& Castro, 2006). Although the specific situational and dispositional factors that may influence the administrative intent of IITs will be discussed in following subsections, it is useful to briefly review the literature on wardens that specifically emphasize these influences on decision-making. This review is intended to more tightly couple Zimbardo's work with the realities of correctional management at the institutional level.

Zimbardo (p.8) asks, "To what extent can an individual's actions be traced to factors outside the actor, to situational variables and environmental processes unique to a given setting?" Interestingly (though not surprisingly), the bulk of current correctional literature appears to be focused on the influence of situational factors. For example, Chase Riveland's (1999) interview with seven prison administrators focuses a great of attention on the situational forces that have influenced correctional decision-making over time. Some of these influences include: changing penal policies, increased sizes of the prison population, media access to prisons, and the 
unionization of line-level employees, to name just a few. Similarly, Vernon Fox (1984) had previously identified a number of internal and external situational forces that may affect correctional management. Fox generally characterizes these influences as the "politics of prison management," and include such influences as inmate politics, economics and inmate conflicts over social status. Situational forces may also include staff politics and influences that derive externally from public political debates over crime control policy and litigation instigated by inmate advocacy groups. Other authors tend to also focus on the internal and external situational influences that affect correctional management and the job of the prison warden (Duffee, 1980/1986; Williamson, 1990; ACA, 1999; Seiter, 2002; Stojkovic \& Farkas, 2003).

On the other hand, prison wardens are considered professionals (Johnson, 1961; Williamson, 1990; Stojkovic \& Farkas, 2003) and are hired and tasked with institutional management projects based on specific, dispositional qualities and are not expected to be "buffeted by the winds of change" without taking some informed, proactive action. On professions and professionalization, Carr-Sunders \& Wilson (in Nosow \& Form, p.197, p.202) write, It is this characteristic, the possession of an intellectual technique acquired by special training, which can be applied to some sphere of everyday life that forms the distinguishing mark of a profession [...] We recognize a profession as a vocation founded upon prolonged and specialized intellectual training which enables a particular service to be rendered. 
Although additional dispositional qualities will be discussed in later subsections, it is clear from the literature that wardens, as professionals, are expected to utilize at least some of their dispositional characteristics in the management of prison institutions. The dispositional qualities of prison wardens, therefore, are an important part of prison administration, especially when undertaking the implementation of discretionary policy designed to solve problems within the institution.

The greatest advocate of managerial influence and autonomy among prison wardens may be John DiIulio (1987) who essentially argues that managers' dispositional qualities, as they interact with the institutional environment (situational factors), may determine the difference between a "good" or "bad" institution. Dilulio's claims are supported elsewhere in the literature. For example, Barak-Glanz (1981), argues that multiple management styles have emerged as a result of changing, external factors since World War II. Barak-Glanz, in normatively assessing these stylistic evolutions, echoes Dilulio in his assertion that not all management styles contribute to positive outcomes but that nonetheless, management styles were (and are) influential within the prison environment. Finally, Cullen, Latessa, Kopache, Lombardo, \& Burton (1993) in their research on prison wardens' job satisfaction, found that the wardens who had a higher level of job satisfaction, felt, in part, that it was due to higher levels of autonomy and freedom to exercise discretion in accordance with their own correctional management philosophy (especially among those who managed institutions that emphasized 
rehabilitation, p.154; also see Cullen, Latessa, Burton \& Lombardo [1993]: The Correctional Orientation of Prison Wardens: Is the Rehabilitative Ideal Supported?).

The research conducted here, in challenging the new penology as an explanatory framework, re-emphasizes the potential power of dispositional forces on administrative intent under "normal" and "stressful" circumstances. Based on Phillip Zimbardo's work this research will analyze interview and survey data in each case in relation to three main categories: 1) What dispositional factors were perceived to have influenced administrative intent in relation to IITs? 2) What situational factors were perceived to have influenced administrative intent in relation to IITs? And 3) how do the results of the previous two analyses compare with the assumptions of the new penology? The following subsections are divided into "Situational" and "Dispositional" categories and the literature is reviewed in relation to each of these categories.

\section{Situational Factors}

\section{"Black letter" Law: An Overview of the Legal Foundations, Types and Current}

Status of Interstate Inmate Transfers

In discussing the current use of IITs by prison wardens, it is necessary to discuss the political culture and laws that guide, constrain and/or facilitate their use as situational factors of influence. Because a thorough literature review on the area of compact law would necessarily require one or more chapters on its own, only the essential elements of federalism and compact law are discussed, and only in relation 
to their potential impact on administrative intent. However, it is important to discuss the three, explicit corrections compacts (and the possibility for individual, state-to-state variations) because they represent explicit, publicly accessible statements of intent with regard to IITs and thus, are likely to influence the intent of IITs.

For well over thirty years, state-level prison administrators have utilized interstate inmate transfers (IITs) to manage their institutions (USDOJ, NIC, 2006; Warden A, June 9, 2008). Currently, IITs are used by 46 states and are implemented by correctional managers situated at multiple levels within state correctional bureaucracies (p.2). Typically, and as the term suggests, IITs involve the transfer of incarcerated offenders from one state correctional facility to another. Jurisdictionally speaking, these transfers are facilitated (and constrained) by DOC policy and unique interstate agreements, state and federal law, the territorial boundaries of the United States and by the availability of receptive correctional facilities (USDOJ, NIC, 2006). IITs may also be used to transfer inmates to or from local jails or from jails or state-level correctional institutions to federal correctional facilities (Kerle, 1999 in Carlson \& Garrett; B. DeHaan, personal communication, 2005).

In addition to state and federal legislation influenced by the U.S. Constitution permitting their use (Article I, Section 10), and the Supreme Court's decision upholding legislation authorizing their use (Olim v. Wakinekona, 461 U.S. 238 [1983]), IITs are also an artifact of American political culture (i.e., federalism). Simply stated American law and political culture have greatly influenced the intent 
and uses of IITs in the past and continue to do so today and act to constrain and/or legitimize the use of IITs for both instrumental and constitutive purposes.

IITs are, in many ways, a familiar policy manifestation closely associated with traditional notions of federalism, interstate compact law, and the accepted notion that states may (and should) form agreements with one another in order to solve problems (Wildavsky, 1998, p.5; Gary McConnell, 2001; The Council of State Government, 2001). In very simple terms, interstate compacts are contracts between states and include legal elements (i.e., limitations, sanctions, protocols, \& etc.) much as any other contract. The interstate compact of today is a much more versatile and widely used policy instrument than it was in earlier times. Donald Kettle (1998, in Wildavsky, p.5) argues that "[n] early everything has become intergovernmental. [In our time] it has become far more difficult to differentiate national, state and local functions." Interstate compacts are utilized today in a number of policy areas "from conservation and resource management to civil defense, education, emergency management, energy, law enforcement, probation and parole, transportation, taxes" (Mountjoy \& Bell, p.42, 2005) and, of course, to facilitate interstate inmate transfers (United States Department of Justice, 2006). Compact agreements can be made between as few as two states or as many as 50 (Penchoff, 2005, p.22). ${ }^{11}$ In sum, IITs (in one form or another) have become a widely accepted and legitimate 
administrative practice in American corrections and almost every State DOC can or does transfer inmates to other states (p.2).

However, not all IIT transfers occur under the auspices of the interstate corrections compact (ICC) (e.g., some bed rental programs), and the legal means by which these inmates are transferred remains somewhat unclear. ${ }^{12}$ In any case, roughly half of the inmates transferred as of Jul 1,2005 were transferred within the auspices of one or more ICCs (p. 6). As is the case with other types of interstate compacts, ICCs have been developed to suit changing state correctional needs needs that are more often characterized as correctional "emergencies" (Ben DeHaan, Personal Communication, 2005), as in the case of overcrowded prisons, than as the destructive or banal desires of legislators or correctional officials as some critics argue (Talvi, 2006). However, specific ICC agreements appear to act as constraints on administrative action - constraints which appear to influence the administrative use of IIT's (United States Department of Justice, NIC, Biasca, 2006). Although it is currently impossible to document every variation on the three main types of interstate corrections compacts and bed rental agreements (and their variable relationship to one another), it is informative to document and describe the three main types of ICCs.

\footnotetext{
${ }^{12}$ USDOJ Data reports that 345 inmates were transferred to the BOP and 2,466 inmates were transferred to private prisons. None of these transfers were accomplished through an interstate corrections compact agreement. The report does not specify how they were accomplished and as of this writing, I am waiting for a response from the NIC regarding the legal mechanism of these transfers.
} 
One interstate corrections compact is national in scope and two are

"regional arrangements between geographically proximal states (pp. 2-3)" and all of them specify a general, administrative intent. They are:

1. The National Interstate Compact for Corrections (pp. 2-3): "Provides for uniform procedures and treatment of prisoners who are transferred from the supervisory agency of one state to that of another." The intent of this compact, as stated, is to "provide for the mutual development and execution of programs of cooperation for the confinement, treatment, and rehabilitation of offenders with the most economical use of human and material resources." As of July 1, 2005, 40 states were party to this compact (p.3).

2. The Western Corrections Compact: "The Western Corrections Compact has 11 signatory states" and "provides for the joint use of corrections facilities in the West." As is the case with the national agreement, the intent is the same. Party states are: Alaska, Arizona, California, Colorado, Hawaii, Idaho, Montana, Nebraska, Nevada, New Mexico, Oregon, Utah, Washington, and Wyoming (p.3)

3. The New England Corrections Compact: "Provides for cooperation in the confinement, treatment, and rehabilitation of offenders." Six northeastern states have adopted this compact: Maine, New Hampshire, Vermont, Massachusetts, Connecticut, and Rhode Island.” (p.3)

All of these agreements also specify constraints on behavior and include a number of variations within each state-to-state agreement. Alaska (among others), for example, has included a number of conditions (i.e., administrative constraints) in its IIT 
agreements with other states (United States Department of Justice, NIC, Biasca, 2006, p.5). For example, Alaskan provisions include rigorous selection criteria, to include a "non-transfer" determination for Alaskan native inmates, but only if they have maintained a traditional or rural lifestyle (p.7).

Complicating matters even further is the fact that some states are involved in more than one type of compact or inmate transfer program and with more than one state (United States Department of Justice, 2006). This reality makes the study of IITs, and corrections compacts generally, difficult because the complexity of these various arrangements shroud the intent, type and actual number (frequency) of inmates transferred. Additionally, multiple transfer agreements potentially increase the number of administrative constraints, and thus, their influence on administrative intent between cases. Simply, without a great deal of case-specific research to form a rudimentary base of knowledge, the ability to generalize about the administrative intent of IITs may be impossible.

Ultimately, the interstate compact has evolved to become an especially useful tool for states interested in implementing mutually beneficial, multi-jurisdictional policies. In this sense then, IITs, and interstate corrections compacts (ICCs) generally, embody, rather than contradict, the promise of federalism. This spirit of legitimacy has facilitated the ability of states to contract with one another for the purpose of transferring inmates across state lines and clearly impacts the administrative intent of IITs. That is, IITs are a legitimate way, for example, to facilitate both instrumental, institutional maintenance concerns (e.g., reducing the 
number of inmates in overcrowded institutions) and/or more constitutivelyoriented inmate repatriation agendas and treatment or training demands.

Unfortunately, due to the great deal of dynamic variation between agreements, we are not able to generalize about the conditions and constraints placed on correctional managers in every ICC agreement, or their reaction to these conditions and constraints. As stated previously, this work must be done on a caseby-case basis. However, one of the purposes of this study was to examine a warden's perception of the conditions and constraints placed upon them by the specific rules and laws guiding IITs in their own jurisdiction and determine the extent to which their use of IITs reflects an understanding and appreciation for the multiple values served by IITs. Understanding these perceptions is an important part of this research because it allows us to better decipher the administrative intent of IITs and the values and perceptions that may influence discretionary behavior, generally, in each case. Because discretionary decision-making by prison wardens is assumed by this research to be situational (i.e., “Can all wardens use IITs?”) and variable (i.e., "Do all wardens use IITs?'), and not assumed to vary at all by the new penology, it is important to discuss discretionary decision-making in relation to IITs as a situational decision-making factor in order to better understand how dispositional factors may be influential.

Discretionary Decision-making: The IIT as a Discretionary Tool of Corrections

The ability to transfer inmates across state lines is a discretionary tool typically utilized at two levels of prison administration: 1) At the prison/institutional 
level IITs are utilized to manage specific inmates; and 2) at the Department of Corrections level IITs are utilized to manage the entire inmate population ${ }^{13}$. As discussed previously, the new penology construct assumes a purely instrumental administrative intent and does not allow for the possibility that some prison warden's and DOC's, under some conditions, may be inclined to use the tool both instrumentally and/or constitutively. Simply, variability - and its causes - in discretionary decision-making are largely overlooked by the new penology construct. In fact, the new penology does not appear to focus much attention at all on the variable roles that discretionary power plays in public administration. This may lead to a distortion in our understanding of the administrative intent of IITs. For the purpose of this study, much attention is paid to the exercise of discretion, which in part and to varying degrees, is influenced by a manager's beliefs about their role and their beliefs about best way to implement policy in a particular field and within a particular institutional context (Rohr, 1989; Scott, 1995). These beliefs and contexts will be discussed in following subsections. In this subsection, the public administration literature will be briefly reviewed in order to provide a foundation for a main assumption of this research: that the administrative intent of IITs is likely to vary from new penology assumptions due to a warden's perceived ability to use it as a discretionary management tool and their perceptions regarding how and why they may use it.

\footnotetext{
${ }^{13}$ Although it is clear that in some correctional contexts both levels of prison governance utilize interstate inmate transfers for different reasons (DeHaan, 2005, personal communication), it is not entirely clear what relationship prison-level and system-level interstate inmate transfers have to one another.
} 
Discretionary decision-making has the force of law and is relatively unconstrained by black letter law (Cooper, p.300). It is a complex and essential part of any governance system and thus, always an important area of research especially when one is attempting to determine the administrative intent of discretionary policies like the IIT. Administrative discretion is defined by Phillip Cooper (2000, p. 300) as: "[...] the power of an administrator to make significant decisions that have the force of law, directly or indirectly, and that are not specifically mandated by the Constitution, statutes, or other sources of black letter law." Administrative discretion is a form of power identified by Kenneth Culp Davis (1971, p.4) as that which occurs "whenever the effective limits on [a public administrator's] power leave him [or her] free to make a choice among [a number of] possible courses of action or inaction." "It is through discretion [...]," writes John Rohr (1989, p. 42), "that bureaucrats govern." To understand the role of public administrators simply in terms of their ability to "control" or "serve (Cooper, 2000, p.89)," without delving into how or why they do so, is to oversimplify our understanding of public administration.

Davis (1971, p.25) and others (Arendt, 1964; Lipsky, 1980; Adams \& Balfour, 1998; Vinzant \& Crothers, 1998; Morgan, 2002) continue to point out the power of discretionary decision-making by public administrators and the importance of understanding the values, variability and dynamism of multiple internal and external institutional forces which influence it. In understanding administrative 
discretion we need to avoid sweeping normative judgments and must be very specific in our analysis. As Morgan (2002, p. 2) advises, [understanding discretion] requires some understanding of the contextual setting, including who is exercising the discretion, what kind of discretion is being exercised, and the potential dangers for abuse [italics added].

Importantly, discretionary freedom provides a public administrator with the ability to individualize decisions in accordance with their beliefs about "good" management or public service (Morgan, D.F., 1988; Cook, 1996; Goodsell, 2004). Public law scholar Phillip Cooper (2000, p.303) writes:

The demand for individualized attention [in public administration] is never ending. Eliminating the discretion to make individual assessments could wreak havoc on those who must deal with agencies.

Simply, this is because the implementation of policy developed in the state or federal legislatures often require public administrators to exercise discretion in order to fill in the "gaps" intentionally (or unintentionally) left by law makers (Lindblom, 1980; Lipsky, 1980; Kingdon, 1995; Morgan, D.F, 2002, p.4; Hill \& Hupe, 2002). Thus, the implementation of public policy often requires the development of additional formal or informal policies by the implementing organization or individual (Kingdon, 1995, p.31) - policy that is largely informed by the context in which the policy is to be implemented (Selznick, 1949; DiMaggio \& Powell, 1983; March, J.G. \& Olsen, J.P., 1989; Wilson, 1989; Derthick, 1990; Kingdon, 1995, p.31) and the 
administrator's beliefs about the best course of action (Wilson, $1989^{14}$; Bolman \&

Deal, 1991; Pfeffer, 1992; Schein, 1992).

On the one hand, administrative discretion must be "grounded in accountability (Cook, 1996)" in order for the implementing organization or individual to gain or maintain legitimacy (Davis, 1971; Cooper, 1996; Morgan, D.F., 2002; Cooper, 2000). On the other hand, the manner in which discretion is utilized during the implementation of policy is, in large part, informed by an administrator's personal and professional beliefs about "what will work" and, importantly, what they believe will work based on their perception of the context in which they are situated. ${ }^{15}$ In sum, the way discretion is utilized is often informed by the management "ideology" (Perrow, 1986, p.60) of a particular public manager ideologies which, in part, differ according to the level at which manager's are situated and the nature of an administrator's particular task environment (Morgan, D.F. \& Shinn, 2002). Therefore, the administrative intent of any given discretionary decision is not always easy to discern. Due to the somewhat shrouded nature of corrections (Garrett, 1999; Also see: Freeman's [2000, Chapter 5] discussion of

${ }^{14}$ James Q. Wilson (1989), while acknowledging the importance of beliefs in the exercise of administrative discretion (Pp. 50-55), seems to imply that beliefs, or as he calls them, "attitudes," are so constrained by the institutional context that they rarely influence discretionary action. This research assumes (and found) that only under stressful institutional conditions may this - sometimes - prove to be true. However, Wilson makes a good point when he explains the connection between how well a particular role is defined and the influence of attitudes on the exercise of discretion. In short, an administrator working within the context of a well defined role (e.g., highly specified by laws, rules, and circumstances) will be able to implement policy based on their beliefs less often than an administrator who has a more open, or more loosely defined role. This may be key to understanding variation in the administrative intent of IITs between wardens and state DOCs.

${ }^{15}$ Brian Cook (1996, p.178) writes, "[...] administrative discretion must be grounded in accountability, which means that discretionary decisions are based on the giving of reasons linked to clear, substantive rules and to the underlying values and democratic consensus that constitutes the public interest." 
"correctional silence"; Surette, 2007), this is especially true of decisions made by prison wardens.

In corrections and in correctional management specifically, discretionary decision-making is just as prevalent (and as necessary) as it is in other areas of public administration. Prison wardens, writes Dilulio (1987, p.47) are “governmental keepers" who, in relation to the unique institutional context in which they are situated, exercise varying degrees of discretionary power. Although we can get a general (and very anecdotal) sense of why interstate inmate transfers are used by state correctional officials - typically through media accounts and [rare] statements of purpose by correctional authorities (e.g., to relieve prison crowding) - we do not fully understand how or why inmates are chosen for transfer, the role that correctional managers (at various levels) play in the transfer decision, the ends that correctional managers hope to achieve by using interstate transfers, or the factors which influence correctional managers to use interstate inmate transfers in the first place. Simply, understanding the role that discretion plays in the day to day decision-making of prison wardens-and the normative drivers that influence discretion - are an important first step in understanding variations in the administrative intent of IITs.

\section{The Correctional Environment}

As mentioned above, another group of situational influences that are important to our understanding of administrative intent is the institutional (and institutionalized) nature of correctional practices. This study assumes that correction 
officials are more than simply managers of an organization. Phillip Selznick (1994, p.233) writes, “A 'pure' organization is a special-purpose tool, a rational instrument engineered to do a job, a lean, no-nonsense system of consciously coordinated activities." Although some would like to view prisons as such organizations, this is simply not the case. Rather, prison wardens are agents of institutions that are embedded in multiple communities and therefore may be greatly influenced by internal (e.g., unionization, employee/staff issues, and inmate issues) and external forces of change (e.g., news \& other mass media [Freeman, 2000; Surette, 2007], the politics of crime control [See: Cohen, 1996; Scheingold, 1995]; the politics of criminology [See: W. de Haan, 1990]; inmate advocacy coalitions, judicial and other court interventions). In other cases, the institutional environment may exert little or no influence at all on administrative intent and the warden may feel free to implement IITs in accordance with his/her beliefs and experience. Due to the potential variation in the administrative intent of IITs influenced by the correctional context, it is important to discuss the institutional environment in which a prison warden is situated.

An important point to remember about prisons, write Latessa and Holsinger (2006, p.3), is that "When considering the history and present of corrections in the United States, the only constant appears to be dynamic change." Prison and jail populations in America are currently at an all-time high. There are currently 1,470,045 people in American prisons and 691,301 in American jails, bringing the current total of incarcerated persons to over two million people. The prison 
population has escalated over the last decade, putting correctional officials in the difficult position of trying to manage a demand for space (and the myriad of problems generally associated with overcrowding) that may exceed the supply. Problematically, for wardens and their DOCs at least, they must do so in a manner that successfully meets the community's many expectations regarding incarceration (e.g., public and institutional safety, retribution and punishment, and offender rehabilitation and successful reentry, to name a few). This study was interested in determining whether institutional factors influence the exercise of administrative discretion with respect to IIT prison transfers. In particular, this study was interested in determining if, and how, the institutional environment influenced the administrative intent of IITs.

Prior to the 1960 s, prisons operated within "closed" systems, simply described by Williamson (1990) as systems in which correctional administrators defined and controlled the internal environments of their organizations with little or no external pressure (also see: Jacobs, 1977; Duffee, 1986). In a closed correctional system then, the "universe of interesting things" to study (Hall \& Fagen, 1956, in Scott [1987], p.119) - i.e., the institutional environment - was somewhat limited. Today, prison institutions are considered "open systems" (Jacobs, 1977 \& 1983; Tyrner-Stastny \& Stastny, 1977; Scott, 1981/1987; Williamson, 1990) situated within, and greatly influenced by, complex (and often adversarial) institutional environments (Tyrner-Stastny \& Stastny, 1977; Williamson, 1990; Duffee, 1980/1986; Seiter, 2002; Stojkovic \& Farkas, 2003). Selznick (p.237) writes, "For an 
open system, with permeable boundaries, no transaction with the environment is more important than negotiating its place in the moral order, that is, dealing with demands that it be responsible and responsive." Simply, the prison institution (and its warden) needs to adhere, or appear to adhere, to a variety of externally-derived normative values in order to become a part of, and to retain legitimacy within, a much broader community. Therefore, in "open systems," criminal justice institutions are likely to be variably influenced (and more or less coupled to each other: Weick, 1976; Meyer \& Rowan, 1977; Hagen, 1989; Renauer, 2003) by a number of formal and informal structural, economic, political, cultural, and historical elements (Scott, 1987).

To begin with, prison wardens are uniquely constrained by two over-riding administrative concerns, or rather, institutionalized "values": safety and security (Dilulio, 1990; Stojkovic \& Farkas, 2003, p.97). Powerful institutionalizing forces ${ }^{16}$ attempt to ensure that the goals of safety and security remain a high priority in the correctional environment (DiIulio, 1990; Stojkovic \& Farkas, 2003, p.97, Duffee, 1986). These institutionalized goals can place a great deal of stress on correctional managers and may create a significant level of tension for some prison wardens attempting to govern their institutions in accordance with their own unique perceptions (Hensley \& Tewksbury, 2005), and hierarchy of values and goals under variable (and sometimes stressful) institutional conditions (Duffee, 1980/1986; DiIulio, 1987; Stojkovic \& Farkas, 2003, p.98; Gibbons \& Katzenbach, 2006).

\footnotetext{
${ }^{16}$ Regulative, Normative, and cognitive forces (Scott, 1995). Also: coercive, mimetic and normative isomorphism, DiMaggio and Powell, 1991. These are more fully discussed in Chapter VII.
} 
Understanding when, where, and why these value conflicts occur may help us to better understand some of the problems associated with the discretionary use of interstate inmate transfers and an assortment of prison governance problems more generally.

Additionally, prison wardens, and other correctional employees, are subject to a never ending onslaught of internal and external institutional pressures (Duffee, 1986; Williamson, 1990; Dilulio, 1987/1990; Gondles, 1999; Bennett \& Johnson, 2000; Sims, 2001; Seiter, 2002; Stojokovic \& Farkas, 2003; Foster, 2006). From distorted media portrayals of correctional work and correctional management (Freeman, 2000; Rafter, 2006; Surette, 2007), to public and political pressure to punish offenders more severely - while also being pressured to facilitate and enhance rehabilitation and reentry opportunities (Fox, 1984; Scheingold, 1991; Zimring, Hawkins, \& Kamin, 2001), the external pressures exerted on correctional managers appear to be highly variable, dynamic and unending. However, prison wardens also face a variety of internal pressures. From staff-related issues and concerns to prison crowding and inmate race, illness and violence issues, correctional managers face increasingly dynamic and difficult internal decisionmaking environments on a daily basis.

Most prison systems are continuing to wrestle with the problem of overcrowding caused, primarily, by a populist-driven punitive swing in sentencing (Zimring, et. al., 2001) typically focusing on non-utilitarian criminal justice values (Warr, et al., 1983), and involving increasingly lengthy prison sentences (Seiter, 
2002; Tonry, 2004; Hassine, 2004; Irwin, 2005). Prison overcrowding, however, is just one of many significant issues that continue to "impact the job of every [corrections] administrator in changing ways (Phillips \& McConnell, 2005 p.5)". In addition to expanding prison populations, correctional leaders are facing a number of "critical junctures," including labor shortages, increased workforce diversity (which may intensify workplace conflict), and a large number of "baby boomer" retirements (Stojkovic \& Farkas, 2003). Stan Stojkovic and Mary Ann Farkas write, "Correctional leaders will...be confronted with the need to manage their relationships with many internal and external audiences in a time of declining resources, labor shortages, limited funds and infinite demands, and shifting politics."

It is argued that this dynamism is caused by changing philosophical [public] beliefs about the nature, extent and treatment of crime and criminal behavior (Jacobs, 1977; Clear, et al., 2006) and the politics surrounding crime control (Clear, et al., 2006; Scheingold, 1991; Nicholson-Crotty \& Meier, 2003; Tonry, 2004) rather than actual increases in crime (Clear, et al., 2006). Thus, prison wardens, and the prisons they manage, are responsible for housing criminal offenders and treating them in accordance with a variety of (and often conflicting) normative goals and policies developed in the political process (e.g., rehabilitation, penal harm \& "No-Frills punishment") - an often thankless and seemingly impossible task since it does not appear that crime reduction efforts (both inside and outside the prison) are actually reducing the size of prison populations. Todd Clear and colleagues (2006) write in support of this conclusion when they assert that " $[\ldots]$ researchers now recognize that 
the size of the prison population is not driven by the amount of crime; it is driven by public policy."17

Corrections scholar, and former head of Ohio corrections, Richard Seiter (2002, p.10) argues that "corrections is both influenced by the broader approaches to private and public management, and by public opinion and political reaction regarding the issue of crime [italics added]." As will be discussed in the findings section of this research, the media's coverage of corrections and the public's distorted perceptions of crime and criminal justice loom large for corrections officials (Freeman, 2000). Not only do news media accounts distort the bigger crime picture (Glassner, 1999; Bennett, 2001; Jewkes, 2005; Welch, Fenwick \& Roberts, 2006; Surette, 2007), leading to wildly distorted perceptions of crime - causation and prevalence - among the general population, but news and other mass media accounts of corrections negatively distort the image of the correctional professional.

For example, the 1994 film Shawshank Redemption has had a wide audience and is a highly entertaining film. However, the film, writes Rafter (2006), "[...] closely follow the formulas of earlier classics while piling on profanity and sex [and rely on narratives in which wardens and other] government authorities [are portrayed as despotic crooks]. These types of films may negatively influence public perceptions of corrections. That is, "while films do not determine our emotions, they do provide narratives that we use to frame our emotional responses to [...] events (Rafter, p.78; also see: Surette, 2007). Similarly, television news media portrayals 
of corrections tend not to focus on the mundane elements of correctional work but rather, if corrections are focused on at all, on dramatic episodes (e.g., escapes, riots or high-profile inmates) and management "problems" related to high-profile incidents (Surette, 2007). This, argues Freeman (2000, p.69), has led to what he refers to as a "correctional silence" - defined as "[...] the withholding of contextual information [by correctional workers] that can inform crime control policy debates, change the outcome of those debates, and educate the general public." Simply, Freeman argues, because the mass media cannot be trusted to portray corrections accurately or even positively, correctional workers will say nothing at all about the job that they do or about the context in which they do it. In short, managing a prison or a prison system and implementing public policy within its confines is a technically complicated, highly politicized, and often tedious affair (Duffee, 1980/1986; Wilson, 1989; Toch, 1997; Dilulio, 1998; Seiter, 2002; DeHaan, Personal Communication 2005; Latessa \& Holsinger, 2006).

In concluding this subsection, it is useful to organize the many factors that may influence a prison warden's use of an IIT. In neatly organizing the correctional environment into somewhat overlapping (but not all inclusive) categories, Harold Williamson (1990) has developed the following typology:

1. The social environment: In today's "open system" prison environment, Williamson (pp.32-33) describes the social environment of corrections to include both internal and external sources of social influence to include: the courts, inmates, prison rights activists, the relationship of correctional employees 
to management; crime rates; and popular and elite concern over the effectiveness of correctional programs. Scholars specifically identify public opinion (Duffee, 1980/1986, p. 342) and the news or other mass media (Freeman, 2000; Jamieson \& Campbell 2006; Surette, 1998 \& 2007) as having an influence on incarceration rates and/or decision-making by correctional managers (Carlson \& Garrett, 1999, p.391, Seiter, 2002; Surette, 2007).

2. The political environment: Williamson (p.32) writes that "the administration of a correctional agency must balance the competing interests [of interest groups, public officials, and the public], promote legitimate policies of appropriate processes, and cultivate outside support for the agency." He points to a number of political influences on correctional agencies to include: elected officials using crime and criminal justice issues to develop public support for their campaign or who appoint correctional leaders to achieve short-term, politically expedient political goals; competition for scarce funds with other public agencies; public opinion; and prison activists or other interest groups.

3. The bureaucratic environment (p.33): In corrections, the bureaucratic structure is best characterized by Max Weber's bureaucratic ideal-type: A hierarchical, systematic division of labor, conforming to written, formal rules, norms of impersonality and impersonal measures of competence (Weber, 1958 [in Gerth \& Mills]; Barak-Glantz, 1981). The bureaucratic environment of corrections, argues Williamson, has intensified due to the influence and constraints placed on it by external forces (e.g., court decisions standardizing the 
implementation process). He argues that, as a result, the bureaucratic environment of corrections has: Reduced creativity and autonomy necessary to adaptation within dynamic institutional environments; resulted in a decrease in the power of administrators to "coerce and reward"; increased the likelihood that experts with advanced degrees will enter the field of correctional management leading, he implies, to a technocratic, rule-bound tendency to rely on formal policy at the expense of informal problem solving or a "dual command" structure in which there is confusion between "expert" sources of authority and positional sources of authority; employee burnout as a result of increased bureaucratization, the failure to self-actualize and perceptions of personal and organizational ineffectiveness; and the development of adversarial relationships among employees and between managers and line-level staff, all of whom may become critical of the organization. David Duffee (1980/1986) identifies a similar bureaucratic environment in corrections. Additionally, he contributes a nuanced understanding of inter-organizational relationships (i.e., conflicting and cooperative behavior).

4. The institutional environment: Prior to the 1960s, argues Williamson (pp.3536) prisons were places in which behavior was "highly regimented and controlled" and the prison institution (aside from periodic escapes, episodes of inmate violence and etc.) were "relatively safe, predictable, and unambiguous" places (Jacobs, 1977). A number of variables have made the prison institution a less safe and less predictable place to manage: Prison overcrowding and the 
correlate diseases (e.g., AIDS, TB, Hepatitis C) and violence (sexual [See: The Prison Rape Elimination Act of 2004; Stop Prisoner Rape, 2006] and otherwise) (Clear \& Dammer,2006); special needs inmates such as juveniles, the mentally ill or mentally retarded inmates; sex offenders, (Clear \& Dammer, 2006; Foster, 2006, pp.282-317; Vera Institute of Justice, 2006); inmate substance use and abuse; the implementation of various treatment and rehabilitation programs in response to the political environment or an institutional desire to address serious inmate problems; increasing reliance on security classifications and the development of prisons and prison wings devoted to ever more dangerous and "risky" offenders; increasing variation in the role of the line-level corrections officer which has lead to role confusion, "apathy, and cynicism"; variations in inmate behavior and conduct while in prison (p. 37: "[ A great deal of] extortion, lying, cheating, and stealing are, unfortunately, all part of [prison] institutional environments."); changes in institutional design which provide more "space of all kinds to inmate inhabitants" - which make them harder to manage; and increases in violence on correctional officers since the 1960 s which contributes to employee attrition.

5. The community environment: The rise of very vocal prison activism (both from within and from without the prison) since the 1970s and the "[public's rejection] of earlier correctional methods" have pushed legislatures and correctional officials to develop and implement a wide variety of punitive and rehabilitative correctional policies. Regardless of public opinion, however, community 
corrections programs (i.e., alternatives to incarceration) have expanded over the past 20 years because prisons simply could not hold any more inmates. Community corrections programs - to include probation and parole, for example - are much cheaper than institutionalization and are favored by many pragmatic correctional officials and state officials. However, community corrections programs require complex risk assessments, local community approval, and inter-organizational cooperation, all of which significantly complicate the task of correctional management.

6. The legal environment (p.39): In the mid-1960s, the U.S. Supreme Court took a significant interest in how correctional managers handled their prisons and became increasingly concerned with the conditions of inmate confinement. This period of judicial activism ended what was previously known as the "hands-off" period. ${ }^{18}$ This activity has since waned, to some degree. Although the U.S. Supreme Court interferes less with the administrations of prisons than they used to, the "hands-off" doctrine is not reinstated, as evidenced by the courts continued insistence that inmates have rights beyond those granted by the states. These court decisions continue to influence correctional management practices and standards of professional conduct within prison institutions (Foster, 2006).

7. The system environment: Finally, writes Williamson, "The criminal justice system is actually a loosely coupled, or uncoordinated (Hagen, 1989, p.119),

${ }^{18}$ The U.S. Supreme Court created the "hands-off" doctrine in the 1871 case, Ruffin $v$. the Commonwealth of Virginia. Richard Seiter (2002, p.128) writes, "This case held that inmates were, for all intents and purposes, slaves of the state and had no rights that were not granted to them by the state." 
system in that each subcomponent functions largely independent of the other subcomponents." However, John Hagen (1989) argues that although looselycoupled criminal justice system is characteristic of the American system, criminal justice agencies can become more tightly coupled if “[...] political power ...is directed toward particular crime-linked goals [...]." In any case, Williamson correctly identifies corrections as a subcomponent of a larger criminal justice system and points out the influence that the police and the courts, sometimes unknowingly (or uncaringly), can have on correctional management. He writes, "The [prison] population size is dependant upon the number of criminals caught by the police, the number convicted and committed [to prison] by the court, and the length of sentence imposed [as determined by the courts and the political process], [...] release dates determined by parole boards [working under guidelines determined by the legislature]", prison overcrowding, and the inmates themselves depending on how well they behave in prison (e.g., "good time").

In the following subsection, this review of the literature moves away from a discussion of situational factors to a discussion on the dispositional factors that may influence the administrative intent of IIT. To review, Zimbardo (p.vi, p.7) simply defines dispositional forces of influence as those "inner" influences which inhere in, or can be attributed to an 'individual [decision-maker's] inner nature, genetic makeup, dispositions [e.g., beliefs and experiences], personality traits, and character." Clearly, situational forces can (and sometimes do) overwhelm the dispositional 
tendencies of an individual. However, it is also clear in the literature that dispositional characteristics can be influential as well. Because dispositional factors of influence on discretionary decision-making are largely ignored by the new penology (and minimized to a great extent in Zimbardo's current work), this study was interested in discovering to what degree a prison warden's beliefs, attitudes, knowledge and experiences are perceived to influence the administrative intent of IITs and prison management more generally.

\section{Dispositional Factors}

Correctional Management Philosophy: The Influence of Management Styles and

Beliefs on Administrative Intent

The new penology ignores - and to some degree, caricatures - the administrative intent of discretionary correctional policy due to its failure to recognize the potential influence of unique, dispositional influences. The new penology's failure to incorporate an understanding of the unique dispositional characteristics that may affect discretionary decision-making by prison wardens and criminal justice actors generally - may distort our understanding of prison management. It is important that our understanding of prison wardens involve more than abstract esoteric or ideologically-oriented speculation (Crank, 2004). This is because the accuracy of our understanding of correctional management can have serious practical consequences for the administration of corrections (Duffee, 1980/1986) - which in turn can have significant effects on the correctional work group, inmates, and society. Correctional management, asserts Duffee (1986, p.9), is 
a specialty in its "own right," the quality of which "[influences] the behavior of offenders, and hence the quality of correctional organizational performance." The quality of managerial performance, according to Duffee, may be simply (and in part) gauged by looking at organizational effectiveness, or rather, the ability of a correctional manager to translate correctional policy (e.g., reintegration, rehabilitation, reform, restraint, and/or punishment) into an operational reality that is in accordance with their management philosophy (p.109-110). In order to accomplish these tasks, a prison warden requires a level of autonomy and flexibility. However, this autonomy and flexibility operates within the context and against the bảckdrop of each warden's unique set of beliefs, knowledge and experience.

Theorizing about correction management philosophies, and their impact on decision-making, has been inconsistent and no consensus has been reached on what a "correctional management philosophy" actually is. This makes it very difficult to operationalize for purposes of this research. However, this study draws on criminal justice and public administration literature in order to better identify and understand potential variability in correctional management philosophies as well as the potential impact that these philosophies have on the behavior of correctional managers in relation to their use of IIT's. As will be discussed in each of the case chapters and in the concluding chapter, the dispositional characteristics of each warden appear to have a great deal of influence generally and the case data collected in this research point to high levels of ideological and behavioral autonomy, high levels of individualized and moralistic thinking with regard to inmates and inmate 
management, and a general feeling that correctional management at the institutional level is only situationally (rather than perpetually) stressful.

Charles Peirce (1878 in James, 1960/1907, p.43) has pointed out that "our beliefs are really rules for action." In public administration, understanding how an administrator's beliefs structure (and are structured: Harmon, 1981; Schein, 1992 or bounded: Simon, 1976; Ostrom, 1971) and inform an administrator's actions especially in their exercise of discretion - is important (Ostrom, 1974; Rohr, 1989; French \& Bell, 1990; Block, 1993, p.209; Cook, 1996; Morgan, D.F., Shinn, C.W., \& Green, R., 2002). Dilulio writes (1987, p. 165), “[...] obscured is the fact that prison officials at all levels do have beliefs, often well-reasoned and passionately held beliefs, about the purpose of imprisonment" and argues that it is important to understand that what a corrections official thinks influences how prisons are run. Simply, as Dilulio (1987, p. 187) found in his study on prisons as governance systems, this is because "what correctional leaders [think] about the purpose of imprisonment" may influence how they run their prison. Not only may beliefs influence how correctional (and other public) administrators behave, they may also have a large effect on how they initially define their tasks (Wilson, 1989).

It is clear from the existing public administration and correctional management literature that a correctional manager's philosophical outlook toward their task may influence their decision-making and, thus, the administrative intent in the use of IITs (Duffee, 1986; Dilulio, 1987; Wilson, 1989; Pfeffer, 1992; Cullen, Latessa, Burton, \& Lombardo, 1993; Kouzes \& Posner, 2003; Seiter, 2004). 
Similarly, Ulmer (1997) and Kautt \& Spohn (2007) place importance on understanding variations in an individual criminal justice manager's personal attributes (e.g., race, gender, "biographies and backgrounds" [Ulmer, 1997, p.24]) and the subjective beliefs and perceptions (e.g., "[...] definitions, attitudes, perspectives, and ideologies": Ulmer,1997; Kautt \& Spohn, 2007) they hold in regard to their institutional environment.

“Correctional managers," writes Richard Seiter (2002, p.32), "conduct traditional supervision of activities...ensuring day-to-day functions of an organization are accomplished." However, in the current social and political correctional context (discussed previously), the ability to lead - as opposed to merely manage - correctional organizations is a skill increasingly crucial to the success of any correctional agency or individual institution (Seiter, 2002; Stojkovic \& Farkas, 2003). Correctional "leadership," writes Seiter (p.32), "is associated with higher level functions of mission and vision" and leaders help to guide a correctional agency through "internally and externally created challenges." Correctional administrators must be leaders in the sense that they are responsible for “[intensifying] their constituents' commitment to a common cause (Kouzes \& Posner, 2003, p.xxiii)" through a continuous commitment to recognized and respected leadership values (Kouzes \& Posner, 2003). In this sense, the term "leader" has a normative component because of: 1) the importance of value-guided, organizational leadership and influence during the implementation process (Pfeffer, 1992) - which tends to be an ongoing and complicated affair requiring a great deal of 
discretionary decision-making, and;2) the vagaries of the implementation process

(Scott, R.W., 1995; Hill \& Hupe, 2002), the navigation of which requires capable leadership and a management philosophy compatible with the institutional environment.

Ultimately, Richard Seiter (2004) identifies the "problem" of good leadership in complex institutional environments as an inherently normative one. He concludes that the ability to successfully lead and manage a correctional institution in the "modern era" (Seiter, 2002, p.13) requires a correctional management philosophy compatible with the variably dynamic political and social environments in which American prisons are usually situated (Tonry, 2004; Stojkovic \& Farkas, 2003) ${ }^{19}$. Similarly, DiIulio (1991; 1998 in Cole \& Gertz) argues that management must remain responsive to the institutional environment in which they are situated and utilize correctional strategies and philosophies which are both: 1) compatible with the institutional environment; and 2) consistent with good correctional management practices.

Unfortunately, Hensley \& Tewksbury (2005, p.186) assert, “[Comparatively,] limited research exists on wardens' attitudes pertaining to the general operations and management of correctional institutions." However, there is a small body of research that is highly informative, if not necessarily generalizable to the current

${ }^{19}$ An especially poignant illustration of this assertion is the dramatic shift in American sentencing and corrections policy beginning in the 1970 s and the resulting adaptation of correctional management philosophies to new [external] social and political sensibilities regarding crime and punishment. As Joan Petersilia (2003, p.13) writes, “The sentencing reform movement [of the 1970s]...created in its wake dramatic [and ongoing] prison population growth." David Garland (2001, p.63) writes of this period, "The assault on individualized treatment [i.e., the traditional focus of correctional managers] opened the floodgates for a period of change that has been with us ever since." 
correctional context (to name a few: Jacobs, 1977; Dilulio, 1987; Lord, 1993;

Cullen, et al., 1993; and Cullen, Latessa, Kopache, Lombardo, \& Burton, 1993;

Glaser, 1995; Hensley \& Tewksbury, 2005; Kim, et al., 2003; Owen, 2006).

Additionally, there does not seem to be clear consensus in the public administration or correctional literature on an applicable, conceptual term describing the normative drivers which influence correctional management and leadership. These actions (i.e., styles) and beliefs (i.e., correctional philosophy) are alternatively (and sometimes simultaneously) referred to as a management style (Duffee, 1980/1986; DiIulio, 1998; Foster, 2006), philosophical perspectives (Duffee, 1980/1986; Wilson, 1989; Schein, 1992, p.101; Dilulio, 1998 in Flanagan, et al.; French \& Bell, 1990) ${ }^{20}$, “penological credos" (DiIulio, 1998), values (Schein, 1992, p.101) or some other word or phrase referencing the [mostly] normative outlook undergirding a correctional manager's decision-making process. Burk Foster $(2006$, p.152) writes, "There are as many different management styles in operating [prisons] as there are personalities and philosophies.”

In sum, management style refers to the "way in which the administrator attempts to steer his or her organization towards its goals (Duffee, 1980/1986, p.111)." Management philosophy in corrections refers to a "[...] manager's own beliefs and values about what they thought was right or 'good' correction or [beliefs based] on their own idiosyncratic assumptions and hunches $[\ldots]$ (p.39)." Distinct as the concepts style and philosophy may appear, it also seems that they may be

${ }^{20}$ French and Bell (1990, p.300) identify four interrelated aspects of "management philosophy": 1) experiences; 2) work force expectations; 3 ) values; and 4) stimuli arising from the external environment. 
combined under one conceptual rubric. While recognizing that there may be a number of idiosyncratic variations between correctional philosophies and technical styles among American prison wardens, this study argues that in order to more easily understand the influence that normative drivers have on the administrative intent of interstate inmate transfers, they must be conceptualized more simply so that they can be more easily measured and compared.

The concepts of management style and management philosophy have many overlapping normative qualities. French and Bell $(1990$, p.300) identify four interrelated influences on management philosophy:

1. Experience \& Research: Management practices which have proven to be the most effective;

2. Expectations and influences of the work force;

3. Values: "The values managers hold about how people should be managed" and;

4. External environment: Pressures exerted on managers from outside of the institution itself.

From this description, we might conclude that a correctional manager's "style" and "correctional philosophy" are more, rather than less, related to one another. Thus, this study has defined the concept "management philosophy" in corrections to refer to a combination of substantively different, but measurable, normative and technical drivers and techniques influencing a correctional manager's decision-making process. Drawing from the work of French and Bell and the work of David Duffee (1980 \& 1986), “management philosophy” might be simply defined as “a manager's 
style working in conjunction with their normative beliefs about the best way in which he or she should attempt to steer their organization towards their goal."

Many correctional management philosophies appear to be related to trends in public philosophies regarding crime and punishment (Morris \& Rothman, 1998; Pratt, 2005; Schumaker, 2008). Most descriptions of correctional management philosophies today continue to center around a few "ideal-types" (Weber, 1949/1964) and assume a certain set of characteristics. Within these ideal-typical descriptions of prison governance, a few management philosophies have been identified. Barak-Glantz (1981) has identified the following: 1) The authoritarian model; 2) the shared-powers model; and 3) the inmate control model, all of which share (to one degree or another) the "traditional" assumption that the correctional focus should remain on the individualized treatment (e.g., punishment, discipline, rehabilitation, prison governance) of inmates. Barak-Glantz (p.45) also identifies the bureaucratic model, which, as discussed in Chapter I, is in keeping with the technical-rational tradition in public administration. Simply, the bureaucratic prison management style is influenced by broader, external demands "that principles, rules, and regulations be formulated to rationalize (in the Weberian sense) correctional policy and practice." In these cases, the warden perceives him/herself (and is perceived) to have less autonomy and the new penology may be somewhat more explanatory here than in other cases.

John Dilulio (1987) has identified and characterized three types of management philosophies - all of which are variations on a central "keeper" 
philosophy. The keeper philosophy is essentially a "traditional" ideology primarily focused on the individualized treatment and management of inmates. The keeper philosophy revolves around two main principles: 1) Prisoners should not suffer beyond the depravation of liberty; and 2) prisoners should be treated humanely and in accordance with how they behave within the institution. Dilulio's essential argument is that a prison warden who is "true" to a contextually (and normatively) "correct" keeper philosophy will be able to run an orderly prison and maintain a great deal of autonomy (though not full autonomy), even in the face of multiple internal and external stressors.

As has been previously discussed, no prison warden may be completely autocratic in today's "open system" environment. Although all "good" (DiIulio, 1987) correctional management philosophies tend to focus on and prioritize institutional safety security concerns and inmate incapacitation, wardens must remain somewhat sensitive to internal and external demands. However, a well-run prison, argues Dilulio, must focus on improving three key elements of prison life: Order, Amenity \& Service. Order, according to Dilulio is the most important because without order, you cannot have inmate amenities (e.g., ample recreational opportunities, good food, clean cells \& etc) or inmate services (i.e., any program or service "intended to improve the life prospects of inmates: remedial reading, GED programs, vocational training, \& etc.)

Ultimately, DiIulio identified three types of "keeper philosophies" in his 1987 study on prison governance within higher-custody institutions: 1) The Control 
Model; 2) The Responsibility Model; and 3) the Consensual Model. The Control Model is a paramilitary model of prison governance emphasizing institutional safety and security, inmate discipline and routine, visual uniformity (e.g., short haircuts \& uniforms), inmate work, and inmate accountability for their behavior within the institution. The Responsibility Model emphasizes rehabilitation and reentry through inmate accountability (i.e., responsibility), programming, some degree of inmate autonomy and participatory decision-making processes extended to inmates. Finally, the Consensual Model is a cooperative form of prison management that emphasizes formal and informal (i.e., "going with the flow," p. 128) consensus processes between management, staff and inmates. Importantly, the consensual model is context specific and anticipates a great deal of decision-making variability between prison institutions even within the same state. Although he clearly preferred the Texas Control Model due to his perception that they best facilitated the three essentials of prison governance - Order, Amenity, \& Service - the other models may be well suited within certain contexts and at lower-custody institutions.

Additionally, much less theoretical attention is paid in the literature to the "duties" of a warden and the pragmatic, "day-to-day" aspects of their institutional existence. These expectations likely inform (and/or are informed by) both a prison wardens correctional management philosophy and the administrative intent of discretionary policy. Burke Foster (2006, p.156), citing a 1988 National Institute of Corrections workshop, describes a list of the twelve most important "duty areas" of a prison warden, a list which neatly summarizes and encapsulates the correctional 
management literature regarding "good" correctional management. In this

literature, a warden must:

1. Manage human resources;

2. Manage the external environment;

3. Manage litigation;

4. Manage change within the institution;

5. Manage the office;

6. Manage inmates individually and as a group;

7. Review/inspect institutional operations/physical plant;

8. Maintain professional competence and awareness;

9. Manage security processes;

10. Develop long-and short-term goals and objectives;

11. Manage emergencies; and

12. Manage the budget.

In sum, the literature on prison management points to the possibility that prison wardens may be far more autonomous than the new penology hypothesizes.

Similarly, the literature indicates that a warden's values are important to their exercise of discretion and the implementation of discretionary policy. Indeed, it appears that the ability and willingness to do so is a prerequisite for the job. As is revealed in the cases discussed in following chapters, autonomy is both an explicit and implicit expectation of the prison wardens spoken to in this research and it is clear that their dispositional tendencies influence - to a large degree - their decisionmaking processes.

One way in which a correctional manager's beliefs manifests is through the amount and kind of discretionary action taken as they attempt to implement public policy in a way consistent with their beliefs about good management and good prison governance (Dilulio, 1987). Simply, this research assumes that a prison warden's 
philosophical outlook toward their task is likely to influence the administrative intent of an IIT. By consolidating multiple theories of management "style," "beliefs," and "philosophy" under the conceptual rubric of "correctional management philosophy," this study hopes to make the key dispositional characteristics among prison wardens somewhat easier to identify, measure and discuss. Although other dispositional characteristics such as age, race, gender, religious beliefs (to name a few) aren't discussed (or measured) here due to confidentiality agreements and protocols (i.e., respondents may be revealed by such identifiers), in the future, research might tap into a more comprehensive list of dispositional categories when measuring the influence of a wardens dispositional characteristics (See for example: Kim, et al.'s [2003] work, Female Wardens: Results from a National Survey of State Correctional Executives; and Hensley \& Tewksbury's [2005] work, Warden's Perception of Prison Sex in which gender and race are correlated with perceptions of the frequency of prison sex.).

In the following subsection, the assumptions of this research are briefly summarized and linked to the relevant area of literature. This will enable the reader to better link the assumptions of this research with its methodological foundations and approach. Following this discussion, Chapter III will more thoroughly discuss the methodology employed by this study and Chapters IV-VII will discuss this study's findings in relation to its original assumptions. 


\section{Research Assumptions}

This study asks three broad questions of wardens: What correctional goals do you hope to accomplish with interstate inmate transfers? Why? And what contextual factors (if any) are felt to inhibit or facilitate these goals? In challenging the new penology, a basic, underlying assumption of this research is that administrative intent in IIT cases is driven by a highly dynamic combination of dispositional and situational factors (Zimbardo, 1972 \& 2008). Zimbardo (p.vi, p.7) simply defines dispositional forces of influence as those "inner" influences which inhere in, or can be attributed to an “individual [decision-maker's] inner nature, genetic make-up, dispositions [ $\&$ beliefs], personality traits, and character." He describes situational forces of influence as forces external to the individual actor such as the social and political environment, the "system" in which an individual is ensconced, and other factors external from, and [at least, initially] unrelated to, an individual's dispositional characteristics. Zimbardo emphasizes the impact of situational factors and (p.8) asks, "To what extent can an individual's actions be traced to factors outside the actor, to situational variables and environmental processes unique to a given setting [italics added]?" This study includes this question but goes further to ask: "To what extent (and under what conditions) can an individual's actions be traced to factors within the actor - to their attitudes, beliefs, experiences and knowledge?"

Based upon the preceding literature review, the number of influences impacting the administrative intent of IITs would seem to be both dynamically 
variable and, potentially, endless in number. This seems to contradict the easy parsimony of the new penology which simply argues that the administrative intent of all discretionary criminal justice policy is actuarial in nature and a result of postmodern social conditions. It is useful here to briefly review and link the assumptions of this research with essential elements of the literature review. In each case chapter, and in the concluding chapter, these assumptions will be discussed in relation to the findings of this research.

General Assumptions of Research:

1. The new penological assumption that criminal justice actors have no autonomy or exhibit human agency during the implementation of discretionary policy may be incorrect in relation to prison wardens and the administrative intent of all IITs.

2. The new penological assumption that inmates are only thought of in the aggregate or actuarial terms by criminal justice actors may be an incorrect assumption in relation to prison wardens and the administrative intent of all IITs.

3. New penological assumptions regarding the administrative intent of IITs may have some explanatory power in some circumstances (e.g., prison crowding and/or court or media intervention on behalf of [or because of] inmates) and/or when explaining the use of IITs implemented at the DOC level of the correctional organization).

Specific Assumptions of Research:

1. Situational factors of influence: 
a. Law \& Political Culture: The U.S. Supreme Court has found IITs (with some substantive and procedural due process constraints) to be legal (Olim v. Wakinekona, 461 U.S. 238 [1983]). Additionally, the legislative intent and legal mechanisms by which IIT transfers are accomplished (largely influenced by U.S. political culture), more or less vary by jurisdiction. This research anticipated that political culture and legal rulings (i.e., the IIT, as a form of interstate cooperation between correctional agencies, is an expected and legitimate product of American federalism) and formal IIT agreements would influence the administrative intent of interstate inmate transfers in the cases examined here.

b. Discretionary Decision-making: A prison warden's ability to use the IIT as a discretionary management tool exists but their ability to use it as such likely varies by jurisdiction. However, this research anticipated that the prison wardens in this research possessed both the ability and the willingness to formally and/or informally use the IIT tool on a discretionary basis and in accordance with their beliefs about "good" correctional management practices.

c. The Correctional Context: The elements that are most likely to impact the decision-making processes of a prison warden within a given correctional context are likely to vary by jurisdiction. However, this research anticipated that a number of elements - to include: political environment and culture; inter- and intra- organizational relationships; news and mass media accounts of corrections; court interventions; prison crowding; inmate types, attributes and behavior; and 
other elements within a prison warden's institutionalized environment - would influence, in some cases, the administrative intent of interstate inmate transfers.

2. Dispositional factors of influence:

a. Correctional management philosophy: Because IITs are discretionary correctional management tools, this research anticipated that, in most cases, they would be used in accordance with a prison warden's correctional management philosophy.

In assessing the assumptions of this research, this study utilized a case study methodology based upon the epistemological foundations of ethnographic research. The following chapter will discuss the methodological approach taken by this study in more depth. In sum, the case data gathered during the course of this research are presented as the wardens personal "stories" of IITs and correctional management generally. From these stories, evidence supporting or refuting the assumptions described above will be discussed. In Chapter VII, these findings will be discussed in relation to broader theoretical, practical and policy implications. 


\section{CHAPTER III: METHODOLOGY - VIEWING PRISON WARDENS}

\section{THROUGH THE LENS OF INSTITUTIONAL ETHNOGRAPHY}

"Institutional ethnography explores actual people's activities as they coordinate in those forms we call institutions. "-Dorothy Smith, 2006

\section{Telling Stories: Underlying Influences \& Goals of Research}

Stories are important. As Gubrium \& Holstein (1995; 1998, p.163) point out, “[...] the personal story is being resuscitated [by researchers] as an important source of experiential data." In the case of this research, personal stories, derived from interview data, have been useful in developing a better understanding of institutional processes and "ruling relations" (Smith, 1999; DeVault \& McCoy, 2006). Although it is nice to see the literature reflect this seemingly common-sense finding, it is a lesson I learned first hand some time ago. It is helpful to begin this chapter by using a story-telling example from my personal life as a way to introduce the methodological approach taken by this research.

I was fortunate enough to have grown up with a (proudly Irish) grandmother, now 93 years old, who was (and still is) fond of regaling the family with stories of her childhood. The narrative mode of my grandmother's stories can be typified-as most people, perhaps, of Irish descent intuitively know and as Sköldberg (1994) discusses in relation to organizational narratives - in terms of "tragedy, romantic comedy, and satire." Her most interesting stories were those that focused on her immediate relatives (my ancestors). These stories centered primarily on the Irish immigration experience--including the burning of the family's transport ship in a 
Boston harbor during the latter part of the $19^{\text {th }}$ century, and the family exodus to Nevada during the same period.

However, my favorite tales centered on stories of my grandmother's uncle, a prison warden who worked at the Nevada State Prison in Carson City, Nevada in the early $20^{\text {th }}$ century. In every one of these narratives, the warden appears as a benevolent and dutiful hero. The warden stories include (to name only a few) tales about my youthful grandmother (and her younger cousin) driving around with the warden to feed the hungry families of incarcerated offenders or driving long distances in a dilapidated car to find a "gas capsule" needed for an execution (though he did not believe in capital punishment). These stories are important to my grandmother because they humanize and add complexity to people - in this case, relatives - who often existed as one-dimensional caricatures in the public's imagination (i.e., the cruel and arbitrary prison warden). The take-home lessons of my grandmother's story-telling were (and are) clear: people are complex and popular opinion is usually wrong. This is a reoccurring theme in my grandmother's life. Simply, my grandmother's youthful experiences with the warden had a profound influence not only on her beliefs about prisons and prison wardens, but influenced her beliefs about the nature and source of reality. Today, she continues to pass these lessons along to the rest of the family through story telling.

To a large degree, my grandmother has been successful, as these tales of heroism and duty had (and still have) a profound influence on my interest in both prison wardens and in the stories that prison wardens tell. These stories provide 
glimpses into a world that is rarely seen or heard from, and when it is, the reality of this world is often distorted (e.g., through the lens of news and mass media accounts). My grandmother's stories continue to give me added insight into her worldview, belief systems, and perceptions - and thus, a better understanding of her (still somewhat mystifying) past and present behavior. Similarly, it is hoped that the warden narratives discussed in this study will add a layer of complexity and offer additional insights to our current understanding of a prison warden's use of IITs.

\section{Organization of Chapter}

This chapter introduces and discusses the methodology employed by this research. However, it first discusses why prison wardens are an especially interesting topic of study and provides examples of some of the more prominent case studies on correctional management and leadership. Following this discussion, an overview of the methodology is provided and a description of the research protocol is discussed. Beginning with a discussion regarding the many access issues encountered during the course of this research, this chapter then reviews ethnographic interview and case study literature and reviews the specific data gathering and analytic protocols employed in this study. This chapter concludes with an introduction to the organizational structure of the case write-ups discussed in Chapters IV-VI.

\section{Why study prison wardens?}

Before we ask why we should study prison wardens, it is important to first clarify what a prison warden actually is. Often, the term "prison warden" is thought 
of pejoratively. In large part, this is because prison wardens - in contradiction to any current data-driven, generalizable reality - typically loom large in the public's imagination as authoritarian and autonomous men, and very often depicted as cruel, corrupt and arbitrarily punitive figures situated within decaying and/or brutal and isolated maximum security prison institutions. Primarily, this is because popular narratives regarding "prison wardens" tend to be fairly negative, highly dramatized accounts designed to titillate rather than educate (Freeman, 2000; Rafter, 2006; Surette, 2007) ${ }^{21}$. These popular narratives typically do not provide the public with a comprehensive description of what a prison warden actually does (beyond routine acts of "despotism", Rafter, p.46; also see; Surette, 2007), or their relationship to the larger governance system. Interestingly, and as expected, Wikipedia - a very popular, but highly problematic (Poe, 2006), online research tool - does not have a descriptive, analytical, or even a historical link (and only a brief definition) regarding the role of a "prison warden." In sum, the job of a prison warden is often distorted, shrouded in mystery and is generally misunderstood by the general public. It is therefore useful to clarify the term and discuss its usage in this research.

As opposed to popular narrative accounts, the term "prison warden" is a traditional term used to reference state or federal officials (of all races, genders and ethnicities) tasked with managing individual prison institutions at all levels of security classification (i.e., minimum, medium and maximum security institutions) (Clear, 2009). Except in the case of private prisons, prison wardens are public 
officials generally tasked with implementing crime control policies developed in the political process. Unlike media portrayals of prison wardens, and as discussed in the previous chapter, prison wardens are not "isolated" or disconnected from society or from the rest of the governance system. Rather, they and their institutions are coupled (to greater and lesser degrees; see: Hagen, 1989; Renauer, 2003) to other political and criminal justice institutions and to the broader political and social interests of society (Clear, p.317).

Additionally, and in much the same way lawyers, doctors and teachers are considered professionals, today the "prison warden" is considered a professional functioning within a career field (corrections) that is continuing to professionalize. Through the process of professionalization (Mays \& Winfree, 2009), the terms "prison warden" and "prison" have, in some cases, been formally exchanged for the terms "superintendent" and "correctional facilities," respectively, and the entire profession is now formally referred to as "corrections (Stojkovic \& Farkas, 2003)." Although the terms "superintendent," "warden," "prisons" and "correctional facilities" continue to be used throughout the United States, they do not appear, in many cases, to be formally interchangeable (i.e., they are context specific terms). On the other hand, in the correctional management literature (to include introductory textbooks on corrections, see: Clear, 2009) and in personal communications with correctional officials, it appears that they are terms that are (in some cases) informally interchangeable. Therefore, as has been done in other research on prison wardens and superintendents (e.g., Mears \& Castro, 2006), for the purposes of this 
research, the term "warden" (and/or "prison warden") has been utilized generically as a way to ensure consistency in terminology.

Unfortunately, wardens - in contrast to other types of prison research - tend to be [mostly] ignored in the academic literature (DiIulio, 1997; Hensley \& Tewksbury, 2005). Wardens have certainly been ignored in relation to their use of IITs. This may be hampering our ability to more fully understand the role that wardens play in the IIT system. However, four narrative-based case-studies of prison wardens standout as influences on this research: 1) Tocqueville \& Beaumont's 1833 study of Elam Lynds, the builder and first warden of Sing-Sing prison; 2) James Jacob's 1977 historical and sociological case study of warden Joseph Ragen, "Stateville" and the transition of Stateville from a closed system to an open system over time; 3) James Q. Wilson's 1989 case-study of prison wardens as managers and prisons as bureaucracies; and 4) John DiIulio's popular 1987 three-state comparative case study of prison wardens and prisons as "governance systems". In varying degrees, all of these works focus on understanding the institutional lives of prison wardens - from the perspective of the wardens themselves - and point to the need to talk to those who actually implement policy within the prison if we are to gain a better understanding of why, and to what end, they implement policy. This study takes its cue from the spirit and intent of these works and attempts to build upon them by assessing the assumptions of the new penology in relation to context specific correctional management narratives. 


\section{Overview of Methodological Approach}

This case study generally challenges the idea that all IIT's can be attributed to the emergence of a "new penology" in corrections. The specific goal of this research is to explain variation in the administrative intent which has guided the discretionary use of ITT's by prison wardens and their DOC in each of the three cases examined in this study. In challenging the new penology, a basic, underlying assumption of this research is that administrative intent in IIT cases are driven by a highly dynamic combination of dispositional and situational factors (Zimbardo, $1972 \&$ 2008). While Zimbardo emphasizes the impact of situational factors and (p.8) asks, "To what extent can an individual's actions be traced to factors outside the actor, to situational variables and environmental processes unique to a given setting [italics added]?", this research also asks, "To what extent (and under what conditions) can an individual's actions be traced to factors within the actor - to their attitudes, beliefs, experiences and knowledge?"

In seeking to answer the above two questions at the center of this study, the researcher has employed an exploratory case-study methodology. This methodology was chosen because it seemed most compatible (at least for this research) with the assumptions of institutional ethnographic research, which the researcher chose as the overarching framework for the study. The case study methodology utilized here (and described in more depth below) incorporates semi-structured telephone interviews designed to facilitate the discovery and exploration of unanticipated data and improve upon our understanding of correctional management and IIT's generally. 
Specifically, the interviews utilized here are designed to capture the respondent's perceptions and beliefs about their use of interstate inmate transfers in unique implementation contexts. This study "analytically brackets" (Gubrium \& Holstein,1998) the dispositional and situational elements of the gathered correctional management narratives and, using illustrative quotes (Yin, p.306), analyzes these stated factors of influence in relation to the assumptions of the new penology.

\section{Research Setting: Access to Respondents and Case Anonymity}

Due to ongoing access problems and strict (and increasingly constricting) confidentiality agreements (both formal and informal), this study has completely screened the identities of the wardens and their state DOC. This was a late revision (i.e., in the midst of data collection) and includes: Completely altering the original title of the study; removing any identifiers and identifying comments from wardens or DOC officials from the final analysis and the research generally; Replacing the respondent's names with "coded" titles reflecting both the order in which their interview took place and key elements of their management perspective and experiences; and the complete shielding of all of this information from any outside sources. In the three cases analyzed and discussed in Chapter's IV-VII, Case 1 is referred to as Warden A: "Old School"; Case 2 is referred to as Warden B: "New Blood"; and Case Three is referred to as Department of Corrections (DOC):

"Command and Control."

Although completely screening the identities and jurisdiction of the research conducted here was not its original intent, nor a desired outcome, it was felt that the 
level of concern (from the Human Subjects Review Board [See: Appendix C], wardens and their DOC) over breeches in confidentiality were so high, that the approach taken by this study needed to entirely mask the identities of respondents and the context in which they were situated. As was discussed in the literature review, much of the concern from the respondents and the DOC likely stem from a tradition of "correctional silence" (Freemen, 2000), the need to speak with a "unified voice" (p.75; also see discussion below regarding follow-up call to a potential respondent) and the possibility that negative media portrayals of respondent data may lead to career termination (p.74). Of course, this is a real risk and one that has always been taken quite seriously by this research (see: Risks and Benefits of research, See: Appendices F \& D).

A number of potential respondents - as evidenced during second or third follow-up conversations - continued to express a view that they were not very comfortable discussing their subjective opinions in relation to formal DOC policy or [known or unknown] statements made by the commissioner/director of corrections. In some cases, refusals to participate were expressed in deeply shrouded language that, essentially, indicated that they did not want to participate in the research but did not want to say so directly. In some of these cases, the mere prospect of participating in this research seemed to create a level of stress that I decided may violate core ethical elements of human subjects' research. In these cases, I discontinued the conversation and all plans for future follow-ups. Additionally, as pointed out to me by other criminal justice scholars, research was halted due to the possibility that I- 
through repeated and aggressive requests for information - may damage my own career as a prison researcher. As matter of academic interest, and as a guide to future research on prison wardens, it is useful to further discuss the role of the DOC in my attempt to gain access to prison wardens.

\section{Getting into (and out of) Prisons: Respondent Access Issues}

Encountering problems in gaining access to prison wardens was not unanticipated by this research. Hart (1995, p. 165) writes, "Workers in prisons have a vested interest in controlling access to information which often produces the impression of a "fortress mentality." As is the case in other prison research, this statement appeared to be true here. However, when viewed in light of the problems potentially posed by breeches in confidentiality (e.g., career termination), this was not an entirely unexpected nor unwarranted response by prison wardens or the DOC.

Dilulio (1987) writes, "For good reasons, correctional people are not highly solicitous of outside researchers. Permitting scholars to roam about freely in their archives, to interview personnel... and to observe operations does not make their lives any easier." Interestingly, even Dilulio - a Harvard educated political scientist who has an established reputation among correctional officials around the countryencountered a great deal of difficulty in conducting his research for his famous and well-regarded book, Governing Prisons. The level of difficulty he encountered clearly inspired a discussion on the topic in his introductory chapter as well as a chapter-length primer on prison research in his appendices. Similarly, Cynthia Baroody Hart (1995) lists a number of "rules" to researching in the prison context. 
Poignantly, she reminds us that prison research is often considered a "security threat" because it can break the routine of the prison (p.174).

\section{DOC Constraints}

The implementation of this research was a great reminder as to why research on prison wardens is not done very often and provided a number of "how-to" lessons on conducting this type of research in the future. Although this study made every attempt to follow the warnings and rules discussed by DiIulio and Hart and made every effort to follow both DOC and established research protocols, this research quickly became "routed" through the DOC public affairs office and respondents were told not to participate with me directly (name withheld, personal communication, June 18, 2008). Although the redirection of my research exclusively through DOC-level personnel was not intended, desired nor anticipated, all of the DOC personnel that I dealt with were highly responsive, courteous and enthusiastically met all my proposed timelines for information. Although the "control" exerted by the DOC makes sense in the correctional context, it did limit my ability to gather additional cases involving the views of individual prison wardens.

On the other hand, I was able to gather very useful and interesting data from the DOC. These data provide a great compliment to the other two cases I was able to obtain. Additionally, both prison wardens and the DOC expressed a direct interest in reviewing this research when it has been completed. Although this was not part of any formal or informal access agreement, it is in keeping with good research etiquette to "follow-through" on these requests (See: the "Capstone Rule," in Hart, p. 
174). This goes to the heart of successful prison research: building a reputation for cooperation and follow-through that will facilitate further research of this kind in the future.

\section{Methodology: Institutional Ethnography and the Exploratory Case Study}

There are a number of methodological possibilities (and combinations of possibilities) for the type of research undertaken here. Due to the dearth of information on IIT's - and decision-making by prison wardens generally - it was clear that a qualitative research design was a good first step in this type of research. But this methodological approach requires some explanation. Therefore, the first task of this sub-section is to discuss the overall logic of applying a case study analysis to a study of prison wardens, the specific logic of implementing semistructured, telephone interviews (as opposed to other instruments or approaches), and the logic of choosing a particular type of narrative analysis (from among many) to the collected data.

Institutional Ethnography: Understanding "Ruling Relationships" through Narrative Analyses

In their study of Supermax prisons, Mears and Watson (2006, p.238) argue that "[...] qualitative research serves as an essential exploratory tool that can establish a foundation for guiding future efforts to systematically and empirically evaluate...policy." Qualitative research is particularly suited to correctional environments and ethnographically-oriented field research in particular (Singleton \& Straits, 1999). Singleton and Straits (1999, p.323) write, 
[These approaches are] recommended (1) when it is essential to preserve 'whole' events in all their detail and immediacy (Weick, 1968); (2) when a situation is complex, involving interrelated phenomena that must be studied simultaneously and as a whole - for example, the study of a prison as an institution (Weiss, 1966); and (3) when the focus is on the relationship between the person and the setting, so that it is important not to separate one from the other.

The strength of "well-collected qualitative data," write Miles \& Huberman (1994, p. 10 ), "is that they focus on naturally occurring, ordinary events in natural settings so that we have a strong handle on what 'real life' is like." Properly conducted qualitative research then is well suited "for locating the meanings people place on the events, processes, and structure of their lives: their 'perceptions, assumptions, prejudgments, presuppositions' (Van Maanen 1977, in Miles \& Huberman, p. 10) and for connecting these meanings to the social world around them" (Miles \& Huberman, p. 10). Additionally, qualitative research may prove to be highly informative and explanatory if, as in the case of interstate inmate transfers, we know very little about a given phenomenon (Singleton \& Straits, 1999; Cresswell, 2003). Singleton \& Straits (p.323) sum it up neatly by asserting, "The less you know about the subject, the less you can afford to limit data collection."

It was felt that in order to better understand and organize the experiences and beliefs of the prison wardens interviewed for this research, an ethnographic sensibility should also inform the narrative analyses of the collected interview data. The exploratory case study methods utilized here borrows and builds on some of the 
epistemological assumptions of institutional ethnography (Smith, 1978 \& 2006;

DeVault \& McCoy, 2006; Babbie, 2007). Institutional ethnography, writes Babbie (2007, p.300), is an approach developed by Canadian sociologist Dorothy Smith (1978; Graham, 1998; McCorkel \& Meyers, 2003) to study the every day experiences of women and was initially designed to better understand the experiences of “oppressed subjects (Babbie, p.300)." Institutional ethnography, writes Babbie (p. 300), is a "research technique in which the personal experiences of individuals are used to reveal power relationships and other characteristics of the institutions within which they operate." Dorothy Smith (2006, p.14) writes, "Institutional ethnography explores actual people's activities as they coordinate in those forms we call institutions."

Smith's pioneering “feminist standpoint” (Campbell \& Wasco, 2000) position has focused on a number of micro-social problems over the years but initially gained traction from her "[critical feminist] standpoint perspective.... and usage of the category "women"' to reveal oppressive institutional power relationships (Doran, p.48). Additionally, and from the perspective of Dorothy Smith and others (Clough, 1993; Doran, 1993; Grahame, 1998; DeVault \& McCoy, 2006), institutional ethnography is a pioneering form of critical micro-sociology that largely draws its inspiration from Marxism. Smith's explicit linkage to a specific ideological stance and its (arguably) earlier lack of reflection on sociology as a "dominant discourse of experience" has drawn criticism (See: Doran, 1993 \& Smith's "ideological recursion"; Clough, 1993). However, taken more simply as a 
"standpoint epistemology" and its effort to link the micro-social experiences of marginalized subjects to macro-social structures and trends, it has generally been well regarded (Grahame, 1998; DeVault \& McCoy, 2006). Grahame (p.347) writes, "The principle tasks of institutional ethnography include describing the coordination of activities in the everyday world, discovering how ideological accounts define those activities in relation to institutional imperatives, and examining the broader social relations in which local sites of activity are embedded."

Importantly, interview research based upon an institutional ethnographic sensibility is useful in revealing the "ruling relationships" (Smith, 1999) that "shape local experiences (DeVault \& McCoy, 2006, p.15)." Dorothy Smith's concept of "ruling relationships" - simply defined by DeVault \& McCoy (p.15) as the "[...] linkages among the local settings of everyday life, organizations, and translocal processes of administration and governance - is an important empirical consideration of this research. Borrowing from Smith's conceptualization of institutional ethnography and her emphasis on the importance of empirically discovering ruling relationships, this study attempts to understand how these relationships impact a prison warden's use of an IIT.

An institutional ethnography is a perfect approach for understanding the perceptual realities of prison wardens. Although this study does not take, as Smith does, a Marxist or feminist stance, it does argue that the traditional assumptions and approaches of institutional ethnography can be expanded to include a more thorough understanding of the "official voice" - a voice that is intentionally avoided in prison 
research (Mears \& Watson, 2006, 239). This is especially true in the case of prison wardens whose day-to-day duties remain a shrouded (or distorted) mystery for most of the public and who, unfortunately, are rarely heard from - primarily because their voices have been marginalized as a response to organizational centralization, professionalization and the "opening" up of a previously closed system (e.g., problems with media access and portrayals of corrections).

In the cases studied here, institutional ethnography is useful for gaining a better understanding of a prison warden's perception of their institutional environment and the perceived influence of this environment on their use of IITs. As will be more thoroughly discussed below, the data in cases 1 and 2 were organized and analyzed in terms of ruling relationships and narrative clauses (Labov, in press; Franzosi, 1998) categorically divided into dispositional and situational factors of influence. Case Chapter 3 - the official DOC response - was not analyzed in this way due to a lack of data but is compared to the responses in the first two cases. The results were then written-up for each case chapter and all of the results broadly discussed in Chapter VII. On the following page is a sample preview of the tabular format used to organize and analyze data in each case: 
Table 2

\section{Analytical Bracketing}

\begin{tabular}{|l|l|l|}
\hline \multicolumn{2}{|c|}{ Ruling Relationships and Administrative Intent of IITs } \\
\hline & Dispositional Factors of Influence & \multicolumn{1}{|c|}{ Situational Factors of Influence } \\
\hline Case 1: Warden A & Question: & Question: \\
& Descriptive Phrase: & Descriptive Phrase: \\
& Causal Phrase: & Causal Phrase: \\
& (repeat for each question) & (repeat for each question) \\
\hline Case 2: Warden B & Question: & Question: \\
& Descriptive Phrase: & Descriptive Phrase: \\
& Causal Phrase: & Causal Phrase: \\
& (repeat for each question) \\
\hline
\end{tabular}

There are fairly clear distinctions between ethnography and narrative analysis (as well as between types of narrative analyses, Bachman \& Schutt, 2007) that should be clarified here. To begin with, in discussing the differences between narrative analysis and ethnographic analysis, Gubrium \& Holstein (1999, October, p. 561) write:

Narrative analysis refers loosely to the examination of the diverse stories, commentaries, and the conversations engaged in everyday life [...] Ethnography points broadly to the careful and usually long term observation of a group of people to reveal the patterns of social life that are locally experienced.

Gubrium and Holstein assert that narrative analyses and ethnographies, though quite different analytical approaches, have traditionally been considered "overlapping" analytical strategies (p.561). Others (Silverman, 1998) argue that they are not "overlapping" strategies at all but rather, quite distinct and a "border" should be clearly articulated distinguishing the two types of analytical strategies (Silverman, 1998; p.562; see also a more abstract discussion in relation to the "state" of 
ethnography and various epistemological "divides" in Marcus, 2008). This research takes the position, as do Gubrium and Holstein, that there is a clear border between the two analytical methods but that both approaches may be used together as a way to "tame and balance the analytical excesses" of both. Gubrium and Holstein (p.569) conceptualize this type of approach as "border work."

Although the last statement invites an additional and lengthy discussion as well, suffice to say that the use of a "simple" narrative analysis nested within an [institutional] ethnographic sensibility in this research is intentionally designed to discourage (or "tame") excessive "external narrative patterning" (i.e., ethnographic biases toward favoring "dominant" perspectives among a given population - in this case, understanding the warden's subjective view, as opposed to official DOC statements was an important concern; also see problems with external narrative patterning in William Whyte's [1943] Street Corner Society) and an overgeneralization from the anecdotal (i.e., via conclusions drawn from narrativeonly analyses). In sum, the narrative analysis utilized here will allow for the individual, idiosyncratic "story" to be told (and heard) and an ethnographic sensibility will allow for the retelling of these stories in the context of broader institutional forces and factors that shape (but do not absolutely determine, p.567) local, national, and perhaps, global narrative preferences and perceptual realities within a given field. Ultimately, by combining narrative analyses with an ethnographic sensibility, we are able to move from the individual, idiosyncratic 
narrative to an understanding of broad patterns and influences that help to shape individual stories.

Therefore, as the final analysis does here, individual narratives are discussed in light of a prison warden's perceptions of ruling relationships - categorized here as internal and external situational and dispositional decision-making influences -and the resulting patterns of similarity and variability based upon these individually perceived (and experiential and belief shaded) influences. An analysis of these responses are then used to discuss the original assumptions of this research and, in Chapter VII, are used to look at the IIT through an alternative theoretical lens (i.e., institutional theory). Following a discussion of the case study design and interview instrument, the specific narrative analysis methodology will be discussed.

\section{The Case-study Design}

\section{Target Population and Sampling}

As discussed previously, the selection of respondents was initially based upon strict, pre-established criteria, but was altered during the course of the research due to a lack of response and problems with access. The original goal was to focus only on the prison-level of the DOC organization and was to include face-to-face interviews with four-six purposively and "snowball" sampled prison wardens. However, for the reasons discussed previously, and due to the constraints placed upon the researcher by the isolated and distant location of various institutions, the study was only able to obtain telephone interviews from two prison wardens and a written response from their DOC. 
Additionally, this study attempted to draw from a pool of retired, former and active DOC employees who have previously held the position of "Warden" and/or "Assistant Warden" and who have used (or given the option, chose not to use) IITs. However, again due to reasons previously discussed, this study was only able to interview one former and one active prison warden, one of whom did not use the IIT but expressed a willingness to do so if given the opportunity. The latter respondent agreed to discuss their hypothetical use of IITs.

The sampling of prison wardens was ultimately based upon both purposive and "snowball" sampling logic and techniques. Purposive sampling is sampling in which "an investigator relies on his or her expert judgment to select units that are "representative" or "typical" of the population (Singleton \& Straits,1999). Purposive sampling is also referred to as "nonprobability" or "convenience" sampling (Salant \& Dillman, 1994, p.62) because it "depends on a subjective judgment." They write, The surveyor selects a [nonprobability sample] because it is convenient, because he or she believes it is "typical," or perhaps because it is composed of especially interesting cases.

"Snowball" sampling on the other hand, was employed in this study due to the difficulties encountered in accessing prison wardens. For access reasons discussed previously, and due to time (and other) constraints, desired respondents were not willing or able to participate in the research. Snowball sampling, at least in this study, is a "referral" sampling strategy that assumes [qualified and potentially willing] respondents who know one another and may refer one another to this study. 
Interestingly, the "snowball" sample obtained in this research did not come from a warden or a current DOC official but from an entirely unexpected source (name withheld, personal communications, May 26, 2008). This was unanticipated but did provide this study with an additional case that it would not otherwise have obtained.

Neither one of these sampling techniques will provide statistically generalizable data (Salant \& Dillman, 1994; Singleton \& Straits, 1999; Mears \& Watson, 2006). However, choosing "representative" samples is not required or, often, desired in qualitative research (Morse, 1998). In fact, attempting to achieve a "representative" sample may well harm rather than aid qualitative research (p.733). Simply, in an initial, exploratory case study research such as this one, a sampling methodology should be based on finding willing and able respondents qualified to discuss their use and/or specific knowledge of IITs.

The sample obtained and analyzed in this research is relatively small. Using Yin's logic (pp. 39-41), however, this study could have, conceivably, utilized only one case and there are at least two significant justifications for implementing this research, even with a small sample: 1) There is only one, recent empirical (though not theoretical) work regarding IITs and their administrative intent (USDOJ, NIC, Biasca, 2006); and 2) the new penology is currently the only (non-tested) theoretical explanation for the use of IIT's by prison wardens and other correctional managers. Thus, as Yin (2003, p. 40) asserts (and as discussed in more depth below), even single-case designs are acceptable when the case represents an "extreme case or a unique case." Based upon Yin's "holistic" model, I looked at one unit of analysis 
(prison wardens) but used multiple cases within the DOC. The collected DOC-

level data, though unexpected, are contrasted and compared with statements made by prison wardens.

Case studies "focus attention on one or a few instances of some social phenomenon, such as a village, a family, or a juvenile gang," to name only a few examples (Babbie, 2007, p.298), or, as mentioned previously, on the institutional lives of prison wardens. Extended case studies (Burawoy, et al., 1991), include descriptive information and a focus on one or more instances of a social phenomenon but are most useful for testing hypotheses drawn from larger theoretical frameworks and for "discovering flaws in, and then modifying, existing social theories (Babbie, 2007, p.298)." Although this research does not test hypotheses, it does challenge the assumptions of the new penology in the hope of either suggesting modifications to the framework or proposing alternative theoretical frameworks.

Each warden, and the correctional facility under (or formerly under) their control, is considered to be a unique case "embedded" (Yin, 2003, p.52) within a larger case - i.e., The Department of Corrections. Comparing multiple cases within the Department of Corrections will help us to better understand the variation (or lack of variation) in the administrative intent of interstate inmate transfers in this correctional context. Robert Yin (p.46) argues that multiple-case, case studies, though not statistically generalizable, are often "more compelling" and "robust" due to the amount of evidence collected. Yin (p.40) has modeled the design of a 
multiple-case, case-study depicting a single unit of analysis and is utilized in this case as follows (Table 3):

\section{Table 3}

\begin{tabular}{|c|c|}
\hline Context & Context \\
\hline $\begin{array}{c}\text { Case 1: Prison } \\
\text { Warden 1 }\end{array}$ & Case2: Prison \\
& \\
\hline Context & \\
\hline Case 3: DOC & \\
\hline & \\
\hline
\end{tabular}

Note: This table is a modified replication drawn from Yin, $\mathrm{R}$ (2003). Case siudy Research: Design and methods. Thousand Oaks, CA: Sage Publications.

Yin (2003, p.37) argues that the referral to statistical generalizability in relation to a specific case study - especially an initial, exploratory study - is incorrect. Rather, the usefulness of a case study is in its ability to hone the replication logic employed - replication logic being "analogous [but not the same as] that used in multiple experiments." In other words, as is the case in this research, analytical generalization to theory is the ultimate goal. Yin (p.47) writes, "[Cases are selected so that they] either: (a) predict similar results (a literal replication) or (b) [they] predict contrasting results but for predictable reasons (a theoretical replication)." This study has anticipated that there will be both similar and contrasting results for predictable reasons and the findings, discussed in following chapters, support this assumption. 
Semi-structured and open-ended, topically organized active interviews are utilized because they may, in accordance with the assumptions of institutional ethnography (Dorothy Smith, 1978; DeVault \& McCoy, 2006), be useful in moving prison wardens beyond their "official voice" and into more unscripted realms of thought and behavior so that their use of interstate inmate transfers may be better understood. By maintaining a somewhat flexible and open interview structure it was hoped that the voices of wardens will be encouraged rather than silenced through their increased ability to contribute unguided commentary regarding their perceptions and understandings of the correctional environment in which they inhabit. Similarly, it was anticipated that these unscripted and spontaneous discussions will allow the expertise of various wardens to provide a corrective function in the sense that the interview instrument may be adjusted, as research progresses, to reflect the realities of their unique correctional environment.

Extensive pretesting was done prior to the implementation of the interview instrument (see discussion below). However, the natural conversational flow of the first interview led to some interview questions being asked out of their preestablished order. Although this was not anticipated, it did not necessarily hinder the interview process. In fact, it resulted in discussing the administrative intent of IITs sooner than expected and may have led to more complete answers than if asked toward the end of the interview as originally intended. Both interviews were fairly lengthy (over an hour each) and interview fatigue, though not expressed, might have 
factored in to less complete responses with regard to administrative intent and the IIT. In the second interview, Question cluster 5 was simply moved up in the order. For the sake of consistency and clarity, the number of the question was not changed, simply the order in which it was asked.

\section{The Telephone Interview}

As discussed previously, due to time and distance constraints, telephone interviews were substituted for face-to-face interviews. Telephone interviews are widely considered to be a valid and effective means of gathering information (Salant \& Dillman, 1994; Singleton \& Straits, 1999), especially if respondents are notified in advance of the call. This research, due to the small number of respondents, utilized only one telephone interviewer and conducted the interviews in accordance with the accepted tenets of proper telephone interview techniques (See: Salant \& Dillman, pp. 170-174 for a complete discussion).

For purposes of this research - and with the respondents signed permission telephone recording devices were utilized in order to capture the exact words of each respondent. These recordings were later transcribed and the transcriptions utilized during the data organization and analysis portion of the study. For reasons of confidentiality discussed above and below, the transcripts - in their entirety - are not included in this study. However, illustrative selections that are not likely to reveal the identity of respondents are presented in each case chapter. 


\section{Pretesting}

Prior to the implementation of the interview instrument, it was pretested in order to ensure that the instrument "serve[d] the purposes it was designed (Singleton \& Straits, 1999, p. 266)." The purpose of the pretest was to determine whether the questions asked during the interview would be understood by the respondent in the way the interviewer would like them too. Should revisions be made? These questions were best answered - as well as they could be - prior to the actual implementation of the survey.

In order to ensure the clarity of the questions, this study utilized two respondents to help pretest the interview instrument. Both respondents had at least a college degree, the second of whom had a master's degree in education. The first respondent served to answer the general question: "Do the questions [generally] make sense?" The second respondent served to answer the more specific question, "Do these questions make sense from the perspective of someone [potentially] possessing an advanced degree and whom is a leader situated within a complex institutional environment?" All of the respondents were given the instrument over the phone in order to ensure that the wording of the questions could be understood over [sometimes] distorted telephone lines or cell phone networks. Based upon the results of a number of pretests, the interview instrument was revised and modified in accordance with the needs, desires and requirements of the respondents. This served to make the actual interview process quite seamless with regard to the clarity and quality of the core interview questions, though as discussed previously some 
questions were reordered based upon their "natural place" in the interview instrument.

\section{Developing Rapport}

Taking its cues from Holstein and Gubrium (1995), this study employed an “active interview" approach to interviewing. As Miller, Manning \& Van Maanen (1995 in Holstein \& Gubrium, series editors note) argue, interviews are more than a series of "clean" questions followed by "crisp" answers that are readily processed into a recognizable reality. This is especially true in ethnographically-oriented research. Rather, they write, $[\ldots]$ interviews are "social productions" [in which] respondents are better seen as narrators or story tellers, and ethnographers are cast as participants in the process. Working together, the interviewer and narrator actively construct a story and its meaning.

An "active interview" then necessarily requires the interviewer to remain ready, willing and able to go "off script" in order to recover relevant and interesting narrative data. As Holstein and Gubrium report (p.14), an active interview is much more than an opportunity for information gathering. Rather, an "active view" of interviewing is also "dynamic and based upon communicative contingencies designed [to activate opinion in order to retrieve stories of] "interpersonal drama with a developing plot."

In developing and maintaining rapport with respondents, it was common to go "off script" in order to hear unanticipated stories or, in some cases, tell stories that 
would provoke additional responses and allow the researcher to more deeply probe responses (Holstein \& Gubrium, p.45). For example, I began a discussion regarding my interest in researching prison wardens by discussing my grandmother's history of telling stories about her uncle, the prison warden of Nevada State Prison (discussed above). In another example, I used my teaching experiences in media studies to more deeply probe a discussion regarding the potential influence of the mass media on a wardens' decision-making process. Additionally, I used my casespecific background knowledge of the institutional environment to further discuss a variety of factors that may or may not influence decision-making. In both interviews, rapport was quite good and the interviews lasted well over an hour each.

\section{Interview Protocol \& Screening criteria}

Originally, selection criteria were quite strict and based upon the answers to the following three questions: 1) Are you a current or former Department of Corrections employee?; 2) Do you hold, or have you held, the position of "Warden" or "Assistant Warden?"; and 3) Have you utilized (or, given the choice, did not utilize) interstate inmate transfers at some point during your career? However, due access problems discussed above, these criteria were loosened and only one respondent met the original criteria. The second respondent, though never having directly implemented an IIT was willing to discuss their use hypothetically and in the third case, the DOC was willing to provide explicit policy information regarding their use at all levels of the DOC. 
Prior to initiating contact with potential respondents, I felt that it was first necessary to contact specific personnel within the Department of Corrections for permission to implement my study. I placed two phone calls and forwarded my approved Human Subjects Review application via email to a particular DOC employee. However, in order to ensure I would have willing respondents, I began making contact with potential respondents prior to any type of formal response from the DOC. Although I did not receive any response from the DOC employee initially contacted, I did eventually receive a response from other DOC employees. However, the responses that I received cannot be strictly considered a form of approval, but rather, are better characterized as an expressed willingness to cooperate with the research.

The following protocol was used during the implementation of my research: First Contact: After informally developing a list of possible willing respondents with committee member, Brian Renauer, I mailed (e-mail and via the U.S. Postal Service) a solicitation letter to each potential respondent. There were 15 respondents identified in the initial round of mailings.

Second \& Third Contacts: Ten and twenty days (respectively) following the initial mailing, I contacted, by phone and/or mail (Appendix D \& E), each potential respondent. Upon making phone contact, I introduced myself and my research proposal. If the potential respondent was interested in taking part in my research, I then asked them three screening questions: 
1. Are you a current or former Department of Corrections employee? (In the first round, this was usually established prior to the call).

2. Do you hold or have you held the position of "warden" or "Assistant warden"? (This too was sometimes established prior to the call).

3. Have you utilized, or given the option, did not utilize, interstate inmate transfers at some point during your career?

If the answer given to all three questions was "yes," I included them in the study and set an appointment for either a phone or face-to-face interview (See Questions in Appendix B). However, as discussed above, exceptions were made to this protocol due to the problems associated with accessing respondents.

Risks and Safeguards (See also: Informed Consent Letter, Appendix E)

As is the case in any research involving human subjects, there are potential risks to the subject. Thus, the development of adequate safeguards is both ethical and legally required of research involving human subjects. I will briefly discuss the identifiable risks to the respondent's research below. Following this discussion, I will elaborate on the safeguards I have developed to protect the respondent's confidentiality.

Risks: The respondent may be asked questions that they feel uncomfortable answering. They may also feel inconvenienced by participating in this study. Although multiple safeguards have been put in place to protect confidentiality (discussed below), while participating in this study there is always a small risk that the confidentiality of the respondent's information may be compromised. In the case 
correctional officials, this may lead to adverse political or career consequences

for the individual respondent.

Safeguards: The respondent was in no way required to answer any question they felt uncomfortable answering and were not be pressured to do so. Additionally, every effort was made by the researcher to accommodate the respondent's schedule so that they did not feel inconvenienced. Finally, every effort was made by the researcher to keep any information obtained in connection with this study, and that can be linked to the respondent or used to identify them, confidential. This data (and confidentiality) is protected in the following ways:

1. Only the principle researcher will have access to the data.

2. Results of this research will never be presented in a way which may compromise the privacy of the respondent.

3. Any reports generated utilizing this data will employ pseudonyms in order to mask the actual names of individuals and/or institutions involved in the study.

4. No public or private discussions will occur regarding individually named respondents and/or their institutions.

5. Data will be kept at home, under lock and key on a computer (and in hard-copy files) that are under the sole control of Robert Swan.

6. Upon request, respondent was able to review their own "raw" transcripts of the interview prior to analysis in order to ensure transcript accuracy and screen transcripts for possible statements which may inadvertently identify the respondent to others. 
7. Interview tape recordings will be destroyed immediately after transcription.

Based upon additional questions from the HSRRC Board (2008, May 5; See:

HSRRC Memo, Appendix C), additional clarifications were made. It is a lengthy discussion and is included in Appendix $\mathrm{C}$ for a full disclosure. After clarifying my methods of data protection and my method of protecting confidentiality, the HSRRC Board approved my research on May 12, 2008 (Appendix F).

\section{Interview Instrument (See Appendix B)}

The interview instrument designed for this study consists of semi-structured and loosely coupled questions that are closely tied to each dimension of administrative intent discussed previously. As was also discussed previously, in an effort to preserve the internal validity of this research, in questioning respondents this study did not cling too rigidly to the development of question schedules or their implementation during the interview process. Primarily, this was to avoid creating and implementing an interview instrument that may "lead" the respondent to "correct" line of thinking and to "correct" answers (Salant \& Dillman, 1994; Yin, 2003, p.112-113: "stacking the deck"; Brian Renauer, personal communication, 2007). Rather, it was intended that the interview would remain "active" and fairly open-ended in order to leave room for unanticipated data. 


\section{Data Analysis}

\section{Data Organization}

In qualitatively researching complex institutional environments such as corrections, the challenge lies in the coherent organization and analysis of [often] massive amount of collected data. As discussed previously, this research has chosen to focus on the narratives of prison wardens in relation to their use of IITs. Narratives are defined by Labov (in Franzosi, p.519) as "one method of recapitulating past experience by matching a verbal sequence of clauses to the sequence of events which (it is inferred) it actually occurred." More simply stated, narratives are stories, and include all of the elements of traditional stories. Franzosi writes, "A story...implies a change in situations as expressed by the unfolding of a specific sequence of events." "The presence or absence of a story is what distinguishes narrative from non-narrative texts (Rimmon-Kenan, 1983, p.15)." In taking an "active" interview approach, this study attempted to co-produce stories designed to reveal the influences that affected (or not) a prison warden's use and administrative intent of IITs. Analysis of the data collected during the course of this research involved four tasks: 1) Organizing the collected narratives by analytically bracketing relevant narrative clauses and organizing these portions of the interview into dispositional and situational factors of influence (see example below); 2) Individual case write-ups based upon the organization of this data, to include the use of illustrative quotes (Chapter's IV-VI); 3) "Writing up" the results of the analysis in terms of broad themes (Chapter VII); and 4) A discussion and sample (but not 
exhaustive) reinterpretation of the results through an alternative theoretical lens.

Institutional theory is used for this purpose in Chapter VII.

\section{Narrative Clauses \& Analytic Bracketing}

In order to avoid delivering a "descriptive broadside" to the reader, Harry Wolcott (1990, p.32) advises the qualitative researcher to sort and organize raw interview (or other) transcript data into basic categories. This study has done just that. The data in each case were organized and analyzed in terms of ruling relationships and narrative clauses (Labov, in press; Franzosi, 1998) categorically divided into dispositional and situational factors of influence. Narratives may be divided in any number of ways (Skoldberg, 1994 [narrative modes: Tragedy, Satire \& Drama]; Franzosi, 1998 [ referential and evaluative]; Labov, in press [temporal, structural, evaluative, causal]), to name only a few. This study has chosen to divide the recorded interviews into narrative clauses based upon their emphasis on dispositional and situational factors of influence. These narrative clauses then may be referential (descriptive) and evaluative (causal) and may include elements of tragedy, satire and drama.

Analytic bracketing is discussed by Gubrium \& Holstein (1998) as a way to narrowly focus on certain aspects of narratives. They write (p.165), "We may focus, for example, on how a story is told, while temporarily deferring our concern for various whats that are involved [...]." For the purposes of this research, the what's and the whys are somewhat more important that the how's. Therefore, bracketing the narrative data in terms of "what and how" - in relation to a variety of dispositional 
and situational factors influencing (or not) the administrative intent of IITs - is

the focus of the data analysis.

The following example (Table 2), has been introduced previously (p. 108)

and is used again as a preview of the data analysis process utilized in the following

chapters. Questions and responses are organized in the order in which they were

asked and analytically bracketed both in terms of dispositional and situational factors

of influence and in terms of descriptive and causal phrases. In some cases, narrative

phrases are both descriptive and causal due to the latent causal explanations

embedded in certain descriptions of events (For full data display, see: Appendices H-

J). Additionally, responses have been edited for clarity and confidentiality purposes.

\section{Table 2}

\section{Analytic Bracketing}

\begin{tabular}{|c|c|c|}
\hline \multicolumn{3}{|c|}{ Ruling Relationships and Administrative Intent of IITs } \\
\hline & Dispositional Factors of Influence & Situational Factors of Influence \\
\hline $\begin{array}{l}\text { Case 1: Warden } \\
\text { A- "Old School" } \\
\text { Questions and } \\
\text { responses are } \\
\text { organized in the } \\
\text { order in which } \\
\text { they were asked } \\
\text { and analytically } \\
\text { bracketed in terms } \\
\text { of Dispositional } \\
\text { factors and } \\
\text { Situational factors } \\
\text { of influence and in } \\
\text { terms af of } \\
\text { descriptive and }\end{array}$ & $\begin{array}{l}\text { Question 1b Cluster: During the } \\
\text { course of your career with the } \\
\text { Department of Corrections, were } \\
\text { you authorized at all to directly } \\
\text { implement interstate inmate } \\
\text { transfers (IITs) to manage your } \\
\text { institution[s]?" } \\
\text { Descriptive: One time I had to [...] } \\
\text { find a way to move an inmate to } \\
\text { another state because [offender] was } \\
\text { better served out-of-state. }\end{array}$ & $\begin{array}{l}\text { Question 1b Cluster [probe]: } \\
\text { When you say "better served" what } \\
\text { do you mean by that? } \\
\text { Descriptive/causal: "Well, it was a } \\
\text { high-profile inmate in [name } \\
\text { withheld] so we needed to move } \\
\text { [offender] out of [name withheld]. } \\
\text { Descriptive: Usually, the interstate } \\
\text { compact is managed by the central } \\
\text { office [...] through the interstate } \\
\text { compact unit. And usually they } \\
\text { work with states that are willing to } \\
\text { work with us at moving inmates } \\
\text { around...but in this case, nobody } \\
\text { would take [offender]. }\end{array}$ \\
\hline $\begin{array}{lr}\text { causal phrases. In } \\
\text { some cases, } \\
\text { narrative phrases } \\
\text { are } r \text { both } \\
\text { descriptive and } \\
\text { causal due to the } \\
\text { latent } \quad \text { causal } \\
\end{array}$ & $\begin{array}{l}\text { Question 5a: "At the beginning of } \\
\text { the interview, you stated that you } \\
\text { have used (or referred) interstate } \\
\text { inmate transfers } \\
\text { times over the course of } \\
\text { your career. Can you describe some } \\
\text { of the factors that influence your }\end{array}$ & $\begin{array}{l}\text { Question 5a: "At the beginning of } \\
\text { the interview, you stated that you } \\
\text { have used (or referred) interstate } \\
\text { inmate transfers } \\
\text { times over the course of } \\
\text { your career. Can you describe } \\
\text { some of the factors that influence }\end{array}$ \\
\hline
\end{tabular}




\begin{tabular}{|c|c|c|}
\hline $\begin{array}{l}\text { explanations } \\
\text { embedded } \\
\text { certain } \\
\text { descriptions of } \\
\text { events. } \\
\text { In most cases, } \\
\text { responses have } \\
\text { been edited for } \\
\text { clarity and } \\
\text { confidentiality } \\
\text { purposes. }\end{array}$ & 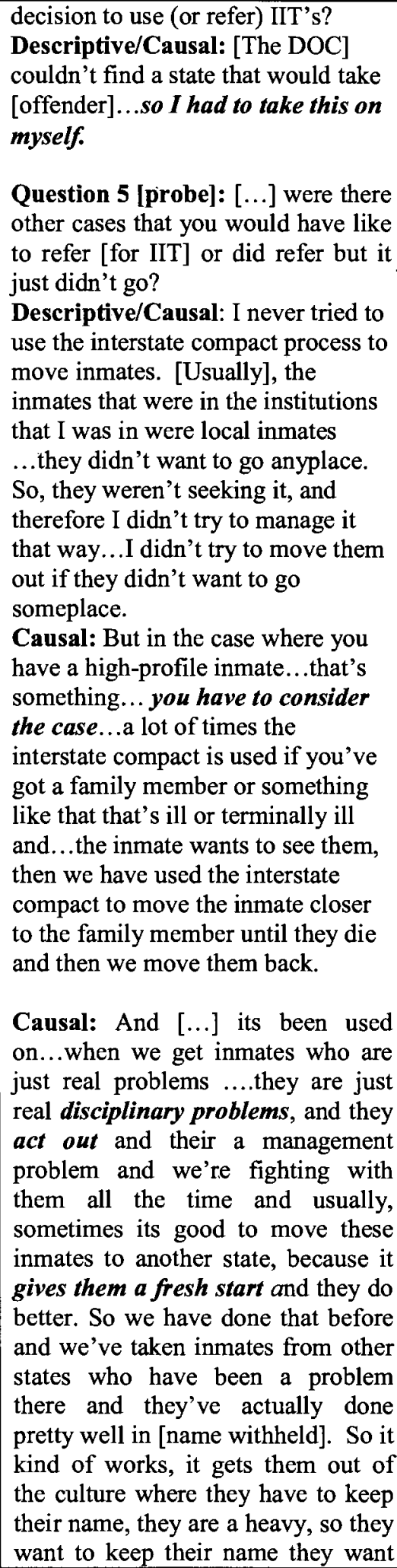 & 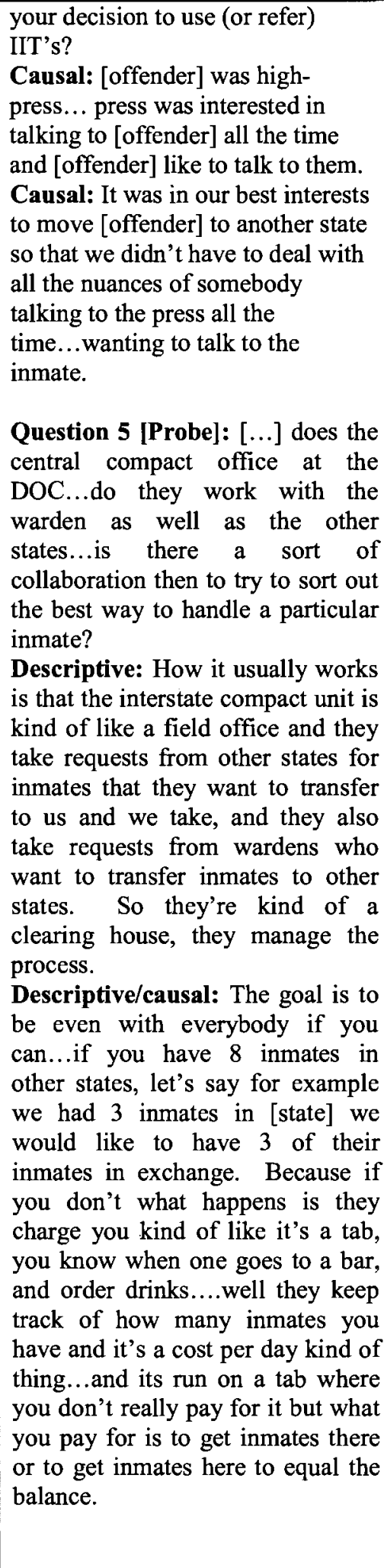 \\
\hline
\end{tabular}




\begin{tabular}{|l|l|l|}
\hline & $\begin{array}{l}\text { to be on the top of the heap of bad } \\
\text { guys. And it takes them out of that } \\
\text { scenario so that they can start out } \\
\text { fresh, nobody knows who they are, } \\
\text { and if you get them started right, } \\
\text { generally speaking they are usually } \\
\text { not too much trouble. } \\
\text { Descriptive: There are lots of ways } \\
\text { that the interstate compact is } \\
\text { helpful. It's really not a bad thing. }\end{array}$ \\
\hline $\begin{array}{l}\text { Case 2: Warden } \\
\text { B- "New Blood" }\end{array}$ & $\begin{array}{l}\text { Question: } \\
\text { Descriptive: } \\
\text { Causal: }\end{array}$ & $\begin{array}{l}\text { Question: } \\
\text { Descriptive: } \\
\text { Causal: }\end{array}$ \\
\hline
\end{tabular}

The above example is incomplete, and is fully bracketed prior to the final analysis in the following chapter (Appendix G). However, from these (and other data), one conclusion that might be reached in relation to administrative intent in Warden A's case is that dispositional characteristics and tendencies (and, in the case of Warden A, a focus on the individual needs and attributes of offenders) may have more influence on the intent of IITs than situational factors-except in cases of extensive media coverage of inmates (although interestingly, Warden A was able to facilitate an IIT in that case due to their unique set of dispositional qualities and the character of their unique external relationships). In particular, the statement that IITs are not a "bad thing" and can be "helpful," is a clear indication that dispositional influences (e.g., beliefs about good management) may have some influence on the administrative intent of IITs.

However, in "high-press" cases, the institutional needs of the prison and the DOC appear to be prioritized over the needs of the individual offender (though the latter's needs are not forgotten). In light of the data collected (and presented more fully in Chapter IV and in Appendix G), the relationship between Warden A's use of 
the term "helpful" and "not a bad thing" in reference to IITs appears to be related to a pragmatic belief about IITs in relation to the safety \& security needs of inmates, the prison institution, and the DOC organization - though external factors may sometimes act to prioritize the needs of the institution and DOC over the needs of the inmate (e.g., "high-press" inmates, and inmates who want to talk to the press, may pose a public relations and security threat to the institution and to themselves). The data gathered in this case (See: Chapter IV) appears to contradict new penology assumption that situational stressors are perpetually influential and that institutional needs are always prioritized over individual offender needs and that individual offender needs are marginalized or ignored.

\section{Case Write-ups}

The results of the data organization and analysis will then be "written-up" (Wolcott, 1990) for each case (Chapters IV-VI) and more broadly discussed in Chapter VII. Grahame (p.347) writes, The principle tasks of institutional ethnography include describing the coordination of activities in the everyday world, discovering how ideological accounts define those activities in relation to institutional imperatives, and examining the broader social relations in which local sites of activity are embedded.

This is a good general description regarding the substance of each case write-up and the final analysis in Chapter VII. More specifically, each case write-up utilizes illustrative quotes in order to emphasize the perceived influence of dispositional and situational factors on the administrative intent of IITs. This analysis will discuss 
whether these factors were seen as explicitly causal (or not) or are merely

descriptions that imply a latent influence or, perhaps, no influence at all. The data from each case will be discussed in relation to the administrative intent of IITs and in relation to the assumptions of the new penology. In Chapter VII, all of the data will be discussed more broadly in relation to the new penology and briefly discussed in relation to institutional theory.

The following organizing format is used to structure each of the following three chapters:

Introduction to Case

Dispositional Factors

Situational Factors

Case Findings in Relation to Administrative Intent and the New Penology As discussed previously, each of the following three case chapters have been given a "coded" designation in order to preserve the confidentiality of the respondents and their state DOC. Additionally, each case is "subtitled" in accordance with the substantive content of the interview or survey. For example, Case 1 is entitled: "Warden A: "Old School." This title is based upon the order in which the respondent was interviewed and is subtitled in accordance with the substantive content (e.g., themes, influences \& stories) that emerged over the course of the interview. The subtitles were given in each case in order to emphasize the narrative "plot line" of each story and to hint at the overall perspective of each respondent. 
Finally, for purposes of clarity and readability, Appendices $\mathrm{G}$ and $\mathrm{H}$ contain the full data organizational tables and are not included within each chapter. Rather, selected, illustrative excerpts are used in each chapter analysis in order to highlight main points and draw attention to some of the more interesting and unexpected findings. Additionally, the data have been altered or paraphrased in some cases in order to preserve the clarity of statements and/or the identity of respondents. The following chapter begins by examining Case 1: "Warden A: "Old School" and the respondent's use of an IIT over the course of a long career in corrections. 


\section{CHAPTER IV: CASE 1 WARDEN A - "OLD SCHOOL"}

"So [IITs] kind of work, [they] get [inmates] out of the culture where they have to keep their name - they are a heavy-so they want to keep their name they want to be on the top of the heap of bad guys. And it takes them out of that scenario so that they can start out fresh, nobody knows who they are, and if you get them started right, generally speaking they are usually not too much trouble. "--Warden A

\section{Introduction to Case}

The first case presented here is that of a prison warden who has directly implemented an IIT. In order to protect confidentiality, the respondent in this case has been designated "Warden A" and given the avatar "old school" as a reflection of both the respondent's time on the job as a prison warden and the expressed origins of his management philosophy and training. Although very few specifics in relation to Warden A's age, race, gender, ethnicity and other potentially identifying personal attributes will be discussed in this study, a general description of the warden, the particular correctional context in which he is situated, and his use of IITs will be briefly discussed. Prior to this discussion — and prior to an in-depth analysis of this case--this study's research questions and assumptions are generally reviewed. Review of research questions, assumptions, and categories of influence

To review, the purpose of this study is to develop a better understanding of the discretionary role that prison wardens play in the IIT system. This study asks three broad questions of wardens: What correctional goals do you hope to accomplish with interstate inmate transfers? Why? And what contextual factors (if any) are felt to inhibit or facilitate these goals? The study is designed to challenge the new penology and its theoretical assumption that the administrative intent of 
discretionary criminal justice policy serves purely instrumental goals and will always avoid serving individual offender and community needs in favor of the broad actuarial and economic interests of the state. To summarize, the new penology construct implicitly assumes that the correctional context either: 1) does not vary; or 2) varies but contextual variability has no impact on the administrative intent of IITs. Similarly, it assumes that human agency is nonexistent or not possible among criminal justice actors in the current penal context.

A basic, underlying assumption of this research is that administrative intent in IIT cases is driven by a highly dynamic combination of dispositional and situational factors (Zimbardo, 1972 \& 2008). Zimbardo (p.vi, p.7) simply defines dispositional forces of influence as those "inner" influences that inhere in or can be attributed to an 'individual [decision-maker's] inner nature, genetic makeup, dispositions [\& beliefs], personality traits, and character." He describes situational forces of influence as forces external to the individual actor such as the social and political environment, the system in which an individual is ensconced, and other factors external to, and (at least, initially) unrelated to an individual's dispositional characteristics. While Zimbardo emphasizes the impact of situational factors and (p.8) asks, "To what extent can an individual's actions be traced to factors outside the actor, to situational variables and environmental processes unique to a given setting?" [italics added], this research also asks to what extent (and under what conditions) can an individual's actions be traced to factors within the actor-to their attitudes, beliefs, experiences, and knowledge? Borrowing from the work of 
Dorothy Smith (1987 \& 2006) and viewing the interview data though the lens of institutional ethnographic research (DeVault \& McCoy, 2006), the data were organized and analyzed in terms of ruling relationships and categorically divided into dispositional and situational factors of influence.

\section{An Introduction to Warden A}

Warden A is a congenial and very knowledgeable former prison warden who was situated in a (comparatively speaking) mid- to small-size department of corrections in a mid- to small-size state. The respondent enjoyed a long career with the department of corrections and was originally trained (and worked as) a line-level correctional officer, eventually attaining the position of warden or assistant warden at a number of different state-level prison institutions. The respondent had this to say about his initial training and experiences:

[...] when I first started ... we had really good training [...] Our job, when I first started, was to change these [convicted] kids, because at that time, [the state] felt that this was the time to intervene in their lives and try to change them before they became long-term convicts in the system and try to get them out of the system so ... a lot of the training I [initially] received was directed at how to change inmate behavior ... So, right from the very beginning, that's how I was trained.

Additionally, Warden A-though implementing an IIT only one time during the course of his career-has a fairly extensive knowledge of their historical use in the state. From the perspective of Warden A, IITs serve (and have served) a variety of purposes over the years. In generally (and normatively) characterizing the utility of IITs, the respondent had this to say:

There are lots of ways that the interstate compact is helpful. It's really not a bad thing. 
This statement provides good insight into Warden A's overall perception of IITs.

The respondent also had this to say about his personal use of IITs:

One time I had to [...] find a way to move an inmate to another state because the [offender] was better served out of state. I [usually] never tried to use the interstate compact process to move inmates. [Usually], the inmates that were in the institutions that I was in were local inmates ... They didn't want to go anyplace. So, they weren't seeking it, and therefore I didn't try to manage it that way ... I didn't try to move them out if they didn't want to go someplace.

And he had this to say about his state's use of IITs:

It's just something that's evolved [...] It probably started in the [date], before I even started. Wardens were doing it ... so it just kind of evolved and states agreed and wardens agreed, and other states agreed to take these inmates. There was an ability to transfer inmates but the warden did it with the warden of the other state. And we did transfer inmates back in [date]. We transferred [number] inmates to [state] that we were having a lot of trouble with...down in a car! We did that back then but it wasn't a formalized process like it was later. [Then DOCs] became centralized organizations, then the centralization took over [leading to centralized IIT] management.

How it usually works [now] is that the interstate compact unit is kind of like a field office, and they take requests from other states for inmates that they want to transfer to us $[\ldots]$ and they also take requests from wardens who want to transfer inmates to other states. So they're kind of a clearinghouse, they manage the process.

In sum, Warden A possessed a great deal of knowledge not only in relation to his personal use of IITs, but also in relation to their use by others within (and outside of) the DOC and the history of IITs in his state generally. Overall, the interview was quite informative and provided an "inside" historical view of IITs in the state.

In the following two subsections, the dispositional and situational factors influencing Warden A's decision-making will be discussed in depth. Following these discussions, an analysis of the potential influence of these factors on Warden A's discretionary decision-making processes, and on his use of an IIT in particular, 
will be presented and discussed. Finally, the findings in this case will be discussed in relation to the results anticipated by this research and in relation to the theoretical assumptions of the new penology.

\section{Dispositional Factors}

During the interview with Warden A, it was clear that a number of dispositional factors may have had some influence on the respondent's use of an IIT and on inmate management more generally. In most (non-IIT) circumstances Warden A appeared to feel (and exercise) a great deal of autonomy in the management of his prison institution. Thus, Warden A's discretionary decision-making, with some exceptions (discussed in the following subsection), appears to be largely influenced by a number of dispositional attributes and tendencies. Broadly speaking, the dispositional factors that emerged from the interview as most influential were:

1. Respondent's beliefs about the purpose of incarceration;

2. Respondent's experience, early training and guidance in corrections;

3. Respondent's beliefs about good correctional management practices;

4. Respondent's beliefs about the best management styles and attitudes. $\underline{\text { Respondent's beliefs about the purpose of incarceration }}$

As was discussed in Chapter II, wardens' beliefs about the purpose of incarceration are likely to influence the way they run their institution. Thus, this research anticipated that such beliefs were likely to influence discretionary decisionmaking in the IIT case examined here. In particular, a warden's beliefs about the purpose of incarceration were anticipated to influence the administrative intent of 
IITs. To some degree, this was true. However, as will be discussed below and in the following subsection, the administrative intent of the IIT used here appears to have been driven primarily in response to the "high-press" status of an inmate, and thus, was largely informed by external, situationally stressful factors.

Warden A made clear statements with regard to his beliefs about the purpose of incarceration:

From my perspective, there are two purposes. One is punishment. That is what the public and judges are there for ... because the person needs to be punished for the crimes that they committed. And the second purpose, in my opinion, what we ought to be doing with inmates once we have them, is that we ought to be trying to change them.

This statement reflects three sensibilities that consistently guide and inform Warden A's management philosophy: 1) responsiveness to public desires and court-ordered sanctions (offender punishment); 2) offender accountability; and 3) offender transformation. The notion of offender accountability, both to the public and to the institution in which they are incarcerated is a reoccurring theme throughout this research. In the case of Warden A, statements of offender accountability tends to focus on the individual offenders circumstances and behavior prior to incarceration, their behavior within the institution and its relationship to public accountability, and an inmate's willingness (or unwillingness) to transform themselves into better citizens. Warden A's comments, excerpted here, are highly illustrative of this threepronged sensibility:

Comment 1 - Prior behavior: So [inmates] probably see me as pretty authoritarian but overall that's probably a good thing when you're dealing with inmates because they're manipulators and they spent their entire lives 
trying to manipulate themselves either into or out of situations they have no business getting in to.

Comment 2 - Public accountability: We had inmates that were out for [many] days on temporary leave ... and these inmates were not being responsible and they weren't being accountable... They were out there just committing crimes. That created a lot of stress in the community and the public wasn't happy about that. So we got a lot of bad press for that but at the time it was the only way we could manage all of those inmates who were close to their release dates. Plus they were coming back in as fast as they were going out because they knew that there wasn't any accountability for them. They knew that they would just turn around and be released again, because what they were doing was just, you know, little crappy things in the community that wouldn't get them in a lot of trouble but it certainly got them sent back for a few days and then they would just turn around and be sent back out again.

Comment 3 - Possibilities for offender transformation: And [IITs have] been used ... when we get inmates who are just real problems ....They are just real disciplinary problems, and they act out and they're a management problem and we're fighting with them all the time and ... sometimes its good to move these inmates to another state, because it gives them a fresh start and they do better.

Many of the statements made by Warden A reflect, in some form, this three-pronged approach to inmate management (See: Appendix G). The administrative intent of Warden A's management decisions then, generally appear to be tightly coupled to the needs of the institution, the needs of the inmate and the needs of the community in most cases. The question then becomes, how did Warden A develop these beliefs?

$\underline{\text { Respondent's experience, early training and guidance in corrections }}$

As was also discussed in Chapter II, a warden's professional training and experiences are likely to influence the way they run their institution. Thus, this research expected that they were likely to influence discretionary decision-making in 
the IIT case examined here. In particular, a wardens training and experiences

were anticipated to influence the administrative intent of IITs. To some degree, this was true. However, as will be discussed below and in the following subsection, the administrative intent of the IIT used here appears to have been driven primarily in response to the "high-press" status of an inmate, and thus, was largely informed by external, situationally stressful factors.

Warden A's early correctional training was, and has remained, highly influential as a decision-making factor and has had a clear influence on his beliefs about incarceration. As illustrated by previous quotations, Warden A's early training as a line-level correctional officer emphasized the need to focus on the individual attributes and circumstances of offenders in order to transform them into productive citizens. Warden A's long-term experience in prison management positions appears to have reinforced this early training and guidance. Warden A has this to say about those who trained him and the relationship of this training to what he has learned from experience:

[...] not much has changed in all the years I have been in this business. It's pretty much the same as when I started except that equipment is a little better, and the staff is probably trained a little bit better. Otherwise it is pretty much the same system that I started in. I think that probably that is a testament to the people that were there when I started ... They probably knew what they were doing because we really haven't made many changes [Italics added].

In terms of Warden A's own management philosophy, he states:

[My management philosophy has] been stable since about [date]. I pretty much adopted that model then, and I've stayed with it because I haven't seen anything better come along. 
When the data are viewed and reflected upon in their entirety, this last statement does not reflect a philosophical rigidity as much as it underscores a general sense that Warden A regularly evaluates his beliefs in comparison to what is actually going on in the immediate correctional environment. Simply, it appears that extensive experience in the correctional environment has made Warden A highly reflective and pragmatic about his task, rather than dogmatic and rigid. For example, in recognizing the potential influence of the correctional environment on an inmate's ability to make a pro-social transformation, Warden A has this to say:

I know that's difficult when you're in an environment that's [...] not a real environment, it's a manufactured environment ... Its one we create, and I know it's difficult because [...] it's not a real environment that they live in [...] when they get out. But you try to do the things that change who they are. You try to model for them and you try to hold them accountable and make them act like they are supposed to act when they return to the community.

In generally discussing the utility of IITs, Warden A continues to reference the individual inmate. From Warden A's perspective, the IIT is particularly useful in providing opportunities for transformation - a transformation that is linked directly to offender accountability. For example, in the case of "problematic" inmates, Warden A's comments (presented above but repeated here for emphasis) are insightful:

And [IITs have] been used [...] when we get inmates who are just real problems .... They are just real disciplinary problems, and they act out and they're a management problem and we're fighting with them all the time and [...] sometimes its good to move these inmates to another state, because it gives them a fresh start and they do better. 
From Warden A's perspective, a focus on inmate accountability and the goal of transformation and reentry - based upon an individualized understanding of each inmate - are key components of his management philosophy. In facilitating these goals, Warden A discusses a number of other beliefs related to his relationship to staff and management practices more generally.

$\underline{\text { Respondent's beliefs about good correctional management practices }}$

As was also discussed in Chapter II, wardens' beliefs about good correctional management practices are likely to influence the way they run their institutions.

Thus, this research expected that such beliefs were likely to influence discretionary decision-making in the cases examined here. In particular, a warden's beliefs about good correctional management practices were anticipated to influence the administrative intent of IITs - itself a potentially beneficial practice. Illustrative of Warden A's beliefs about IITs, the following quote is repeated from an earlier discussion:

There are lots of ways that the interstate compact is helpful. It's really not a bad thing.

To some degree, the assumptions of this research in relation a warden's beliefs about good management practices were accurate. However, as will be discussed below and in the following subsection, the administrative intent of IITs in this case was largely informed by external, situationally stressful factors, and did not necessarily conform to all of Warden A's beliefs about good management practices.

Warden A generally describes his professional role and his management practices this way: 
Well, what you do as a warden is you manage an operation of an institution ... You really don't get involved in what people are actually doing, what you do is you create the programs and you put the people in charge of the programs that you want to manage them. They try to manage a program in a fashion to change inmate behavior but as a warden you really don't get involved in that [...] down to that level.

And, in terms of preventative decision-making:

You try to anticipate as much as you can, and what you can't anticipate, you get on as quick as you can after you find out about it and then be sure that you're right. Do your work and make sure that you have all of the correct information before you make a decision. It might take you several days to get that information but do what it takes to get it ... so that when you do make a decision, it's a right decision [...] so you don't have to change it later.

However, as is evident from the interview excerpts discussed below, and from my interpretation of the overall conversation, these statements may be somewhat misleading in the sense that they are oversimplified and, alone, do not indicate the deep and extensive thought that Warden A has obviously put into the management of his institutions. It is useful to dig a bit deeper.

Warden A has strongly held opinions and beliefs about good management practices. This is likely due to his initial training and his long experience as a correctional manager. During the interview, much of our discussion regarding Warden A's management practices centered around inmate accountability and the respondent's ability to ensure that everyone is working together to accomplish that goal. Thus, another concern — tightly coupled to inmate accountability-is staff accountability. For example, staff who - for unjustifiable reasons-fail in their performance of their duties, suffer the consequences. Although these consequences 
were not specified, Warden A had this to say about some of his management

practices in relation to wayward staff:

I think that [staff] think that I'm a easy person to get along with and an easy person to work for. They like to work for me. I always had that type of feedback ... I'm pretty patient [...] as long as people have legitimate reasons for either not getting something done or not following the process at a particular time. It's only when I know for sure that something is not working right that I get in it and make somebody's life miserable if I have to.

Simply, Warden A does not suffer fools or slackers and appears to be well liked by those who are neither. Based upon other statements made by Warden A, the quotation excerpted above neatly sums up his relationships with staff and inmates and is perhaps a dispositional characteristic that carries through, beyond the prison walls, to other aspects of the respondent's life.

That being said, the above excerpt may paint too harsh a portrait of Warden A's management practices. Empathy - tightly coupled to pragmatism - is clearly a dispositional characteristic possessed by Warden $\mathrm{A}$, and it became evident in his discussions of an inmate's circumstances. In a revealing discussion regarding intrastate transfers, Warden A clearly links his pragmatic approach to his empathetic management sensibility. Warden A:

[...] for example, if we had a [mother] who was terminally ill over in [city] and we had the inmate here in [institution] as soon as we found out about that we would have to start thinking about what to do with that inmate and whether or not we would transfer him over to [city] so that [offender] could be close to his mother ... and probably, we would. But when would we do that? [...] See, we have to start looking in to it and determine how ill the person is, try to determine how long she has to live, and then determine at what point - and if - we would transfer that inmate over to [city] to be close to her before she died. So you know, all of these things that we deal with in these places cause us a lot of work but you have to check into every one of those details because sometimes it's a lie and sometimes its fabricated so that 
the [inmate] can get themselves over to the [city] because they don't like it [here]. So the [inmate] [tries] to create things that force us to send them over there. So we are always in the mode of checking and modifying, and searching and verifying information to make sure that we don't flat-out tell somebody, 'No, you're not doing that' without having all of the information, and the correct information, to make a responsible decision.

A consideration of the individual plight of inmates came up frequently during the course of the interview and clearly influenced Warden A's management practices. In another example, Warden A states:

You're going to have a certain level of stress at all times with inmates because of the issues that they have because their lives are stressful too. You know, they've got family that's out there [that are] having all kinds of problems and they can't do anything about it. That creates stress for them $[\ldots]$.

However, Warden A's empathic management concerns do not only extend only to inmates. His management practices also appear to stem from a deep sense of empathy toward the plight of staff, and as illustrated previously in relation to inmate escapes, toward the general public. For example, Warden A, in discussing the needs of the staff in relation to offender transformation, asserts:

[...] on the other side, [inmates] create stress for you [...] I think we have better control over [...] inmates now; we have better ways to manage them than we used to. I mean, we used to have to take our watches off and our belts off in order to go take an inmate out of a cell and we had to do that physically without a shield or anything else and things have progressed to the point now where we have all kinds of equipment, coveralls, we have electronic shields, tasers ... all kinds of equipment where staff can enter a cell without getting hurt and take the inmate and do what you have to do with him in order to modify his behavior. Where it used to be we just didn't have those resources - and inmates loved that kind of contact - where they could try to hurt a staff member ... they really aren't getting those opportunities anymore. So, I think inmates are seeing the professionalism and the fact that they aren't able to impact anything as much. I think it helps to modify their behavior a little bit. 
Empathy was also evident in Warden A's discussion regarding other correctional managers. For example, when the respondent was asked if he had ever refused an IIT transfer from another state, he responded:

No, I didn't [refuse inmates from other states] ... I took every inmate that they offered because I've been in that situation where I've had, you know, inmates that I didn't like to manage and I thought that they might do better someplace else ... I never turned anybody down.

Overall, Warden A's management practices appear to stem from a type of empathic pragmatism developed initially developed during his early training and was reinforced by years of practical experience. This sensibility appears to directly inform his specific management style and the general intent of his policies, though it does not seem to have influenced his use of an IIT as explicitly.

Respondent's beliefs about the best management styles and attitudes

As was also discussed in Chapter II, wardens' beliefs about the best management style are likely to influence the way they run their institution. Thus, this research anticipated that such beliefs were likely to influence discretionary decision-making in the case examined here. In particular, wardens' beliefs about the best management style were expected to influence the administrative intent of IITs. To some degree, this was true. However, as will be discussed below and in the following subsection, the administrative intent of the IIT used here appears to have been driven primarily in response to the "high-press" status of an inmate, and thus, was largely informed by external, situationally stressful factors.

When asked directly (Question $2 \mathrm{~b}$ ) how he would describe his management style, Warden A was very clear: 
I try to manage by consensus. And you can't do it all the time. It's a real time-involved process where you have to sit down with people and talk about things until you reach a space where people generally agree that this is what we are going to do.

Additionally, Warden A has found that this type of management style has served him well throughout his tenure with the DOC. Some of the themes that emerged from this discussion are linked to themes that emerged (or partially emerged) throughout the interview. For example, fairness, staff loyalty, and staff members' willingness to make their best effort to stay with a mutually agreed upon plan were important considerations for Warden A. This type of staff behavior was rewarded, though behavior that deviated from a mutually agreed upon and negotiated plan was punished. Warden A:

I've used [the consensus] process a lot; I find it's a most effective process when you are trying to get things done because you are trying to get everybody on the same ship going the same direction and you try to talk about everything that's a problem and get people to agree on the direction that you are going to go.

I don't use that [consensual] process when I run into problems and I find out somebody is not on the ship anymore and [has] decided to get into their own canoe and go a different direction. Then the consensus process is over with, that person, as far as I am concerned, and I get real direct with them. [...] they hurt the group because they are no longer complying with the philosophy of management by consensus. Which is to bear out your grievances, talk about things and solve your problems and get on with the process... and then stay honest to the process.

In either case, treating people fairly was a key concern for Warden A and an obviously influential component of his management style. On treating inmates and staff with fairness, Warden A has this to say:

I try to deal with people as fairly as I can. I don't change that. When you [are fair], they understand that and they see that and they're willing to work 
with you. Even if the answer is no, people understand [fairness] especially if you went through ...the process to make your determination and you were fair about it. You can do anything you want as long as you are fair. People will go along with it, whether they are staff or inmates.

In prefacing the discussion in the following subsection, it is interesting to

note that even in cases in which situational factors appear to be driving the administrative intent of an IIT, Warden A's dispositional characteristics and tendencies remained somewhat influential. In the one (1) IIT transfer implemented by the respondent, administrative intent was most likely influenced by the mass media (discussed below) and an implicit desire to protect the victims of the offender, ensure the safety of the inmate, and adhere to institutional security requirements (both formal and informal). ${ }^{22}$ Interestingly, it was Warden A's dispositional characteristics - which likely influenced his relationship with out-of-state correctional managers - that made the transfer possible at all. For example, after being asked whether he had ever used an IIT, Warden A responded:

Warden A: One time I had to [...] find a way to move an inmate to another state because [offender] was better served out of state.

Interviewer: When you say "better served" what do you mean by that? Warden A: "Well, it was a high-profile inmate in [name withheld] so we needed to move [offender] out of [name withheld]. [The DOC] couldn't find a state that would take [offender] ... so I had to take this on myself [italics added to indicate emphasis].

${ }^{22}$ Extensive media coverage may be hurtful to victims and/or pose a security risk to the institution and to inmates, especially in "high-profile" inmate cases (Freeman, 2000). Although in some cases, media access is restricted due to the likelihood that media portrayals will negatively distort the work of correctional employees (Freeman, p. 101; Conover, 2001), in the IIT case described here media interest was extraordinarily high and clearly posed personal and institutional security risks. It is assumed here that the respondent was not explicit about these reasons because he assumed I was aware (as a prison researcher) of the security risks that "high press" inmates pose. I was, but most people do not know this and it needed further elaboration here. 
It is clear in the statements made by Warden A that even in the case of a stressinducing, "high-press" inmate that "nobody wanted," and that nobody could place, it was his responsibility to deal with the problem. His ability to do so was enabled by numerous correctional relationships that allowed the transfer to happen, and thus, relieve the institution and the DOC of a highly problematic inmate. This implicates the importance of dispositional factors as more than a decision-making influence. Rather, one might conclude from Warden A's description of his IIT experience that these dispositional characteristics (i.e., a willingness to develop relationships and work with others over time) act as an important tool during the implementation process-perhaps most especially when facing challenging and potentially stressful institutional situations. In stressful correctional environments, or in short-term stressful correctional emergencies (Freeman, 2000; DeHann, personal communication, 2005), it is likely that experienced and autonomous wardens-like Warden $\mathrm{A}-$-who are willing and able to use their experience and influence to facilitate institutional and DOC policy objectives are highly valued.

\section{Situational Factors}

As discussed in Chapters I and II, the correctional context in which a warden is situated varies from state to state. However, in much of the literature, the institutional environment of prisons is depicted as generally stressful—if not constantly in the throes of one correctional emergency or another. Therefore, this study expected that respondents would be situated within similarly stressful 
environments and that a number of situationally stressful factors might act to mitigate (or reinforce) the dispositional tendencies and attributes of each respondent. Although this study expected the correctional environment to have some influence on Warden A's discretionary decision-making process, it did not expect it to completely mitigate his dispositional attributes and tendencies. In the one IIT case discussed here, situational factors appear to have influenced the administrative intent of an IIT but dispositional factors (though not as influential) appear to have informed and facilitated the IIT to some degree. Additionally, and as opposed to the assumptions of the new penology, the correctional environment was neither perpetually stressful nor, on its own, perpetually influential for Warden A.

Warden A surprised me with his response to a question regarding the level and type of stress wardens encounter from outside sources (Question 3a). When asked, "In relation to your decision-making processes as a warden, generally speaking, how would you characterize the operational environment of your institution[s] [while you were warden]? Would you say that it was: VERY STRESSFUL SOMEWHAT STRESSFUL or NOT AT ALL STRESSFUL? Warden A responded:

[...] generally speaking, life in the institution is pretty low stress ... as long as everything is working right.

However, he adds:

What's stressful is if something happens in the institution ... you have a hostage situation, or you've got a riot situation, then it becomes really stressful, but you don't live for those things and you don't expect them. You just try to prepare so you're ready when they do happen... and if they do 
happen, they are very stressful and you know, it takes you even weeks to get over something like that by the time you get finished with it.

These statements - when considering them in light of all the interview dataindicate that though numerous factors both internal and external to the institution may be stressful, they are only stressful if the institution is poorly managed. This is a theme that emerges fairly quickly and remains a constant throughout the interview. In another example, when asked about overcrowding, Warden A responds:

It's not all that stressful. The way you managed that is ... well back when I started, everything was single-cell housing. No inmates were doubled up. In order to manage the incoming population when we didn't have any space, we doubled up inmates. But at the same time we opened up their access to the institution. We allowed them a lot more time out of their cells. That seemed to take care of the stress that [was] created by putting two inmates into a cell. So I didn't really see a change when we did that. So to say that crowding was something that caused more stress; I'd say ... I think it depends on how you manage it. You can do a lot of things to relieve that by allowing inmates more time out of their cells and still manage their behaviors and reduce the stresses. You still come out even.

On the other hand, and as hinted at in the above excerpts, Warden A acknowledged during the course of the interview that managing a prison is situationally stressful. Interestingly, only two factors emerged as being truly stressful to him: 1) excessive media attention paid to inmates (and excessive inmate attention paid to the media); and 2) court interventions on behalf of inmates. Both of these factors were stressful primarily because they infringed upon wardens' autonomy and, possibly, their ability to manage the institution in accordance with their beliefs about good management. In other words, high-profile media and court interventions - once they occurred - appeared to Warden A to be difficult to manage. Warden A clearly felt that one of his tasks as a good correctional manager was to 
develop and implement policy in such a way that external interventions were

avoided - since these were forces that, ultimately, would likely cause the institution to be run poorly.

When asked about legal or other court interventions (Question 3b), Warden A responded:

Well, there was only one time that we really had a real major court thing that was working against us, that was back when, [organization] ... this was back in the [date] when [organization] took us to court regarding crowding in the institutions.

[...] They wanted to set a cap on how many inmates can be in each institution and they wanted to actually reduce the amount of inmates that were in each institution and they wanted us to release them. They wanted to bring in a court monitor to make sure that we did what the courts said we should do...It was a real stressful time because, I mean, what do you do? [...] The public doesn't want the inmates back in the community ... or just not [to] be released out of the institution before their time was up, and this was basically what [the public was] saying - and [having] a court monitor run the department of corrections was ridiculous in my mind.

Because we knew that it was something that the public wasn't going to buy ... But if the court ordered it, you're stuck with it. So, you have to live with it after that...You've got to win these things before you lose them ... or then everybody loses.

Simply, court interventions represented a threat to the autonomy of the warden and the DOC, which - if compromised - might result in a threat to their ability to remain accountable to the public. However, although Warden A appears to feel that the possibility (or actuality) of a court intervention into the affairs of the DOC was more stressful than media intervention, it was media attention towards a particular inmate that initiated the IIT he helped to facilitate. 
Much has already been discussed with relation to the "high-press" inmate Warden A felt compelled to transfer. However, it is important to point out that though Warden A's transfer of this inmate was both anomalous and primarily influenced by excessive media attention, Warden A's dispositional attributes and tendencies were not eclipsed by the pressure to transfer the inmate. Rather, Warden A —in accordance with his beliefs about good management practices—clearly felt that this transfer would benefit everybody: the institution, the offender, the prison staff, and the public. Therefore, though he probably would not have transferred the inmate at all if the offender had not wanted to go and had not been "high-press," his use of the IIT in this case appears to have been intended to serve everyone's interests.

\section{Case Findings in Relation to the New Penology}

Generally speaking, Warden A appeared to exercise a management philosophy consistent with Dilulio's general concept of a "keeper philosophy." Building on this foundational belief system, Warden A appeared to focus a great deal of attention on order and service (amenities were not discussed) and appeared to represent a slightly recombinant example of Dilulio's Responsibility and Consensual Models of prison governance. The narrative themes that emerged from the interview focused on accountability and an individualized focus on offenders and discussed various elements of the institutional environment as situationally stressful- - though these latter elements did not necessarily dictate the terms of Warden A's management approach more generally. Clearly, Warden A prioritized institutional 
safety and security concerns, but he did not lose sight of the offenders under his control and continued to emphasize offender transformation through offender and staff accountability.

In summarizing the finding of this case, it appears that the new penology may be too simplistic (Figure 2A) and lacks the power to adequately explain either the IIT used by Warden $\mathrm{A}$ or his general decision-making behavior as a warden. In particular, the motivations for the IIT were based on very case-specific criteria and were not a result of an actuarial risk assessment or a desire to save (or make) money—nor was it a part of a larger, "bulk" transfer. However, a hierarchy of influence (Figure 2D) was found to exist between Warden A's dispositional tendencies and attributes and situational factors in relation to the administrative intent of an IIT. In the case of IITs and "high-press" inmates, the dispositional tendencies and attributes of Warden A became somewhat subordinate to immediate situational demands and may not have influenced the administrative intent of the IIT to a large degree.

On the other hand-and unlike Zimbardo's model (Figure 2B)-the warden's dispositional characteristics continued to wield some influence. In particular, though the IIT was initially prompted by media attention to a high-profile ("high-press") inmate and used to remove an institutionally problematic offender, Warden A continued to use an IIT in partial accordance with his beliefs about good management practices (e.g., institutional security concerns, inmate safety, and, latently, the possibility for inmate transformation). Importantly, the IIT could not 
have been implemented at all if Warden A had not been able to locate a place for the transferred inmate. The ability of Warden A to do this was facilitated by his correctional management experience, knowledge and training and his established long-term relationships with other correctional managers. The path model below (Figure 3) depicts the influence of situational and dispositional factors on the administrative intent of the IIT.

As anticipated, the case examined here shows that the new penology's omission of influential, dispositional factors in its framework may be problematic when studying powerful, uniquely situated and ideologically fixed prison wardens in relation to their use of IITs. However, the data also show that some situational factors (i.e., excessive media coverage and/or court interventions) cannot be ignored and may have some influence on the administrative intent of IITs. In sum however, the case data collected here generally point to high levels of ideological and behavioral autonomy, high levels of individualized and moralistic thinking with regard to inmates and inmate management, and a general feeling that correctional management at the institutional level is only situationally (rather than perpetually) stressful. Figure 2, depicted on the following page, models anticipated and actual relationships. 


\section{Figure 2}

Modeling the Hierarchies of Anticipated and Actual Influence of Situational and Dispositional Factors on the Administrative Intent of IITs

A. The New Penology: Anticipated

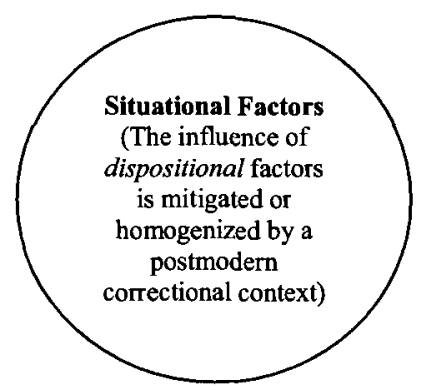

C. This Study: Anticipated

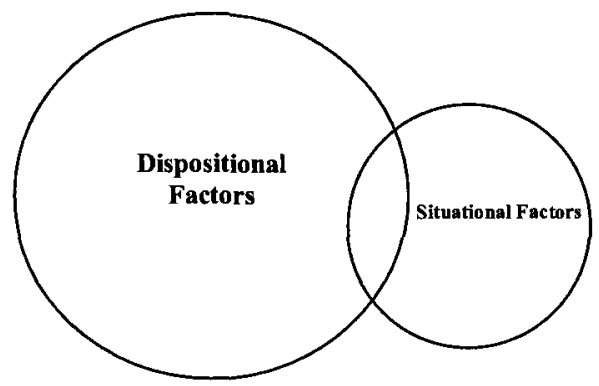

B. Zimbardo's Model: Anticipated

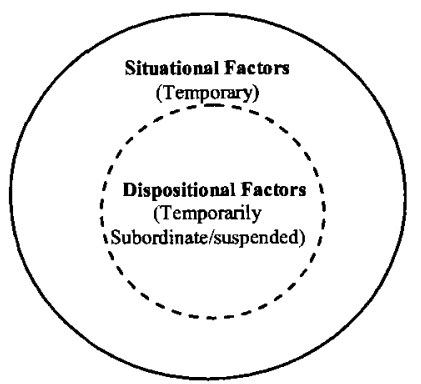

D. Case 1 - Warden A: Findings

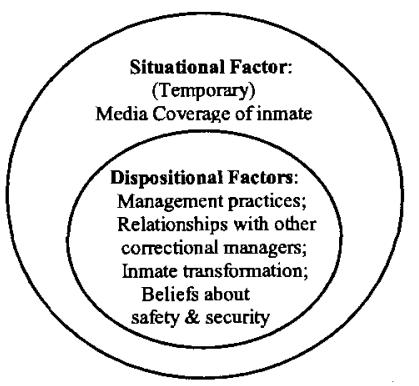

Due to the large number of "moving parts" (i.e., multiple theoretical

frameworks and their attendant variables) in this research, it is useful to model and discuss each perspective. In visually summarizing the anticipated and actual influence of situational and dispositional factors on the administrative intent of an IIT, Figures 2A through 2D are illustrative. Borrowing, in part, from Wright's (2000) theoretical modeling of relationships between national, state and local governments in the United States, simple diagrams are used here to model hierarchies of influence and the proportion of power that each set of factors may exert upon one another and upon the administrative intent of an IIT. 
In the cases modeled in Figure 2, the area of each circle represents the proportion of influence that each set of factors may exert on one another. These relationships are expected to influence the administrative intent of an IIT. In Figure $2 \mathrm{~A}$, the new penology anticipates that situational factors ${ }^{23}$ will always dictate the administrative intent of an IIT. In this diagram, the new penology does not anticipate human agency or autonomy so dispositional factors are not depicted in this diagram.

The diagram in Figure 2B depicts Zimbardo's (2008) conclusions and is represented in hierarchical terms. In this diagram, both situational and dispositional factors are accounted for but in some circumstances, it is anticipated that situational factors will temporarily "trump" the dispositional tendencies and attributes of an individual decision-maker. Simply, in some situations dispositional factors will have no impact on decision-making. While the dispositional tendencies and attributes of an individual do not "disappear," they may be subordinated when an individual encounters an unusual and/or stressful situation. Zimbardo's model assumes that dispositional factors may continue to inform the respondent's beliefs about the "correctness" of what they are doing, but that these factors (depending on the situation) may not be powerful enough to induce the respondent to actually act and to do (from his own perspective) "the right thing." In these cases, Figure $2 \mathrm{~B}$ depicts a temporary hierarchy of influence in relation to the administrative intent of an IIT, in 
which case, an individual will do anything to get through the crisis- even if these actions contradict what he believes to be the "right" or "best" thing to do.

In Figure 2C, a non-hierarchical Venn diagram is utilized. This research anticipated that interaction between some situational factors and a warden's dispositional tendencies and attributes would influence the administrative intent of an IIT. However, it was also anticipated that wardens would continue to implement IITs primarily in accordance with their beliefs about good correctional management practices. The findings in this case support this model in relation to Warden A's general ability to manage the institution, but only in non-IIT cases and only in cases in which there are not high levels of media interest in specific inmates.

In Figure 2D a hierarchy of influence was found, in this case, to exist between Warden A's dispositional tendencies and attributes and situational factors in relation to the administrative intent of an IIT. However, as opposed to the assumptions of Figure 2C, in the case of IITs and "high-press" inmates (i.e., those inmates who received extensive media coverage and who had a desire to speak to the press), the dispositional tendencies and attributes of Warden A became somewhat subordinate. On the other hand — and unlike Zimbardo's model (Figure 2B)Warden A's dispositional characteristics continued to wield some influence. In particular, though the IIT was initially prompted by the media's attention to a highprofile ("high-press") inmate and was used to remove an institutionally problematic offender, Warden A continued to use an IIT in partial accordance with his beliefs about good management practices (e.g., institutional security concerns, inmate 
safety, possibility for inmate transformation). It is important to note that the IIT could not have been implemented at all if Warden A had not been able to locate a place for the transferred inmate. The ability of Warden A to do so was facilitated by his correctional management experience, his knowledge and training, and his established long-term relationships with other correctional managers.

The path model (Figure 3) depicts the influence of situational and dispositional factors on the administrative intent of IITs and is presented in order to simply illustrate why IIT's are used in this case.

Figure 3

IIT Case 1: Ruling Relationships

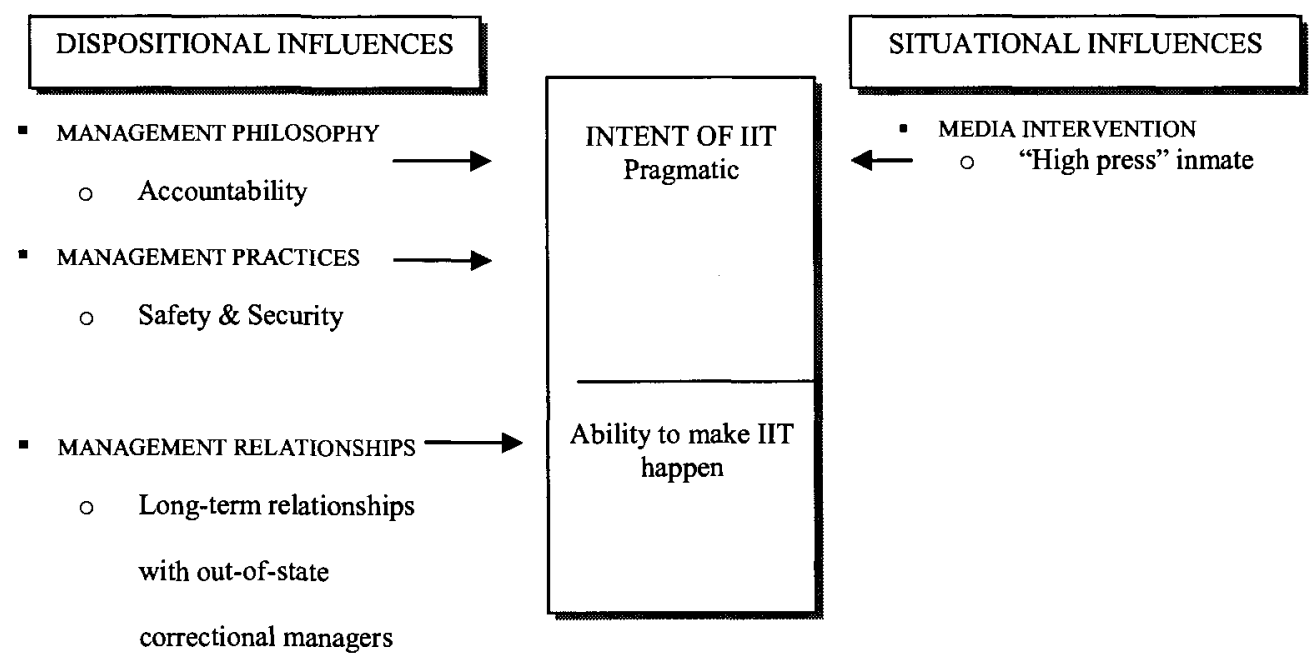

In concluding this chapter, a number of important themes are drawn from the case study discussion above and listed in simplified form below. The following narrative themes are presented again because: 1) They represent clear deviations from the new penology construct; and 2) They illustrate the potential influence of situational and dispositional factors on administrative intent: 
1. Dispositional Factors: Warden A clearly thought of the inmates under his supervision as individuals and not simply "numbers."

- Dispositional Factors: Warden A clearly understood the stresses inmates were under. Although he believed that they were responsible for their circumstances (i.e., incarceration), he also believed in the ability of most inmates to transform themselves into productive citizens if given the chance and managed properly.

2. Dispositional Factor: Warden A feels that inmate and staff accountability are critical to the proper functioning of the institution. Accountability, from Warden A's perspective, has a two-tiered, three-pronged emphasis:

- Inmates: Accountability to the public; to the institution; and to themselves (in terms of transformational goals).

- Staff: Accountability to the public; to each other; and to the goal of offender transformation.

3. Dispositional Factors: The following sensibilities - explicit and latentappear to inform much of Warden A's decision-making:

- Empathic pragmatism: A practical focus on the plight of others, to include: inmates, staff and the general public.

- Fairness: To inmates and staff

- Consensus-building: Developing solutions to correctional problems through planned interactions with key staff. 
- Loyalty: Treating employees with respect and fairness in return for loyalty to the institution, to other staff, and to agreements forged through the consensus process.

4. Situational Factors: For Warden A, the correctional context is only stressful if you don't prepare for it or, once a crisis has occurred, you don't handle it properly. Beliefs about good correctional management practices are strongly held and are an influential dispositional factor in this case.

5. Situational factors-Media attention \& court interventions: Throughout the interview, very little was said about the DOC. Additionally, and except when asked directly, very little was said about the influence of external stressors. However, when evaluating those factors likely to create stress for Warden A, and thus, the administrative intent of an IIT or any other policy, it seems that any problem-from prison crowding, to riots, to other correctional emergencies-is only stressful if there is media attention and/or court intervention on behalf of (or because of) inmates. For example, overcrowding was not seen as a problem by Warden A, as it was clearly an internal management problem he could handle. However, when the courts became involved in the issue of overcrowding, this created stress. Similarly, the inmate that Warden A transferred was not an "unmanageable" problem on his/her own. Rather, it was the media's excessive involvement with the offender's case that created stress and, thus, provoked an IIT.

In the following chapter, the second case will be discussed in terms of Warden B's hypothetical use of an IIT. The analysis will follow a similar format as 
Case 1. The second case is, in many ways, similar to the case just described.

However, although Warden B has also spent a long career in corrections, he has only somewhat recently become a warden. Thus, Case 2 provides an interesting contrast to Case 1 for a several reasons related, primarily, to the length of time each respondent has been a warden. 


\section{CHAPTER V: CASE 2 \\ WARDEN B - "NEW BLOOD"}

"I enjoy a great relationship with our management team. We have a great commissioner/director, all of the assistant commissioners/directors are really good people, very committed to following the [established correctional program], which talks about communication [...] I think that the administration is very caring about the health and wellness of its staff, as this is a high-stress area, we have people who get ill, who get cancer, and I think our director is very concerned about that."Warden $B$

\section{Introduction to Case}

The second case presented here is that of a prison warden who has not directly implemented an IIT as a warden but expressed a willingness to do so if given the opportunity. In this case, the respondent-who has some knowledge and experience related to IITs - agreed to discuss his use of IITs as a warden hypothetically. As was the case with Warden A, in order to protect the confidentiality of the respondent, this case has been designated "Warden B" and the respondent given the avatar "new blood" as a reflection of his time "on the job" as a prison warden, the origins of his management philosophy and key (temporal \& pedagogical) aspects of his initial training. Although very few specifics in relation to Warden B's age, race, gender, ethnicity and other potentially identifying personal attributes will be discussed in this study, a general description of the warden, the particular correctional context in which he is situated, and his hypothetical use of IITs will be briefly discussed.

Introduction to Warden $B$

Like Warden A, Warden B is a congenial and very knowledgeable prison warden currently employed in a mid to small sized department of corrections in a 
mid to small sized state. The respondent has enjoyed a long career with the department of corrections, was originally trained (and worked) in a correctionsrelated field and has only recently attained the position of warden at a state correctional institution. Additionally, the respondent possesses a high level of practical and theoretical knowledge about crime causation—-gained, perhaps, through a combination of prior employment experiences and formalized training. The respondent had this to say about his training and experiences prior to obtaining the position of warden:

You know, it's interesting ....In the very beginning, when I entered corrections, I felt a responsibility that we are dealing with human beings here who for one reason or another, because of whatever reason [wound up in prison]-dysfunctional family, or improper [...] misdirected value systems; not enough education; or there may be some organic issues; or developing criminal thinking because of associating with criminal types.

Warden B, though never implementing an IIT as a warden, did possess a fair amount of knowledge about their use generally (to include the use of ICCs), and some level of knowledge about their current use in his state. In characterizing his personal use of IITs:

[...] my initial contact with interstate compacts [ICCs] was as a [correctional employee] ... It was not uncommon to have inmates who wanted to relocate to another state because they had lived there or whatever, or conversely, inmates coming from other states who wanted to be supervised here in [state].

I was not really too involved in [the IIT system in my previous positions] other than being involved in rental bed situations where we moved inmates out of state because of capacity issues. So, my association and knowledge of that since [date] is fairly limited.

I can't in my recollection, recall the opportunity to [use an IIT as a warden]. I would be more than happy to be involved. But I know that those decisions about incarcerated inmates moving from one correctional system to another 
usually is done at a higher level than my own, or a different level than my own.

I don't know if you have spoken with other wardens in the state but really the decision to move an inmate to another state or from another state to here would not be under my purview [...] at all.

As a matter of fact, I don't even think that I would be involved in that process at all, in any way. Other than since we maintain files on inmate's compliance with [state's] corrections plan and so on and so forth, and those sorts of things that someone wanted to look at $[\ldots]$ behavior issues.

Once I got into the prison environment, most of that, the administration of transfers of prisoners to other jurisdictions was handled basically by, what is now called our [transfer] unit.

In generally characterizing the use of IITs, the respondent had this to say:

The reality is that a state receiving an inmate from our system...there would be considerations in relation to capacity, classification level, behavior, all that sort of stuff, so you know, I could only make ... any referral that I make would primarily be based on my staff's observation of the inmate's behavior in the institution, and compliance with our rules and issues like that.

From the respondent's perspective IITs serve a variety of purposes. In characterizing his hypothetical use of IITs, Warden B had this to say:

[...] inmates are moved to other states for a variety of reasons including highprofile cases or cases where an inmate could not be safely supervised in this state for one reason or another. So normally that's done outside of, and independent of what I am involved in.

[...] hypothetically, if I was involved in that function ... like I said, you know, there are certain issues that I would want to look at ... the primary issue [...] would be around inmate behavior. I know that a lot of transfers of inmates or prisoners have to do with high-profile cases, wherein the individual to be incarcerated in the state [...] would create safety and security issues for that particular [inmate] and issues for staff and the department of corrections generally. 
In sum, Warden B expressed a fair amount of knowledge not only in relation to his personal use of IITs (and ICCs), but in relation to their use by others within the DOC and by correctional managers in other jurisdictions. However, because the IIT case discussed here was hypothetical, our discussion on the topic was not as thorough as it was in the first case. Therefore, any conclusions related to the administrative intent of an IIT in this case are cautiously speculative. That being said, Warden B offered a number of insights into his institutional environment and management philosophy. In the following two subsections, the dispositional and situational factors influencing Warden B's decision-making will be discussed in depth. Following these discussions, an analysis regarding the potential influence of these factors on Warden B's discretionary decision-making processes, and his hypothetical use of an IIT in particular, will be presented and discussed. Finally, the findings in this case will be discussed in relation to the results anticipated by this research and in relation to new penology assumptions.

\section{Dispositional Factors}

As was the case with Warden A, during the interview with Warden B it was clear that a number of dispositional factors may have some influence on the respondent's hypothetical use of an IIT. Warden B's dispositional tendencies and attributes clearly had an influence on his general management of the institution. In most (non-IIT) circumstances Warden B appeared to feel (and exercise) a great deal of autonomy in the management of his prison institution. Thus, Warden B's discretionary decision-making - with some exceptions (discussed in the following 
subsection)-appears to be largely influenced by a number of dispositional attributes and tendencies. Broadly speaking, the dispositional factors that emerged from the interview as most influential were:

5. Respondent's beliefs about the purpose of incarceration;

6. Respondent's experience, early training and guidance in corrections;

7. Respondent's beliefs about good correctional management practices;

8. Respondent's beliefs about the best management styles and attitudes.

Respondent's beliefs about the purpose of incarceration

As was discussed in Chapter II, wardens' beliefs about the purpose of incarceration are likely to influence the way they run their institution. Thus, this research anticipated that they were likely to influence discretionary decision-making in the hypothetical IIT case examined here. To some degree, this was true, especially in cases in which inmate misconduct is the central concern. However, as will be discussed below and in the following subsection, the administrative intent of an IIT may, in some cases, be driven in response to overcrowding and/or the "highprofile" status of an inmate, and thus, be largely informed by external, situationally stressful factors.

Warden B made clear statements with regard to his beliefs about the purpose of incarceration:

The purpose of incarceration is for individuals who commit felony crimes to follow the mandate of the court, we provide a safe and secure environment that is $[\ldots]$ as punishment not for punishment and to do our very best to 
provide programming and environments that can address some of the barriers to successful transition.

And adds:

We know that there are certain segments of the population of inmates [that], based on the severity of their crime ... need to be incarcerated for the rest of their lives. But there is also a segment of the population of inmates who, for one reason or another, came from a dysfunctional background, have substance abuse issues, mental health issues, and my belief is that we carry some responsibility in reducing recidivism and expense to the tax payer by providing programs in support that will help keep them out of prison once they're released.

As was the case with Warden A, Warden B's statements reflect three, consistently guiding sensibilities that inform his management philosophy and his attitudes towards incarceration: 1) Responsiveness to public desires and court ordered sanctions (offender punishment); 2) offender accountability; and 3) offender transformation. The notion of offender accountability — to themselves (e.g., transformation and reentry), to the public and to the institution in which they are incarcerated is a reoccurring theme. Typically, statements of offender accountability tended to focus on the individual offender's circumstances and behavior prior to incarceration, their behavior within the institution and its relationship to public accountability, and an inmate's willingness (or not) to transform themselves into better citizens. Warden B's comments, excerpted above are highly illustrative of this three-pronged sensibility. Warden B also neatly sums up his beliefs about his position and the purpose of incarceration this way:

So, primarily, [my job is to ensure the] safety and security of the institution, the inmates, the staff and the community. Which is really what our department of corrections...it's our motto, what we premise our entire operation on. And secondly to provide programs that can reduce the 
probability of them coming back into any [prison] institution. That's our mission, the DOC mission....in a nutshell.

Although these statements are not all inclusive, many of the statements made by Warden B reflect, in some form, a three-pronged approach to inmate management discussed previously (See: Appendix H). The administrative intent of Warden B's management decisions then, like those of Warden A, generally appear to be tightly coupled to the safety and security needs of the institution, the program needs of the inmate and the political and practical needs of the community in most cases. The question then becomes, how did Warden B develop these beliefs?

Respondent's experience, early training and guidance in corrections

As was also discussed in Chapter II, wardens' training and experience are likely to influence the way they run their institution. Thus, this research anticipated that they were likely to influence discretionary decision-making in the hypothetical IIT case examined here. To some degree, this was true, especially in cases in which inmate misconduct is the central concern. However, as will be discussed below and in the following subsection, the administrative intent of an IIT may, in some cases, be driven in response to overcrowding and/or the "high-profile" status of an inmate, and thus, be largely informed by external, situationally stressful factors.

Warden B's early correctional training was, and appears to have remained, influential in relation to his beliefs about incarceration. As illustrated by previous quotes, Warden B's early training as a correctional employee emphasized the need to focus on the individual attributes and circumstances of offenders in order to transform them into productive citizens. Though only recently taking on the task of 
warden, Warden B's long-term experience in corrections appears to have

reinforced this early training. Indeed, throughout our discussions (some of them not included here or in Appendix $\mathrm{H}$ due to confidentiality concerns), Warden B displayed an applied knowledge of criminological theory in relation to his understanding of offenders. It is useful to repeat Warden B's statement regarding his early experiences:

You know, it's interesting ... in the very beginning when I entered corrections, I felt a responsibility that we are dealing with human beings here who for one reason or another, because of whatever reason [wound up in prison]-dysfunctional family, or improper ... misdirected value systems; not enough education; or there may be some organic issues; or developing criminal thinking because of associating with criminal types.

Throughout our conversation, Warden B emphasized the importance of maintaining institutional safety without compromising the many facets of inmate accountability discussed previously. Importantly, like Warden A, Warden B sees offenders [with a few exceptions] as individually flawed, but redeemable, human beings. His statements are often illustrative of this sensibility. For example, Warden B asserts:

[...] as you know in your research, there are several criminogenic factors that we're trying to help them overcome: associates, substance abuse, family, and [many] others, so...safety first [but], I just feel the human being is important, that anyone in the correctional system understand the delicate balance between holding offenders accountable to rules and policies of the institution so that we have a safe environment and at the same time being responsive to their needs as best we can and providing programs that will help them be successful once they're out.

In discussing inmate accountability in more depth however, it is clear from Warden

B's statements regarding his earlier correctional experiences that he includes himself and his staff in his conceptualization of accountability: 
[Offenders] come into the system, commit a crime, and it's our responsibility to follow the laws and statutes of the state [...] And as warden, I need to ensure that when they come here that they're safe, but even as a [DOC employee], which was a very humanizing process because I had to have face-to-face contact with everyone ... And you know, you become more than just a [DOC employee], you become a social worker and many ways, an ear for these people and you try to humanize the process as much as possible, which I think is an important function and aspect and responsibility of a prison environment, because [...] we need to get them ready to be successful when they go back into the community.

Similarly, Warden B also appears to regularly evaluate his beliefs in comparison to what is actually going on in his own, as well as the larger, correctional environment. Simply, and like Warden A, it appears that extensive experience in the correctional environment has made Warden B highly reflective and pragmatic about his task, rather than dogmatic and rigid. The following statement made by Warden B during our discussion of situational stressors (discussed in more depth below) is another good example of this reflexive approach to correctional management:

I am very sensitive to the overcrowding issue because of what I [know about it], the information I get from other states, my association with wardens from other states [...] I think [that in other states] it's a problem. [For example], when your entire health services is run by a special master [who] approves all the hiring. I mean, the [courts], they're tough with corrections. People don't want to go there.

Throughout our discussion, it became clear that Warden B was very sensitive to his context and kept an eye out for internal and external situational factors that were likely to impact his institution and his ability to manage it in accordance with his beliefs about good correctional management practices. This is likely a result of Warden B's training, experience and on-going self-education about problematic correctional issues. This training, experience and education appear to be tightly 
coupled to Warden B's beliefs about how best to ensure offender and staff accountability, as well as to his desire to remain generally accountable to the public (e.g., punishment, rehabilitation, reentry, public safety, to name a few).

$\underline{\text { Respondent's beliefs about good correctional management practices }}$

As was also discussed in Chapter II, wardens' beliefs about good correctional management practices are likely to influence the way they run their institution. Thus, this research anticipated that they were likely to influence discretionary decision-making in the hypothetical IIT case examined here. In particular, wardens' beliefs about good correctional management practices were anticipated to influence the administrative intent of IITs-itself a potentially beneficial practice. In the case of misbehaving inmates and the linkage of this behavior to inmate accountability and the use of an IIT, this may be true - in this case. For example, when discussing his knowledge of IITs (and ICCs in particular), Warden B tended to place individual inmate behavior at the top of any list as reason for a transfer. However, and as will be discussed below and in the following subsection, the administrative intent of an IIT may be more closely linked to conditions and inmate designations largely influenced by external, situational factors, such as the DOC's systemic responses to overcrowding and/or the portrayal and/or designation (by the media and/or the DOC) as a "high-profile" inmate.

Warden B discussed a number of practices that he feels facilitate his ability to run his institution. In discussing his strengths, he states: 
I think that probably my greatest strength is [...] that I communicate well with my staff and with inmates. I am very sensitive to their issues and their liabilities and assets as well. I don't see the inmate population [...] I don't see myself as separate [...] a person who wants to sit in the office, I think I need to know what's going on, so my style is as interactive as it can be, understanding that there are limitations to that because I have to remember that anything I tell an inmate as a warden, I better be darn sure that that information is understood and communicated to the correctional staff, the lieutenant, the sergeant's [...] it's a big mistake to go out and be making all kinds of promises and commitments, or talking about rules or policies that would differ from the way the operation is ... so, I try to be as sensitive as I can, if I can't answer a question, I'll tell them I can't and write it down and get back to them. But usually, when it is a policy issue, I will discuss that with staff.

[For example], it would be easy to put other staff on the spot if you're making some proclamation about something ... For example: Inmates wanting to have a [sports] tournament. We've got a [sports] tournament coming up and that required coordination with security, and programs, and physical plant and so, you know, before I make a commitment, I'm going to make sure that it is something we can do, number one, number two that it is feasible within our operational limitations.

Communication and interaction with staff and inmates appear to be a constant in Warden B's institutional life. In recognition of the dynamic nature of his institutional environment - and his responsibility to ensure inmate and staff accountability-it is clear that Warden B does not see a "hands-off" approach to prison management as effective.

As discussed previously, a focus on inmate accountability and the goal of transformation and reentry—based upon an individualized understanding of each inmate -is a key component of Warden B's management philosophy. Hinted at in previously introduced interview excerpts is the notion that accountability is also an aspect of prison life that is a shared responsibility. In much the same way that Warden A conceptualizes accountability, Warden B appears to believe that 
accountability is a two-tiered, three-pronged responsibility - a responsibility that involves both staff and inmates. In fact, the bulk of Warden B's job appears to be ensuring that the many facets of accountability are maintained on a daily basis. This approach can be summarized in the following way:

Dispositional Factor: Warden B (like Warden A) feels that inmate and staff accountability are critical to the proper functioning of the institution. Accountability, from Warden B's perspective, has a two-tiered, three-pronged emphasis:

a. Inmates: Accountability to the public; to the institution; and to themselves (in terms of transformational goals).

b. Staff: Accountability to the public; to each other, and to the goal of offender transformation.

In facilitating these goals, Warden B discussed a few, key management practices. Generally speaking however, "management by walking around (MBWA)" was a key management strategy practiced by Warden B. However, because it is more tightly coupled to Warden B's management style, it will be discussed in more depth in the following subsection. Rather, the remaining focus of this subsection will be on Warden B's hypothetical use of an IIT as a way to facilitate offender and institutional accountability.

In terms of Warden B's hypothetical use of an IIT, it was clear from our conversation that Warden B, in some cases, thought it would be a useful tool and would be willing to use it if he could. Although a number of situational stressors related to the use of IITs are discussed in more detail below (e.g., problematic inmate 
behavior, overcrowding, and "high-profile" inmates), it is useful to link inmate behavior, in particular, to Warden B's use of an IIT because it is directly related to his beliefs about inmate and institutional accountability. ${ }^{24}$ However, due to the hypothetical nature of my discussion with Warden B on IITs, the following conclusions are cautiously speculative due to a lack of data.

A well-behaved inmate desiring a transfer may receive (upon request) an IIT if they meet certain criteria (USDOJ, NIC, 2006; B. DeHaan, personal communication, 2005). Problematic inmates may be transferred against their will (though, technically, not as a form of punishment). Individual inmate behavior continued to emerge, though subtly, as a potential concern for Warden B. Unlike my discussion with Warden A, however, the type of inmate behavior deemed problematic was not entirely clear. However, it is assumed from the case data here that well-behaved, participatory inmates are not problematic (i.e., they are accountable for their actions). It is also assumed, as was the case with Warden A, that misbehaving inmates (e.g., inmates who do not follow rules, are not involved in programming, \& etc.) may be the focus of an IIT transfer. However, an inmate's problematic behavior may be linked to mental health (or other) issues-issues that Warden B's institution may not be equipped to handle. In sum, although the reasons for transferring a problematic inmate were not expressed directly, when taken as a

\footnotetext{
${ }^{24}$ Overcrowding and "high-profile" inmate transfers appear to be related more to the DOCs beliefs about accountability and systemic management concerns. This is an entirely different research topic on administrative intent at the DOC level and will only be addressed briefly in Chapter VI. However, in terms of Warden B autonomously implementing (or not) an IIT in relation to these two issues seems highly unlikely. These transfers are likely to originate from the DOC directly.
} 
whole, the interview data imply that the IIT would not be used so much as a form of punishment as it would be used to facilitate offender and/or institutional accountability by finding the offender a more appropriate institution in which to be incarcerated-in another state, if necessary.

It is interesting to note as a preface to the following chapter that though Warden B feels that he does not have the power to implement an IIT, according to statements made by his DOC, he in fact does have the power to use them (See:

Appendix I). Alternatively, and as discussed in the previous chapter, Warden A felt that he could use IITs if he wanted to (though never citing a specific DOC authority to do so), but simply never made it a routine practice. Though the process by which IITs may occur are clearly laid out in the DOCs statement (Appendix I), the reasons for this apparent misunderstanding between Warden B and the DOC remain unclear. However, there are a number of possible explanations and they will be discussed in the following chapter.

Respondent's beliefs about the best management styles and attitudes

As was also discussed in Chapter II, wardens' beliefs about the best management style are likely to influence the way they run their institution. Thus, this research anticipated that a manager's style was likely to influence discretionary decision-making in the hypothetical IIT case examined here. To some degree, this was true, especially in cases in which inmate misconduct is the central concern. However, as will be discussed below and in the following subsection, the administrative intent of an IIT may, in some cases, be driven in response to 
overcrowding and/or the "high-profile" status of an inmate, and thus, be largely informed by external, situationally stressful factors.

Warden B's management style emphasizes two key elements: Management by Walking Around (MBWA) and face-to-face interactions with inmates, staff, and the local community. Simply, Warden B considers himself to be a "hands-on" manager. He states:

I would consider myself by comparison, fairly hands-on and my sense is ... that I think I see a lot of positives [from this approach] ... in other states, that, historically have been very conservative ... I mean we're talking about [multiple states], the inmates are in the cells, behind the walls, the warden stays remote ... I see a huge change in that, and I think I've seen more wardens nationwide who are becoming more engaged, more involved, generally.

Through this style of management, Warden B feels that he gets a better sense of "what's going on" and is able to develop and maintain positive relationships with individuals and groups within and outside of the prison institution. These aspects of Warden B's management style appear to have served him well. Warden B discusses his MBWA style and his efforts to develop and maintain working relationships with inmates in this way:

We try to do as much as we can with the inmates, in terms of walking around, I mean, a warden walking around and providing access to inmates to talk with ... it makes a big difference because they think I have the ultimate power in making anything happen and I have some power, but it provides me with the opportunity to describe what my limitations are and try and be as responsive as I can to some of their issues.

Interestingly, and as opposed to Dilulio's (1987) description of "Walking George" Beto (discussed in Chapter II of this study), Warden B spends his time "walking 
around" less as a form of authoritarian control, and more as a way to establish

informal, collaborate working relationships with inmates. However, though Warden

B would like to spend more time developing relationships in this way, feels that the

demands placed on a warden necessarily prevent him from doing so. Warden B:

[In previous positions], I spent a lot more time individually with inmates [...] but I still do ... I still attend activities [...] we have some groups that are ethnic groups [and/or] religious groups ... I walk around the institution, I answer their questions that come in writing, and I am actually interested ... I don't have as nearly an intimate understanding of the individual population now because I just don't have time to do that. [But] I do manage to talk to individual inmates, and with some, develop some type of communication relationship ... in some cases, I try and solve some issues or refer them to somewhere that they can get some resolution, so it's not as great as it used to be but I'm pretty satisfied ... from a [wardens] perspective, it's pretty good.

I agree with that walking around, I think it's great, but there has to be some limitation ... If I spent all my time with the inmates, then I wouldn't be doing what my primary function is.

... and the inmates appear to notice:

I can tell you that inmates have given me some feedback lately that I'm not getting around enough. I had gone to a meeting of [inmates] ... they had some issues and complaints and I went and spoke to them, and it was somewhat tense, not in terms of concerns about physical safety, but ... [some] feedback I got was that I-recently-haven't been getting around enough. [However], I would think that [inmates] say that I generally get around fairly well. I think staff would say the same thing. And, incidentally, I require the same of my management staff. They get around too, so ... I would say that I want to get around more, its good feedback [...] in fact in the last 2 or 3 weeks I've been making an attempt to get around more, [to be] more visible.

This last statement reflects a reoccurring theme throughout our discussion: Warden

B's strong desire to collaboratively interact with individual inmates while balancing the demands of his job and other institutional requirements. Clearly, Warden B feels 
that MBWA gives him a better sense of what is actually going on in the institution and his style of MBWA appears to be tightly coupled to his beliefs about his accountability to offenders, staff and the general public.

In terms of Warden B's style of MBWA and his relationship to staff-and aside from the statement that they have also adopted a MBWA style — the link to staff is less explicit. However, it appears that MBWA may also act to facilitate the development and maintenance of Warden B's relationships with staff. Though never explicit, it is somewhat implied in some of Warden B's statements. The following statement may be a good example:

One of the challenges here was that this is a [...] facility and a lot of the correctional staff came from [different types of] institutions-which are run a little bit differently. I think the important thing is that staff know what the vision is, what the direction is, and that we're all role-modeling that and moving in the same direction at the same time.

This last statement appears to deemphasize a consensual model of management (as described by Warden A in Chapter IV), but, when considered in light of all of the interview data, may offer another rationale for Warden B's MBWA style. Simply, and like Warden A, it is important that everyone understand their role and coordinate their efforts in order to achieve the mission of the institution and that perhaps the best way to do that is to actually get out there and talk to staff.

Warden B also emphasizes the importance of fostering good relationships with the local community. Discussions regarding these beliefs were extensive, and Warden B clearly felt that the success of his institution was partially dependent upon 
his ability to build a positive, collaborative working relationship with the

community. The following statement is illustrative of this sensibility:

This institution was built in a [...] community, who, when I first came here had [...] trepidation about a correctional facility coming into their area. My work in developing relationships with the community was one of my primary goals and we enjoy a wonderful relationship with the community [today]. One of the reasons [for this], ironically, is because of the work that our inmate work crews did [helping out] senior citizens. We do a lot of community related work in this county and in this city because this county and this city do not have a lot of funding to a lot of the things that otherwise would be done if they had adequate tax support so we do things like working on little league ball fields, working in the fair grounds, shoveling snow and doing various things. The relationship here, from my perspective, with the community is a critical piece in terms of the success of this institution-we now have the credibility, we now are an accepted part of the community and, in fact, my whole correctional career ... community contacts, relationship with other law enforcement and services entities has always been a critical and important.

In the case of Warden B, there was clear and strong linkage between his management style, accountability issues, and his relationships with inmates, staff and the local community. Although these linkages remained consistent throughout the interview, Warden B did not present a dogmatic or rigid portrait of his decisionmaking processes. Rather, all of Warden B's beliefs about good management point toward a fairly profound understanding of the correctional context and the dynamic and changing nature of a warden's role. These beliefs, perhaps, allow him to remain somewhat (though never fully) autonomous through long-term planning and an informed consideration of his task. That being said, and like Warden A, the correctional environment is likely to create stress and some factors more than others. 
In the hypothetical IIT case discussed here, some of these situational factors may be more likely to influence the administrative intent of an IIT than others.

\section{Situational Factors}

As discussed in Chapter's I and II, the correctional context in which a warden is situated varies from state to state. However, in much of the literature, the institutional environment of prisons is depicted as generally stressful - if not in the throes of one correctional emergency or another. Therefore, this study expected respondents would be situated within similarly stressful environments and that a number of situationally stressful factors might act to mitigate the dispositional tendencies and attributes of each respondent.

Although this study expected the correctional environment to have some influence on Warden B's discretionary decision-making process, it did not expect it to completely mitigate his dispositional attributes and tendencies (Figure 4). In the case of a hypothetical IIT discussed here, situational and dispositional factors may influence the administrative intent of an IIT. Additionally, and as opposed to the assumptions of the new penology, the correctional environment was neither perpetually stressful nor, on its own, perpetually influential for Warden B. Rather, although managing prisons is not an easy job and requires a certain level of vigilance, Warden B does not always experience a high-level of stress. In initially discussing the nature and level of stress in managing a prison (Question 3a), Warden B simply states: 
I think it is situational, I think it is somewhat stressful.

However, he adds:

I think correctional environments are stressful, no matter what they are because you're dealing with individuals who are damaged [...] and can beand are-very demanding. Yeah, I think for people it is very rewarding on the one hand, because you can see [results] - you go to a GED graduation and listen to inmates talk about how they have had a revelation, how their thinking has changed ... they didn't know that they could do what they could do... [on the other hand], when it is very stressful ... we have a lot of work to do, there are human resource issues, and staff difficulties and things like that, so I would say [my operational environment is] somewhat stressful.

When asked further about the overall effect of his institutional environment, Warden

B continued to emphasize the situational nature of stress:

Interviewer: Well one word that you use that I think is interesting and consistent in my discussions is "situational" ... these [factors] aren't sort of "axes" hanging over your head all the time?

Warden B: Oh, No. they tend to be a situational stressor [...] Everyday is a different challenge, it's never been boring and I think there is something to be said for feeling obligated to try and provide proper resources for these inmates before they go back into our communities.

As an example of a situational stressor, Warden B offered this story:

For example, this winter we had a huge amount of snow here. We had 6 and 7 foot drifts which kind of cut us off. And during those times when it's hard for staff to get here and we feel a little bit cut off ... this is a very remote facility. But this comes with the business and we are prepared for that, those kinds of contingencies. But, you know, they cause stress...I'm much better now as I'm older ... much better than I used to be in terms of compartmentalizing. I think, there is always in the back of my mind, I hope we don't have an escape, I hope there's no fight, I hope there's no assault, those kinds of things ... but it certainly doesn't preoccupy me all the time.

These statements-when considering them in light of all the interview dataindicate that though numerous factors internal and external to the institution may be stressful, they are only situationally stressful, and, perhaps, only if one does not 
guard against their effects, as Warden B attempts to do through his MBWA style

of management. This is a theme that emerges fairly quickly and remains a constant throughout the interview.

In another discussion regarding situational stressors and when asked directly about overcrowding, Warden B responds (in part):

[...] I'm happy to be in [state] because I think we have a brilliant [...] management team and the overcrowding issue, has not-since I've been here-has not been an issue. We've always been at or below capacity. But I am very sensitive to the overcrowding issue because of what I [know about it].

[...] I know that my perspective probably differs from wardens and superintendents from across the nation, but I think there is a general belief that we need to get a handle on capacity and figure out how we can keep some of these offenders in the community successfully without endangering the safety and security of everybody.

In terms of an IIT's utility in relieving overcrowding, Warden B states:

I was at a conference in [state] ... I think it is an advantage for some states [to use IITs] for budget reasons [if] they have space available to receive some of those inmates. It's a good situation to be getting that revenue. It also creates [some problems] ... you have to have staff, adequate facilities and treatment programs and everything else.

Additionally, types of inmates can create a situationally stressful institutional

environment. In discussing mentally ill inmates, drugs, and gangs, Warden B

summarizes his concerns about inmate populations in this way:

I think that the big area [in correctional management] is the area of mental health and co-occurring disorders. For lack of mental health facilities [and/or] out-patient facilities in the community, we are getting a gradually increasing number of inmates with mental health issues, some with mental health and substance abuse issues. That is one aspect-and of course, as you well know, that [another state] especially is experiencing increasing problems with gangs and ... I mean it's the same old drugs, gangs, and mental health. I think that kind of sums it up for me. 
However, in summarizing his current situation in comparison to past situations,

Warden B asserts:

I'm lucky because we don't have any mental health inmates here, we don't have the mental health resources for it, so ... but the institution I came from did and we-I'm trying to remember what percentage of our populationaround $18 \%$ had some degree of mental health issues and they are, at times, problems. Adjusting to an environment, a correctional environment, being in open-dorms where there is a high degree of stimulation, being confined, maybe not having the medical resources available to them [are possible situations leading to misbehavior by inmates with mental health problems].

In terms of stresses coming from outside of the prison institution, Warden B has this to say:

I think in [state] [relationships are] very good between the department of corrections and other [agencies]. We have a director who is a fabulous guy with a lot of heart and works very well with other agencies and, you know, we have to have that relationship because ... we supervise felons, so [...] we understand the community has concerns, and we want to be able to work with the community and answer their concerns and get them as involved as possible ... some are volunteers, some are just outside support.

I enjoy a great relationship with our management team. We have a great director, all of the assistant directors are really good people, very committed to following the [state's correctional model], which talks about communication and, I think that the administration is very caring about the health and wellness of its staff, as this is a high-stress area, we have people who get ill, who get cancer, and I think our commissioner/director is very concerned about that.

In terms of negative media coverage and public relations generally, Warden

B states:

[...] we've had a little [negative media coverage]. We've had one escape here since [date]. Actually, because of that, a county commissioner asked me to convene a prison advisory meeting in the community. I had 45 people come, 43 of which said nothing but good things about the institution. The worst thing they said was ..."what a stupid guy ... the guy's going to be released in [a short time], and he got out." The media has been very good to 
us, has put out a lot of articles about the positive things we are doing. Not only for work crews but for our education program and other programs, so it has been-and not everyone may share this, because I know there is a lot of negative media - in my perspective it has been very positive. And, a moderate stressor because if something happens, then I know there is going to be, I'm going to have to respond. So, it hasn't been much of [a stressor].

On the other hand- and implicit in some of his statements - is that proposals for additional, more punitive legislation cause Warden B some concern and that, if actually enacted, may cause him—from a prison management perspective—stress.

He states:

[My state] has always had a reputation as a cutting edge state ... and now we are looking at increasing [the punitiveness of our laws]. The other states were astounded because they are all going in ... a lot of them, not all ... are going in a different direction and try to give more discretion to parole boards and sentencing courts and invest more money in community corrections [...] believing that a lot of offenders would do much better on supervision in the community than putting them in prison.

\section{Case Findings in Relation to the New Penology}

Generally speaking, Warden B-like Warden A — appeared to exercise a management philosophy consistent with DiIulio's general concept of a "keeper philosophy," discussed in Chapter II of this study. Building on this foundational belief system, Warden B appeared to focus his attention on order, amenities (e.g., sports programs) and service. Like Warden A, the narrative themes that emerged from the interview focused on accountability and an individualized focus on offenders. Warden B also discussed various elements of the institutional environment as situationally stressful, and those, not necessarily dictating the terms of an IIT or of Warden B's management approach more generally. 
Interestingly, though Warden B emphasized a form of MBWA

("Management by Walking Around," See: Warden "Walking George" Beto, in

DiIulio, 1987) he, like Warden A, appeared to represent a slightly recombinant example of Dilulio's Responsibility and Consensual Models of prison governance rather than Warden Beto's Control Model. Clearly, Warden B prioritized institutional safety and security concerns in his actual or hypothetical responses to situational stressors, but he did not lose sight of the offenders under his control and continued to emphasize offender reentry and transformation through offender and staff accountability.

In summarizing the findings of this case, it appears that the new penology may be too simplistic (Figure 4A) and lacks the power to adequately explain Warden B's general decision-making behavior as a warden. However, it may help to partially explain the use of bed rentals and IITs in cases of overcrowding. On the one hand, the motivations for the hypothetical IIT were based, in part, on very casespecific criteria (inmate behavioral problems) and not a result of an actuarial risk assessment or an explicit desire to save (or make) money. On the other hand, an IIT may be used as a response to overcrowding and may involve the possibility of a group inmate transfer to out-of-state bed rental locations. These types of transfers appear to be related to space and economic factors rather than the individual attributes of an inmate. In the case of bed rentals and group IITs however, this decision may, necessarily, originate with the DOC rather than with Warden B. Although the data is not entirely clear on this point, it appears that "bed rental" 
transfers, for the most part, are designed to facilitate management of the entire prison system and aggregate inmate management rather than to separately manage individual inmates or institutions.

In either case, because this was a hypothetical discussion, it was not entirely clear what the motivation for an IIT transfer may be if actually used by Warden B. However, in focusing only on the institutional (i.e., prison-level) implementation of IITs, a hierarchy of influence may exist between a warden's dispositional tendencies and attributes and situational factors (inmate behavioral issues) in relation to the administrative intent of an IIT. In the case of IITs and behaviorally problematic inmates (a situational factor), the dispositional tendencies and attributes of Warden B are likely to directly influence the administrative intent of an IIT (Figure 4C). However, in the case of IITs and "high-profile" inmates (or overcrowding), the dispositional tendencies and attributes of Warden B may become somewhat subordinate to immediate situational demands and may not influence the administrative intent of an IIT to a large degree (4D).

On the other hand - and unlike Zimbardo's model (Figure 4B) -the warden's dispositional characteristics may continue to wield some influence in cases of "highprofile" inmates or overcrowding. In particular, though the IIT may initially be prompted by media attention to a high-profile inmate or the DOC's systemic concerns regarding overcrowding, Warden B would likely attempt to use an IIT in at least partial accordance with his beliefs about good management practices (e.g., 
institutional security concerns, inmate safety, inmate accountability and perhaps, latently, the possibility for inmate transformation).

Again, and as anticipated, the hypothetical case examined here shows that the new penology's omission of influential, dispositional factors in its framework may be problematic when studying powerful, uniquely situated and ideologically fixed prison wardens in relation to their use of IITs. However, the data also show that some situational factors (i.e., capacity issues/overcrowding; high-profile inmates/media coverage; inmate/institutional safety and security; and individual inmate behavior) cannot be ignored and may have some influence on the administrative intent of IITs. In sum however-and as was the case in Chapter IVthe case data collected here generally point to high levels of ideological and behavioral autonomy, high levels of individualized and moralistic thinking with regard to inmates and inmate management, and a general feeling that correctional management at the institutional level is only situationally (rather than perpetually) stressful. Figure 4 (depicted on the following page) illustrates and compares the findings of this case to new penology assumptions, Zimbardo's research findings and the original assumptions of this research. 


\section{Figure 4}

Modeling the Hierarchies of Anticipated Influence of Situational and Dispositional

Factors on the Administrative Intent of IITs

A. The New Penology: Anticipated

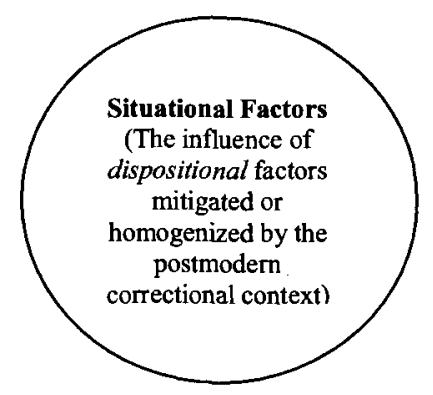

C. This Study: Anticipated

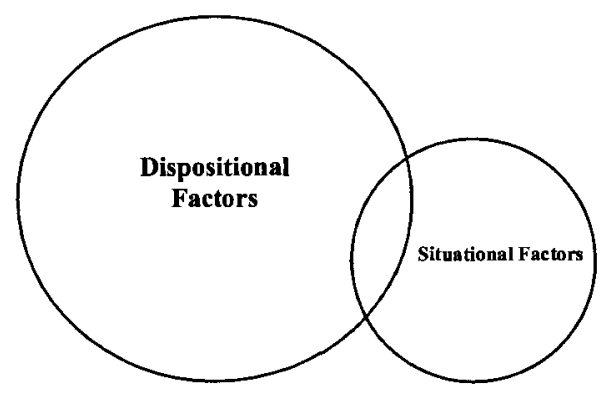

B. Zimbardo's Model: Anticipated

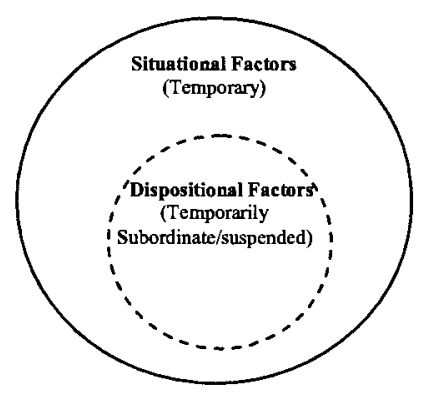

D. Case 2-Warden B:

Hypothetical IIT Findings

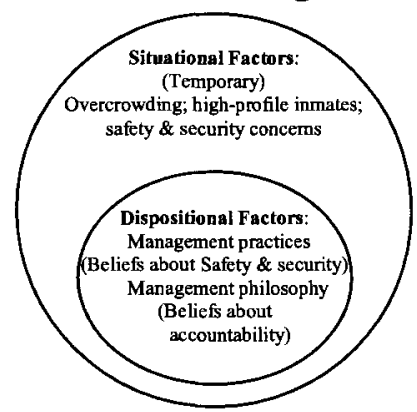

As was the case in Chapter IV, it is useful to model and discuss each perspective. In visually summarizing the anticipated and actual influence of situational and dispositional factors on the administrative intent of an IIT, Figures

4A through 4D are illustrative. Borrowing, in part, from Wright's (2000) theoretical modeling of relationships between national, state and local governments in the United States, simple Venn diagrams are used here to model hierarchies of influence 
and the proportion of power that each factor may exert upon one another and upon the administrative intent of an IIT.

In the cases modeled in Figure 4, the area of each circle represents the proportion of influence that each set of factors may exert on one another. These relationships are expected to influence the administrative intent of an IIT. In Figure 4A, the new penology anticipates that situational factors will always dictate the administrative intent of an IIT. In this diagram, the new penology does not anticipate human agency or autonomy so dispositional factors are not depicted in this diagram.

The diagram in Figure 4B depicts Zimbardo's (2008) conclusions and is represented in hierarchical terms. In this diagram, both situational and dispositional factors are accounted for but in some circumstances, it is anticipated that situational factors will temporarily "trump" the dispositional tendencies and attributes of an individual decision-maker. Simply, in some situations dispositional factors will have no impact on decision-making. While the dispositional tendencies and attributes of an individual do not "disappear," they are subordinated when an individual encounters an unusual and/or stressful situation. Interesting in Zimbardo's model is the notion that dispositional factors may continue to inform the respondent's beliefs about the "correctness" of what he is doing, but that these factors (depending on the situation) may not be powerful enough to induce the respondent to actually act and to do (from his perspective) "the right thing." In these cases, Figure 4B depicts a temporary hierarchy of influence in relation to the administrative intent of an IIT 
and, in which case, an individual will do anything to get through the crisis - even if these actions contradict what he believes to be the "right" or "best" thing to do.

In Figure 4C, a non-hierarchical Venn diagram is utilized. This research anticipated that interaction between some situational factors and a warden's dispositional tendencies and attributes would influence the administrative intent of an IIT. However, it was also anticipated that wardens would continue to implement IITs primarily in accordance with their beliefs about good correctional management practices. The findings in this case support this model in relation to Warden B's general ability to manage the institution and in relation to IITs (hypothetically) used to deal with behaviorally problematic inmates. However, in the case of IITs in which high-profile inmates or overcrowding are the central concern, figure 4D appears to be a more accurate representation.

In Figure 4D a hierarchy of influence might (i.e., due to the hypothetical nature of this case) exist between a warden's dispositional tendencies and attributes and situational factors in relation to the administrative intent of an IIT. However, as opposed to the assumptions of Figure $4 \mathrm{C}$, in the hypothetical use of IITs due to overcrowding and "high-profile" inmates, the dispositional tendencies and attributes of Warden B appear to become somewhat subordinate. On the other hand - and unlike Zimbardo's model (Figure 4B)—-the warden's dispositional characteristics continued to wield some influence. In particular, though an IIT may be initially prompted by overcrowding or the presence of a high-profile inmate, Warden B may likely continue to use an IIT in at least partial accordance with his beliefs about good 
management practices (e.g., institutional security concerns, inmate safety, and public accountability).

The path model (Figure 5) depicts the influence of situational and dispositional factors on the administrative intent of IITs and is presented in order to simply illustrate why IIT's are used in this case.

\section{Figure 5}

\section{Hypothetical IIT Case: Ruling Relationships}

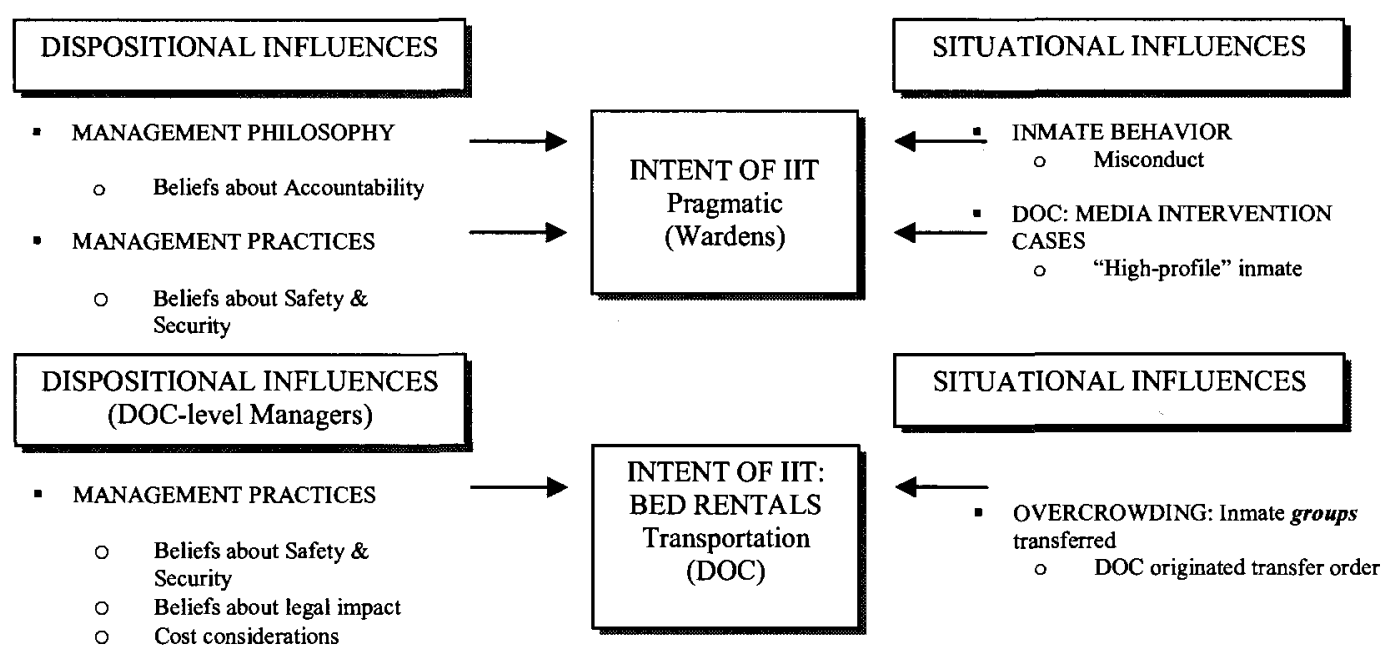

In concluding this chapter, a number of important themes are drawn from the case study discussion above and listed in simplified form below. The following narrative themes are re-presented because: (1) they represent clear deviations from the new penology construct; and (2) They represent possible situations in which the new penology may be supported; and (3) They illustrate the potential influence of situational and dispositional factors on administrative intent: 
1. Dispositional Factors: Warden B clearly thought of the inmates under his supervision as individuals and not simply as "numbers."

- Dispositional Factors: Warden B clearly understood the stresses inmates were under. Although he believed that they were responsible for their circumstances (i.e., incarceration) he also believed in the ability of most inmates to transform themselves into productive citizens if given the chance and managed properly.

2. Dispositional Factor: Warden B feels that inmate and staff accountability are critical to the proper functioning of the institution. Facilitating and ensuring accountability is facilitated through Warden B's beliefs about the efficacy of MBWA. Accountability, from Warden B's perspective, has a 2-tiered, threepronged emphasis:

- Inmates: Accountability to the public; to the institution; and to themselves (in terms of transformational goals).

- Staff: Accountability to the public; to each other, and to the goal of offender transformation.

3. Dispositional Factors: The following sensibilities - explicit and latentappear to inform much of Warden B's decision-making:

- Empathic pragmatism: A practical focus on the plight of others, to include: inmates, staff and the general public.

- Safety and security of institution, inmates and staff; and the general public. 
- The co-production of prison governance and the creation of safe, sound and effective institutional conditions: Building positive relationships with inmates, staff, DOC and other correctional managers and political leaders, and the local community.

4. Situational Factors: For Warden B, the correctional context is only stressful if you don't prepare for it. Beliefs about good correctional management practices are strongly held and are an influential dispositional factor in this case (e.g., MBWA).

5. Situational factors-Media \& court linkage: When asked about court interventions, Warden B simply stated that he had no problems with the courts. When asked about the media and public opinion, he admitted to having had a little trouble with the media but that mostly media coverage was positive and public opinion was also positive.

In the following chapter, the third case, "DOC_Command and Control," will be discussed in relation to the DOC's written statements about IITs in their state. The analysis will follow a similar format as the previous two cases. However, due to the dearth of information provided by the DOC (in part, due to the failure of the researcher to anticipate every relevant question, and in part, because the DOC simply didn't answer some questions), the discussion in Chapter VI will be much shorter in length and focus only on comparisons between official DOC statements and the behavior, beliefs and knowledge of Wardens' A \& B in relation to IITs, as well as some of the more significant access issues encountered by this research. 
CHAPTER VI: CASE 3

THE DEPARTMENT OF CORRECTIONS - “COMMAND AND CONTROL"

"We move inmates for protective custody reasons: safety for the inmate, safety of others, and/or high-profile such as media." - The Department of Corrections

\section{Introduction to Case}

The third and final case presented here is drawn from data collected from a short, open-ended survey that was emailed to the state's department of corrections on June $13^{\text {th }}, 2008$ (Appendix I). Due to confidentiality reasons discussed previously, the respondent in this case has been designated "Department of Corrections" and given the avatar "command and control" as a reflection of both the respondent's centralized role in the IIT process and the formal and informal role they played during the interview process (i.e., warden-access control). The survey was completed by an unnamed source within the central DOC office [specific name of DOC office withheld]. Although the survey was not answered as exhaustively as the researcher would have liked, this is more the fault of the researcher than it was of the DOC or their representatives. ${ }^{25}$ As was the case in Chapters IV \& V, prior to this discussion—and prior to an in-depth analysis—-this study's research questions and assumptions are generally reviewed and a brief summary of findings in relation to the DOCs statements is presented.

${ }^{25}$ Originally, respondents at the DOC-level of the organization were not intended to be a part of this study. However, and as discussed in Chapter III, potential respondents were directed to defer to the central DOC agency as the authoritative source of information on IITs. This directive essentially ended my ability to recruit additional respondents at the prison-level. When contacting the DOC, I was asked to submit a written, open-ended survey instrument that they would return to me in 2 weeks. Although the survey was carefully crafted and written in very straightforward manner, it was not, unfortunately, able to anticipate all of the nuances of the IIT phenomenon in this state. 
Introduction to the Department of Corrections

As mentioned previously, the state DOC surveyed here is (comparatively speaking) a mid to small-sized organization located within a mid to small-sized state. Additional specifics regarding the DOC will not, in this study, be discussed for two reasons: 1) Confidentiality requirements, both formal and informal; and 2) pertinence to this study. The collected data will be used here simply for comparative purposes in relation to Warden A and Warden B's stated use of an IIT.

When making contact with the DOC, their representatives were congenial, accessible and returned phone calls, emails and the survey document in a timely manner. However, it was clear that the information they provided was intended to be the "last stop" for my study. This requires further explanation. As is the case with all DOC organizations today, the organization surveyed here is centralized and hierarchically organized (see: Chapter II for further discussions on this). What this means for a researcher is that all requests for research must be approved and channeled by the DOC. There are many reasons for this, and have been previously discussed throughout this research (See: Chapter II and the relationship between media access and career termination, for one example).

In this case, approval was not received (after multiple inquiries and requests) but, rather, an agreement to participate in the research was eventually offered by the DOC. Unfortunately, what that also meant was that my access to wardens was informally curtailed (and their willingness to participate chilled) and all data regarding the state's use of IITs were, at this point, channeled through the DOC. 
That being said, the DOC offered very useful technical and legal information and some information regarding the administrative intent of IITs.

When asked if they transfer inmates to out-of-state locations, the DOC responded that they did (about 20 inmates per year) and they did so in two ways: (1) through one or more ICC agreements; and (2) through an out-of-state bed rental program (Appendix I). In the case of ICCs, inmates are chosen on an individual basis and "exchanged" on a 1-for-1 basis with other states participating in an ICC agreement. In the case of "bed rental" programs, typically, groups of inmates are transferred to out-of-state locations in response to capacity/crowding issues. These latter transfers are not based upon an inmate exchange or any type of compact or treaty. Rather, cell space (i.e., "beds") are temporarily contracted (for a fee) in other states with public or private providers who are willing and able to take additional inmates.

In the following subsections, discussions regarding the influence of dispositional and situational factors on the administrative intent of IITs are brief due to a lack of data. This is especially true in relation to the DOC's statements regarding the potential influence of dispositional factors on the administrative intent of IITs. However, the DOC did provide data not gathered in either of the previous two cases with regard to a warden's ability to implement IITs. Although these statements do not directly discuss specific dispositional factors that may influence a warden's use of an IIT, it does leave room for the possibility that IITs, in some cases, may be influenced by a warden's dispositional attributes and tendencies. 


\section{Dispositional Factors}

As discussed previously, not much is known about IITs because they have rarely been a research concern. Compounding that problem is that there appears to be a great deal of variation in the use of IITs by each state. For example, in one state a warden may have the power to implement an ICC transfer but not use bed rentals or other forms of non-ICC interstate transfers. In other states, there may be little or no use of IITs at all (e.g., Louisiana) and in yet other states, no ICC is used at all and all transfers are primarily based on rentals and group transfers. On top of those factors, there are a number of unique constraints placed on sending and receiving states in relation to conditions of confinement, who can be sent out-of-state, and who will (and when) pay certain transport costs (amongst many other constraints) (USDOJ, NIC, 2006). For the most part then, the survey instrument administered to, and completed by, the DOC was a simple request for technical information regarding the state's use of IITs. Therefore, not a great deal of information was asked for, nor received, with regard to the dispositional tendencies that may influence the administrative intent of an IIT.

That being said, a few of the DOC's responses were interesting because they implied that a warden's dispositional tendencies and attributes may influence the administrative intent of an IIT in some cases. Specifically, when asked if wardens were formally or informally involved in IITs, the DOC provided a detailed response and elaborated on the process by which a warden is involved in an [unspecified type] of IIT transfer: The DOC writes: 
The warden discusses an individual inmate transfer case with his/her Security team and Counselors handling the inmate's caseload. There is an institution internal interdisciplinary committee that reviews any cases that are brought up to them by staff within that institution to determine if the inmate should be placed in another state for their protection or safety of others. If the team decides the inmate would be best served by an out of state transfer, the Counselor will complete a packet of information on the inmate stating all pertinent information and rationale for the transfer. The packet then is forwarded to the warden for review and approval and then it is submitted to the [central DOC office] for approval and submission to another Compact State for consideration.

It is interesting to note that neither of the wardens that I spoke with were fully aware that they could formally initiate an IIT. There may be a few reasons for this:

1. The formalized policy has been implemented very recently (and is, perhaps a response to this research) or the stated policy does not formally exist (i.e., in writing);

2. The autonomy experienced by prison wardens is even greater than the collected data indicate (i.e., they are too busy running their institutions to pay heed to evolving DOC policies); and/or

3. The wardens interviewed here have simply not used IITs in a long time or have had no need to use them at all.

In terms of dispositional attributes that may influence the administrative intent of an IIT, the DOC is quiet. However, it is clear from their statements that the warden, at least in some types of IIT transfers, is an integral part of the IIT process. Therefore, and based upon the previous two interviews, it is assumed that a warden's dispositional attributes and tendencies will influence the administrative intent of 
some IIT transfers. Some of the possibilities will be described in the following subsection.

\section{Situational Factors}

The DOC had a little bit more to say regarding some of the situational factors that may influence the administrative intent of an IIT. When asked why the state uses IITs, the DOC responded:

We move inmates for protective custody reasons: safety for the inmate, safety of others, and/or high-profile such as media.

The Rental Beds program is different than any compact or treaty; it is for sending inmates out of state for temporary housing based on lack of adequate beds in the department, not on an exchange basis, but a contracted fee basis.

Due to a lack of data, it is hard to say who, exactly, initiates an IIT in each of the situations described by the DOC. Thus, it is difficult to determine what the administrative intent is in each case. However, drawing from the previous two cases, some tacit conclusions may be reached.

From the descriptions given in the previous two cases, it seems likely that the warden is most likely involved in IITs (an ICC) used to transfer inmates due to behavioral problems or protective custody issues. These are individual cases that, largely, affect the security and safety of a warden's institution, staff and the offender themselves. On the other hand, although a "high-profile" inmate also affects a warden's institution, and warden's are likely to have some influence over the administrative intent of an ICC in these cases, it is likely that "high-profile" inmates are chosen for transfer by the DOC due to their potential, systemic threat to 
institutional safety and security. This threat, largely, stems from excessive media coverage, attempts to access the inmate by the media and the inmate's willingness (and eagerness, in some cases) to speak to the media.

Finally, in cases of overcrowding, it does not appear that the warden is involved in implementing an IIT. Rather, the administrative intent of IITs (i.e., Bed Rentals) used in these cases stem from a systemic need to manage inmate populations. Although it is not clear how inmates are chosen for these transfers (i.e., are specific inmates chosen or is it a random selection?), it is obvious that overcrowding does lead to the use of IITs. Beyond the obvious reasons for doing so (i.e., overcrowding begets all sorts of correctional management and inmate livability problems; budget constraints on building additional capacity, \& etc. See: Chapter II in this study), numerous court cases brought by prisoner advocate groups over the past few decades have ensured that DOCs pay close attention to their population levels (Angelos \& Jacobs, 1985; Kaufman, 1985; Williamson, 1990). As Warden A implied in our discussion, [successful] court interventions into the affairs of the DOC will likely lead to a loss of autonomy for correctional managers and, thus, a [perceived] decrease in the ability of wardens and DOCs to remain accountable to the public.

\section{Case Findings in Relation to the New Penology}

In summarizing the findings of this case, it again appears that the new penology may be too simplistic (Figure 6A) and lacks the power to adequately explain a warden's general decision-making behavior. However, it may help to 
partially explain the use of bed rentals and IITs in cases of overcrowding. On the one hand, the motivations described by the DOC for IITs were based, in part, on very case-specific criteria (inmate behavioral/protective custody problems) and not a result of an actuarial risk assessment or an explicit desire to save (or make) money.

On the other hand, an IIT may be used as a response to overcrowding and may involve the possibility of "group" inmate transfers to out-of-state bed rental locations. These types of transfers appear to be related to space and economic factors rather than the individual attributes of an inmate and appear not to involve a warden's input. In sum, it appears that the new penology may explain the use of "bed rentals" by the DOC, but only temporarily and only in the case of overcrowding (Figure 6E). Although the data is not entirely clear on this point, it appears that "bed rental" transfers, for the most part, are designed to facilitate management of the entire prison system and aggregate inmate management rather than to separately manage individual inmates or institutions.

The DOC data indicate that prison wardens are able to implement some (unspecified) form of an IIT. Additionally, the DOC details a fairly elaborate process by which the warden may do so. Although this finding contradicts some of the findings in the previous cases, it does imply that the new penology's omission of influential, dispositional factors in its framework may be problematic when studying powerful, uniquely situated and ideologically fixed prison wardens in relation to their use of IITs. On the other hand, the data from this case show that some situational factors (i.e., capacity issues/overcrowding; high-profile inmates/media 
coverage; inmate/institutional safety and security) may have some influence on the administrative intent of IITs.

In sum however, the case data collected from the DOC in this case do not provide enough data to come to any solid conclusions about the administrative intent of IITs at the prison-level (i.e., wardens). There is some data, however, that may contribute to our tacit knowledge of administrative intent at the DOC level. Additionally, a few themes do emerge from these data that are consistent with data collected in the other two cases: (1) Individual and institutional safety and security influence the administrative intent of an ICC; (2) Excessive media intervention and/or the presence of high-profile inmates influence the administrative intent of an ICC; and (3) overcrowding may influence the use of "group" IITs by the DOC. Figure 6 (depicted on the following page) illustrates and compares the findings of this case to new penology assumptions, Zimbardo's research findings and the original assumptions of this research. 
Figure 6

Modeling Hierarchies of Influence: The Anticipated Influence of Situational and Dispositional Factors on the Administrative Intent of IITs

A. The New Penology: Anticipated

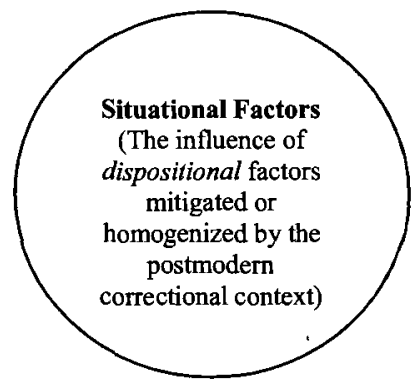

C. This Study: Anticipated

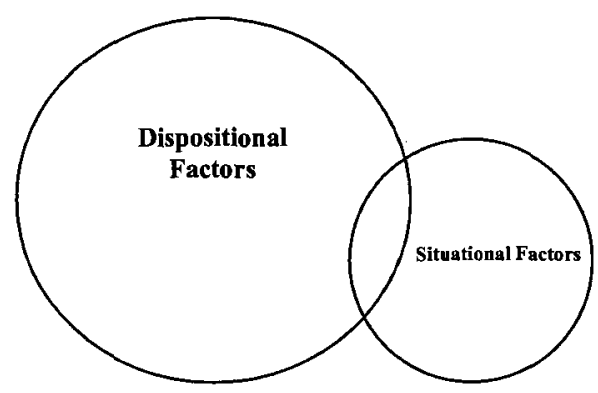

B. Zimbardo's Model: Anticipated

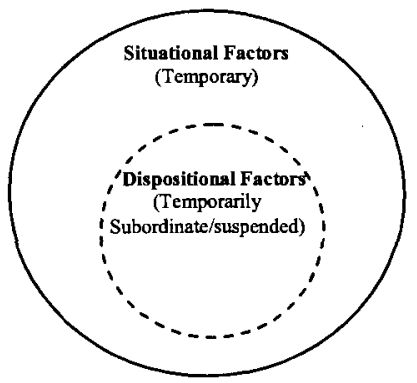

D. Case 3 - The DOC: ICC Findings-Wardens

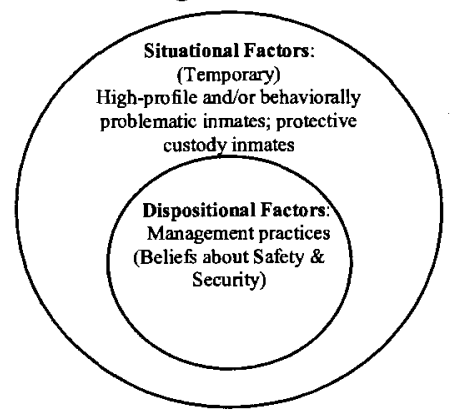

E. Case 3 - The DOC: IIT Bed Rental Findings-DOC

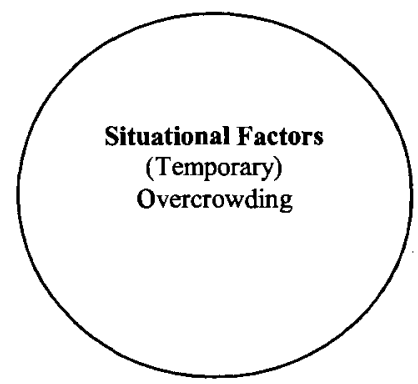


In visually summarizing the anticipated and actual influence of situational and dispositional factors on the administrative intent of an IIT, Figures 6A through 6E are illustrative. Borrowing, in part, from Wright's (2000) theoretical modeling of relationships between national, state and local governments in the United States, simple Venn diagrams are used here to model hierarchies of influence and the proportion of power that each factor may exert upon one another and upon the administrative intent of an IIT.

In the cases modeled in Figure 6, the area of each circle represents the proportion of influence that each set of factors may exert upon one another. These relationships are expected to influence the administrative intent of an IIT. In Figure $6 \mathrm{~A}$, the new penology anticipates that situational factors will always dictate the administrative intent of an IIT. In this diagram, the new penology does not anticipate human agency or autonomy so dispositional factors are not depicted.

The diagram in Figure 6B depicts Zimbardo's (2008) conclusions and is represented in hierarchical terms. In this diagram, both situational and dispositional factors are accounted for but in some circumstances, it is anticipated that situational factors will temporarily "trump" the dispositional tendencies and attributes of an individual decision-maker. Simply, in some situations dispositional factors will have no impact on decision-making. While the dispositional tendencies and attributes of an individual do not "disappear," they are subordinated when an individual encounters an unusual and/or stressful situation. Interesting in Zimbardo's model is the notion that dispositional factors may continue to inform the respondent's beliefs 
about the "correctness" of what he is doing, but that these factors (depending on the situation) may not be powerful enough to induce the respondent to actually act and to do (from his perspective) "the right thing." In these cases, Figure 6B depicts a temporary hierarchy of influence in relation to the administrative intent of an IIT and, in which case, an individual will do anything to get through the crisis - even if these actions contradict what he believe to be the "right" or "best" thing to do.

In Figure 6C, a non-hierarchical Venn diagram is utilized. This research anticipated that interaction between some situational factors and a warden's dispositional tendencies and attributes would influence the administrative intent of an IIT. However, it was also anticipated that wardens would continue to implement IITs primarily in accordance with their beliefs about good correctional management practices. The data collected in this case are insufficient to come to a conclusion about the administrative intent of IITs when implemented by wardens. However, based on the data collected here and from the other two cases, the use of IITs in which high-profile inmates, protective custody inmates, or overcrowding are the central concern, figure $6 \mathrm{D}$ and $6 \mathrm{E}$ may be a good representation of administrative intent and its relationship to situational factors.

In Figure 6D a hierarchy of influence may exist between a warden's dispositional tendencies and attributes and situational factors in relation to the administrative intent of an IIT. However, as opposed to the assumptions of Figure $6 \mathrm{C}$, the use of IITs due to the presence of "high-profile" inmates, protective custody issues, and behaviorally problematic inmates, the dispositional tendencies and 
attributes of wardens may become somewhat subordinate. On the other handand unlike Zimbardo's model (Figure 4B)—-the warden's dispositional characteristics may continue to wield some influence. In particular, though an IIT may be initially prompted by the presence of a high-profile or otherwise problematic inmate, wardens would likely continue to use an IIT in at least partial accordance with his beliefs about good management practices (e.g., institutional security concerns and inmate safety).

In Figure 4E, the relationship between situational and dispositional factors in "bed rental" IIT cases is somewhat unclear due to a lack of data. However, statements made by the DOC in relation to their "bed rental" program and the purpose of transfers (specifically, as a response to prison crowding), indicate that a warden may not be involved in these decisions at all. Rather, this type of "group" transfer may be implemented solely by the DOC. In modeling the relationships in these cases then, dispositional factors are not included. Although the model appears similar to the new penology diagram, they differ in one significant way:

Overcrowding (in this case) is a temporary, rather than a perpetual situational factor. Therefore, the new penology may be explanatory in "bed rental" cases, but only on a temporary basis.

The path model presented on the following page (Figure 7) depicts the possible influence of situational and dispositional factors on the administrative intent of IITs. 


\section{Figure 7}

DOC Statements Regarding IIT Usage: Ruling Relationships

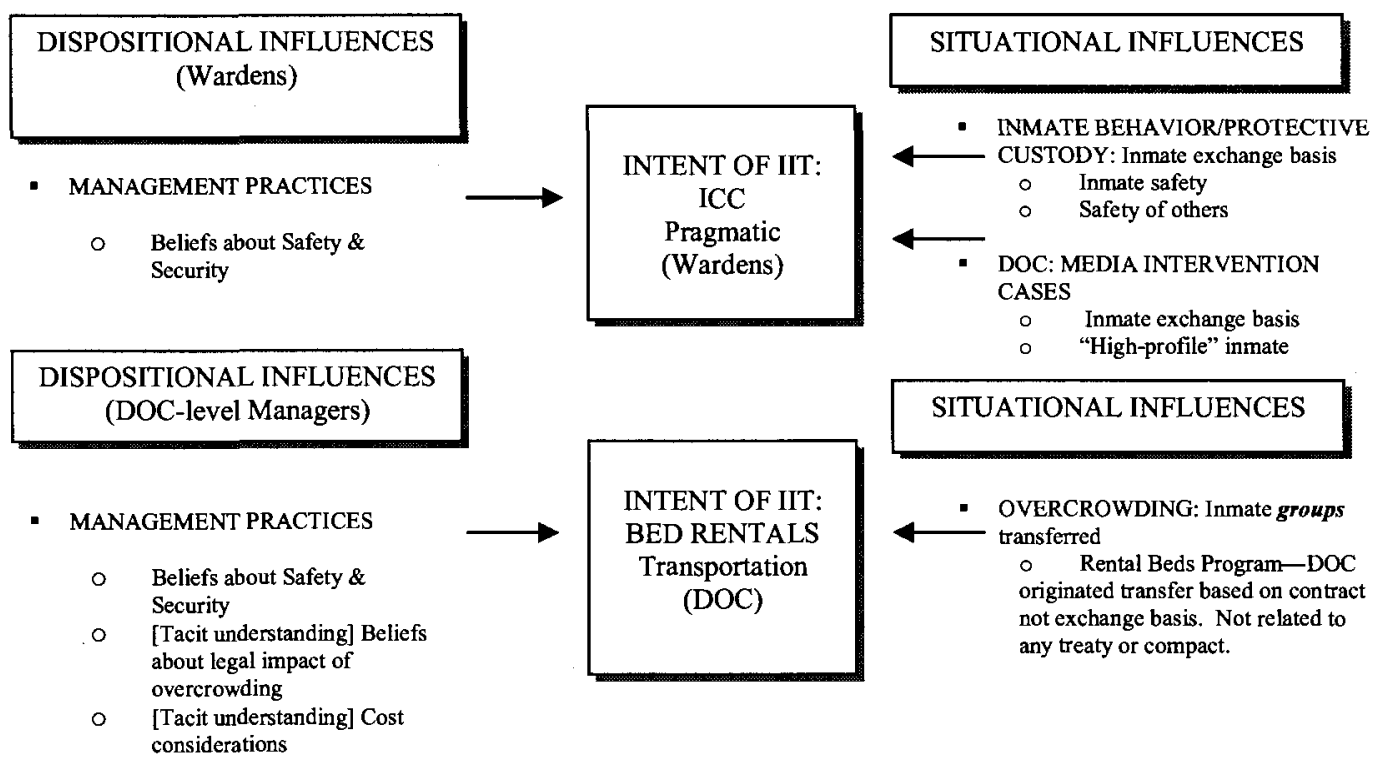

In concluding this chapter, a number of important themes are drawn from the case study discussion above and listed in simplified form below. The following narrative themes are re-presented because: 1) They represent support for the new penology construct; and 2) They also illustrate the potential influence of situational and dispositional factors on administrative intent:

1. Dispositional Factors: Based on DOC statements, wardens are allowed to implement some form of IIT within their institution.

- Dispositional Factors-Wardens: The clear ability to initiate and use IITs implies that the dispositional attributes and tendencies of wardens may influence the administrative intent of some IITs. 
2. Dispositional Factors - DOC: The following sensibilities - explicit and latent- appear to inform the DOCs use (and approval) of IITs:

- Empathic pragmatism: A practical focus on the plight of others, to include: inmates, staff and the general public.

- Safety and security of institution, inmates and staff, and the general public.

- Beliefs about cost saving practices.

- Beliefs about the legal impact of overcrowding on DOC functions.

3. Situational Factors: From the DOC's perspective, excessively problematic inmates (behavioral and/or protective custody cases) are situations in which an inmate may, and should, be transferred.

4. Situational Factors-High-profile inmates: A reoccurring theme throughout this project has been the case of "high-profile" inmates, especially those who receive, and desire, a great deal of media coverage. The reasons for wanting to transfer these types of inmates have been discussed previously, but it is clear that media attention to these types of inmates poses a number of management problems at the DOC and prison-level.

5. Situational factors-Overcrowding: Overcrowded institutions have been a fact of life for most institutions since at least the 1980s (See: Chapter II). DOCs around the country attempt to avoid the situation whenever they can for a number of reasons previously discussed and often use some form of IIT to 
accomplish this task. However, data on how inmates are chosen for these types of transfers remains unclear and it appears that wardens are not involved in the bed rental (or other group) transfer process. The administrative intent of these transfers may be best explained, at least on a temporary basis, by the new penology. However, the data is still not clear enough to make that assessment.

In the following, concluding chapter, the three cases examined here are described and discussed in relation to their implications for correctional theory, practice and policy. The limitations of this study and the limitations of the new penology framework are also discussed in relation to our understanding of IITs. In particular, this study concludes that though the new penology may be explanatory in some cases, in order to better understand and possibly predict the administrative intent of IITs, an alternative theoretical framework should be utilized - one that better captures the dynamism and variability of influence that unique situational and dispositional factors (and their interaction) may have on administrative intent. Toward this end, institutional theory is proposed, briefly introduced and some of the findings of this study briefly viewed through an institutional lens. 
CHAPTER VII-CONCLUDING DISCUSSION: FINDINGS,

\section{DIFFICULTIES, AND VALUE OF RESEARCH TO PRACTICE, THEORY}

\section{AND POLICY}

"When a gang is already well established in a state, moving a leader out of state creates a power vacuum that may allow prison staff to eliminate some prestige, and possibly power, from a gang. "--Richard Seiter, Former Secretary of Ohio

Corrections.

\section{Organization of Concluding Chapter}

In presenting the findings of this research, this chapter will begin by discussing (in an aggregate sense) the findings in all three cases and the problems and limitations of the study in relation to these findings. Questions often arise in relation to the value of purposively sampled, qualitative research, especially when the research is drawing conclusions from a very small sample, as this one has. From an applied perspective then, there may be limited immediate value. However, from a theoretical and descriptive perspective, this research hopes to contribute significantly to our understanding of interstate inmate transfers and their use by prison wardens. Therefore, a discussion regarding the value of this study to correctional practice, policy and theory is explored below. This chapter concludes with a brief discussion regarding the potential research value of institutional theory as an alternative to the new penology, especially as it relates to the study of IITs and discretionary decisionmaking in correctional management. 


\section{Findings}

In summarizing the relationship between administrative discretion and the influence of situational and dispositional influences on prison-level management (generally), this project anticipated (and found) that a prison warden's discretionary decision-making process is influenced, in varying degrees, by both their correctional management philosophy and the correctional environment. Thus, the assumptions (and findings) of this research suggest that we view prison wardens as something more than uniformly self-serving and instrumentally-inclined public administrators. However, although this study has found some evidence of variability in the administrative intent and discretionary use of IITs due to variation in the individual dispositional characteristics of prison wardens (i.e., such as their beliefs about the need to focus attention on individual inmates and the needs of the community), it also found evidence that the administrative intent driving the discretionary use of IITs may be influenced exclusively by situationally powerful institutional forces.

Understanding the ruling relationships in the three cases examined here was an important consideration when attempting to understand the administrative intent of IITs. The ruling relationships that became apparent during the course of this research are, for the most part, related to what a warden believes, what the DOC wants (and why) and what the inmate actually does. These appear to be powerful, though variably influential, relationships-relationships that have led to both instrumental and constitutive use of IITs. 
This study found that in some situations (i.e., during periods of overcrowding and the DOC's use of out-of-state bed rentals) the new penology may appear to have some explanatory power, but overall the new penology does not seem to be well supported by the case data. In part, this is because the new penology's assumptions place a significant emphasis on the emergence of "perpetually" influential contextual forces and does not appear to assume, or even anticipate, the variable impact that these forces may have on individual decision makers. Significantly, the new penology does not assume or anticipate the influence of individual-level dispositional factors on decision-making, nor does it assume or anticipate the influence of these factors in relation to an individual correctional manager's feelings of human agency and autonomy during implementation (Cheliotis, 2006).

As anticipated by this study, the cases examined here show that the new penology's omission of these individual dispositional factors results in a theory that does not fully explain practice. Stated more precisely, the new penology assumption that criminal justice actors have no autonomy or human agency may be an incorrect or incomplete assumption in relation to prison wardens and the intent of IITs. Additionally, the new penological assumption that inmates are thought of only in the aggregate or in actuarial terms by criminal justice actors may also be an incorrect or incomplete assumption in relation to prison wardens, the intent of IITs and in generally understanding the management of prison institutions. Although we should not overstate any conclusion drawn from the limited data collected here, it seems 
clear that the new penology likely overstates their case in relation to the administrative intent of discretionary criminal justice policy.

Similarly, Zimbardo's assumption that situational factors are likely to trump the dispositional tendencies and attributes of powerful decision makers situated within stressful environments, did not entirely ring true in this study either. There are a few possible explanations for that. First, prison wardens, unlike the individuals in Zimbardo's original, 1971 study or those in his 2008 case study of Abu Ghraib, are already powerful actors who, typically, have a great deal of training and authoritative experience in the correctional environment. Thus, wardens are less likely to be overwhelmed by circumstances than Zimbardo's college students and/or the low-ranking soldiers of Abu Ghraib who, suddenly, were thrust into positions of power.

Second, and related to the first, it is clear from these few case studies that wardens' beliefs about appropriate actions in a variety of correctional circumstances are strongly held. Thus, wardens are not likely to behave in ways that they do not feel are correct or in keeping with their beliefs about good correctional practices or the mission of the DOC generally. In sum, the case data collected in this research point to high levels of ideological and behavioral autonomy among prison wardens as well as high levels of individualized and moralistic thinking with regard to inmate management, and a general feeling that correctional management at the institutional level is only situationally (rather than perpetually) stressful. 
On the other hand, in cases of situational stressors such as "high-profile" inmates or prison crowding/capacity issues, a warden's dispositional tendencies and attributes may be somewhat subordinated or, in the case of overcrowding, not at all influential. In the first case, "high-profile" inmates pose a number of threats to the institution and to the inmate themselves. This makes the "high-profile" inmate a direct concern to the warden.

However, "high-profile" inmates (unlike merely misbehaving or mentally ill inmates, for example) also pose a security threat to the management of the entire prison system. Additionally, "high-profile" inmates may (intentionally or not) invoke the political ire of politicians, the inmate's victims and/or families or others who have an interest in the case. Thus, "high-profile" inmates also pose a political threat to the DOC. Therefore, it seems likely that the DOC would be more involved in a warden's decisions regarding the disposition of a "high-profile" inmate than not and, to some degree, influence the administrative intent of an IIT in these cases (e.g., simply seeking a willing facility rather than a suitable facility may be an indicator of DOC influence).

Although the data are not entirely clear on this, implementing IITs in order to relieve prison crowding appears to be a situation in which the warden is not at all involved. The new penology may help to explain the administrative intent of IITs in these cases. In "bed rental" transfer cases, typically groups of inmates are chosen (though it not clear how they are chosen: Random selection or case-specific criteria?) and sent to out-of-state facilities due to overcrowded prison conditions in the home 
state. Unlike other types of transfers (i.e., ICCs), these transfers are not exchange-based, but rather, are cells (i.e., "beds") contracted (for a fee) with receptive public or private correctional facilities in another state. Although there is too little data to form anything more than a tacit conclusion, the correctional literature would lead one to believe that actuarial, legal and economic concerns may override the individual needs of the transferred inmates in "bed rental" cases. However, and based on the data collected here, it seems that because group-oriented, "bed rental" transfers are intended to be temporary "fixes," the new penology may not be explanatory over the long term.

\section{Problems, Difficulties \& Limitations of Study}

Problem 1: Criminal justice scholar John Crank (2004) asserts that there is a growing divide in criminal justice research. This divide, writes Crank, is normative in nature and has contributed to an emergent intellectual conflict between criminal justice practitioners and criminal justice academics - to the detriment of criminal justice research. In many ways, the divide Crank speaks of appeared to be true in this research - the effects manifesting themselves in primarily in two ways: (1) Difficulty in gaining access to respondents; and (2) A clear distrust of the proposed research agenda by some potential respondent's and, possibly, the DOC. On the other hand, the wardens with whom the researcher spoke were intellectually engaged and engaging, and recognized the research as a reflection of genuine curiosity about the job they do. Therefore, they were quite willing to "bridge" this divide. 
Problem 2: Applying any methodological approach to a study of the correctional environment is problematic. Simply, though some research may have a negative political impact (e.g., evaluation research or reform-oriented approaches), even "value-neutral" correctional research may be irrelevant to a correctional manager's day-to-day efforts to implement value-laden public policy. Stojkovic \& Farkas (2003, p.138) write:

[...] the world of corrections is inherently a political world where values preferences dominate. In such a world, the factual revelations of social science research are often irrelevant. In the long, sordid history of correctional reform, empirical facts have been a poor defense to the onslaught of political preferences of the day. This research, however, aims to offer something other than a politically risky or potentially irrelevant correctional evaluation. Simply, in attempting to gain a better understanding of a prison warden's perception of their institutional life, this study hopes to better inform the "political preferences of the day" (e.g., public opinion, legislators, and academic commentators) about the relationship that situational and dispositional institutional factors may have on prison wardens' use of IITs and their ability to manage prisons generally. Therefore, rather than proposing or suggesting another in a long series of generalized reforms based on evaluations of typical cases and problems, this research simply suggests that we gain a better understanding of the correctional manager's perception of their atypical world (McGee, Warner \& 
Harlow, $1985^{26}$ ) and their response to unusual, problematic, or "unmanageable"

correctional phenomena. As opposed to the impact that the "anomalous case" has on many other types of organizations, these cases are quite relevant to the correctional manager because anomalous corrections cases have a disproportionate ability to harm or otherwise significantly disrupt the entire prison institution. ${ }^{27}$ Understanding IITs is important because this is how wardens, and their DOCs, attempt to handle the anomalous, but potentially disruptive cases they encounter in their day-to-day job.

Problem 3: The small sample prohibits statistical generalization. Due to the low number of actual IITs discussed (1 actual, 1 hypothetical and a general statement by the DOC) and the small number of interviews, it is not possible to generalize about the administrative intent of interstate inmate transfers. However, as stated previously, the goal of this research is not to generate generalizable data but rather, to improve upon our understanding of IITs and to evaluate the veracity of the new penology in a small number of cases. This study is simply a precursor to more comprehensive research.

Additionally, the small sample is not a methodological problem in this case due to the unique and vastly understudied problem it seeks to understand. Even with a small sample, a multiple case study can be useful in clarifying and improving upon

\footnotetext{
${ }^{26}$ For example, in discussing the difficulties posed by a small number of special management inmates, McGee, et al. (1985, p.99) write, "Simply being atypical, the Special Management Inmate poses problems for the prison administration."

27 Stojkovic \& Farkas illustrate this point using the example of a sex offender who kills somebody while on parole. These atypical case characteristics have a deep impact on public perceptions of correctional management and "reverberate" politically long after the incident has been technically handled (e.g., capture and imprisonment of the sex offender). In the case of IITs, they are sometimes used to break up gangs, preserve the life of vulnerable and high-profile inmates, or otherwise mitigate potential violent eruptions within the institution.
} 
the replication logic employed. Therefore, the conduct of this study, and an evaluation of its problems, will greatly inform future research on the topic. For example, during the implementation of the interview-and even after a number of pretests-it became clear that the order of questions needed to be altered in order to maximize responses to questions about IITs. Additionally, a number of access problems and informal relationship-building protocols were revealed during the course of this research that will be closely considered (and used) in future research.

\section{Value of Study}

Correctional management realities are clearly complex (Jacobs, 1977; Barak-Glantz, 1981; Fox, 1984; Duffee, 1986; Hart, 1995; Dilulio, 1997; Seiter, 2002). Bolman \& Deal (1991, p.309) argue that understanding “[ ...] complex [organizational] realities require complex approaches." In adding complexity to our understanding of IITs and administrative intent, this study utilized descriptive, historical, legal and theoretical frameworks that can be used to contribute to the field of correctional management and theory in three ways. First, this study intended to develop a better descriptive understanding of correctional management, the correctional environment, and interstate inmate transfers generally. Adding descriptive clarity to all three phenomena will facilitate future research on the IIT phenomenon.

Second, this study intended to qualitatively evaluate the assumptions of the new penology with an eye toward analytical generalization (rather than statistical generalization) and theory development. Eventually, the development of a 
falsifiable, theory-based understanding regarding how, why, and under what conditions prison wardens use discretionary administrative tools such as the IIT may allow for the development of more nuanced implementation strategies which, in turn, may achieve more predictable and more desirable outcomes (Menzel, 1987; Bolman \& Deal, 1991; Hill \& Hupe, 2002). Theory testing and development is important in the case of IITs because new penological assumptions have not been tested in relation to IITs, nor have alternative theoretical frameworks been proposed. Thus, by default the new penology framework has been left to stand as the only theorybased explanation for their use. Although this study did not directly test institutional theory, it did use the framework informally to help describe and conceptually organize a prison warden's institutional environment. For example, institutional theory assumes that public institutions are situated in complex, (variably) valueladen institutional environments. It also assumes (in part) that these environments may (or may not) have a variable impact on individual decision makers. Importantly, institutional theory-unlike the new penology- focuses on the potential influence of rules, norms and individual perceptions (and reactions) to the institutional environment in relation to organizational decision-making. Therefore, institutional theory appears to provide for the possibility for a more complex and richer understanding of a prison warden's use of IITs.

Finally, through descriptive and theory-based research, this study intended to contribute to a prescriptive understanding of how correctional managers might use IITs in the future. David Duffee (1986) and John DiIulio (1987) argue that 
developing a "policy-oriented knowledge" of prisons is important in helping us intentionally affect desired outcomes and avoid undesired outcomes. Dilulio argues that policy-oriented knowledge about prisons should be derived from research that focuses primarily on those who implement policy within the prison environment (e.g., wardens, administrators, correctional employees) and which attempts to understand the context in which desired and undesired penal outcomes occur (Dilulio, 1987, p.12). From this knowledge, argues Dilulio (p.12), we can better assess whether and how correctional policy should be altered. As opposed to implementing generalized reform policy based upon good intentions and deeply held assumptions regarding “good" prison policy (See also: Rothman, 1980/2002), correctional policy research must begin to be both: 1) focused on those who actually implement policy within the prison; and 2) be based upon solid empirical foundations. Gaining a better empirical understanding of the IIT tool (and variations), the contexts in which they are implemented, and by whom they are used (and why), will help us to better assess and modify (if necessary) the IIT as a tool of corrections. From this knowledge we may tailor, and better link IITs to inmate needs, institutional needs and conditions and externally derived crime control mandates.

Ultimately, it is reasonable to conclude that through this (and continued) research on IITs, we might increase our ability to tailor interstate inmate transfer policies in such a way that unwanted outcomes (e.g., prison riots and increased offender alienation from family and community support systems) may be avoided in 
the future and desired outcomes become both predictable and achievable. For example, although the decision to use bed rentals by the DOC may be inevitable (See: Chapter VI) perhaps it is best to leave the choice of the individual inmates to be transferred to those who know their inmates best: prison wardens. Although it would be a mistake to adhere too rigidly to a prescriptive policy proposal at this stage of research, it seems likely that prison wardens would be more selective of the inmates they choose for an IIT than the DOC. Thus, inmates, individual prison institutions and the community (generally) might be less likely to suffer the consequences of IITs based on aggregate (as opposed to individualistic) criteria. By leaving the choice of the individual inmates to be transferred, for example, in a bed rental arrangement to the warden, we may be able to avoid aggregate-based, DOClevel choices that do not accurately reflect the needs of specific prisons, inmates or the community more generally. In sum, aggregate-based IIT transfer decisions may only continue to feed criticisms of the IIT tool and lead to unwanted policy outcomes.

\section{Value of Study to Correctional Practice}

\section{Correctional Environment}

There is a plethora of general, specific and anecdotal literature available regarding correctional environments and their influence on decision-making by prison wardens. However, there is no comprehensive or theory-driven research on the impact of a correctional environment in relation to a warden's use of IITs or how these environments influence the administrative intent of IITs. Drawing from the 
interview data collected here, this study intended to develop a more sophisticated understanding of the situational influence that a warden's correctional environment may have on their decision making, in relation to IITs, than is currently available.

In future research, institutional theory (discussed below) may be used to better categorize and map the [variable] relationship between situational and dispositional factors and their effect on discretionary decision-making in correctional management (at all levels). This will enhance understanding of the complexity of the corrections profession and give policymakers and the public generally, a more sophisticated understanding of the factors which impact the functionality of their correctional institutions. From this, and follow up research, it is possible to imagine the creation and implementation of crime control policy, facilitated by the use of IITs, which better consider and link the needs of inmates, public crime control mandates and the limitations of state correctional systems. Some of the more practical consequences of these studies are suggested in the following sections.

\section{Interstate Inmate Transfers}

Problematically, and in the relative absence of descriptive and theory-driven research on interstate inmate transfers, the vacuum has been filled, for the most part, with anecdotal "horror stories" of inmate transfers. Unfortunately, these stories fail to offer an accurate technical, legal, or an even vaguely clear description of how and why these transfers take place. The focus of these stories tends to be on the absurd and catastrophic experiences of a few transferred inmates, which, while not unimportant, have the potential to distort our understanding of the practice. This 
research intended to provide a much more thorough descriptive and nuanced understanding of interstate inmate transfers and the correctional managers who use them than currently exists. In doing so, this study provided a comprehensive historical, legal and legislative description (and some discussion of legislative variability) of interstate inmate transfers.

By adding clarity to our understanding of interstate inmate transfers, this study hoped to diffuse some of the more polemical and distorted descriptions of administrative intent in the hope that we can proceed with more caution in our understanding of the various forms that these transfers actually take and variation in the ends they are intended to achieve. From this research, correctional managers, policymakers, researchers, and the general public may gain additional insights on interstate inmate transfers and on their potential benefits and limitations as correctional management tools.

\section{Correctional Management}

A prison warden's personal beliefs, experience, knowledge and other attributes are widely believed to influence their decision making. Understanding variations in these beliefs and attributes is important. DiIulio (1987, p.6) writes, "[...] different ideas give rise to different practices, and different practices give rise to different outcomes." However, the terminology used to describe the beliefs and attributes of correctional managers can be confusing. Often, the literature utilizes interchangeable terms such as style, beliefs, attitudes, philosophy, and other concepts to indicate a general philosophical outlook toward their task - an outlook which 
influences the action they take. Unfortunately, where correctional management is discussed at all—and where it is discussed in terms of its relationship to management philosophy and the impact of management philosophy on decisionmaking - there is a lack of clarity and consensus. Simply stated, where there is clarity in the literature, the concept is oversimplified (e.g., DiIulio, 1995) and where its description is rich and complex, there is little clarity (e.g., Duffee, 1980).

Fortunately, there is some common ground in the literature. Without oversimplifying, this study attempted to add more clarity to the concept of "correctional management philosophy" through a synthesis of the literature on the topic. By integrating the sometimes contradictory or overlapping literature on correctional management philosophies, this study hoped to offer more clarity on the normative drivers which influence decision making. This understanding will make the concept easier to measure and will allow practitioners, researchers, policymakers and the general public to better understand the relationship between correctional managers and their institutional environment. This understanding may, in turn, be utilized as a way to evaluate a manager's suitability for a particular correctional environment and/or be utilized as a way, in some cases, to assess the administrative intent of IITs. ${ }^{28}$

${ }^{28}$ For example, upon the passage of a highly punitive law in the state studied here-a sentencing law seen as representing a "punitive swing" in public attitudes-a number of correctional managers resigned from the department of corrections due to differences in philosophical attitudes towards the purpose of prisons. A former commissioner/director of the DOC, who resigned, argues that rehabilitative minded managers will have a hard time during this punitive phase in corrections. 
Additionally, the concept "administrative intent" was developed during the course of this research. It is a concept that is not found explicitly in the literature on public administration or correctional management. However, its existence is implied throughout the literature. This study felt that it was an important concept because it conceptualizes intended outcomes rather than actual outcomes, which is often confused in the corrections literature. In the real world, this may lead to a number of "blame games," and even career termination when undesirable outcomes occur (e.g., prison riots in response to IITs). The specious linkage between what we see (actual outcomes) and an immediate conclusion about administrative intent merely "shortcuts" the hard work necessary to discover what actually occurred that led to a particular outcome. The real question is: "What was the intended outcome and why did that not occur?" By helping to operationalize the concept of "administrative intent," this study hope to contribute to a more nuanced and sophisticated understanding of correctional outcomes.

\section{Public Policy}

David Duffee (1986) and John Dilulio (1987) argue that developing a "policy-oriented knowledge" about prisons is important to our ability to intentionally affect desired outcomes and avoid undesired outcomes. From Dilulio's perspective, policy-oriented knowledge about prisons is derived from research that focuses primarily on those who implement policy within the prison environment (e.g., wardens, administrators, correctional employees) and that attempts to understand the context in which desired and undesired penal outcomes occur (Dilulio, 1987, p.12). 
From this knowledge, argues Dilulio (p.12), we can better assess whether and how correctional policy should be altered. As opposed to implementing generalized reform policy based upon good intentions and deeply held assumptions regarding “good" prison policy (See also: Rothman, 1980/2002), correctional policy research must begin to be both: 1) focused on those who actually implement policy within the prison; and 2) be based upon solid empirical foundations.

This research intended to contribute to the refinement and further development of IITs as a tool of corrections and as public policy generally. Gaining a better empirical understanding of the IIT tool (and variations), the contexts in which they are implemented, and by whom they are used (and why), will help us to better assess and modify (if necessary) the IIT as a tool of corrections. From this knowledge we may tailor, and better link, IITs to inmate needs, institutional conditions and externally derived crime control mandates. Ultimately, it seems reasonable to conclude that through this (and continued) research on IITs, we might increase our ability to tailor interstate inmate transfer policies in such a way that unwanted outcomes (e.g., riots) may be avoided in the future and desired outcomes become both predictable and achievable.

\section{Value of Study to Corrections Theory}

This study emphasizes the fact that there is no theory-driven (and thus predictive or falsifiable) research on interstate inmate transfers. Thus, any claim that has been made about the practice has not been backed-up by systematic, theorydriven research. Rather, claims made about interstate inmate transfers are, and have 
been, assertions of "fact" based upon anecdotal evidence or normative beliefs and assumptions about the practice. From a policy perspective, this should be of concern to all of us. In light of the multiple interstate transfer possibilities that include the movement of thousands of inmates to a variety of cross-national locations_-and the possible risks and benefits associated with such transfersgaining a theory and data-driven understanding of interstate inmate transfers would seem to make sense. This study has taken a first step towards that end.

The application of theory toward understanding the administrative intent of IITs is important. In this way theory development - through repeated hypothesis testing - is encouraged and a more accurate picture of the phenomenon will emerge. This study contributes to this process in four ways. First, this study is interested in developing a general theoretical and methodological framework which may be applied to a variety of discretionary decision-making problems in correctional governance.

Second, this study is concerned with evaluating the new penology as an explanatory framework, especially as it relates to understanding the administrative intent of IITs. This has not been done previously. Doing so will enhance our understanding of the power of the new penology framework in explaining the use of IITs and point out areas in which the new penology is both explanatory and where it falls short. Similarly, the data gathered during this study may be used later to develop a more comprehensive mixed methods study which will further our knowledge of the IIT phenomenon and contribute to the theory-building process 
through the refinement and testing of hypotheses. The hope embedded in this study, and in this line of research generally, is that an increasingly sophisticated body of theoretical knowledge in relation to the IIT will enhance its use as a policy tool of corrections administrators - much the same way theory and theory testing has enhanced other areas of correctional policy (e.g., reentry programs).

Finally, although this study does not directly test institutional theory, it has used the framework informally as a way to conceptually organize a prison warden's institutional environment. Institutional theory may be especially useful in the future in that it provides a framework for understanding the many situational and dispositional factors which may influence the administrative intent of IITs. In the following subsection, this study hopes to illustrate the potential usefulness of the institutional framework for the field of correctional management and suggests that subsequent studies include hypotheses drawn directly from institutional theory and tested in the correctional context. The following discussion is utilized here to highlight the potential usefulness of institutional theory in our understanding of IITs.

\section{Viewing the Results through the Lens of Institutional Theory}

Selznick (p.233) writes, "A 'pure' organization is a special-purpose tool, a rational instrument engineered to do a job, a lean, no-nonsense system of consciously coordinated activities." Although some would like to view prisons as such organizations, this is simply not the case. As discussed earlier, the underlying assumptions of this research require that we view correctional managers and agencies as something more than purely self-serving and instrumentally-inclined 
(Selznick, 1992; Scott, 2008). Rather, this study views correctional agencies as institutionalized organizations - organizations (and the individuals that preside over them) that, over time, have become increasingly concerned (or "intimately connected"; Selznick, p.232) with both the realization of their own goals as well as the realization (or perception that they are being realized, Duffee, $1980 \& 1986$ ) of value-laden goals derived, mostly, from external sources.

"A major contribution of the institutional [theory] school," writes Charles Perrow (1986, p.166), [is its] emphasis on the [institutional] environment." Hall \& Fagen (1956, in Scott [1987], p.119) define an environment "for a given system" as being:

$[\ldots]$ the set of all objects a change in whose attributes affect the system and also those objects whose attributes are changed by the behavior of the system. [...] a system together with its environment makes up the universe of all things of interest in a given context.

Institutions and the institutionalizing process are important elements of institutional theory (Scott, 1995; DiMaggio \& Powell, 1983; Zucker, 1987). Richard Scott (1995) identifies the "three pillars" of legitimacy on which institutions rest.

"Institutions," he writes (p.33), consist of cognitive, normative, and regulative structures and activities that provide stability and meaning to social behavior. Institutions are transported by various carriers - cultures, structures, and routines - and they operate at multiple levels of jurisdiction. 
Each pillar of institutional legitimacy has been the focus of organizational study since Durkheim (1895/1965) but the focus on each of the three "pillars" has been weighted unequally (Scott, pp. 34-35).

In studying prisons as institutions, we can link, and perhaps give equal weight to, all three pillars of institutional theory in the sense that each may identify and explain important influential variables related to decision-making by correctional leaders. In other words, we can gain a better understanding of the prison institution by drawing from and integrating multiple institutional perspectives in our identification and organization of dependent and independent variables. In an integrated conception of institutional theory, D'Andrade (184, in Scott, 1995, p.34) writes,

[institutions ore over-determined systems], over-determined in the sense that social sanctions, plus pressure for conformity, plus intrinsic direct reward, plus values, are all likely to act together to give a particular meaning system its directive force.

Scott (1995) has neatly organized and summarized the "history" and basic assumptions of institutional theory and the various academic emphases placed on the three "pillars" of institutional legitimacy: the regulative, the normative, and the cognitive (Table 4). Uniting these three pillars allows us to better integrate a macro, meso and micro understanding of organizational behavior and thus, the context in which administrative intent can be understood. Table 4 illustrates these relationships and has been placed on the following page: 
Table 4

3 Pillars of Institutional Theory

Regulative

Normative

Cognitive

\begin{tabular}{|l|l|l|l|}
\hline \multicolumn{1}{|c|}{$\begin{array}{c}\text { Basis of } \\
\text { Compliance }\end{array}$} & \multicolumn{1}{|c|}{ Expedience } & \multicolumn{1}{|c|}{ Social obligation } \\
\hline Mechanisms & Coercive & Normative & Mimetic \\
\hline Logic & Instrumentality & Appropriateness & Orthodoxy \\
\hline Indicators & $\begin{array}{l}\text { Rules, laws, } \\
\text { sanctions }\end{array}$ & $\begin{array}{l}\text { Certification, } \\
\text { accreditation }\end{array}$ & Prevalence, isomorphism \\
\hline $\begin{array}{l}\text { Basis of } \\
\text { legitimacy }\end{array}$ & Legally sanctioned & Morally governed & $\begin{array}{l}\text { Culturally supported. } \\
\text { Conceptually correct }\end{array}$ \\
\hline
\end{tabular}

Note: Table is an exact replication of W. Richard's Scott's (1995) synthesis in Institutions and Organizations, Newbury Park: Sage Publications.

Institutional theory also assumes dynamic variation in the institutional environment of any given organization - environments, for example, that may cause one or more pillars to have a disproportionate impact on administrative intent. Explaining the results of this research through the lens of institutional theory may help to explain variation (or a lack of variation) in the administrative intent of IITs.

The Table 5, depicted on the following page, outlines the essential elements of institutional theory and its possible application to IITs in the correctional environment. 
Table 5

Institutionalizing Forces and IITs

\begin{tabular}{|c|c|}
\hline \multicolumn{2}{|c|}{ Institutionalizing Forces \& IITs } \\
\hline $\begin{array}{l}\text { Institutional Theory: Types of } \\
\text { Institutionalizing Influences }\end{array}$ & Definitions \& Examples \\
\hline $\begin{array}{l}\text { Pillar One: Regulative } \\
\text { institutional isomorphism: Coercive }\end{array}$ & $\begin{array}{l}\text { Any reference to the influence of } \\
\text { "rule systems and enforcement mechanisms } \\
\text { (Scott, 2002, p.35)" on administrative intent. } \\
\text { ICCs, for example, are a regulative force. } \\
\text { Additionally, the potential for court } \\
\text { intervention is a regulative and coercive } \\
\text { force. To use another example, a prison } \\
\text { warden may state that they do not use "bed } \\
\text { rental" transfers because state law prohibits } \\
\text { it. } \\
\text { Any reference to political or other } \\
\text { inter-organizational pressure to conform, at } \\
\text { the risk of facing some formal or informal } \\
\text { organizational sanction. }\end{array}$ \\
\hline $\begin{array}{l}\text { Pillar Two: Normative } \\
\text { institutional isomorphism: Normative }\end{array}$ & $\begin{array}{l}\text { Any reference to the influence of } \\
\text { culture, values and norms on administrative } \\
\text { intent. For example, normative beliefs about } \\
\text { the riskiness of media intervention clearly } \\
\text { influence the use of IITs in "high-profile" } \\
\text { cases. } \\
\text { Any reference to the influence of } \\
\text { "professionalism" or professionalizing forces } \\
\text { (e.g., professional organizations, education } \\
\text { requirements, certification, \& etc.). }\end{array}$ \\
\hline $\begin{array}{l}\text { Pillar Three: Cognitive } \\
\text { institutional isomorphism: Mimetic }\end{array}$ & $\begin{array}{l}\text { Any reference to the influence of } \\
\text { respondent's previous personal experiences, } \\
\text { previous perceptions, and correctional } \\
\text { management philosophy in relation to their } \\
\text { current context. } \\
\quad \text { Any actual or implied reference to } \\
\text { the influence of the interaction between } \\
\text { previously held beliefs \& experiences and } \\
\text { current context in relation to the } \\
\text { administrative intent of IITs. } \\
\quad \text { Any reference to the influence of } \\
\text { the behavior of other prisons in relation to } \\
\text { IIT. For example, a warden may state that } \\
\text { they use IITs because other prisons have } \\
\text { used them successfully to relieve } \\
\text { overcrowding or deal with high-profile or } \\
\text { otherwise problematic inmates. }\end{array}$ \\
\hline
\end{tabular}


In discussing the statements made by respondents in this study, institutional theory may offer some additional insights. Drawing from the table above, explanations for consistency and variation between cases could be enhanced through the application of institutional-based explanations rather than through the new penology framework. For example, the use of group transfers to "bed rental" locations in other states may not be evidence so much of an emerging new penology but rather, evidence of influential normative and mimetic institutional forces.

Another example of institutional theory is its ability to shed light on the regulative forces that may influence the administrative intent of an IIT. In one example drawn from the findings in this research, because the state (in this case) has a binding agreement with other states to "exchange" similar inmate types on a onefor-one basis (i.e., the ICC agreement), the DOC is bound to send an inmate out-ofstate - whether any inmates want, or need, to transfer out-of-state. Simply, from the perspective of the state DOC, to do otherwise would result (at least) in a "balance owing" (i.e., in the form of taxpayer money) to the other state.

Additionally, in ICC cases, typically, inmates have to be non-violent and well-behaved. To unexpectedly send an inmate with more volatile attributes may invoke both an informal act of retribution (i.e., returning a similarly violent inmate to the sending state) and formal sanctions (i.e., in relation to the violation of the ICC agreement) (Name withheld, personal communication, 2005). Thus, a number of coercive institutionalizing forces - enforced though formal and informal sanctions might help to explain why and how a warden (or the DOC) may use an IIT. 
Over time, however, coercive institutionalizing forces may interact with and change correctional manager's beliefs (the cognitive pillar) about IITs. In the cases discussed here, for example, the mass media and the creation of a "highprofile" inmate category have had an influence on the way wardens and DOC officials uniformly perceive the media and its effect on their institutions. Simply, the media have become an informally coercive institutionalizing force in the sense that at least in the case of the manager's interviewed here-its influence has led to the belief that the best way to avoid media "punishment" (safety and security risks, distorted coverage of correctional behavior, \& etc.) is to transfer an inmate out-ofstate.

\section{Concluding Statement}

This study was intended simply to provide an introductory understanding of the role that discretion plays in prison administration, and the normative drivers that influence discretion. This is an important first step in understanding variations in the administrative intent of IITs. From the results of this research, a general (and anecdotal) sense of why interstate inmate transfers are used by correctional managers has been developed. Importantly, a rare look inside the decision-making lives of individual prison wardens has been documented and contrasted with the assumptions of critical criminologists. Based upon the emergent narrative themes discovered here (e.g., empathic pragmatism, fairness, offender transformation and reentry, to name a few), it seems clear that the new penology may not be the best lens though which to view IITs. 
That being said, we still cannot generalize about the administrative intent of all IITs and we still do not fully understand how or why inmates are chosen for transfer in most cases. These are important topics that will be explored in future research. From the "guideposts" developed in this research, it is anticipated that future research will utilize a more explanatory theoretical framework and develop testable hypotheses and generalizable data more conducive to policy development. 


\section{REFERENCES}

Adams, G.B. \& Balfour, D.L. (1998). Unmasking administrative evil. London: Sage Publications.

Agamben, G. (1998). Homo sacer: Sovereign power and bare life (D. HellerRoazen, Trans.). Stanford: Stanford University Press.

Agamben, G. (2003). Stato di eccezione. Torino: Bollati Borighieri.

Angelos, C. \& Jacobs, J.B. (1995). Prison overcrowding and the law. Annals of the American Academy of Political and Social Science, 478, 100-112.

Associated Press. (2007, April 25). Riot halts transfer of Arizona inmates: Plans suspended after 'full-scale' riot at facility run by private company. The Associated Press. Retrieved August 30, 2007, from http://www.msnbc.com/id/18294136/

Associated Press. (2007, August 13). 2 managers quit private prison in Eloy for Hawaiian convicts. The Arizona Daily Star, p. B5.

Associated Press. (2008, June 4). Court rules California inmate transfers legal. CBS 5 CrimeWatch. Retrieved June 5, 2008, from http://cbs5.com/local/california.inmate.transfers.2.740593.html Arendt, H. (1963/1992). Eichmann and the holocaust. New York: Penguin Books. Arendt, H. (1964). Eichman in Jerusalem: A report on the banality of evil. New York: Penguin Books.

Argyris, C. (1957). Personality and Organization. New York: Harper and Brothers. 
Associated Press. (2005, June 6). State looks elsewhere for 300 more jail beds

[Electronic Version]. The Oregonian. Retrieved June 9, 2005, from

http://www.oregonlive.com/search/index.ssf?/base/news/111805170279866.xml?

oregonian? $\operatorname{lcg} \&$ coll $=7 \&$ thispage $=3$

Babbie, E. (2007). The practice of social research, $11^{\text {th }}$ Edition. Belmont, CA:

Thomson - Wadsworth.

Bachman, R. \& Schutt, R.K. (2007). The practice of research in criminology and criminal justice. Los Angeles: Sage Publications.

Barak-Glantz, I.L. (1981). Toward a conceptual schema of prison management styles. The Prison Journal, 61(2), 42-60.

Beaumont, G. \& Tocqueville, A. (1833/1979). On the penitentiary system in the

United States and its application in France. Carbondale, Ill.: Southern Illinois University Press.

Bell, M.T. (2004, Fall). Interstate compacts: Obstacles and support. Spectrum: The Journal of State Government,77(4), 12-15.

Bennett, K.J., \& Johnson, W.W. (2000). African American warders: Managerial perspectives and attitudes. Corrections Management Quarterly, 4, 52-63.

Bennis, W. (1967/1992). Organizations of the future. In J.M Shafritz \& A.C. Hyde (Eds.), Classics of Public Administration, pp.284-296).

Bleichmar, J. (1999, Fall). Deportation as punishment: A historical analysis of the British practice of banishment and its impact on modern constitutional law. 
Georgetown Immigration Law Journal, 14, 1-61. Retrieved April 20, 2003, from http://web.lexis-nexis.com

Block, P. (1993). Stewardship: Choosing service over self-interest. San Francisco: Berrett-Koehler Publishers.

Bohm, R.M. (2006, March). "McJustice": On the McDonaldization of criminal justice. Justice Quarterly, 23(1), 127-146.

Bolman, L. G. and Deal, T.E. (1991). Reframing Organizations: Artistry, Choice, and Leadership. San Francisco: Josey-Bass Publishers.

Brown, M.M. (2005, November). Penal transportation in the $21^{\text {st }}$ century:

Consequences of contemporary prison abroad programs. Paper presented at the $57^{\text {th }}$ annual meeting of the American Society of Criminology, Toronto, Ontario, Canada.

Bruner, J. (1990). Acts of meaning. Cambridge: Harvard University Press.

Bui, L. (2002, July 6). Transplanting aloha spirit: Eloy prison aims to make its Hawaiian inmates at home in desert. The Arizona Republic, pp. B1, B6.

Burawoy, M., Burton, A., Ferguson, A.A., Fox, K.J., Gamson, J., Gartrell, N., Hurst, L., Kurzman, C., Salzinger, L., Schiffman, J., and Ui, S., (Eds.). (1991). Ethnography unbound: Power and resistance in the modern metropolis. Berkeley: University of California Press.

California Correctional Peace Officers' Association et al., v. Arnold Schwarzenegger, as Governor, etc. et al., (2008) June 04 CA1/3 C055327. 
Carlson, P.M. (2001). Prison interventions: Evolving strategies to control security threat groups. Corrections Management Quarterly, 5(1), 10-22.

Carlson, P.M. \& Garrett, J.S. (Eds.). (1999). Prison and jail administration: Practice and theory. Gaithersburg, MD: Aspen Publishing.

Cheliotis, L.K. (2006). How iron is the iron cage of new penology? Punishment and Society, 8(3), 313-340.

Clay, J. (2001). Maconochie's experiment. London, England: John Murray (Publishers) Ltd.

Clear, T.R \& Dammer, H.R. (2003). The offender in the community. Belmont, CA: Thomson - Wadsworth.

Clear, T.R., Cole, G.F. \& Reisig, M.D. (2009). American Corrections. Belmont, CA: Thomson - Wadsworth.

Clough, P.T. (1993). On the brink of deconstructing sociology: Critical reading of Dorothy Smith's standpoint epistemology. The Sociological Quarterly, $34(1), 169-182$.

Cohen, S. (1996). Crime and politics: Spot the difference. The British Journal of Sociology, 47(1), 1-21.

Cole, E.P. (1991, June). Preemption doctrine. Maine Townsman, "Legal Notes." Retrieved on April 28, 2003 from http://www.memum.org Conover, T. (2001). Newjack. New York: Random House, Inc. 
Cook, B.J. (1996). Bureaucracy and self-government: Reconsidering the role of public administration in American politics. Baltimore, MD: The Johns Hopkins University Press.

Cooper, P. J. (2000). Public Law and Public Administration ( $3^{\text {rd }}$ ed.). Itasca: F.E. Peacock Publishers, Inc.

Cooper, T.L. (2004). Big questions in administrative ethics: A need for focused collaborative effort. A paper prepared for presentation at the Ethics Forum Section on Ethics of the American Society for Public Administration, March 26-27, 2004 in Portland Oregon.

Crank, J. P. (2003). Imagining justice. Cincinnati: Anderson Publishing.

Crank, J. P. \& Langworthy, R. (1992). An institutional perspective of policing. The Journal of Criminal Law \& Criminology,83(2), 338-363.

Cresswell, J.W. (2003). Research design: Qualitative, quantitative, and mixed methods approaches $\left(2^{\text {nd }}\right.$ ed.). Thousand Oaks, CA: Sage Publications.

Cullen, F.T., Latessa, E.J., Burton, V.S. Jr., Lombardo, L.X. (1993). The correctional orientation of prison wardens: Is the rehabilitative ideal supported? Criminology, 31(1), 69-92.

Cullen, F.T., Latessa, E.J., Kopache, R., Lombardo, L.X., Burton, V.S. Jr. (1993). Prison wardens job satisfaction. The Prison Journal, 73(2), 141-161.

Culp, Richard F. (2005). The rise and stall of prison privatization: An integration of policy analysis perspectives. Criminal Justice Policy Review, 16(4), 412442. 
Davis, K.C. (1971). Discretionary justice: A preliminary inquiry. Chicago: University of Chicago Press.

De Haan, W. (1990). The politics of redress: Crime, punishment and penal abolition. London: UNWIN HYMAN.

De Vault, M.L. \& McCoy, L. (2006). Institutional ethnography: Using interviews to investigate ruling relations. In D. Smith (Ed.), Institutional Ethnography as practice (pp. 15-88). Oxford: Roman \& Littlefield Publishers, Inc.

Denhardt, R.B. (1984). Theories of public organization. Belmont, CA: Brooks/Cole Publishing/Wadsworth, Inc.

Derthick, M. (1990). Agency under stress: The social security administration in American government. Washington, DC: The Brookings Institute.

Dickens, C. (1842/2000). American Notes. Köln, Germany: Könemann.

DiMaggio, P.J. \& Powell, W.W. (1983). The iron cage revisited: Institutional isomorphism and collective rationality in organizational fields. American Sociological Review,48(1), 147-160.

Dilulio, J.J. (1987/1990). Governing prisons: A comparative study of correctional management. New York: Free Press.

DiIulio, J.J. (1989, Mar.-Apr.). Recovering the public management variable:

Lessons from schools, prisons, and armies. Public Administration Review, $49(2), 127-133$. 
DiIulio, J.J. (1991). No escape: The future of American corrections. United States: Basic Books.

Dilulio, J.J. (1998). Well-governed prisons are possible. In G.F. Cole \& M.G.

Gertz (Eds.), The criminal justice system: Politics and policies (pp.448-457).

Belmont, CA: Wadsworth Publishing Company.

Doran, C. (1993). The everyday world as problematic: Ideology and recursion in Dorothy Smith's micro-sociology. Canadian Journal of Sociology, 18(1), 43-63.

Duffee, D. (1980). Explaining criminal justice: Community theory and criminal justice reform. Cambridge: Oelgeschlager, Gunn \& Hain, Publishers, Inc.

Duffee, D. (1980). Correctional management: Change \& control in correctional organizations. Prospect Heights, Ill.: Waveland Press, Inc.

Duffee, D. \& Maguire, E.R. (2007). Criminal justice theory: Explaining the nature and behavior of criminal justice. New York: Routledge.

Durkheim, E. (1895;1965). The rules of sociological method. New York: The Free Press.

Durkheim, E. (1911; 1974). Sociology and philosophy. New York: The Free Press. Dyer, J. (2000). The perpetual prisoner machine: How America profits from crime. Boulder: Westview Press.

Farmer, J.D. (1997, November). Leopards in the temple: Bureaucracy and the limits of the in-between. Administration and Society, 29(5), 507-529. 
Feeley, M. M. \& Rubin, E.L. (2000). Judicial policy making and the modern state: How the courts reformed America's prisons. Cambridge: Cambridge University Press.

Feeley, M. M. and Simon, J. (1992). The new penology: Notes on the emerging strategy of corrections and its implications. Criminology, 30 (4), 449-474.

Flanagan, T.J., Marquart, J.W., \& Adams, K.G., (Eds.). (1998). Incarcerating criminals: Prisons and jails in social and organizational context. Oxford: Oxford University Press.

Foster, B. (2006). Corrections: The fundamentals. Upper Saddle River, NJ: Pearson/Prentice Hall.

Foucault, M. (1977;1995). Discipline and punish: The birth of the prison. New York: Vintage Books.

Foucault, M. (2003). Society must be defended: Lectures at the Collège de France 1975-1976. (M. Bertani, A. Fontana, F. Ewald, \& A.I. Davidson, Eds.; D. Macey, Trans.). New York: Picador. (Original work disseminated 19751976)

Foucault, M. (1978, September-December). Governmentality. Aut Aut,167-168. Foucault, M. (1980). Power/Knowledge: Selected interviews \& other writings 19721977 (C. Gordon, Ed. and C. Gordon, L. Marshall, J. Mepham, \& K. Soper, Trans.). New York: Pantheon Books. (Original work disseminated 19721977). 
Fox, V. (1984). The politics of prison management. The Prison Journal, 64(2), 97-112.

Franzosi, R. (1998). Narrative analysis: Or why (and how) sociologists should be interested in narrative. Annual Review of Sociology, 24, 517-554.

Freeman, R.M. (2000). Popular culture and corrections. Baltimore: American Corrections Association.

Giddens, A. (1990). The Consequences of modernity. Stanford, California: Stanford University Press.

Glaser, D. (1995). Preparing convicts for law-abiding lives: Pioneering penology of Richard A. McGee. New York: State University of New York Press.

Gondles, Jr., J.A. (1999). From Aids to the internet: Correctional realities. Lanham, MD: American Correctional Association.

Goodsell, C.T. (2004). The case for bureaucracy: A public administration polemic. Washington DC: CQ Press.

Grahame, P.R. (1998). Ethnography, institutions, and the problematic of the everyday world. Human Studies, 21, 347-360.

Greene, J.A. (2002). Entrepreneurial Corrections: Incarceration as a business opportunity. In M. Mauer \& M. Chesney-Lind (Eds.), Invisible Punishment: The Collateral Consequences of Mass Imprisonment (pp. 95-114). New York: The New Press. 
Gubrium, J.F., \& Holstein, J.A. (1998). Narrative practice and the coherence of personal stories. The Sociological Quarterly, 39(1), 163-187.

Gubrium, J.F., \& Holstein, J.A. (1999). At the border of narrative and ethnography. Journal of Contemporary Ethnography, 28(5), 561-573.

Hagen, J. (1989, May). Why is there so little criminal justice theory? Neglected macro - and micro - level links between organization and power. Journal of Research in Crime and Delinquency, 26(2), 116-135.

Hart, C.B. (1995). A primer in prison research. Journal of Contemporary Criminal Justice, 11(3), 165-176.

Hassine, V. (2004). Life without parole: Living in prison today. Los Angeles: Roxbury Publishing Company.

Hensley, C. \& Tewksbury, R. (2005). Warden's perceptions of prison sex. The prison Journal, 85(2), 186-197.

Hill, M. \& Hupe, P. (2002). Implementing public policy. Thousand Oaks, CA: Sage Publications.

Hirsch, P. M. (1997). Sociology without social structure: Neoinstitutional theory meets brave new world. The American Journal of Sociology, 102(6), 17021723.

Holstein, J.A.\& Gubrium, J.F. (1995). The active interview. Thousand Oaks: Sage University Press. 
http://www.adultcompact.org/about/history/historical/Compact Preamble.pdf

ICAOS

http://www.adultcompact.org/legal/advisoryopinions/AdvisoryOpinion1-

2005OregonWithRequest.pdf

ICAOS (compact membership issues)

http://www.adultcompact.org/legal/advisoryopinions/MemoSupervisionofMAOffend

$\underline{\text { ers.pdf }}$

ICAOS (compact complications)

http://www.adultcompact.org/legal/advisoryopinions/PAvsORExecDirOp.pdf

ICAOS (history) http://www.adultcompact.org/about/history/default.shtml

Imel, S., Kerka, S., \& Wonacott, M.E. (2002). Qualitative research in adult, career, and career-technical education. East Lansing, MI: National Center for Research onTeacher Learning. (ERIC U.S. Department of Education Contract No.ED99CO0013). Practitioner File, 1-12.

Irwin, J. (1985). Jail: Managing the underclass in American society. Berkeley: University of California Press.

Irwin, J. (2005). The Warehouse prison: Disposal of the new dangerous class. Los Angeles: Roxbury Publishing Company.

Jacobs, J.B. (1977). Stateville: The penitentiary in mass society. Chicago: The University of Chicago Press.

Jacobs, J.B. (1983). New perspectives on prisons and imprisonment. Ithaca, NY: Cornell University Press. 
James, W. (1907; 1960). Pragmatism. New York: Meridian Books, Inc.

Jamieson, K.H. (2006). The interplay of influence: News, advertising, politics, and the internet. Belmont, CA: Thomson - Wadsworth.

Jones, T. \& Newburn, T. (2005). Comparative criminal justice policy-making in the United States and the United Kingdom: The case of private prisons. British Journal of Criminology, 45(1), 58-80.

Kaufman, G. (1985). The national prison overcrowding project: Policy analysis and politics, a new approach. Annals of the American Academy of Political and Social Science, 478, 161-172.

Kautt, P.M. and C.C. Spohn. (2007). Assessing blameworthiness and assigning punishment: Theoretical perspectives on judicial decision-making. Chapter 7 in Duffee, et al. Criminal Justice Theory: Explaining the Nature and Behavior of Criminal Justice. Wadsworth Press: Contemporary Issues in Criminal Justice.

Kerle, K. (1999). Jails as long-term facilities. In Carlson, P.M. \& Garrett, J.S. (Eds.). (1999). Prison and jail administration: Practice and theory (pp. 66-72). Gaithersburg, MD: Aspen Publishing.

Kingdon, J.W. (1995). Agendas, alternatives, and public policies ( $2^{\text {nd }}$ ed.). New York: Longman.

Kouzes, J.M. \& Posner, B.Z. (2003). Credibility: How leaders gain and lose it, why people demand it. San Francisco: Jossey-Bass. 
Labov, W. (in press). Some further steps in narrative analysis. Retrieved May 19, 2008, from http://www.ling.upenn.edu/ wlabov/sfs.html.

Latessa, E.J. \& Holsinger, A.M. (Eds.) (2006). Correctional Contexts: Contemporary and classical readings ( $3^{\text {rd }}$ ed.). Los Angeles: Roxbury Publishing Company.

Lynch, M. (1998). Waste managers? The new penology, crime fighting, and parole age identity. Law and Society Review 32(4), 839-869.

March, J.G. \& Olsen, J.P. (1989). Rediscovering institutions: The organizational basis of politics. New York: The Free Press.

Marcus, G.E. (1982). Ethnographies as texts. Annual Review of Anthropology, 11, 25-69.

Marcus, G.E. (2008). The ends of ethnography: Social/cultural anthropology's signature form of producing knowledge in transition. Cultural Anthropology, 23(1), 1-14.

Mary, P.H. (2001). Penalty and risk-management: Towards an "actuarial" administration of justice in Europe? Deviance et Societe, 25(1), 33-51.

McCorkel, J.A., \& Meyers, K. (2003). What difference does difference make? Position and privilege in the field. Qualitative Sociology, 26(2), 199-231.

McGarrell, E.F. and D.E. Duffee. (forthcoming). Correctional resources and the structure of the institutionalized environment: A cross-sectional study of the states. Chapter 10 in Duffee, et al. Criminal Justice Theory: Explaining the 
Nature and Behavior of Criminal Justice. Wadsworth Press:

Contemporary Issues in Criminal Justice.

McGee, R.A. Warner, G., \& Harlow, N. (1998). The special management inmate. In T.J. Flanagan, J.W. Marquart, \& K.G. Adams (Eds.), Incarcerating criminals: Prisons and jails in social and organizational context (pp. 99106). New York: Oxford University Press.

Mears, D.P. \& Castro, J.L. (2006). Wardens' views on the wisdom of the supermax. Crime and Delinquency, 52(3), 398-431.

Meyer, J.W. and Rowan, B. (1977). Institutionalized organizations: Formal structure as myth and ceremony. American Journal of Sociology,83, 340-363.

Mears, D.P. \& Watson, J. (2006, June). Towards a fair and balanced assessment of supermax prisons. Justice Quarterly,23(2), 230-270.

Menzel, D.C. (1987). An interorganizational approach to policy implementation. Public Administration Quarterly, Spring, 3-16.

Merton, R.K. (1957). Social theory and social structure. The Free Press.

Miller, L. (2000). Taking it to the streets: Reframing crime prevention through race and community. Studies in Law, Politics, and Society, 20, 207-238.

Miller, L. (2001). Looking for Postmodernism in all the Wrong Places: Implementing a New Penology. British Journal of Criminology,41, 168-184. Mills, C.W. (1959). The sociological imagination. New York: Oxford University Press. 
Mizruchi, M.S. \& Fein, L.C. (1999). The social construction of organizational knowledge: A study of the uses of coercive, mimetic, and normative isomorphism. Administrative Science Quarterly, 44(4), 653-683.

Montgomery, A.C., \& Crittenden, K.S. (1977). Improving coding reliability for open-ended questions. The Public Opinion Quarterly, 41(2), 235-243.

Morgan, D.F. (1998). Bureaucracy and the American Constitution: Can the triumph of instrumentalism be reversed? Public Administration Review. 58 (September/October, 1998) 5: 453-463.

Morgan, D. F. (1994). What middle managers do in public organizations:

Stewardship of the public trust and the limits of reinventing government. Retrieved November 6, 2001, from http://www.eli.pdx.edu/Morgan/MAN1.html

Morgan, D. F. (2002). Public administrator as constitutional balance wheel. Resources. Retrieved July 27, 2002, from Portland state University, Executive Leadership Institute Web site: http://www.eli.pdx.edu

Morris, C. (1970). The pragmatic movement in American philosophy. New York: George Braziller, Inc.

Morris, N. (2002). Maconochie's gentlemen: The story of Norfolk Island and the roots of modern prison reform. Oxford: Oxford University Press.

Morris, N., \& Rothman, D.J. (1995). The Oxford history of the prison: The practice of punishment in western society. Oxford: Oxford University Press. 
Morse, J. (1998). What's wrong with random selection? Qualitative Health Research, 8(6), 733-735.

Mountjoy, J. \& Bell, M. (2005). Interstate compacts: Trends and issues. The Book of the States. Retrieved on September 12, 2006 from: http://csgweb.csg.org/pubs/Documents/BOS2005-InterstateCompactsTrends.pdf

Murphy, T. (2007, April 25). 27 Arizona inmates charged in indiana prison riot. The Associated Press. Retrieved August 30, 2007, from http://news.aol.com

Nicholson-Crotty, S. \& Meier, K.J. (2003, June). Crime and punishment: The politics of federal criminal justice sanctions. Political Science Research Quarterly, 56(2), 119-126.

Nosow, S. \& Form, W.H. (Eds.). (1962). Man, work, and society. New York: Basic Books, Inc.

Olim v. Wakinekona, 461 U.S. 238 (1983)

O'Neill, J. (Ed.). (1996). Hegel's dialectic of desire and recognition: Texts and commentary. Albany: State University of New York Press.

Oregon Department of Corrections (Interstate Corrections Compacts). (n.d.). Retrieved May 26, 2008, from http://egov.oregon.gov/DOC/TRANS/CC/interstate_compact.shtml

Oregon Department of Corrections. (2008, May). Homepage. http://www.oregon.gov/DOC/index.shtml 
Ostrom, V. (1974). The intellectual crisis in American public administration.

$$
\text { University: University of Alabama Press. }
$$

Owen, S.S. (2006). Occupational stress among correctional supervisors. The Prison Journal, 86(2), 164-181.

Penchoff, J. (2005, August). Compacts are contracts. State News: The council of state governments, 48(7), 22-23 \& 36.

Perrow, C. (1986). Complex Organizations: A Critical Essay ( $3^{\text {rd }}$ ed.). New York, et al.: McGraw Hill, Inc.

Perrow, C. (2000). An organizational analysis of organizational theory. Contemporary Sociology, 29(3), 469-476.

Petersilia, J. (2003). When prisoners come home: Parole and reentry. New York: Oxford University Press.

Pew Center on the States. (2008). One in 100: Behind bars in America 2008 (Public Safety Performance Project Report), Washington DC: The Pew Charitable Trusts.

Pfeffer, J. (1992). Managing with power: Politics and influence in organizations. Boston: Harvard Business School Press, 1992.

Phillips, R.L. \& McConnell, C.R (2005). The effective corrections manager: Correctional supervision for the future $\left(2^{\text {nd }}\right.$ ed.). Boston: Jones and Bartlett Publishers.

Poe, M. (2006, September). The Hive. The Atlantic Monthly, 86-94. 
Pollock, J.M. (2004). Prisons and prison life: Costs and consequences. Los Angeles: Roxbury Publishing Company.

Pratt, J. (2005). Punishment and Civilization. London: Sage Publications.

Private Corrections Institute. (2007, August 31). New Castle Correctional Facility. Retrieved August 31, 2007, from http://www.privateci.org/indiana.htm Rafter, N. (2006). Shots in the Mirror: Crime Films and Society. Oxford: Oxford University Press.

Renauer, B.C. (2002). Understanding variety in urban community policing: An institutional theory approach. Unpublished manuscript, Portland State University.

Renauer, B.C. (2003, March). Institutional theory perspectives on the implementation of two community crime prevention programs in Oregon. Paper presented at the annual meeting of the Academy of Criminal Justice Sciences, Boston, MA.

Riveland, C. (1999). Prison management trends, 1975-2025. Crime and Justice, 26, 163-203.

Rohr, J.A. (1989). Ethics for bureaucrats: An essay on law and values ( $2^{\text {nd }}$ ed.). New York: Marcel Dekker, Inc.

Roosevelt, T. (1913). The new penology. Annals of American Academy of Political and Social Science, 46, 4-7. 
Rothman, David J. (1980). Conscience and convenience. Boston/Toronto:

Little, Brown \& Company.

Sarabi, B. \& Bender, E. (2000, November). The prison payoff: The role of politics and private prisons in the incarceration boom. Portland, OR: Western Prison Project - Western States Center.

Schein, E. H. (1992). Organizational culture and leadership ( $2^{\text {nd }}$ edition). San Francisco: Jossey-Bass.

Scheingold, S.A. (1991). The politics of street crime: Criminal process and cultural obsession. Philadelphia: Temple University Press.

Scheingold, S.A. (1995). Politics, public policy and street crime. The Annals of the American Academy of Political and Social Science, 539, 155-168.

Schumaker, P. (2008). From ideologies to public philosophies: An introduction to political theory. Malden, MA: Blackwell Publishing.

Scott, R.W. (1981/1987). Organizations: Rational, natural, and open systems. Englewood Cliffs, N.J.: Prentice Hall.

Scott, R.W. (1995). Institutions and Organizations. Thousand Oaks: Sage Publications.

Seddon, R. (2005). Philosophy as an approach to the spirit: An introduction to the fundamental works of Rudolph Steiner. Forest Row, UK: Temple Lodge Publishing. 
Seiter, R.P. (2002). Correctional administration: Integrating theory and practice. Upper Saddle River: Prentice Hall.

Selznick, P. (1948). Foundations of the theory of organization. American Sociological Review, 13(1), 25-35.

Selznick, P. (1952). The organizational weapon: A study of Bolshevik strategy and tactics. New York: McGraw-Hill Book Company, Inc.

Selznick, P. (1957). Leadership in administration: A sociological interpretation. Evanston, Il: Row, Peterson.

Selznick, P. (1992). The moral commonwealth: Social theory and the promise of community. Berkeley: University of California Press.

Selznick, P. (1996, June). Institutionalism “old" and "new". Administrative Science Quarterly, 41(2), 270-278.

Shichor, D. \& Sechrest, D.K. (2002). Privatization and flexibility: Legal and practical aspects of interjurisdictional transfer of prisoners. The Prison Journal,82(3), 386-407.

Siegel, L.J. \& Senna, J.J. (2005). Introduction to criminal justice $\left(10^{\text {th }}\right.$ ed.). Belmont, CA.: Thomson Wadsworth.

Siegel, L. (2007). Criminology: Theories, Patterns, and Typologies. Belmont, CA: Thomson Wadsworth.

Simon, H.A. (1976). Administrative behavior $\left(3^{\text {rd }}\right.$ ed). New York: The Free Press. 
Simon, J. (1997). Governing through crime. In L. Friedman \& G. Fisher (Eds.), The Crime Conundrum: Essays on Criminal Justice. Boulder, CO: Westview.

Simon, J. (2001). Sacrificing private Ryan: The military model and the new penology. In P.B. Kraska (Ed.), Militarizing the American criminal justice system: Changing roles of the armed forces and the police. Boston: Northeastern University Press.

Sims, B. (2001). Surveying the correctional environment: A review of the literature. Corrections Management Quarterly, 5(2), 1-12.

Singleton, R.A. \& Straits, B.C. (1999). Approaches to social research (3 ${ }^{\text {rd }} \mathrm{ed}$.). New York: \& Oxford: Oxford University Press.

Sköldberg, K. (1994, May). Tales of change: Public administration reform and narrative mode. Organization Science, 5(2), 219-238.

Smith, D. (1987). The everyday world as problematic: A feminist sociology. Boston: Northeastern University Press.

Spierenburg, P. (1995). The body and the state: Early modern Europe. In N. Morris \& D.J. Rothman (Eds.), The Oxford history of the prison: The practice of punishment in western society (pp.44-70). Oxford \& New York: Oxford University Press.

Stojkovic, S. \& Farkas, M.A. (2003). Correctional leadership: A cultural perspective. Belmont, CA: Thomson - Wadsworth. 
Stop Prisoner Rape. (2006). In the shadows: Sexual violence in U.S. detention

facilities. (Alternative NGO Report prepared for the $36^{\text {th }}$ Session of the U.N. Committee Against Torture). Los Angeles, CA: Author.

Sullivan, D.C., \& Tifft, L.L. (1975, July). Court intervention in correction:

Resistance and compliance. Crime and Delinquency, 21(3), 213-222.

Sullivan, L.E. (1990). The prison reform movement: Forlorn hope. Boston: Twayne Publishers.

Surette, R. (2007). Media, crime, and criminal justice: Images, realities, and policies. Belmont, CA: Thomson - Wadsworth.

Sykes, G.M. (1958). The society of captives: A study of a maximum security prison. Princeton: Princeton University Press.

Talvi, S.J.A. (2006, Sep). No room in prison? Ship 'em off. Prison Legal News, 28-29.

The Constitution of the United States of America (1787/1791 [Bill of Rights]; 1984). In F.W. Friendly \& M.J.H. Elliot, The Constitution: That delicate balance (pp. 285-300). New York: Random House.

The Council of State Governments. (n.d.). Interstate compact for adult offender supervision. Retrieved April 17, 2002, from http://www.statesnews.org/clip/policy/isc.htm

Thompson, D. (2007, February 3). Crowding forces California Convicts to be sent out of state. The Arizona Republic, p. A22. 
Thompson, D. (2007, February 20). Judge Rules California inmate transfers are illegal. SFGate.com. Retrieved June 5, 2008, from http://www.sfgate.com/cgi-

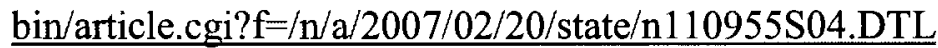

Toch, H. (1977). Living in prison: The ecology of survival. New York: The Free Press.

Toch, H. (1997). Corrections: A humanist approach. Guilderland, N.Y.: Harrow and Heston.

Tonry, M. (2004). Thinking about crime. Oxford: Oxford University Press.

Tyrner-Stastny, G. \& Stastny, C.I. (1977). The changing political culture of a total institution: The case of Walla Walla. The Prison Journal, 57, 43-55.

Ulmer, J.T. \& Kramer, J.H. (1996). Court communities under sentencing guidelines:

Dilemmas of formal rationality and sentencing disparity.

Criminology, 34(3), 383-408.

Ulmer, J.T. (1997). Social worlds of sentencing: Court communities under sentencing guidelines. Albany: State University of New York Press. United States Constitution, Article I, Section 10, Clause 3.

United States Department of Justice, National Institute of Corrections. (2006, February). Interstate transfer of prison inmates in the United States. In D. Biasca (analyst) \& C. Clem (Ed.), Special Issues in Corrections. Retrieved August 8, 2006, from http://www.nicic.org/library/021242. 
Vera Institute of Justice (2006). Confronting confinement: A report of the commission on safety and abuse in America's prisons. Gibbons, J.J. \& Katzenbach, N. de B. (Commission Co-Chairs), Washington DC: Author.

Vinzant, J.C. \& Crothers, L. (1998). Street level leadership: Discretion and legitimacy in front-line public service. Washington D.C.: Georgetown University Press.

Vogel, N. (2007, Feb 3). Thousands of inmates to be sent out of state. LA Times. Retrieved February 3, 2007, from http://www.latimes.com/news/local/la-meprisons 3 feb03,1,5633861.story?coll=la-headlines-california

Warr, M., Meier, R.F., \& Erickson, M.L. (1983, Winter). Norms, theories of punishment and publicly preferred penalties for crimes. The Sociological Quarterly, 24, 75-91.

Weber, M. (1949/1964). Methodology of the social sciences. (E.A. Shills \& H.A. Finch, Trans. \& Eds). New York: The Free Press of Glencoe.

Weber, M. (pre-1914; 1946). Bureaucracy. In H.A. Gerth \& C.W. Mills (Eds. \& Trans.), From Max Weber: Essays in Sociology (pp. 196-244). New York: Oxford University Press.

Welch, M. (2005). Ironies of imprisonment. Thousand Oaks, CA: Sage. Welch, M. \& Turner, F. (2004, June). Globalization in the sphere of penalty: Tracking the expansion of private prisons around the world. Paper presented at the Prisons 2004 conference, Islington, London, England. 
Whyte, W.F. (1993). Revisiting "Street Corner Society." Sociological Forum, $8(2), 285-298$.

Wildavsky, A. (1998). A bias towards federalism. In D. Schleicher \& B. Swedlow (Eds.), Federalism \& political culture (pp. 17-38). New Brunswick, NJ: Transaction Publishers.

Wildavsky, A. (1998). E Pluribus Unum: Plurality, diversity, variety, and modesty.

In D. Schleicher \& B. Swedlow (Eds.), Federalism \& political culture (pp. 116). New Brunswick, NJ: Transaction Publishers.

Williamson, H.E. (1990). The corrections profession. Newbury Park: Sage Publications.

Wilson, J.Q. (1989). Bureaucracy: What government agencies do and why they do it. United States: Basic Books.

Wolcott, H.F. (1990). Writing up qualitative research. Newbury Park, CA: Sage Publications.

Wright, D.S. (2000). Models of national, state, and local relationships. In L.J. O'Toole (Ed.), American Intergovernmental Relations ( $3^{\text {rd }}$ ed., pp74-88). Washington, DC: CQ Press.

Wright, Kai. (2006, March). Prison outbreak: An epidemic of Hepatitis C. The Progressive, 33-36.

Whyte, W. F. (1943). Street corner society. Chicago: University of Chicago Press. Yeoman, B. (2000, May/June). Steel Town Lockdown. Mother Jones, 25(3), 38-47. 
Yin, Robert K. (2003). Case study research: Design and methods. Thousand Oaks, CA: Sage Publications.

Zimbardo, P. (2008). The Lucifer effect: Understanding how good people turn evil. New York: Random House Trade Paperbacks.

Zimring, F.E., Hawkins, G., \& Kamin, S. (2001). Punishment and democracy: Three strikes and your out in California. Oxford: Oxford University Press.

Zucker, L.G. (1987). Institutional theories of organization. Annual Review of Sociology, 13, 443-464.

Zwart, de F. (2002, Nov.). Administrative practice and rational inquiry in postmodern public administration. Administration and Society, 34(5), 482498. 
Appendix A

Table A1. Active Interstate Transfers of U.S. Prison Inmates as of July 1, 2005*

\begin{tabular}{|c|c|}
\hline \multicolumn{2}{|c|}{ Transfers to Other State DOCs } \\
\hline Transfers of men: & 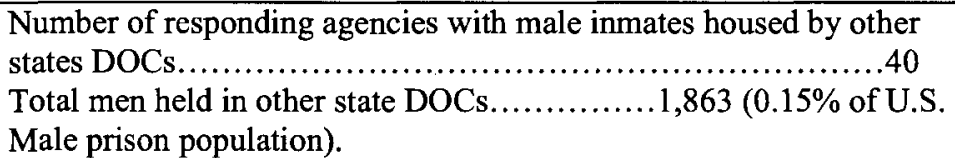 \\
\hline $\begin{array}{l}\text { Transfers of } \\
\text { women: }\end{array}$ & $\begin{array}{l}\text { Number of responding agencies with woman inmates housed by other } \\
\text { states DOCs................................................... } \\
\text { Total men held in other state DOCs } \ldots \ldots \ldots \ldots \ldots 10.11 \% \text { of U.S. } \\
\text { female prison population). }\end{array}$ \\
\hline \multicolumn{2}{|c|}{ Transfers to Federal Bureau of Prisons } \\
\hline Transfers of men: & 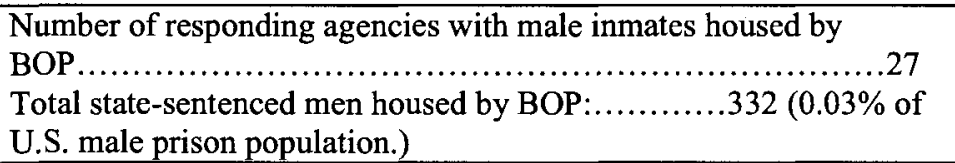 \\
\hline $\begin{array}{l}\text { Transfers of } \\
\text { women: }\end{array}$ & $\begin{array}{l}\text { Number of responding agencies with woman inmates housed by } \\
\text { BOP.............................................................. } \\
\text { Total state-sentenced women housed by BOP } \ldots \ldots \ldots \ldots . . .12(0.01 \% \text { of } \\
\text { U.S. female prison population.) }\end{array}$ \\
\hline \multicolumn{2}{|c|}{ Transfers to Private, Out-Of-State Facilities } \\
\hline Transfers of men: & 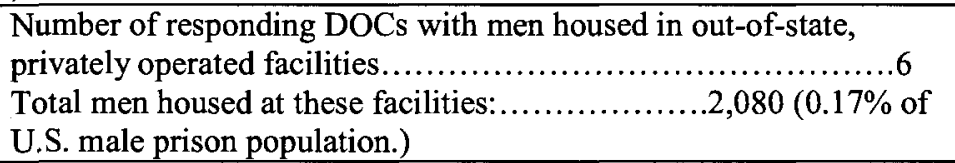 \\
\hline $\begin{array}{l}\text { Transfers of } \\
\text { women: }\end{array}$ & $\begin{array}{l}\text { Number of responding DOCs with women housed in out-of-state, } \\
\text { privately operated facilities......................................... } \\
\text { Total women housed at these facilities:...............386 }(0.42 \% \text { of } \\
\text { U.S. female prison population.) }\end{array}$ \\
\hline & $\begin{array}{l}\text { x. All } 126 \\
\text { BOP." }\end{array}$ \\
\hline
\end{tabular}

* Note. Table format and data adapted from "Interstate Transfer of Prison Inmates in the United States," by D.

Biasca (Ed.), February 2006, Special Issues in Corrections (U.S. Department of Justice and National Institute of Corrections Publication), p.11. Retrieved August 8, 2006, from http://www.nicic.org/librarv/021242. The table utilized here is a recreation of the original table created by Biasca, et al. The data has not been altered. 
Appendix A

\section{Table A2. Active Transfers of U.S. Men and Women Inmates on July 1, 2005, by Receiving Agency*}

\begin{tabular}{|c|c|c|c|c|c|c|}
\hline & \multicolumn{3}{|c|}{ Men Transferred } & \multicolumn{3}{|c|}{ Women Transferred } \\
\hline & $\begin{array}{l}\text { To other } \\
\text { States' } \\
\text { prisons }\end{array}$ & $\begin{array}{c}\text { To the } \\
\text { Federal } \\
\text { Bureau of } \\
\text { Prisons }\end{array}$ & $\begin{array}{l}\text { To private } \\
\text { prisons in } \\
\text { other states }\end{array}$ & $\begin{array}{l}\text { To other } \\
\text { States' } \\
\text { prisons }\end{array}$ & $\begin{array}{c}\text { To the } \\
\text { Federal } \\
\text { Bureau of } \\
\text { Prisons }\end{array}$ & $\begin{array}{l}\text { To private } \\
\text { prisons in } \\
\text { other states }\end{array}$ \\
\hline Alabama & 9 & 0 & 4 & 0 & 0 & 299 \\
\hline Alaska & 4 & 11 & 756 & 2 & 0 & 0 \\
\hline Arizona & 106 & 0 & 0 & 0 & 0 & 0 \\
\hline Arkansas & 32 & 0 & 0 & 22 & 0 & 0 \\
\hline California & 360 & 167 & 0 & 22 & 0 & 0 \\
\hline Colorado & & & & & & 0 \\
\hline Connecticut & 51 & 8 & 0 & 2 & 0 & 0 \\
\hline Delaware & 19 & 0 & 0 & 3 & 0 & 0 \\
\hline Florida & 14 & 0 & 0 & 2 & 0 & 0 \\
\hline Georgia & 0 & 1 & 0 & 0 & 0 & 0 \\
\hline Hawaii & & & & & & 0 \\
\hline Idaho & 14 & 0 & 0 & 1 & 0 & 0 \\
\hline \multicolumn{7}{|l|}{ Illinois } \\
\hline \multicolumn{7}{|l|}{ Indiana } \\
\hline Iowa & 31 & 7 & 0 & 3 & 0 & 0 \\
\hline Kansas & 73 & 1 & 0 & 2 & 0 & 0 \\
\hline Kentucky & 18 & 0 & 0 & 3 & 0 & 0 \\
\hline \multicolumn{7}{|l|}{ Louisiana } \\
\hline Maine & 18 & 22 & 0 & 4 & 2 & 0 \\
\hline Maryland & 2 & 0 & 0 & 0 & 0 & 0 \\
\hline Mass. & 64 & 6 & 0 & 2 & 0 & 0 \\
\hline Michigan & 0 & 27 & 0 & 0 & 1 & 0 \\
\hline Minnesota & 73 & 5 & 0 & 7 & 0 & 0 \\
\hline Mississippi & & & & & & 0 \\
\hline Missouri & 52 & 2 & 0 & 1 & 0 & 0 \\
\hline Montana & 23 & 2 & 0 & 2 & 0 & 0 \\
\hline Nebraska & 25 & 1 & 0 & 3 & 0 & 0 \\
\hline Nevada & 169 & 0 & 0 & 6 & 0 & 0 \\
\hline \multicolumn{7}{|l|}{$\begin{array}{c}\text { New } \\
\text { Hampshire }\end{array}$} \\
\hline New Jersey & 60 & 3 & 0 & 4 & 0 & 0 \\
\hline New Mexico & 81 & 0 & 0 & 0 & 0 & 0 \\
\hline New York & 1 & 2 & 0 & 0 & 0 & 0 \\
\hline \multicolumn{7}{|l|}{ N. Carolina } \\
\hline N. Dakota & 7 & 7 & 57 & 2 & 0 & 0 \\
\hline Ohio & 20 & 11 & 0 & 2 & 0 & 0 \\
\hline Oklahoma & 74 & 1 & 0 & 5 & 0 & 0 \\
\hline Oregon & 62 & 1 & 0 & 2 & 0 & 0 \\
\hline Penn. & 22 & 12 & 0 & 9 & 0 & 0 \\
\hline $\begin{array}{l}\text { Rhode } \\
\text { Island }\end{array}$ & 45 & 5 & 0 & 3 & 0 & 0 \\
\hline S. Carolina & 4 & 0 & 0 & 0 & 0 & 0 \\
\hline S. Dakota & 24 & 0 & 0 & 0 & 0 & 0 \\
\hline Tennessee & 2 & 0 & 0 & 2 & 0 & 0 \\
\hline
\end{tabular}




\begin{tabular}{|c|c|c|c|c|c|c|}
\hline Texas & 10 & 4 & 0 & 0 & 0 & 0 \\
\hline Utah & 36 & 2 & 0 & 0 & 0 & 0 \\
\hline Vermont & 15 & 4 & 373 & 1 & 0 & 0 \\
\hline Virginia & 3 & 0 & 0 & 1 & 0 & 0 \\
\hline Washington & 181 & 6 & 406 & 1 & 0 & 0 \\
\hline W. Virginia & & & & & & \\
\hline Wisconsin & 32 & 12 & 0 & 2 & 0 & 0 \\
\hline Wyoming & 27 & 2 & 484 & 0 & 1 & 87 \\
\hline TOTALS & 1,863 & 332 & 2,080 & 101 & 12 & 386 \\
\hline
\end{tabular}

* Note. Table format and data adapted from "Interstate Transfer of Prison Inmates in the United States," by D.

Biasca (Ed.), February 2006, Special Issues in Corrections (U.S. Department of Justice and National Institute of Corrections Publication), p.11. Retrieved August 8, 2006, from http://www.nicic.org/library/021242. The table utilized here is a recreation of the original table created by Biasca, et al. The data has not been altered 
Appendix B

\section{Oral Interview Schedule Prepared by Robert Swan}

Question 1: Screening Cluster (Purpose: Verify respondent meets screening criteria \& explore criteria in more depth for comparative purposes): 3 Elements of screening - 1) Work or have worked for the DOC; 2) Work or have worked as a Warden or Assistant Warden; 3) Use or used interstate inmate transfers directly AND/OR formally and/or informally referred inmates to another bureau for interstate transfer.

Introduction: "Good [morning, afternoon, evening] [title/name] this is Robert Swan from Portland State University. Is this a good time to speak? Great! As I mentioned before, I am going to record this conversation. Is this still OK with you? OK... I would like to begin this interview by asking you some questions about your position[s] and duties within the [state] Department of Corrections."

\section{Scheduled Question Cluster 1a:}

- Are you currently employed as a full-time, part-time, contract or other type of DOC employee? Yes

No

- Other type of employee:

- "How long have you worked for the DOC?"

- "What is your current title within the DOC?"

- "What other positions have you held within the DOC?"

Probing Themes: Level \& type of management position; name of facility; type/security level of facility.

Possible Probing Questions:

- Have you ever held the position of "Warden" or "Assistant Warden"?

- Which institution[s]?

What is [or was] the type/ level of security of that institution [while you were there]?

\section{Scheduled Questions Cluster 1b:}

"I would like to ask you a few technical questions regarding interstate inmate transfers. During the course of your career with the [state] Department of Corrections, were you authorized to directly implement interstate inmate transfers (IITs) to manage correctional institution[s]?"

If "Yes":

- "In what management positions were you authorized to directly implement IITs?"

- "Did you use IITs?" 
If "No":

- Were you able to formally or informally refer inmates to another DOC department for IIT implementation?

- If "Yes":

- "Did you refer inmates for IITs?"

- Which department were they referred?

- "Can you describe this referral process for me?"

- If "No": "Can you describe how the IIT process works in [state]?"

(Explanatory Statement: There is a great deal of variation between state DOC's and IIT implementation)

CONTINUE INTERVIEW IF RESPONDENT MEETS SCREENING CRITERIA.

THANK RESPONDENT FOR THEIR TIME \& STOP INTERVIEW IF THEY DO NOT MEET SCREENING CRITERIA.

Additional Possible Probing Questions: "Approximately how many times did you use (or refer) inmates interstate inmate transfers?"

- As best as you can recall, when did [state] begin to use IITs?

- As best as you can recall, how many inmates has [state] transferred since

they started using IITs?

"In your estimation, what is [state]'s annual average total of IITs?"

Additional Probing Themes: Use of interstate inmate transfers (i.e., referral to DOC [or other bureau] or direct implementation); Current role in the implementation of IITs.

Lead-in: "Now I would like to ask you a few additional questions about the legal and technical aspects of interstate inmate transfers.

\section{Possible Probing Questions:}

- Direct Implementation or referral: [If so] "By what legal or administrative authority are IITs authorized, as far as you know [for referral or direct implementation]?"

- Do you feel that these (rules/laws) are [were] stressful to you as a correctional manager? (Probe if necessary: Clear up legal and administrative authority allowing IIT referrals or direct implementation.)

o

If "Yes": "How so?"

Scheduled Question 2 (Purpose: Understanding the influence of "Correctional Management Philosophy" on "administrative intent".

Lead in: "Now I would like to ask you some questions regarding your beliefs about incarceration and correctional management."

Scheduled Question 2a: "In your opinion, what is the purpose of incarceration?" 
Probing Themes: Explore development of individuals personal \& role beliefs; Explore respondent's emphasis on individualistic or aggregate management of inmates.

\section{Possible Probing Question:}

- Can you describe how this [these] belief[s] develop[ed]?

- Do you [or did you] attempt to achieve [stated purpose of incarceration] within the institution[s] you managed?

If Yes: How do you do that?

If No: How come?

- In accomplishing [stated purpose of incarceration], how would you characterize the proportion of time you spend [spent] focused on individual inmates in comparison to the time spent managing inmate populations as a whole?

$\circ \quad$ If respondent managed multiple institutions: Does [did] this ratio vary depending upon the particular institution?

- If Yes: Why is that?

\section{Scheduled Question 2b:}

"I would like to discuss your position as Warden a bit more. Can you describe your [previous] role as a Warden (or Assistant Warden) within the DOC?"

+ Discuss variations in this role?

"Generally speaking, how would you characterize your management style?"

Probing Themes: Exploring respondent's correctional management style \& beliefs in depth; Exploring respondent's implementation of correctional management style \& beliefs, Exploring variability in respondent's correctional management style \& beliefs.

- Probe: What type of manager are you? For example, are you a strict authoritarian and "hands on" (e.g., George Beto) manager, Rule and management oriented, delegation of tasks to subordinates, a Consensual model manager (participatory \& cooperative); a "big picture" or aggregate manager.

- Probe: How do you think your employees would characterize your management style?

- Probe: How do you think inmates would characterize your management style?

- Are [were] you able to successfully implement your management style as a Warden/Assistant Warden?

If no: Why is that?

- Did your management style as a Warden - and beliefs about good correctional management generally - vary or remain relatively stable?

$\circ \quad$ [If variable]: Can you explain why it varies?

Scheduled Question 3 (Purpose: Understanding the influence of "Institutional Environment" on "administrative intent."

Lead-in: "Now I would like to ask you some questions related to the operational environment of correctional facilities." 
Question 3a: "Generally speaking, how would you characterize the operational environment of your institution [while you were Warden]?

\section{VERY STRESSFUL SOMEWHAT STRESSFUL NOT AT ALL STRESSFUL}

Question 3b: If respondent answers "Very" or "Somewhat" stressful:

"If you don't mind, I would like to explore the source of this stress a little further. I will read from a short list of possible stressors and you may answer simply in yes or no terms... or you may elaborate on each item as you see fit. Which of the following factors do you feel are causes of stress?"

1. Prison Crowding

2. Organizational interactions or relationships. [PROBE: By this I mean interactions and relationships within the institution itself and interactions and relationships between the institution and other departments within the $\mathrm{DOC}$ and/or other organizations external to both the institution and the DOC]

3. Negative media coverage, negative public opinion

4. Restrictive or overly punitive laws; or court interventions of any kind

5. Increasing number of problematic inmates (illness, violence, \& etc.)

6. Rules, laws or procedures of any kind

7. Other factors?

Can you discuss other factors which have (or do) affect your decision-making but aren't necessarily stressful?

Other factors?

Possible Probe: Would you characterize any of these factors as "stressful?"

Lead-in: "I would like to go into additional detail regarding the stressful elements in your operational environment."

Possible Probing Questions:

- "Why is [the factor] stressful?" Or "Why are these factors stressful?"

Scheduled Question 4 (Purpose: Understanding the interaction between "Institutional Environment" and "management philosophy."

Lead-in: "Now I would like to ask you some additional questions regarding the influence of these factors on your management style and beliefs about correctional management."

"Do you feel as if any of the factors that we have discussed [have or have had] a significant influence on your management style or beliefs about correctional management?"

Probing Theme: Influence of institutional environment on respondent's correctional management philosophy. 
- If Yes: Which factors were most influential?

- In what way do they [does/did it] impact your management style?

- Did your beliefs about correctional management change due to these factors?

- How so?

- Do they [does/did it] influence your beliefs about incarceration generally?

- How so?

- If No: How come?

Scheduled Question 5 (Purpose: Develop a more specific and contextual understanding of IIT's; Develop a case-specific understanding of "administrative intent"; verify number of inmates transferred and explore types of inmates chosen for interstate inmate transfers, and why; discover and explore reasons why, and for what purpose, inmates are transferred; understand influences which affect variability in administrative intent (i.e., purpose of transfer) with regard to interstate inmate transfers.)

Lead in: "Now I would like to ask you some additional questions about interstate inmate transfers."

Scheduled Question 5a: "At the beginning of the interview, you stated that you have used (or referred) interstate inmate transfers times over the course of your career. Can you describe some of the factors that influence your decision to use (or refer) IIT's?

Probing Themes: Inmate type: level of security; behavioral record; voluntary and/or requested; special needs, other reasons?

\section{Possible Probing Question:}

- Generally speaking, how would you characterize the inmates you choose [chose] for an interstate transfer?" (referral or direct implementation)

- $\quad$ Do you think your reasons for transferring an inmate were consistent with your beliefs about good management?

- $\quad$ Do (did) any of the previously discussed factors in your operational environment (stressful or not) influence your decision to use (or refer inmates) IIT's?

Lead-in: "[name], I really appreciate your time today and I'm almost to the end of the interview. But I would like to discuss your feelings about the specific purpose of interstate inmate transfers."

Scheduled Question 5b: "Generally speaking, what do [did] you hope to accomplish with an interstate inmate transfer?" (referral or direct implementation)

Probing Themes: Administrative intent; variation in administrative intent. 
- $\quad$ Did this [these] purpose[s] vary?

If Yes [or "sometimes']: Why did they vary?

- Do you feel as if interstate transfers fulfilled their intended purpose?

If No (or "not always"): How come?

- How much influence does [did] your management philosophy have on your use of interstate inmate transfers?

[name], Do you have any final thoughts or feelings you would like to offer regarding your current or former role as a correctional manager, your operational environment or interstate inmate transfers more generally?

Thank you [name] for taking the time to sit with me and discuss your role as Warden.

As we've discussed, your input into this research will be kept confidential. If you like, I can forward a description of my confidentiality protocols. Would like a copy of this document? The information obtained today will be utilized to construct a better understanding of the factors that impact correctional management.... and the role that interstate inmate transfers play in managing [state]'s correctional institutions.

Thank you again for your time. It has been a pleasure speaking with you. 


\section{Portland State University HSRRC Memorandum}

To: Robert Thomas Swan

From: Chair, HSRRC 2008

Date: May 5, 2008 (Note: Robert Swan's Responses included here: May 8, 2008)

Re: Your HSRRC application titled, "Challenging the New Penology: A Case Study Analysis of Correctional Management and Interstate Inmate Transfers in [name withheld]" (HSRRC Proposal \#08509)

In accordance with your request, the Human Subjects Research Review Committee has reviewed your application for compliance with Department of Health and Human Services policies and regulations on the protection of human subjects. The Committee will be satisfied that your provisions for protecting the rights and welfare of all subjects participating in the research are adequate if you prepare a written response to the following:

Records and Distribution

The Committee wonders if, because there are only 4-6 of 12 possible subjects, it might be likely that people familiar with this group of individuals could guess who said what, even with the use of pseudonyms. Please explain if confidentiality is desirable or even possible in this case?

\section{Robert Swan's Response}

Dear Committee,

Thank you very much for your questions. I am sorry that I did not address and/or was not clear about these questions in my application. I will respond to each query below.

Query 1 (cluster): Confidentiality/Records and Distribution:

Many steps can be taken to ensure confidentiality and minimize the possibility that confidential information will be released. In addition to the summary discussion of these steps discussed in my application (Section VIII), I will more thoroughly elaborate on some of these important steps below. However, and based on your 
query, it is important to first discuss the need for an assurance of confidentiality in this research.

The confidentiality of interview data is a significant concern to correctional practitioners generally (See: Freeman, 2000 and relationship of career termination to media portrayals of corrections). Thus, I feel that an offer of confidentiality (with caveat, see: Risks: Informed Consent Letter) should be made. Without an assurance of confidentiality and the implementation of appropriate safeguards, I am not convinced that this research can be conducted. The concern over confidentiality may go a long way in explaining why so little research has been done on this population in the first place - I would even argue that powerful "voices", especially those of prison warden, have now been marginalized due to a fear of career repercussions and because their "voices" are actively avoided by researchers (See: Mears \& Watson's 2006 methodical attempt to avoid "official voices" in their study of Supermax prisons). However, I do believe that confidentiality is possible in this case and will address this issue below.

In terms of identification, you may be correct to assume that, given the small sample and the nature of [name withheld] correctional culture (i.e., insular \& tight-knit), identification of respondents might be a problem if I only sampled from current, active-duty warden. However, and as stated in my application, subject recruitment will be from the ranks of both current and former Warden's and assistant warden subjects who will be either purposively solicited or solicited as a result of "snowball" sampling (See: Subject Recruitment, Section III, p.3). Thus, the actual population being purposively or snowball sampled will be much larger than 12 . Although the total population number is not clear, in theory, the sample will be drawn from every living current and former [name withheld] prison Warden or assistant Warden. Research findings will then be presented as having been derived from interviews with both current and former warden and assistant warden. Turnover in these positions tends to be very high, thus, the likelihood of respondent identification unlikely.

At first glance, "snowball" sampling would also seem to present a dilemma with regard to confidentiality. However, this research has in place a number of safeguards designed to ensure that the identity of individual prison warden or assistant warden cannot be discerned from the publicly accessible data (please also see: HSRRC Application, Section VI \& VIII). They are:

1. I will be the sole possessor of the collected data. Nobody else will have access to it.

2. The purpose of my research is to document a general sense of decisionmaking stressors and influences at the Warden level and broadly discuss these factors in relation to the New Penology framework. Thus, broad academic terms will be used to describe the context of decision-making within [name withheld] prisons. The specifics of individual cases will rarely, if ever, be utilized and if so, they will be 
used cautiously and only if there is no possibility that they will inadvertently breach confidentiality (see remaining discussion below).

3. The information gathered here is strictly for broad, academic purposes and in no way will be utilized for journalistic, creative or other non-academic purposes. Every effort has been made to eliminate questions that provide a level of detail not necessary to the conduct of this research.

4. No respondent (or anyone else for that matter) will have actual knowledge of another respondent's participation. For example, though I may be referred to another subject via snowball sampling, the referring respondent will not know whether or not the referral interview actually took place. Similarly, I will never discuss who has participated in this research with anyone.

5. No dates will be used. This prevents respondents from identifying one another based upon tenure time-frames.

6. No physical descriptions will be utilized. This prevents respondents from identifying one another based upon physical attributes (age, race, gender, \& etc.).

7. Discussions of well-known incidents will either not be discussed or they will be "masked" in a more general discussion of decision-making stressors.

8. There will be no discussion of specific political actors (e.g., Governors, legislators \& etc.) or specific policies (e.g., 3 strikes, Measure 11). Again, this is to ensure that respondent's cannot be identified via tenure time-frames. The case of interstate inmate transfers is the policy exception, and is one focus of this research. However, since IITs have been an [name withheld] correctional tool for roughly 30 years, a respondent's use of this tool (one of the screening criterion) locates them within a very large temporal window and thus, will not contribute to a breach of confidentiality.

9. There will be no discussion of specific institutions so that individuals may not be identified through secondary data (e.g., public records indicating names of management personnel by institution).

10. Respondents will be given the option to review "raw" transcript data from their interview for the purpose of verifying the accuracy of the transcription and to ensure that self-identifying data is identified and masked (or removed if necessary). Thus, inadvertent identification of individual respondents may be avoided through the use of the respondent's own expertise and knowledge regarding the correctional culture in which they are, or have been, situated. 


\section{Robert Swan's Response}

No.

Where will the data be kept? At Home? PSU? Other?

\section{Robert Swan's Response}

Data will be kept at home, under lock and key on a computer (and in hard-copy files) that are under the sole control of Robert Swan.

\section{Informed Consent}

In the consent document, please include the department from which you are getting your degree.

\section{Robert Swan's Response}

I am receiving my degree from the Public Administration and Policy Program (PAP)

In the consent document, please update the address for the HSRRC from Cramer Hall 111 to Unitus Building, $6^{\text {th }}$ Floor.

\section{Robert Swan's Response}

I will attach the Revised Consent document to include the address of the department from which I am receiving my degree.

Upon receipt of your response to the items mentioned above - which should include a copy of all forms, letters, consent documents and other instruments which the Committee requests that you revise, we will resume the processing of your application.

If you have questions or concerns, please contact the HSRRC in the Office of Research and Sponsored Projects (ORSP), (503) 725-4288, Unitus Building, $6^{\text {th }}$ Floor.

\section{Sources Cited:}

Freeman, R.M. (2000). Popular culture and corrections. Lanham, MD: American Correctional Association.

Mears, J.W. \& Watson, J. (2006, June). Towards a fair and balanced assessment of supermax prisons. Justice Quarterly, 23(2), 230-270. 
Appendix D

Follow-up Letter

\section{Portland State \\ UNIVERSITY}

[Name Withheld]

\author{
Criminal Justice Policy Research \\ Institute \\ Division of Criminology and Criminal \\ Justice \\ Mark O. Hatfield School of Criminal \\ Justice \\ Post Office Box 751 \\ Portland, Oregon 97207-0751 \\ CJPRI Director: Brian Renauer, Ph.D. \\ CJPRI Phone: 503-725-8090 \\ CJPRI Fax: 503-725-5162
}

May 30, 2008

Dear [name withheld],

On May $17^{\text {th }}$, a letter of Introduction and Consent was mailed to you regarding casestudy research that I am currently conducting with current and former [name withheld] Department of Corrections (DOC) Wardens and Assistant Wardens. In particular, my research is interested in learning more about the administrative attitudes, beliefs and institutional factors (both internal and external) that affect the interstate transfer of prisoners by [name withheld] correctional managers. I am also very interested in hearing your views on the factors that affect your decision-making processes more generally. Often, "official voices" are intentionally left out of conversations regarding interstate inmate transfers, correctional management and corrections generally. Therefore, this study hopes to contribute to an enhanced public and academic understanding of complex correctional environments and the dynamic and variable factors affecting correctional management by actually speaking directly with correctional managers.

\section{Sampling}

In addition to sampling from a number of former Wardens, all current DOC Wardens have been sampled for this research (a "census" sample). If you have questions about your selection, please contact me at (503) 449-7508/ (503) 725-5221 or via email: swan@pdx.edu.

If you have already signed and returned the consent form, please accept my sincere thanks. Once I receive the consent letter, I will contact you to schedule an interview. If you have not already reviewed the introduction and consent letter mailed on May $17^{\text {th }}$, I have attached another copy for your convenience. I have also attached a copy of this letter on official stationary, for your records. Finally, if you 
have chosen not to participate in this study, please let me know and I will not send any additional notices.

If you choose to participate in this study (and have not done so already), please sign and return your consent form to:

Robert Swan, MS, Doctoral Candidate Division of Criminology and Criminal Justice

Mark O. Hatfield School of Government

PO Box 751-JUST

Portland, OR 97207-0751

Alternatively, you may return the signed forms at the time of the interview if you decide to participate.

Thank you for your time and assistance in this research.

Sincerely,

Robert Swan

Robert Swan, MS, Doctoral Candidate

Division of Criminology and Criminal Justice

Mark O. Hatfield School of Government

PO Box 751-JUST

Portland, OR 97207-0751 
Appendix E

Informed Consent Letter

\section{\& Portland State}

[Name Withheld]
Criminal Justice Policy Research Institute

Division of Criminology and Criminal Justice

Mark O. Hatfield School of Criminal Justice

Post Office Box 751

Portland, [name withheld] 97207-0751

CJPRI Director: Brian Renauer, Ph.D.

CJPRI Phone: 503-725-8090

CJPRI Fax: 503-725-5162

\section{Title of Study: Challenging the New Penology: A Case-Study Analysis of Correctional Management and Interstate Inmate Transfers in [name withheld].}

May 29,2008

Dear [name withheld],

You are invited to participate in a research study conducted by Robert Swan from Portland State University. The researcher hopes to learn more about the administrative attitudes, beliefs and institutional factors (both internal and external) that affect the interstate transfer of prisoners by [name withheld] correctional managers. This research will be the first systematic, case-study research of its kind on the topic of interstate inmate transfers and will enhance both our limited knowledge of interstate inmate transfers and the factors that most affect decisionmaking by correctional managers at the correctional institution level. This research is being conducted in partial fulfillment of the requirements for a doctoral degree and is being conducted under the supervision of Douglas Morgan, Ph.D. (503-7258216), at Portland State University. You were selected as a possible participant in this study because you may meet the following three criteria: 1) You are a current or former [name withheld] Department of Corrections employee; 2) You hold or have held the position of "Warden" or "Assistant Warden"; and 3) You have utilized (or, given the option, chose not to utilize) interstate inmate transfers at some point during your tenure with the ODOC. If you do not meet these three criteria, please inform the researcher at your earliest convenience.

Requirements and Alternatives: This letter will be followed up by an email and a phone call within 10 days. If you decide to participate, you will be asked to answer a series of questions regarding your experiences as a correctional manager and your use (or non-use) of interstate inmate transfers in that capacity. These interviews will 
be conducted in person at a time and place of your choosing (within the state of [name withheld]) and will last for no more than one hour. These interviews may also be conducted over the phone at a time of your choosing. The researcher intends to tape record and later transcribe these interviews. If this is not possible, the researcher will take hand-written notes.

\section{Benefits of Research, Risks \& Safeguards:}

\section{Benefits of Research:}

1. Enhanced public understanding of complex correctional environments and the dynamic and variable factors affecting correctional management.

2. Enhanced understanding of interstate inmate transfers and reasons for implementation.

Risks: You may be asked questions that you feel uncomfortable answering and you may feel inconvenienced by participating in this study. Although multiple safeguards will be put in place to protect confidentiality, while participating in this study there is a risk that the confidentiality of your information may be compromised. This may lead to adverse political or career consequences.

Safequards: You are in no way required to respond to any question you feel uncomfortable answering and every effort will be made by the researcher to accommodate your schedule so that you do not feel inconvenienced. Additionally, every effort will be made by the researcher to keep the sources of all information obtained in connection with this study confidential. This data will be protected in the following ways:

1. Only the principal researcher will have access to the data.

2. Results of this research will never be presented in a way that may compromise the privacy of the respondent.

3. Any reports generated utilizing this data will employ pseudonyms in order to mask the actual names of individuals and/or institutions involved in the study.

4. No public or private discussions will occur regarding individually named respondents and/or their institutions.

5. Upon request, respondent may review the raw transcripts of their interview prior to analysis in order to ensure transcript accuracy and screen transcripts for possible statements that may inadvertently identify the respondent to others.

6. Interview tape recordings will be destroyed immediately after transcription.

Your participation is voluntary. You do not have to take part in this study, and it will not affect your relationship to Portland State University, its students, faculty or administrators. You may also withdraw from this study at any time without affecting your relationship to Portland State University, its students, faculty or administrators.

If you have concerns or problems about your participation in this study or your rights as a research subject, please contact the Human Subjects Research Review 
Committee, Office of Research and Sponsored Projects, 111 Cramer Hall, Portland State University, (503) 725-4288 / 1-877-480-4400. If you have questions about the study itself, contact Robert Swan at (503)-725-5221, or (503) 449-7508, Division of Criminology and Criminal Justice, Portland State University, PO Box 751JUST, Portland, OR 97207.

Your signature indicates that you have read and understand the above information and agree to take part in this study. Please understand that you may withdraw your consent at any time without penalty, and that, by signing, you are not waiving any legal claims, rights or remedies. The researcher will provide you with a copy of this form for your records. You may return this form in the enclosed envelope or give it directly to the researcher after the interview.

Consent to Participate Signature

Date
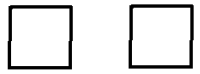

YES

NO

Permission to Tape Record Interview?

Date

Date

I Wish to Review Transcripts

I Do Not Wish to Review Transcripts

Date 


\section{Portland State University HSRRC Memorandum}

To: Robert Swan

From: Nancy Koroloff, Chair, HSRRC 2008

Date: May 12, 2008

Re: Your HSRRC application titled, "Challenging the New Penology: A Case

Study of Correctional Management and Interstate Transfers" (HSRRC Proposal \#08509)

In accordance with your request, the Human Subjects Research Review Committee has reviewed your proposal referenced above for compliance with DHHS policies and regulations covering the protection of human subjects. The committee is satisfied that your provisions for protecting the rights and welfare of all subjects participating in the research are adequate, and your project is approved. Please note the following requirements:

Changes to Protocol: Any changes in the proposed study, whether to procedures, survey instruments, consent forms or cover letters, must be outlined and submitted to the Chair of the HSRRC immediately. The proposed changes cannot be implemented before they have been reviewed and approved by the Committee.

Continuing Review: This approval will expire on Mav 12, 2009. It is the investigator's responsibility to ensure that a Continuing Review Report (available in ORSP) of the status of the project is submitted to the HSRRC two months before the expiration date, and that approval of the study is kept current.

Adverse Reactions: If any adverse reactions occur as a result of this study, you are required to notify the Chair of the HSRRC immediately. If the problem is serious, approval may be withdrawn pending an investigation by the Committee.

Completion of Study: Please notify the Chair of the Human Subjects Research Review Committee (campus mail code ORSP) as soon as your research has been completed. Study records, including protocols and signed consent forms for each participant, must be kept by the investigator in a secure location for three years following completion of the study.

If you have questions or concerns, please contact the HSRRC in the Office of Research and Sponsored Projects (ORSP), (503) 725-4288, 600 Unitus Building. 


\author{
Case 1: "Warden A-Old School" \\ Length of Interview: 50 minutes \\ Analytic Bracketing of Questions and Responses
}

\begin{tabular}{|c|c|c|}
\hline \multicolumn{3}{|c|}{ Ruling Relationships and Administrative Intent of IITs } \\
\hline & Dispositional Factors of Influence & $\begin{array}{c}\text { Situational Factors of } \\
\text { Influence }\end{array}$ \\
\hline $\begin{array}{l}\text { Case 1: Warden A- } \\
\text { "Old School" } \\
\text { Questions and responses } \\
\text { are organized in the } \\
\text { order in which they } \\
\text { were asked and } \\
\text { analytically bracketed in } \\
\text { terms of dispositional } \\
\text { factors and situational } \\
\text { factors of influence and } \\
\text { in terms of descriptive } \\
\text { and causal phrases. In } \\
\text { some cases, narrative } \\
\text { phrases are both } \\
\text { descriptive and causal } \\
\text { due to the latent causal } \\
\text { explanations embedded } \\
\text { in certain descriptions of } \\
\text { events. }\end{array}$ & $\begin{array}{l}\text { Question 1b Cluster: During the } \\
\text { course of your career with the } \\
\text { Department of Corrections, were } \\
\text { you authorized at all to directly } \\
\text { implement interstate inmate } \\
\text { transfers (IITs) to manage your } \\
\text { institution[s]?" } \\
\text { Descriptive: One time I had to [...] } \\
\text { find a way to move an inmate to } \\
\text { another state because [offender] was } \\
\text { better served out-of-state. }\end{array}$ & $\begin{array}{l}\text { Question 1b Cluster } \\
\text { Iprobe]: When you say } \\
\text { "better served" what do you } \\
\text { mean by that? } \\
\text { Descriptive/causal: "Well, it } \\
\text { was a high-profile inmate in } \\
\text { [name withheld] so we } \\
\text { needed to move [offender] } \\
\text { out of [name withheld]. } \\
\text { Descriptive: Usually, the } \\
\text { interstate compact is } \\
\text { managed by the central office } \\
\text { [...] through the interstate } \\
\text { compact unit. And usually } \\
\text { they work with states that are } \\
\text { willing to work with us at } \\
\text { moving inmates around... } \\
\text { Causal: but in this case, } \\
\text { nobody would take } \\
\text { [offender]. }\end{array}$ \\
\hline $\begin{array}{l}\text { In most cases, responses } \\
\text { have been edited for } \\
\text { clarity and } \\
\text { confidentiality purposes. }\end{array}$ & $\begin{array}{l}\text { Question 5a: "At the beginning of } \\
\text { the interview, you stated that you } \\
\text { have used (or referred) interstate } \\
\text { inmate transfers } \\
\text { times over the course of } \\
\text { your career. Can you describe some } \\
\text { of the factors that influence your } \\
\text { decision to use (or refer) IIT's? } \\
\text { Descriptive/Causal: [The DOC] } \\
\text { couldn't find a state that would take } \\
\text { [offender]...so I had to take this on } \\
\text { myself. } \\
\text { Question } 5 \text { [probe]: [...] were there } \\
\text { other cases that you would have like } \\
\text { to refer [for IIT] or did refer but it } \\
\text { just didn't go? } \\
\text { Descriptive/Causal: I never tried to } \\
\text { use the interstate compact process to } \\
\text { move inmates. [Usually], the } \\
\text { inmates that were in the institutions } \\
\text { that I was in were local inmates }\end{array}$ & $\begin{array}{l}\text { Question 5a: "At the } \\
\text { beginning of the interview, } \\
\text { you stated that you have used } \\
\text { (or referred) interstate inmate } \\
\text { transfers } \\
\text { course of your career. Can } \\
\text { you describe some of the } \\
\text { factors that influence your } \\
\text { decision to use (or refer) } \\
\text { IIT's? } \\
\text { Causal: [offender] was high- } \\
\text { press... press was interested } \\
\text { in talking to [offender] all the } \\
\text { time and [offender] like to } \\
\text { talk to them. } \\
\text { Causal: It was in our best } \\
\text { interests to move [offender] } \\
\text { to another state so that we } \\
\text { didn't have to deal with all } \\
\text { the nuances of somebody } \\
\text { talking to the press all the }\end{array}$ \\
\hline
\end{tabular}


...they didn't want to go anyplace.

So, they weren't seeking it, and therefore I didn't try to manage it that way... I didn't try to move them out if they didn't want to go someplace.

Causal: But in the case where you have a high-profile inmate...that's something... you have to consider the case... a lot of times the interstate compact is used if you've got a family member or something like that that's ill or terminally ill and...the inmate wants to see them, then we have used the interstate compact to move the inmate closer to the family member until they die and then we move them back.

Causal: And $[\ldots]$ its been used on...when we get inmates who are just real problems ....they are just real disciplinary problems, and they act out and their a management problem and we're fighting with them all the time and usually, sometimes its good to move these inmates to another state, because it gives them a fresh start and they do better. So we have done that before and we've taken inmates from other states who have been a problem there and they've actually done pretty well in [name withheld]. So it kind of works, it gets them out of the culture where they have to keep their name, they are a heavy, so they want to keep their name they want to be on the top of the heap of bad guys. And it takes them out of that scenario so that they can start out fresh, nobody knows who they are, and if you get them started right, generally speaking they are usually not too much trouble.

Descriptive/Causal[normative/ beliefs]: There are lots of ways that the interstate compact is helpful. It's really not a bad thing. time... wanting to talk to the inmate.

Question 5 [Probe]: [...] does the central compact office at the DOC...do they work with the warden as well as the other states... is there a sort of collaboration then to try to sort out the best way to handle a particular inmate?

Descriptive: How it usually works is that the interstate compact unit is kind of like a field office and they take requests from other states for inmates that they want to transfer to us and we take, and they also take requests from wardens who want to transfer inmates to other states. So they're kind of a clearing house, they manage the process.

Descriptive/causal: The goal is to be even with everybody if you can... if you have 8 inmates in other states, let's say for example we had 3 inmates in [state] we would like to have 3 of their inmates in exchange. Because if you don't what happens is they charge you kind of like it's a tab, you know when one goes to a bar, and order drinks....well they keep track of how many inmates you have and it's a cost per day kind of thing....and its run on a tab where you don't really pay for it but what you pay for is to get inmates there or to get inmates here to equal the balance. 
Question Cluster 1 [probe]: Prior to that then there was no compact agreement...

Descriptive: No.

Probe: Just an ability to transfer inmates?

Descriptive/Causal: There was an ability to transfer inmates but the warden did it with the warden of the other state. And we did transfer inmates back in middle [date]. We transferred 3 inmates [to state] that we were having a lot of trouble with...down in a car! We did that back then but it wasn't a formalized process like it was later.

Question Cluster 1 [probe] Were you able, when you received requests to accept inmates, did you take a look at the inmates to see how they would fit within your institution, or was it just a matter of the "tab" being settled...

Descriptive/Causal: No...I didn't have to take the inmates and I was allowed to review the file and everything else...we knew what we were getting before the person would show up.

Question Cluster 1 [probe] And, were you ever...or did you at any point decide not to take an inmate?

Causal: No, I didn't ...I took every inmate that they offered because I've been in that situation where I've had, you know, inmates that I didn't like to manage and I thought that they might do better someplace else...but I never turned anybody down.

\section{Question}

Cluster

[continued]: Generally, or as best as you can recall, do you know when [state] began to use interstate inmate transfers?

Descriptive/causal: [at least] 1964. I'll clarify that. When ... I started, we didn't have a central office. Each institution had its own warden, and each warden reported to the governor....and there was nothing in-between...there was no department of human resources, or no department of corrections or anything else. The budget was handed down by the governor to the warden and the warden ran the institution and was responsible to the governor for the budget. That's the way it worked back in the middle [date]. Now when the department of corrections was granted the authority or given the money to start a central office in [date], along with that came the interstate compact ...that's when they started managing that centrally...that's when they created that unit.

\section{Question Cluster 1 [continued]:}

In the one case that you referred to, were any of the rules, laws or the centralization of the DOC...were those at all stressful to you as a correctional manager, or were they not stressful and actually helpful.

Descriptive: I really never had a lot of problems with the transfers. I was always able ...I didn't really seek them, so I really didn't ever get turned down, except for 
that one inmate that nobody wanted. So, and I was always willing to take in inmates from other states whenever I got a call. So, I really didn't have a lot of problems with the process.

Question 2a: Well I'd like to turn to the topic of correctional management and your style and beliefs a little bit. I guess I'll start with a basic question which is: In your opinion, what is the purpose of incarceration?"

Descriptive/Causal: From my perspective, there are two purposes. One is punishment. That is what the public and judges are there for...because the person needs to be punished for the crimes that they committed. And the second purpose, in my opinion, what we ought to be doing with inmates once we have them, is that we ought to be trying to change them.

Question 2a [probe]: So your beliefs about incarceration are pretty consistent with...the things that the DOC has stated as a purpose of corrections then?

Descriptive: Yeah...its...just a repeat of what we have been doing since [date]...it really hasn't changed...they might change the names but we don't change what we do.

Question 2a [probe]: To go a little bit more in depth, and maybe to add a bit to what you've said, can you describe how these beliefs developed...regarding the purpose of incarceration?

Causal: Well it was part of my training when I first started... we had
Question 2a: Well I'd like to turn to the topic of correctional management and your style and beliefs a little bit. I guess I'll start with a basic question which is: In your opinion, what is the purpose of incarceration?"

Causal: I know that's difficult when your in an environment that's its not a real environment, it's a manufactured

environment...its one we create, and I know its difficult because it's not a real environment that they live in when they go back to when they get out. But you try to do the things that change who they are. You try to model for them and you try to hold them accountable and make them act like they are supposed to act when they return to the community.

Question 2a Iprobe]: During [the course of your [career] did you attempt to achieve these purposes within the institutions you managed? Probe: [...] how would you characterize the proportion of time spent focused on individual inmates verses time spent managing the entire inmate population....and you can 
really good training. I started at [state institution] and it was a pretty new institution. It was for youthful offenders...first time offenders. The first time they were in the system and there was no first degree murder, rape or treason. And they had to be between the ages of 16 and 25-26... and first felony offenders ...our job, when I first started was to change these kids because at that time, they felt that this was the time to intervene in their lives and try to change them before they became long-term convicts in the system and try to get them out of the system so...a lot of the training I received was directed at how to change inmate behavior...so, right from the very beginning that's how I was trained.

Descriptive: The penitentiary really didn't operate that way then because they were the "penitentiary" and they were there just to keep inmates locked up. But [institution] was supposed to be the place where they sent these youthful offenders we wanted to get out of the system before they committed their second crime and then got gobbled up and never to return to normal life.

Question 2a [probe]: During [the course of your [career] did you attempt to achieve these purposes within the institutions you managed? Descriptive: Well, what you do as a warden is you manage an operation of an institution... you really don't get involved in the what people are actually doing, what you do is you create the programs and you put the people in charge of the programs that you want to manage them. They try to manage a program in a fashion to change inmate behavior but as a warden you really don't get involved in that....down to that level.

Probe: You set the tone?

Descriptive: Yeah you set the plan, you get the money, you start the speak to your plan if you like because that makes more sense.

Descriptive: Well, most of the inmates that take most of your time are the inmates that act out. Simply because they are management problems...and the inmates that behave themselves and try to be model citizens in the institutions, so to speak, really don't take up a lot of...time. They mainly stay in their cells when they are not out doing what they are supposed to be doing and when they are involved in a program, they comply with the program. They really don't chew up a lot of your time. It's the ones that don't want to comply with anything that are always fighting you...those are the ones that seem to eat up most of your time. I'd say that 60$65 \%$ of your time is used up battling with the inmates who don't want to comply.

Question 2b: Now, just to switch the focus a little bit. Generally speaking, how would you characterize your management style?

\section{Causal}

(following descriptive dispositional statement): I don't use that [consensual] process when I run into problems and I find out somebody is not on the ship any more and decided to get into their own canoe and go a different direction. Then the consensus process is over with, that person, as far as I am concerned, and I get real direct with them. Because they hurt the group because they are no longer complying with the philosophy of management by consensus. 
program, you have them manage the program well, and try to get the results that you are trying to achieve.

Question 2b: Now, just to switch the focus a little bit. Generally speaking, how would you characterize your management style?

Descriptive: I try to manage by consensus. And you can't do it all the time. It's a real time-involved process where you have to sit down with people and talk about things until you reach a space where people generally agree that this is what we are going to do.

Causal: I've used this process a lot, I find it's a most effective process when you are trying to get things done because you are trying to get everybody on the same ship going the same direction and you try to talk about everything that's a problem and get people to agree on the direction that you are going to go. And, as a beginning and as trying to keep something like that going I try to use that process.

Probe: How do you think your employees would characterize your management style?

Descriptive: Well they, I think that they think that I'm a easy person to get along with and an easy person to work for. They like to work for me. I always had that type of feedback... I'm pretty patient...as long as people have legitimate reasons for either not getting something done or not following the process at a particular time. Its only when I know for sure that something is not working right that I get in it and make somebody's life miserable if I have to.

Probe: How do you think inmates would characterize your management style?

Descriptive: Well...I don't know. I
Which is bear out your grievances, talk about things and solve your problems and get on with the process... and then stay honest to the process.

Probe: It's primarily a consensus model except in case where somebody has moved away from the ship then it becomes a somewhat authoritarian model?

Descriptive: Yeah, at that point it does. 
don't really try to manage it from what the inmates believe is fair. I try to do it [from the perspective] of what I think the staff thinks is fair because the inmates are in a situation where they have to do what I tell them to do anyway. And as long as I'm fair with them and honest in my dealings with them, I don't lie to them and I tell them like it is, inmates appreciate that and I'm not afraid to tell them NO, some people get into a situation where they're afraid to tell inmates no, I'm not afraid to tell them no, and I'm not afraid to punish them if they're not doing what they are supposed to be doing. So they probably see me as pretty authoritarian but overall that's probably a good thing when you're dealing with inmates because they're manipulators and they spent their entire lives trying to manipulate themselves either into or out of situations they have no business getting in to. So I think they deal better if they see things are real direct.

Probe: In addition to what we talked about, in terms of a consensus model except in certain cases, do you think your management style as a warden and your beliefs about good correctional management have remained relatively stable or has their been some variation over time? Causal: They've been stable since about 1985 . I pretty much adopted that model then and I've stayed with it because I haven't seen anything better come along. So I have pretty much used that model ever since then. 
Question 3b [cont]: At this point, the next scheduled question seems a bit redundant. But what I'd like to do is read the question and then sum up what you have responded so far. At that point, you may contribute additional information if you feel that it is needed.

Do you feel as if any of the factors that we have discussed [have or have had] a significant influence on your management style or beliefs about correctional management? It sounds like to me that you're correctional management style and beliefs incorporate an understanding that the things are going to happen and that you are going to prepare for them, as opposed to these factors dictating what you do every minute.

Descriptive: Oh, yeah, absolutely. You try to anticipate as much as you can, and what you can't anticipate, you get on as quick as you can after you find out about it and then be sure that you're right. Do your work and make sure that you have all of the correct information before you make a decision. It might take you several days to get that information but do what it takes to get it...so that when you do make a decision, it's a right decision...so you don't have to change it later.

Causal: When you're dealing with people, it's real easy to have to change something later because you don't have all of the information.

Probe: If you feel that it is redundant, we can skip it...but I am wondering if all of these influences and factors ...does this experience or have these experiences changed your beliefs about incarceration in any way...or does it even touch on those original beliefs?

Descriptive: I really don't think about it a lot ...when I was the warden ....I try to deal with people as fairly as I can. I don't change that. When you do that, they understand that and they see that and
Question 3: Ok...Now I would like to ask you some questions related to the operational environment of the correctional facilities you have managed. In relation to your decision-making processes as a warden, generally speaking, how would you characterize the operational environment of your institution[s] [while you were warden]? Would you say that it was: VERY STRESSFUL

\section{SOMEWHAT}

STRESSFUL NOT AT ALL STRESSFUL

Descriptive: The institution operation itself is not very stressful in my opinion.

Causal: What's stressful is if something happens in the institution...you have a hostage situation, or you've got a riot situation then it becomes really stressful but you don't live for those things and you don't expect them. You just try to prepare so you're ready when they do happen....and if they do happen, they are very stressful and you know, it takes you even weeks to get over something like that by the time you get finished with it.

Descriptive: But generally speaking, life in the institution is pretty low stress....as long as everything is working right.

Question 3b: Ok. I'd like to explore this a little bit further. Essentially, I am running some things by you that are discussed in the correctional literature to get your opinion on whether these items are specifically stressful (or not) in your 


\begin{abstract}
they're willing to work with you. Even if the answer is no, people understand that [fairness] especially if you went through ...the process to make your determination and you were fair about it. You can do anything you want as long as you are fair. People will go along with it whether they are staff or inmates.
\end{abstract}

Final Question: Well, the last set of questions I have scheduled... but I am wondering if you have any final thoughts and feelings you would like to offer regarding your current or former role as a correctional manager, the operational environment, or IIT's more generally...do have any ideas about trends in those? Trends in the environment, anything of that nature that you would like to offer?

Descriptive: Well, you know, really, not much has changed in all the years I have been in this business it's pretty much the same as when I started except that equipment is a little better, and the staff is probably trained a little bit better. Other wise it is pretty much the same system that I started in. I think that probably that is a testament to the people that were there when I started...they probably knew what they were doing because we really haven't made many changes. situation. The first issue is prison crowding. Would you say that is a stress on you as a Warden?

Descriptive: Its not all that stressful. The way you managed that is...well back when I started everything was single cell housing. No inmates were doubled up. In order to manage the incoming population when we didn't have any space, we doubled up inmates. Causal: But at the same time we opened up their access to the institution. We allowed them a lot more time out of their cells. That seemed to take care of the stress that [was] created by putting two inmates into a cell. So I didn't really see a change when we did that. So to say that crowding was something that caused more stress; I'd say ...I think it depends on how you manage it. You can do a lot of things to relieve that by allowing inmates more time out of their cells and still manage their behaviors and reduce the stresses. You still come out even.

\section{Question 3b [cont]: Ok...the second} item.........organizational interactions or relationships... That may seem a little vague but by this I mean interactions and relationships within the institution itself (employees, inmates, management). and interactions and relationships between the institution and other departments within the DOC and/or other organizations external to both the institution and the DOC. 
Do you find any of those types of interactions to be a stress on correctional management?

Descriptive/causal:

when you talk about [...] regular bargaining unit staff vs. the institution management, that's, again, how you handle it. If you try to resolve their problems and their grievances, things work out fine you don't have a lot of stress with that. You're going to have a certain level of stress at all times with inmates because of the issues that they have because their lives are stressful too. You know, they've got family that's out there that's having all kinds of problems and they can't do anything about it. That creates stress for them; their are staff in the institution and some inmates that they don't get along with very well, that creates stress for them so...on the other side, they [inmates] create stress for you. That's always going to be there....and, again, you manage it the best you can. I don't see that it is something that effects the operation as long as your out there trying to solve those kinds of problems and work with those inmates.

Probe: So, some level of stress is always part and parcel for the job and is to be expected?

Descriptive: Yes.

Question 3b [cont]: In terms of...there's a lot of discussion in the literature about relationships that institutions and maybe the DOC generally, have with organizations that are external to the DOC and its 


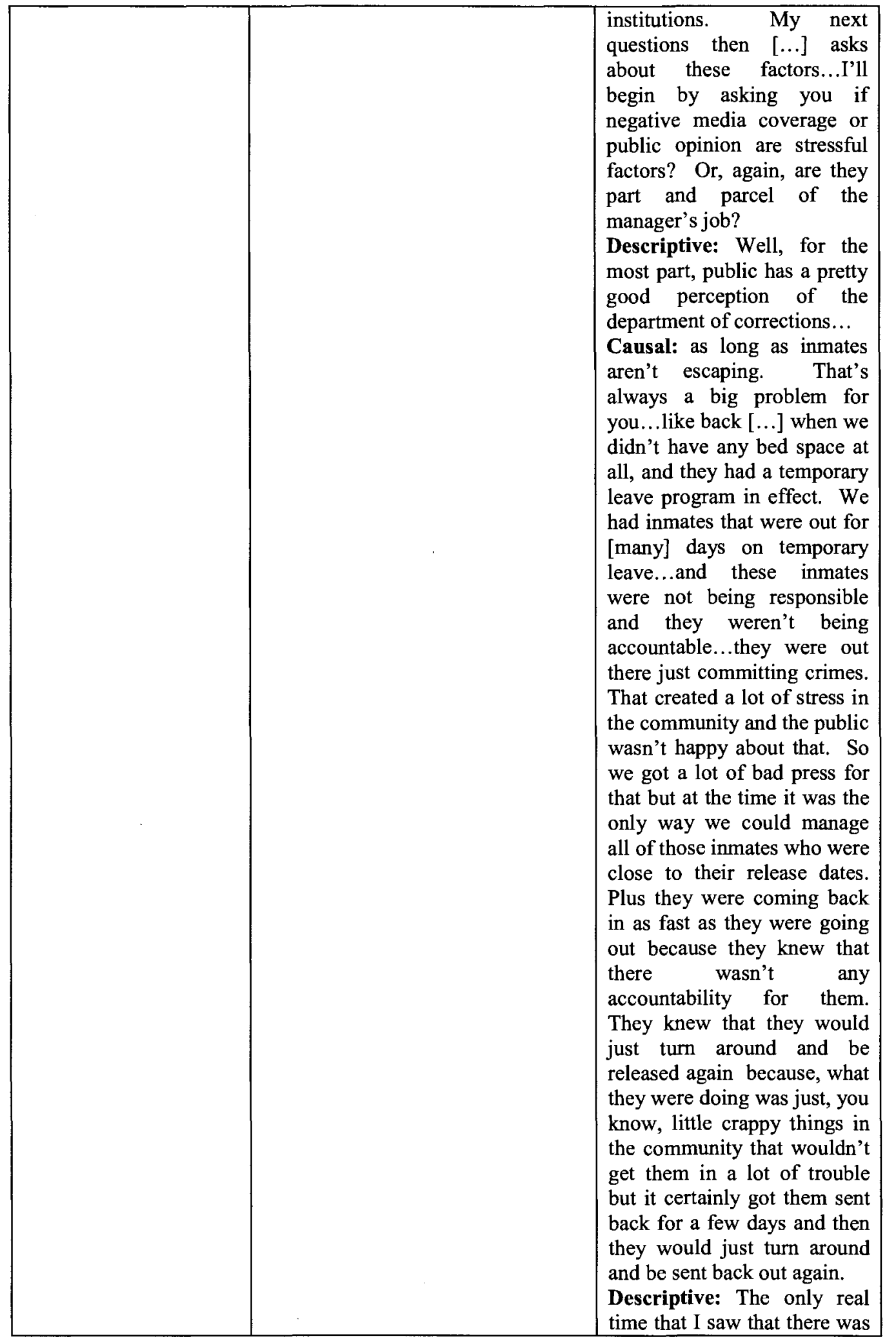


a major problem between the media and the department of corrections was [major incident].

Question 3b [cont]: Well, going on to the next potential stressor on your ability to manage institutions...do restrictive or overly punitive laws or court interventions of any kind...do those cause you stress as a warden?

Descriptive: Well, there was only one time that we really had a real major court thing that was working against us, that was back when, [organization]...this was back in the [date] when [organization] took us to court regarding crowding in the institutions. [...]They wanted to set a cap on how many inmates can be in each institution and they wanted to actually reduced the amount of inmates that were in each institution and they wanted us to release them. They wanted to bring in a court monitor to make sure that we did what the courts said we should do...it was a real stressful time because, I mean, what do you do? [...] The public doesn't want the inmates back in the community ...or just not be released out of the institution before their time was up and this was basically what they were saying, and [having] a court monitor run the department of corrections was ridiculous in my mind.

Descriptive/causal: [...] It was a really stressful time and you don't know if you are going to win a lawsuit like that. Just the fact that you don't know that makes it 
a lot more stressful. Because we knew that it was something that the public wasn't going to buy and, but if the court ordered it, your stuck with it. So you have to live with it after that so you've got to win these things before you lose them...or then everybody loses.

Probe: This sounds like a larger stress than negative media coverage...?

Descriptive: [yes].

Question 3b [cont]: I have a few more questions regarding possible stressors...in the literature you also see mentioned that the number of problematic inmates has been increasing and creating more management

headaches...so...ill inmates, increasingly violent inmates, etc. etc. What do you think about that in terms of a stress on you as a warden?

Descriptive: Well...I don't know about some of that...the number of violent inmates acting out is less than it used to be.

Causal/descriptive: I think we have better control over those inmates now, we have better ways to manage them than we used to. I mean we used have to take our watches off and our belts off in order to go take an inmate out of a cell and we had to do that physically without a shield or anything else and things have progressed to the point now where we have all kinds of equipment, coveralls, we have electronic shields, tasers...all kinds of equipment where staff can enter a cell without getting hurt and take and inmate and 
do what you have to do with him in order to modify his behavior. Where it used to be we just didn't have those resources, and inmates loved that kind of contact, where they could try to hurt a staff member and they really aren't getting those opportunities anymore. So, I think inmates are seeing the professionalism and the fact that they aren't able to impact anything as much. I think it helps to modify their behavior a little bit.

[...] it's a lot more professional. It's handled a lot better, and a lot less people get hurt. And I think there are a lot less times that we have to use [physical force].

[handling

problematic, violent inmates] is not as stressful as it used to be.

Question 3b [cont]: Finally, and in terms of stressors, are their any other factors I haven't touched on here that you think are stressful to you? In terms of managing an institution...?

Descriptive: There are all kinds of things that come up that you're not prepared for...

Causal: I think that probably the greatest stress that you have to deal within an institution is...you try to anticipate all of the things that you're going to have to deal with. The things that create the largest amount of stress for you are things that come up that you really aren't ready for, and that you have to develop a plan for...you know, after it's a 


\begin{tabular}{|c|c|c|}
\hline & 列 & $\begin{array}{l}\text { problem. Whenever you } \\
\text { have to that, it creates stress } \\
\text { for you. The thing you have } \\
\text { to try to identify, the } \\
\text { resources, identify the } \\
\text { people, and stuff and try to } \\
\text { resolve the problem. There's } \\
\text { generally a } 24 \text { - } 48 \text { hour } \\
\text { period where things are } \\
\text { extremely stressful until you } \\
\text { figure out what direction you } \\
\text { want to head. } \\
\text { It's one of those things...in } \\
\text { an institution, you try to } \\
\text { anticipate everything, that's } \\
\text { what your staff do when } \\
\text { they're out there, they're } \\
\text { listening, looking and } \\
\text { searching all the time and } \\
\text { trying to figure out what's } \\
\text { going to happen next. } \\
\text { Probe: ...and head off those } \\
\text { stressful moments? } \\
\text { Descriptive: Yeah....you are } \\
\text { trying to head it off, you're } \\
\text { trying to get a plan, you } \\
\text { develop plans as you go } \\
\text { and... } \\
\text { Causal: for example, an } \\
\text { inmate tries to escape from } \\
\text { inside your fence and you } \\
\text { don't know how he got out. } \\
\text { Now that's extremely } \\
\text { stressful. Because you're } \\
\text { going to get the media right } \\
\text { there, you're going to get the } \\
\text { public who's going to be } \\
\text { upset because somebody got } \\
\text { out of your prison, and this } \\
\text { stuff has happened. } \\
\text { [...]the public perception is: } \\
\text { You got a fence there, how } \\
\text { did they get out? The public } \\
\text { doesn't understand that. So } \\
\text { you know, that creates a lot } \\
\text { of stress for you. So you } \\
\text { have to do things inside all } \\
\text { the time to try to manage } \\
\text { those inmates; if you've got } \\
\text { "minimums" in there, and } \\
\text { you've got } 500 \text { of them, and }\end{array}$ \\
\hline
\end{tabular}


you've got 100 beds that look like they're probably not as secure as the other 400 , you pick inmates who you think are your least amount of risk and you put them in those 100 beds that are higher risk. You do all kinds of stuff like that to try to head it off. So you deal with the problem before you have to deal with it spontaneously.

Probe: Are there other factors that we haven't talked about that aren't stressful but that possibly impact your decision-making, these can be inside the institution or coming from outside the institution...that aren't stressful but that are influential in some way?

Descriptive: Almost everything you do...you are always thinking, whether it's stressful or not, there is always something that impacts your decisionmaking and makes you kind of modify the direction that you're heading.

Causal: Whether it be inmates or whether it be the staff that are working for you, or the public or the media. It's just the fact that you have one person, who is....for example, if we had a [mother] who was terminally ill over in [city] and we had the inmate here in [institution] as soon as we found out about that we would have to start thinking about what to do with that inmate and whether or not we would transfer him over to [city] so that [offender] could be close to his mother.... and probably, we would. But when would we do that...see, we have to start looking in to 
it and determine how ill the person is, try to determine how long she has to live, and then determine at what point - and if - we would transfer that inmate over to [city] to be close to her before she died. So you know, all of these things that we deal with in these places cause us a lot of work but you have to check into every one of those details because sometimes it's a lie and sometimes its fabricated so that they can get themselves over to the [city] because they don't like it [here]. So they try to create things that force us to send them over there. So we are always in the mode of checking and modifying, and searching and verifying information to make sure that we don't flat out tell somebody "no, you're not doing that" without having all of the information, and the correct information, to make a responsible decision.

Final question [Probe]: I am wondering though if you see any trend towards the use of IIT's in [your state] for any reason? Or will their use remain fairly stable?

Descriptive: I don't think there will be much of a change.

Causal: [state] will not look at that as an option to try to manage inmates ...the bottom line is that you have to pay for that. Because either you have to take an inmate from that state or otherwise they hold you accountable for that cost. And while that is like a hidden cost, it is a cost that is down on paper. And they are waiting for you to pay that 


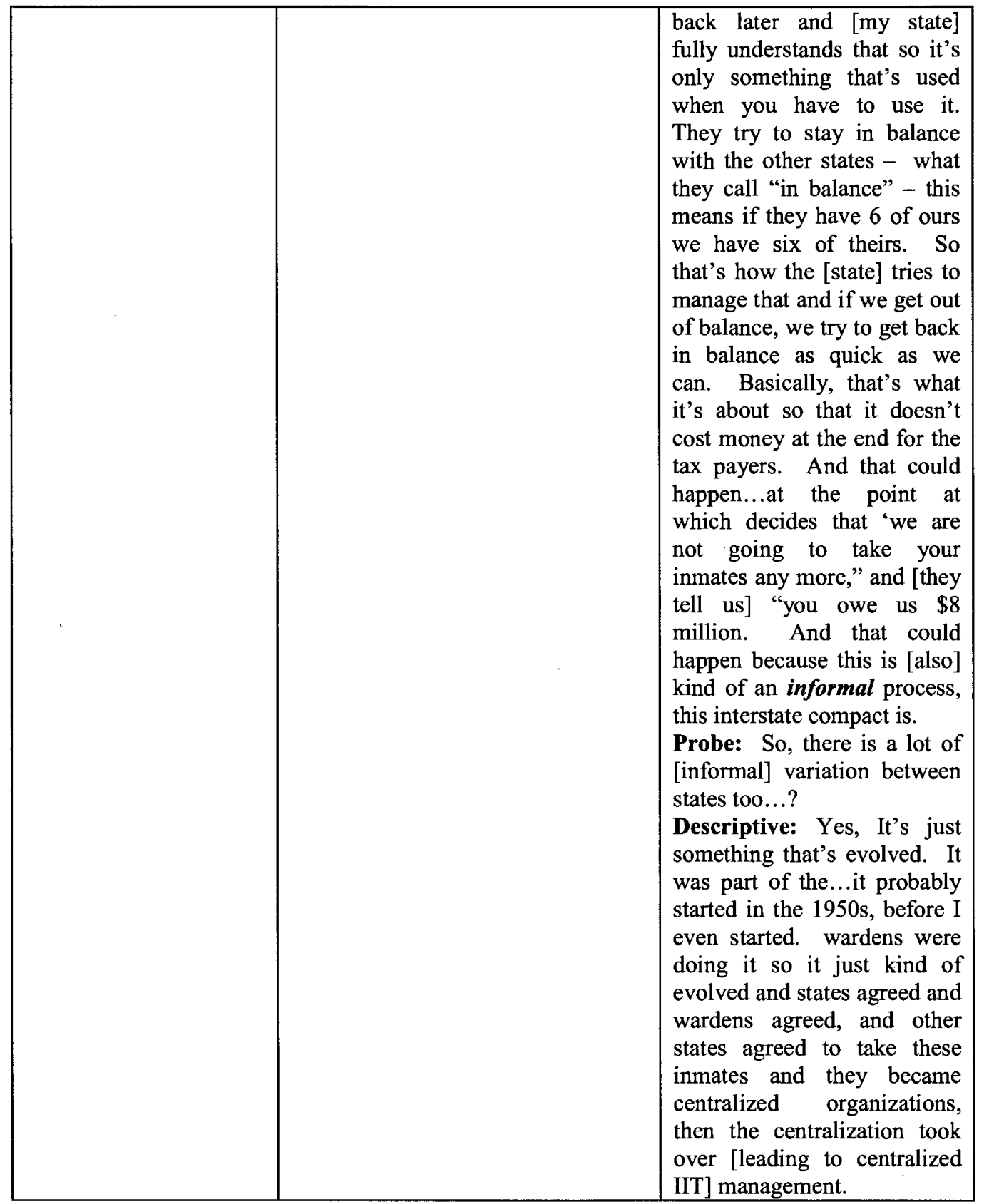




\author{
Case 2: "Warden B-New Blood" \\ Length of Interview: 90 minutes \\ Analytic Bracketing of Questions and Responses
}

\begin{tabular}{|l|}
\hline \\
\hline \\
Case 2: Warden B - "New \\
Blood" \\
Questions and responses are \\
organized in the order in \\
which they were asked and \\
analytically bracketed in \\
terms of dispositional factors \\
and situational factors of \\
influence and in terms of \\
descriptive and causal \\
phrases. In some cases, \\
narrative phrases are both \\
descriptive and causal due to \\
the latent causal explanations \\
embedded in certain \\
descriptions of events.
\end{tabular}

In most cases, responses have been edited for clarity and confidentiality purposes.

Question 1b Cluster: During the course

of your career with the Department of Corrections, were you authorized at all to directly implement interstate inmate transfers (IITs) to manage your institution[s]?"

Causal: Well, my initial contact with interstate compacts was as a [correctional employee]...it was not uncommon to have inmates who wanted to relocate to another state because they had lived there or whatever, or conversely, inmates coming from other states who wanted to be supervised here in [state].

Descriptive: So, I saw it from both perspectives. Once I got into the prison environment, most of that, the administration of transfers of prisoners to other jurisdictions was handled basically by, what is now called our [transfer] unit.

Causal: So I was not really too involved in that [ITS] other than being involved in rental bed situations where we moved inmates out of state because of capacity issues. So, my association and knowledge of that since [date] is fairly limited.

Descriptive: I don't know if you have spoken with other wardens in the state but really the decision to move an inmate to another state or from another state to here would not be under my purview....at all.

Descriptive: As a matter of fact, I don't even think that I would be involved in that process at all, in any way. Other than since we maintain files on inmate's compliance with [state's] corrections plan and so on and so forth, and those sorts of things that someone wanted to look at...behavior issues.
Situational Factors of Influence

Question 1b Cluster [probe]:

R: Have you had an opportunity to talk to other wardens?

I: I have....and there are cases where there is more or less influence on the office of [transfers]. There may be informal referrals or somebody tasked with finding places...or something like that. You know, a lot of the things you talked about earlier were related to that.

Descriptive/Causal: Yeah, I can't in my recollection, recall the opportunity to do that all. I would be more than happy to be involved. But $I$ know that those decisions about incarcerated inmates moving from one correctional system to another usually is done at a higher level than my own, or a different level than my own.

Probe: OK. Then, I guess...I'm a little bit on the run here, I will reframe one question...I'm wondering-you said that you wouldn't mind having that role...

R: No.

I: Do you think it creates stress on you not to be involved in that [IIT] process?

Descriptive/Causal: Not at all. The reality is that a state receiving an inmate from our system...there would be considerations in relation to capacity, classification level, behavior, all that sort of stuff, so you know, I could only make...any referral that I make would primarily be based on my staff's observation of the inmate's behavior in the 


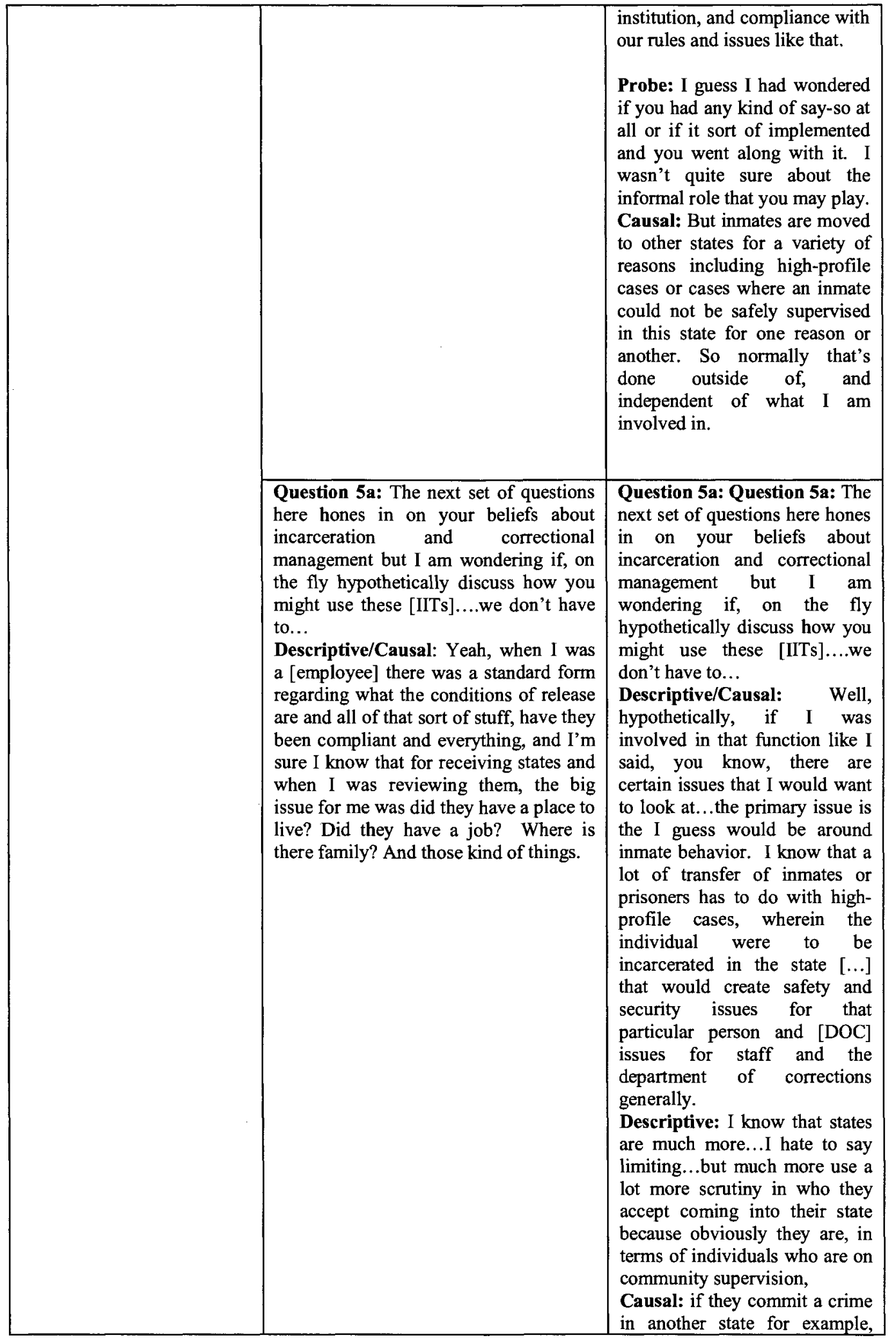




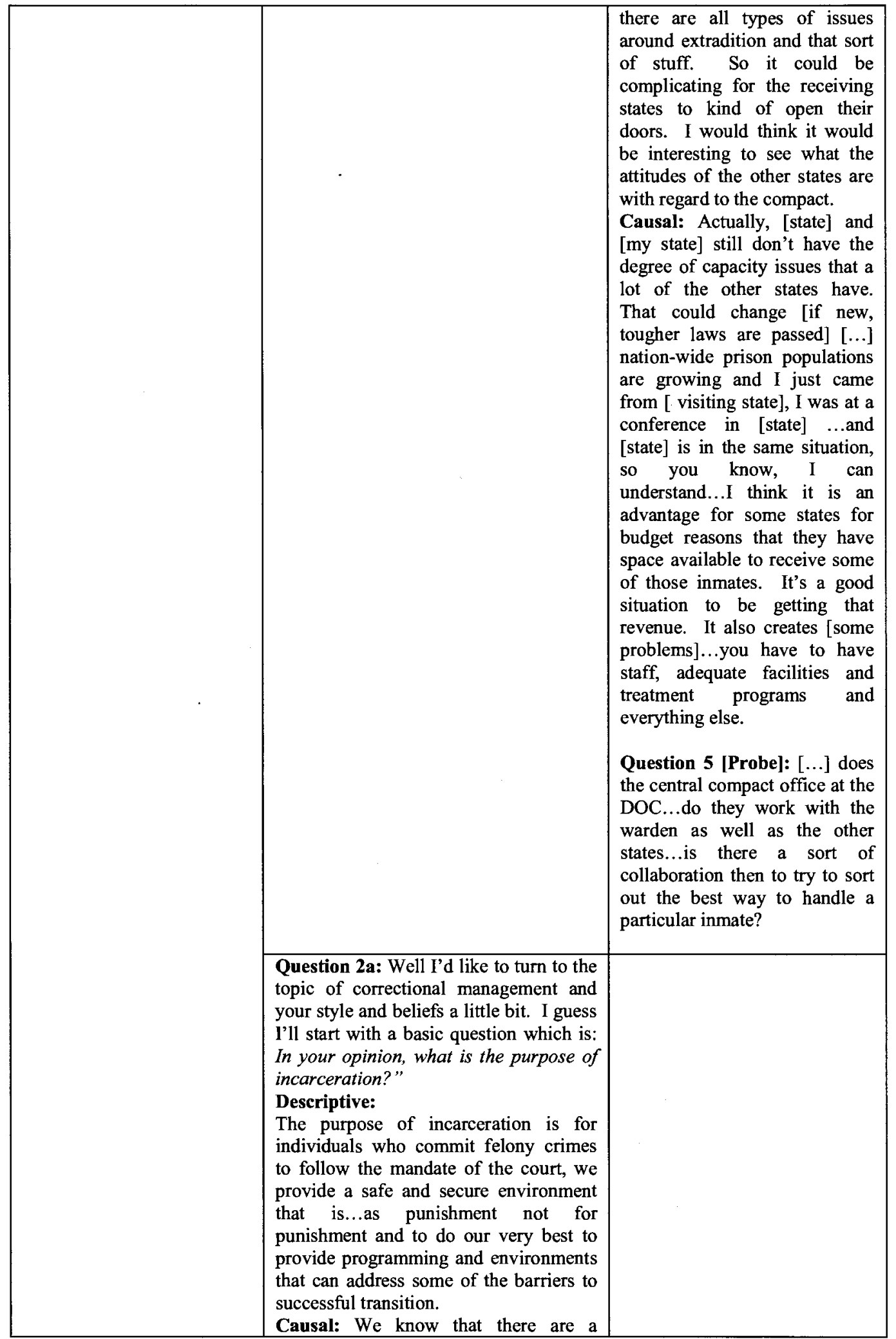


certain segment of the population of inmates based on the severity of their crime that need to be incarcerated for the rest of their lives. But there is also a segment of the population of inmates who for one reason or another came from a dysfunctional background, have substance abuse issues, mental health issues, and my belief is that we carry some responsibility to reduce recidivism and expense to the tax payer by providing programs in support that will help keep them out of prison once they're released. Descriptive: So, primarily, it is safety and security of the institution, the inmates, the staff and the community. Which is really what our department of corrections...it's our motto, what we premise our entire operation on. And secondly to provide programs that can reduce the probability of them coming back in any institution. That's our mission, the DOC mission....in a nutshell.

Question 2a [probe]: Can you describe these beliefs developed...I mean personally how you developed these beliefs?

Descriptive: You know, it's interesting that in the very beginning when I started getting in corrections, I felt a responsibility that we're dealing with human beings here who for one reason or another

Causal: because of what ever reason, dysfunctional family, or improper....misdirected value systems. Not enough education. Or there may be some organic issues or developing criminal thinking because of associating with criminal types or whatever.

Descriptive: [They] come into the system, commit a crime, and it's our responsibility to follow the laws and statutes of the state[...]. And as warden, I need to ensure that when they come here that they're safe, but even as a [DOC employee], which was a very humanizing process because $I$ had to have face-to-face contact with everyone of my case-load...their were about 120 ... a minimum of one time a month. And you know, you become more than just a [DOC employee], you become a social worker and many ways, an ear for these people and you try to humanize the process as much as possible, which I think is an important 
function and aspect and responsibility of a prison environment, because we're trying to, you know, this facility specifically, is all our inmates are within [time frame] of release. So, we need to get them ready to be successful when they go back into the community

Causal: and of course, as you know in your research, there are several criminogenic factors that we're trying to help them overcome: associates, substance abuse, family, and all of the others, so...safety first, and that, I just feel the human being is important, that anyone in the correctional system understand the delicate balance between holding offenders accountable to rules and policies of the institution so that we have a safe environment and at the same time being responsive to their needs as best we can and providing programs that will help them be successful once they're out.

Question 2a [probe]: In accomplishing these purposes and with these attitudes, how would you characterize the proportion of time you spend focused on individual inmates in comparison to the time spent managing entire populations? Descriptive: That's a good question. When I was [a] manager at [institution] and an [employee], I spent a lot more time individually with inmates but I still do, I mean I receive...I still attend activities, clubs, well we don't have clubs here, but we have some groups that are ethnic, groups, religious groups...I walk around the institution, I answer their questions that come in writing, and I actually am interested...it's certainly not...I don't have as nearly an intimate understanding of the individual population now because I just don't have time to do that. I do manage to talk to individual inmates and with some, develop some type of communication relationship with... in some cases, I try and solve some issues or refer them to somewhere that they can get some resolution, so it's not as great as it used to be but I'm pretty satisfied...from a [warden's] perspective, it's pretty good.

Question 2b [probe]: Which is related to my next question, which was... can you describe your role as a warden? If 
there is anything you would like to add....

Descriptive: We try to do as much as we can with the inmates, in terms of walking around, I mean, a warden walking around and providing access to inmates to talk with...it makes a big difference because they think I have the ultimate power in making anything happen and I have some power, but it provides me with the opportunity to describe what my limitations are and try and be as responsive as I can to some of their issues.

Question 2b: Now, just to switch the focus a little bit. Generally speaking, how would you characterize your management style?

Descriptive: I think that probably my greatest strength is ...I think that I communicate well with my staff and with inmates. I am very sensitive to their issues and their liabilities and assets as well. I don't see the inmate population...I don't see myself as separate...a person who wants to sit in the office, I think I need to know what's going on, so my style is as interactive as it can be, understanding that there are limitations to that because I have to remember that anything I tell an inmate as a warden, I better be darn sure that that information is understood and communicated to the correctional staff, the lieutenant, the sergeant's...it's a big mistake to go out and be making all kinds of promises and commitments, or talking about rules or policies that would differ from the way the operation is...so, I try to be as sensitive as I can, if I can't answer a question, I'll tell them I can't and write it down and get back to them. But usually, when it is a policy issue, I will discuss that with staff.

Causal: $[. .$.$] it's very effective, up to a$ point.

Descriptive: Well, first of, in terms of reality, you're not going to be able to do it all the time. There are going to be other priorities that come up, other distractions. I think it is important, but ... [importantly], it would be easy to put other staff on the spot if you're making some proclamation about something... for example: Inmates wanting to have a [sports] toumament. We've got a [sports] tournament coming up and that required coordination with security, and 
programs, and physical plant and so, you know, before I make a commitment, I'm going to make sure that it is something we can do, number one, number two that it is feasible within our operational limitations. I agree with that walking around, I think it's great, but there has to be some limitation...If I spent all my time with the inmates, then I wouldn't be doing what my primary function is. I would consider myself by comparison, fairly hands-on and my sense is...that I think I see a lot of positives .... in other states, that, historically have been very conservative...I mean we're talking about [multiple states], the inmates are in the cells, behind the walls, the warden stays remote....I see a huge change in that, and I think I've seen more wardens nationwide who are becoming more engaged, more involved, generally.

Probe: How do you think your employees would characterize your management style?

Probe: How do you think inmates would characterize your management style?

Descriptive: Well I can tell you that inmates have given me some feedback lately that I'm not getting around enough. I had gone to a meeting of [inmates] ...they had some issues and complaints and I went and spoke to them, and it was somewhat tense, not in terms of concerns about physical safety, but .... one of the feedback I got was that I was - recently - haven't been getting around enough. I would think that they say generally that I get around fairly well. I think staff would say the same thing. And, incidentally, I require the same of my management staff. They get around too, so...I would say that I want to get around more, its good feedback, so in fact in the last 2 or 3 weeks I've been making an attempt to get around more. More visible.

Question 2b [Probe] Has your management style as a warden varied or remained relatively stable since you became a warden?"

Descriptive: It has not changed an iota since I began. I had a vision about what my style was, how I wanted to start up this institution, what the philosophy of this institution would be, and that is the sort of a $[\ldots]$ facility, encouraging 
progressive discipline, encouraging communication, so it has not changed at all, not at all.

Question 3b [cont]: At this point, the next scheduled question seems a bit redundant. But what I'd like to do is read the question and then sum up what you have responded so far. At that point, you may contribute additional information if you feel that it is needed.

Do you feel as if any of the factors that we have discussed [have or have had] a significant influence on your management style or beliefs about correctional management? It sounds like to me that you're correctional management style and beliefs incorporate an understanding that the things are going to happen and that you are going to prepare for them, as opposed to these factors dictating what you do every minute.

Probe: If you feel that it is redundant, we can skip it...but I am wondering if all of these influences and factors ...does this experience or have these experiences changed your beliefs about incarceration in any way...or does it even touch on those original beliefs?

Descriptive:

Final Question: Well, the last set of questions I have scheduled... but I am wondering if you have any final thoughts and feelings you would like to offer regarding your current or former role as a correctional manager, the operational environment, or IIT's more generally...do have any ideas about trends in those? Trends in the environment, anything of that nature that you would like to offer?
Question 3a: Ok...Now I would like to ask you some questions related to the operational environment of the correctional facilities you have managed. In relation to your decision-making processes as a warden, generally speaking, how would you characterize the operational environment of your institution[s] [while you were warden]? Would you say that it was: VERY STRESSFUL

SOMEWHAT
STRESSFUL NOT
ALL STRESSFUL

Descriptive: I think it is situational, I think it is somewhat stressful. I think the important thing is that staff know what the vision is, what the direction is, and that we're all role-modeling that and moving in the same direction at the same time.

Causal: One of the challenges here was that this is a $[\ldots]$ facility and a lot of the correctional staff came from [different type of] institutions. Which are run a little bit differently.

Causal: I think correctional environments are stressful, no matter what they are because you're dealing with individuals who are damaged $[\ldots]$ and can be - and are-very demanding. Yeah, I think for people it is very rewarding on the one hand, because you can see, you go to a GED graduation and listen to inmates talk about how they 
have had a revelation, how their thinking has changed...they didn't know that they could do what they could do, to time when it is very stressful...we have a lot of work to do, there are human resource issues, and staff difficulties and things like that, so I would say somewhat stressful.

Question 3b: Ok. I'd like to explore this a little bit further. Essentially, I am running some things by you that are discussed in the correctional literature to get your opinion on whether these items are specifically stressful (or not) in your situation. The first issue is prison crowding. Would you say that is a stress on you as a Warden?

Descriptive: Yeah. I'm happy to be in [state] because I think we have a brilliant [...] management team and the overcrowding issue, has not...since I've been here, has not been an issue. We've always been at or below capacity. But I am very sensitive to the overcrowding issue because of what I [know about it], the information I get from other states, my association with wardens from other states, but in terms of here, in [state]...do you want me to characterize it on a scale...or just..?

I: No, I don't have a scale...I was just wondering if that in your current context [...] if you thought it was currently a stress on you and your decisionmaking?

R: At his time right now, no.

I: Ok. But previously, you discussed the idea that it could be a stressor...?

R: Oh, absolutely. I think [in some states you talked about] its just crazy.

Causal: When your entire health services is run by a special master, approves all the hiring. I mean, the [courts], they're tough with corrections. 
People don't want to go there. And the [unions in other states] are very strong. I am so happy that I am in [state].

Question 3b [cont]: Ok...the second

item.........organizational

interactions or relationships... That may seem a little vague but by this I mean interactions and relationships within the institution itself (employees, inmates, management) and interactions and relationships between the institution and other departments within the DOC and/or other organizations external to both the institution and the DOC. Do you find any of those types of interactions to be a stress on correctional management?

Descriptive/causal: Well, it does. This institution was built in a very small community, who, when I first came here had limited trepidation about a correctional facility coming into their area. My work in developing relationships with the community was one of my primary goals and we enjoy a wonderful relationship with the community. One of the reasons, ironically, is because of the work that our inmate work crews did [helping out] for senior citizens. We do a lot of community related work in this county and in this city because this county and this city does not have a lot of funding to a lot of the things that otherwise would be done if they had adequate tax support so we do things like working on little league ball fields, working in the fair grounds, shoveling snow and doing various things. The relationship here, from my perspective, with the community is a critical piece in terms of the success of this institution, we now have the credibility, we now are an accepted part of the community and, in fact, my whole 
community contacts, relationship with other law enforcement and services entities has always been a critical and important...

and I think in [state] it is very good between the department of corrections and other [agencies]. We have a director who is a fabulous guy with a lot of heart and works very well with other agencies and, you know, we have to have that relationship because people are, we have felons, we supervise felons, so $[\ldots]$ we understand the community has concerns, and we want to be able to work with the community and answer their concerns and get them as involved as possible....some are volunteers, some are just outside support.

Question 3b [cont]: My third item here is, Do negative media coverage or negative public opinion stressors on your decision-making process?

Descriptive: A little bit, but you know what...we've had a little. We've had one escape her since [date]. Actually, because of that, a county commissioner asked me to convene a prison advisory meeting in the community. I had 45 people come, 43 of which said nothing but good things about the institution. The worst thing they said was... "what a stupid guy...the guy's going to be released in [a short time], and he got out." The media has been very good to us, has put out a lot of articles about the positive things we are doing. Not only for work crews but for our education program and other programs, so it has been, in my - and not everyone may share this, because I know there is a lot of negative media - in my perspective it has been very positive. And, a moderate stressor because if something happens, then 1 know there is going to be, I'm going to have 
to respond. So, it hasn't been much of one [a stressor. Author note].

Probe: Well one word that you use that I think is interesting and constant in my discussions is "situational"...these things aren't sort of "axes" hanging over your head all the time Descriptive: Oh, No. they tend to be a situational stressor.

Causal: For example, this winter we had a huge amount of snow here. We had 6 and 7 foot drifts which kind of cut us off. And during those times when it's hard for staff to get here and we feel a little bit cut off...this is a very remote facility. But this comes with the business and we are prepared for that, those kinds of contingencies. But, you know, they cause stress...I'm much better now as I'm older...much better than I used to be in terms of compartmentalizing. I think, there is always in the back of my mind, I hope we don't have an escape, I hope there's no fight, I hope there's no assault, those kinds of things...but it certainly doesn't preoccupy me all the time.

Question 3b [cont]: Well, going on to the next potential stressor on your ability to manage institutions...do restrictive or overly punitive laws or court interventions of any kind...do those cause you stress as a warden?

Descriptive: No. But I will say this, when I went to the wardens conference, the other states were astounded.

Causal (latent): [My state] has always had a reputation as a cutting edge state... and now we are looking at increasing [the punitiveness of our laws]. The other states were astounded because they are all going in... a lot of them, not all....are going in a different direction and try to give more discretion to parole boards and sentencing 
courts and invest more money in community corrections...believing that a lot of offenders would do much better on supervision in the community than putting them in prison.

Descriptive: But, no, I think...my association with the courts has always been good...I think it really doesn't cause me that much stress.

Question 3b [cont]: I have a few more questions regarding possible stressors...in the literature you also see mentioned that the number of problematic inmates has been increasing and creating more management

headaches...so...ill inmates, increasingly violent inmates, etc. etc. What do you think about that in terms of a stress on you as a warden?

Descriptive: I think that the big area is the area of mental health and co-occurring disorders.

Causal: For lack of mental health facilities, out-patient facilities in the community, we are getting a gradually increasing number of inmates with mental health issues, some with mental health and substance abuse issues. That is one aspect, and of course, as you well know, that [another state] especially is experiencing increasing problems with gangs and...I mean it's the same old drugs, gangs, and mental health. I think that kind of sums it up for me.

Probe: So those do create pressures on you as a warden?

Descriptive: Yeah....and here, I'm lucky because we don't have any mental health inmates here, we don't have the mental health resources for it, so...

Causal: but the institution I came from did and we - I'm trying to remember what percentage of our population around $18 \%$ had some degree of mental health issues and they are, at times, problems. 
Adjusting an environment, a correctional environment, being in open-dorms where there is a high degree of stimulation, being confined, maybe not having the medical resources available to them.

Question 3b [cont]:

Are there other factors that we haven't talked about that aren't stressful but that possibly impact your decision-making, these can be inside the institution or coming from outside the institution...that aren't stressful but that are influential in some way?

Descriptive: No, I enjoy a great relationship with our management team. We have a great director, all of the assistant directors are really good people, very committed to following the [state's correctional model], which talks about communication and, I think that the administration is very caring about the health and wellness of its staff, as this is a high-stress area, we have people who get ill, who get cancer, and I think our commissioner/director is very concerned about that.

Causal: Also in the areas of safety and wellness... which can be stressful,

Descriptive: I think the department is trying to put some focus on that and create resources, provide resources that can help people manage themselves through stressful periods and create resources, outlets for wellness sorts of things. Actually, there is a lot of gratification...I mean, I wouldn't be in this field for as many years as I have if I didn't like it. Everyday is a different challenge, it's never been boring and I think there is something to be said for feeling obligated to try and provide proper resources for these inmates before they go back into our communities. 


\begin{tabular}{|l|l|l|}
\hline & $\begin{array}{l}\text { Final Respondent Comment: I } \\
\text { would be interested in reading } \\
\text { your research. I know that my } \\
\text { perspective probably differs } \\
\text { from wardens and } \\
\text { superintendents from across the } \\
\text { nation, but I think there is a } \\
\text { general belief that we need to } \\
\text { get a handle on capacity and } \\
\text { figure out how we can keep } \\
\text { some of these offenders in the } \\
\text { community successfully } \\
\text { without endangering the safety } \\
\text { and security of everybody. }\end{array}$ \\
\hline
\end{tabular}


Appendix I

Open-ended Survey and DOC Responses

Interstate Inmate Transfers/ Interstate Corrections Compacts in [state]

Questionnaire Prepared by Robert Swan on June 13, 2008

C/O public affairs, [state] Department of Corrections

Note: Contents have been edited in accordance with confidentiality requirements.

1. Question: Does [state] currently transfer inmates to out-of-state locations and... if so, by what legal or administrative mechanism is this accomplished?

Response: Interstate Corrections Compact and a few [regional] Interstate Compact state contracts.

2. Question: Has it been done differently in the past or has it always been done this way?

Response: Not for at least the last 12 years; before that is unknown.

3. Question: Does [state] use any administrative tool besides an Interstate Corrections Compact (e.g., [a regional] compact or the national compact agreement) to facilitate the transfer of inmates to other state prisons? Can you describe that mechanism (e.g., I am unclear about whether the bed rental situation is different or the same with regard to the interstate corrections compact[s])?

Response: No. The National Compact Agreement regards inmates that are on supervision. The Rental Beds program is different than any compact or treaty; it is for sending inmates out of state for temporary housing based on lack of adequate beds in the department, not on an exchange basis, but a contracted fee basis.

4. Question: How long has [state] used IITs? How many inmates are taken in from other states and how many are [typically] transferred out to out-of-state locations each year? (A rough annual count is fine... and I realize that there is an "in-balance" policy so...I am merely interested in the number of IIT transactions and a description of the official "in-balance" policy.)

Response: IITs (actually ICC for Interstate Corrections Compact) may go back to the 1970 s. The count varies, approximately 20 each direction. 
5. Question: In some states, IITs are used to move individual inmates (i.e., one at a time) but in other states, IITs may involve moving large groups of inmates (500-600 at a time, see: Arizona \& California [up to 5000 at a time, potentially] for example), and in other states, both types of transfers (individual \& aggregate) are used. Can you describe, from this perspective at least, how [state] uses IITs (e.g., individually, aggregately, or a combination of both) and why [state] does it this way as opposed to other methods?

Response: Groups of inmates fall under the Rental Bed program, individual inmates fall under ICC.

6. Question: Can you describe why IITs are used? I realize that there may be a number of reasons for these transfers, but I would very grateful if you could list as many reasons as you can... as these reasons are quite germane to my research [questions].

Response: We move inmates for protective custody reasons: safety for the inmate, safety of others, and/or high-profile such as media.

7. Question: Finally, I am interested in the role that warden's play in the implementation of IITs. In some places, it appears that formal \& informal referrals for the IIT of an inmate (or inmates) may be made by a warden. In [state] I realize that there may not be a formal role. However, I am wondering if informal IIT referrals from wardens are (or may be) made to a central DOC office (question deleted)? And, if so, what are some of the reasons given by the warden for the informal IIT request? And, if they do not formally or informally refer inmates for an IIT, I would be interested (from an organizational theory perspective) to know why that might be the case.

Response: The warden discusses an individual inmate transfer case with his/her Security team and Counselors handling the inmate's caseload. There is an institution internal interdisciplinary committee that reviews any cases that are brought up to them by staff within that institution to determine if the inmate should be placed in another state for their protection or safety of others. If the team decides the inmate would be best served by an out of state transfer, the Counselor will complete a packet of information on the inmate stating all pertinent information and rationale for the transfer. The packet then is forwarded to the warden for review and approval and then it is submitted to the [central DOC office] for approval and submission to another Compact State for consideration. 